\title{
TAXONOMÍA Y DISTRIBUCIÓN DE LOS ANOFELINOS EN EL ESTADO DE VERACRUZ, MÉXICO (DIPTERA: CULICIDAE, ANOPHELINAE)
}

\author{
Adriana Beltrán-Aguilar, ${ }^{1}$ Sergio Ibáñez-Bernal, ${ }^{1,3}$ Fredy Mendoza- \\ Palmero, ${ }^{2}$ César A. Sandoval-Ruiz ${ }^{1}$ \& Ruth A. Hernández-Xoliot ${ }^{2}$ \\ ${ }^{1}$ Instituto de Ecología, A.C., Red Ambiente y Sustentabilidad. Carretera antigua a Coatepec No. 351, \\ El Haya, Xalapa, C. P. 91070, Veracruz, México. \\ ${ }^{2}$ Departamento de Control de Enfermedades Transmitidas por Vector, Servicios de Salud de Veracruz. \\ Soconusco No. 31, Col. Aguacatal, C.P. 91130, Xalapa, Veracruz, México. \\ ${ }^{3}$ Autor corresponsal: <sergio.ibanez@inecol.edu.mx>
}

Beltrán-Aguilar, A., S. Ibáñez-Bernal, F. Mendoza-Palmero, C.A. Sandoval-Ruiz \& R. A. Hernández-Xoliot. 2011. Taxonomía y distribución de los anofelinos en el estado de Veracruz, México (Diptera: Culicidae, Anophelinae). Acta Zoológica Mexicana (n. s.), 27(3): 601-755.

RESUMEN. La malaria o paludismo es una enfermedad humana causada por protozoarios del género Plasmodium y es transmitida por hembras de mosquito de ciertas especies de Anopheles. Se estima que en México el 33.1\% de la población vive en áreas donde puede ocurrir la transmisión de la malaria. Veracruz es un estado donde la enfermedad es endémica debido a diversos factores que lo hacen una zona de riesgo para la transmisión, entre ellos las condiciones climáticas y la migración humana. Por lo anterior, en este trabajo se presentan las bases para la reactivación de la vigilancia entomológica del paludismo en el estado de Veracruz, para lo cual se provee la diagnosis ilustrada de la larva, la pupa y los adultos de ambos sexos de las especies de anofelinos del estado, así como las claves taxonómicas que permiten su reconocimiento, con base en el examen de ejemplares recolectados o depositados en colecciones entomológicas de referencia. También se obtuvieron mapas de distribución conocida y potencial de las especies por medio de GARP. Se mencionan además algunos datos bionómicos y la importancia médica de cada especie. Se conocen en Veracruz 18 especies de anofelinos, agrupadas en dos géneros, Chagasia con una especie y Anopheles con 17 pertenecientes a los subgéneros An. (Anopheles), An. (Kerteszia) y An. (Nyssorhynchus). Se reconocen cuatro grupos de especies de acuerdo a su capacidad de transmisión de plasmodios y por su amplitud de distribución: el grupo de alto riesgo constituido por 2 especies; el grupo de riesgo moderado o regional, con 8 especies; el de escaso riesgo, con 3 especies y el de riesgo nulo con 5 especies. Prácticamente todo el estado posee vectores potenciales por lo que debe reestablecerse la vigilancia permanente de sus poblaciones. Este trabajo aporta elementos de juicio para que el estado pueda ser, en un futuro cercano, certificado como área libre de paludismo.

Palabras clave: anofelinos, taxonomía, distribución, vectores, malaria, paludismo.

Beltrán-Aguilar, A., S. Ibáñez-Bernal, F. Mendoza-Palmero, C.A. Sandoval-Ruiz \& R. A. Hernández-Xoliot. 2011. Taxonomy and distribution of the anopheline mosquitoes in the state of Veracruz, Mexico (Diptera: Culicidae, Anophelinae). Acta Zoológica Mexicana (n. s.), 27(3): 601-755.

Recibido: 03/03/2011; aceptado: 24/08/2011. 
ABSTRACT. Malaria is a human disease caused by four species of the protozoon genus Plasmodium which are transmitted by Anophelinae female mosquitoes of some species of the genus Anopheles. It has been estimated that in Mexico 33.1\% of the human population lives in areas where the transmission of malaria is possible. The risk area includes the State of Veracruz that has been a traditional endemic zone in the past. Factors as weather, human density and human migration elevate the potential transmission risk. In this study, basic information needed for the reactivation of the entomological surveillance in the Veracruz State is provided, presenting the check-list with the illustrated diagnosis of larva, pupa, adult male and female, and taxonomic keys for the identification of species based in all postembryonic developmental stages. The known and potential distribution maps were obtained using GARP. Some bionomic data and the medical importance of the species are also mentioned. There are 18 Anophelinae species in Veracruz, grouped in two genera, Chagasia with one species and Anopheles with 17, pertaining to three subgenera An. (Anopheles), An (Kerteszia) and An. (Nyssorhynchus). According to the plasmodium transmission capability and distribution range, four groups of species are recognized: the high risk group, with 2 species; the median risk or regional risk group, with 8 species; the low risk group, with 3 species and the no risk group with 5 species. Potential malaria vectors are present throughout almost the entire state, so permanent surveillance of the anopheline populations must be reestablished. This study contributes strong elements for the future certification of the Veracruz State as an area free from malaria.

Key words: anopheline, taxonomy, distribution, vectors, malaria.

\section{INTRODUCCIÓN}

La malaria, también conocida como paludismo, es una enfermedad humana causada por protozoarios del género Plasmodium. En México P. vivax (Grassi \& Feletti 1890) y $P$. falciparum Welch 1897, son las responsables de la mayoría de los casos registrados, con casos esporádicos de infecciones mixtas por estas dos especies (Russell 1953, Pampana 1966). La enfermedad se transmite mediante la picadura de mosquitos del género Anopheles Meigen 1818, aunque en ocasiones también por transfusión sanguínea y raramente de manera congénita (OPS 1985).

El paludismo es endémico en gran parte de África, el sur de Asia y desde el norte de Argentina hasta México. Cada año se presentan entre 350 y 500 millones de episodios clínicos de malaria humana en el mundo, resultando en alrededor de un millón de defunciones. Independientemente, implica una carga económica significativa debido a que reduce la productividad, provocando una pérdida estimada de $1.3 \%$ del crecimiento económico anual en países con alta transmisión de la enfermedad (OMS 2005).

En América hay 460 millones de habitantes en los 21 países con transmisión activa del paludismo (incluyendo México) (OMS Op. cit.), de los cuales 219 millones $(47,6 \%)$ viven en zonas expuestas a algún riesgo de transmisión y alrededor de 131 millones están expuestos a un riesgo bajo o extremadamente bajo. De esta manera, se calcula que el 19\% (88 millones) de la población vive en zonas con riesgo moderado a elevado de transmisión del paludismo (OPS 2000). En México se estima que el 33.1\% de la población vive en áreas donde puede darse la transmisión de malaria (alrededor de 34 millones) (Rodríguez et al. 2004). 
Los estudios sobre los anofelinos de México iniciaron entre los años 1923 y 1932, cuando Alfonso Dampf recolectó numerosos ejemplares de mosquitos que fueron enviados al Instituto de Enfermedades Tropicales de Hamburgo. En colaboración con el Departamento de Salud Pública de México, los hallazgos fueron publicados bajo el título de "Los Mosquitos de México" (Martini 1935). Por su parte Carlos C. Hoffman de 1926 a 1939 incriminó a las especies vectoras de plasmodios causantes de la malaria humana en México y en 1929 realizó un estudio sobre los Anopheles del estado de Veracruz (Hoffmann 1931, 1939, Martínez-Palacios \& Pletsch 1963, Ibáñez-Bernal et al. 1996).

En 1939 se inauguró el Instituto de Salubridad y Enfermedades Tropicales (hoy Instituto de Diagnóstico y Referencia Epidemiológicos), en cuyo Laboratorio de Entomología se formalizaron los estudios taxonómicos de mosquitos y otros insectos de importancia médica (Ibáñez-Bernal 1988, 1996, Martínez-Palacios \& Pletsch 1963). Entre ellos destaca el trabajo de Vargas \& Martínez Palacios (1950) titulado “Estudio taxonómico de los Anofelinos en México", el cual fue ampliado posteriormente en 1956 y publicado bajo el título de "Anofelinos Mexicanos. Taxonomía y distribución”. Contiene las descripciones de la larva, adultos y genitales del macho de cada una de las 26 especies que informó para México, así como las claves taxonómicas para larva, pupa y adultos de esta subfamilia y además incluye las localidades donde fue colectada cada especie (Vargas \& Martínez-Palacios 1956).

El trabajo más reciente que agrupa a todas la especies de México y Centroamérica es el de Wilkerson et al. (1990), que presenta una clave para la identificación con base en las características morfológicas externas de la hembra. Incluye 39 especies y una subespecie, y proporcionaron un cuadro con la distribución geográfica por país, informando 27 especies para México. Este trabajo fue traducido al idioma español en 1993 (Wilkerson et al. 1993).

Aun cuando los esfuerzos de la Campaña Nacional para la Erradicación del Paludismo (CNEP) y otros programas posteriores del gobierno de México han mantenido bajo control esta enfermedad, es un hecho observable en todo el mundo que en los últimos años varias enfermedades transmitidas por vector han resurgido en los últimos 20 años en nuevas áreas geográficas o han re-emergido en áreas antiguamente afectadas (Gratz 1999, Thowson et al. 2005, OMS 2007). La incidencia de algunas de estas se redujo a niveles insignificantes en décadas pasadas, pero debido a una falsa sensación de seguridad por la ausencia de brotes y a que muchos de los especialistas en el control de los vectores fueron reemplazados con el tiempo, además de que se ha tenido que atender con urgencia el dengue, la capacidad y la experiencia técnica esencial para el control de anofelinos vectores ha disminuido.

En abril del 2006 se publicaron los criterios para la Certificación de áreas geográficas que han logrado la eliminación de la transmisión del paludismo. Dicha certificación se otorgará a las Entidades Federativas que no hayan presentado un caso de 
malaria endémica durante al menos tres años y en las que se cuente con un sistema de vigilancia epidemiológica y un programa de eliminación de hábitats y criaderos de anofelinos efectivos y permanentes (Diario Oficial de la Federación 2006). Para lograr esto, y considerando que las poblaciones de insectos no son estables en su distribución y abundancia a lo largo del tiempo, aunado a los cambios en el paisaje ocasionados por la acción antropogénica, como destrucción de hábitats naturales, colonización humana de nuevas zonas y nuevos asentamientos, se requiere re-evaluar, actualizar y analizar la composición faunística de mosquitos y la distribución geográfica actual, a fin de determinar las áreas de nulo, moderado y alto riesgo en función de la presencia de los mosquitos vectores primarios. En el estado de Veracruz, desde el año 2007 no se ha registrado ningún caso de paludismo autóctono (DGEPI 2009). Sin embargo, se debe tomar en cuenta que el territorio veracruzano cuenta con las condiciones adecuadas para la propagación de la enfermedad, por lo que se requiere una vigilancia constante, tanto epidemiológica como entomológica.

Aunque en las áreas de transmisión de malaria en México las medidas de control son comúnmente exitosas, se debe tomar en cuenta que el estado de Veracruz es tradicionalmente endémico de la enfermedad y las condiciones climáticas de temperatura, humedad y la elevada migración de la población humana lo hacen apto para la transmisión en gran parte de su territorio (Gómez-Dantés \& Birn 2000). Considerando también que se pretende obtener la certificación de la eliminación de la transmisión del paludismo en el Estado, se hace necesaria la vigilancia continua de los vectores. Por estas razones, se requieren estudios que proporcionen la información necesaria para la identificación de las especies, así como de la distribución geográfica conocida y potencial de los anofelinos de Veracruz. El presente trabajo tiene por objetivo proveer herramientas para la identificación de las especies de anofelinos de Veracruz y la lista comentada que incluye la diagnosis para el reconocimiento taxonómico de larvas, pupas, hembras y machos, algunos datos bionómicos importantes y mapas de su distribución conocida y potencial.

\section{MATERIALES Y MÉTODOS}

Este trabajo forma parte del proyecto "Estratificación de tres enfermedades prioritarias en zonas de riesgo con base en sus insectos vectores en el estado de Veracruz" (FOMIX-CONACYT-Gobierno del Estado de Veracruz de Ignacio de la Llave-Salud, No. 68317), Coordinado por el Dr. Sergio Ibáñez-Bernal, del Instituto de Ecología, A. C. (INECOL), y en el cual participan los Servicios de Salud de Veracruz (SESVER) y el Instituto de Diagnóstico y Referencia Epidemiológicos, Secretaría de Salud, México (InDRE).

Área de estudio. El estado de Veracruz se extiende a lo largo del Golfo de México, en una franja costera de $745 \mathrm{~km}$ de longitud, con una superficie de 72,420 km². Es 
el décimo estado de la República Mexicana en extensión y representa el 3.7\% de la superficie total del país. Colinda con siete estados, Tamaulipas al norte, San Luis Potosí, Hidalgo y Puebla al oeste, Chiapas y Oaxaca al sur y Tabasco al sureste (Gobierno del Estado de Veracruz 2008).

La mayor parte del estado es una planicie que abarca la zona costera y se eleva hacia la Sierra Madre Oriental donde el terreno es muy accidentado. La Sierra Madre Oriental se extiende de sureste a noroeste entre los paralelos $16^{\circ}$ a $18^{\circ} \mathrm{N}$ y se continúa de sur a noroeste hacia el paralelo $20^{\circ} \mathrm{N}$, en donde forma una saliente que se prolonga hasta la costa en la Sierra de Chiconquiaco y que divide a Veracruz en dos regiones con paisaje particular, cada uno de los cuales posee diversos tipos de clima y de flora y fauna (Soto \& García 1989).

La temperatura media anual para el estado es de $23^{\circ} \mathrm{C}$, la temperatura máxima promedio es de alrededor de $32^{\circ} \mathrm{C}$ en los meses de abril y mayo, mientras que la temperatura mínima promedio es de $13^{\circ} \mathrm{C}$ y se presenta en el mes de enero (Soto \& García 1989). Se presentan diecisiete subtipos de climas que van desde los cálidohúmedos (en la llanura costera) hasta los fríos perpetuos (en las elevaciones de Cofre de Perote y Pico de Orizaba). Los que abarcan una mayor extensión son: cálido subhúmedo de mayor humedad (31\%), cálido húmedo con lluvias en verano e influencia de Monzón (22\%), subhúmedo intermedio (14\%), cálido subhúmedo con lluvias en verano de menor humedad (10\%), cálido húmedo con lluvias abundantes todo el año (9\%) y semicálido húmedo con lluvias en invierno (4\%) (Soto \& García 1989).

En el estado están presentes siete provincias fisiográficas (INEGI 2009):

a) Provincia de la llanura costera del golfo norte: se extiende paralela a las costas del Golfo de México, desde el río Bravo hasta la zona de Nautla, Veracruz. Los climas en esta región van de los secos cálidos y semicálidos del norte a los cálidos subhúmedos y húmedos del sur. La vegetación se ajusta a dicho patrón climático, con matorrales en la porción boreal y selvas en la austral.

b) Provincia de la Sierra Madre Oriental: es fundamentalmente un conjunto de sierras menores de estratos plegados. En esta región, los climas varían dentro de una amplia gama de temperatura y precipitación, desde los secos cálidos en el norte, hasta los semicálidos y templados subhúmedos del sur. La porción que se encuentra en Veracruz pertenece a la subprovincia Carso Huasteco.

c) Provincia del Eje Neovolcánico: se puede caracterizar como una enorme masa de rocas volcánicas de diversos tipos, acumulada en numerosos y sucesivos episodios volcánicos que se iniciaron a mediados del Terciario (unos 35 millones de años atrás), y continuaron hasta el presente. Uno de sus rasgos característicos es la franja de volcanes que se extienden de oeste a este, casi en línea recta, más o menos sobre el paralelo 19. Otro rasgo esencial lo dan las amplias cuencas cerradas ocupadas por lagos. Los bosques de encinos y coníferas se 
desarrollan en la franja colindante con la Sierra Madre Oriental. Sobre el Golfo de México hay pequeñas áreas de bosque mesófilo y selva baja caducifolia.

d) Provincia de la Sierra Madre del Sur: esta región tiene una litología en la que las rocas intrusivas cristalinas y las metamórficas cobran una importancia mucho mayor que en las del norte. La vegetación que sustenta es la selva baja caducifolia en la Depresión del Balsas.

e) Provincia de la Llanura Costera del Golfo Sur: es una llanura costera de fuerte aluvionamiento por parte de los ríos, los más caudalosos del país, que la atraviesan para desembocar en el sector sur del Golfo de México. La mayor parte de su superficie, a excepción de la discontinuidad fisiográfica de los Tuxtlas y algunos lomeríos bajos, está muy próxima al nivel del mar y cubierta de material aluvial.

f) Provincia de la Cordillera Centroamericana: inicia en el Istmo de Tehuantepec y se extiende hasta la República de Nicaragua. Es un gran batolito ígneo emergido sobre el sitio de subducción de la placa de Cocos. El clima predominante es cálido húmedo, pero en el sureste se registra el semicálido y hacia el noroeste el templado subhúmedo. Hay bosque de pino-encino en las partes más elevadas y selva alta perennifolia hacia el Pacífico y en las costas, excepto las del noroeste, donde se desarrolla selva baja caducifolia.

g) Provincia de las Sierras de Chiapas y Guatemala: en México abarca parte de los estados de Tabasco, Chiapas y Veracruz. Las sierras que las conforman son sierras plegadas relativamente bajas. En el norte de la provincia prevalecen climas semicálidos y cálidos húmedos, asociados los primeros con sabana y bosque de pino-encino, y los segundos con selva alta perennifolia. Al sur pasan a templados subhúmedos y cálidos subhúmedos.

Veracruz posee una gran riqueza hidrológica. El 35\% de las aguas superficiales mexicanas atraviesan el territorio veracruzano. Cuenta con más de 40 ríos integrados en 10 cuencas hidrológicas. Los principales ríos, de Norte a Sur, son: el Pánuco, Tuxpan, Cazones, Tecolutla, Nautla, Misantla, Actopan, La Antigua, Jamada-Cotaxtla, Blanco, Papaloapan con sus afluentes San Juan y Tesechoacán, Coatzacoalcos con su afluente Uxpanapa y el Tonalá. Las corrientes principales son complementadas en la hidrografía estatal por una gran cantidad de cuerpos de agua y pequeños cauces. Todas las corrientes que surcan el territorio Veracruzano, con excepción de pequeños arroyos localizados en la ladera oeste del Cofre de Perote, desembocan en la vertiente del Golfo, la cual comparte con los estados de Tamaulipas, Tabasco, Campeche, Quintana Roo y Yucatán y con cinco estados de los Estados Unidos de América (Gobierno del Estado de Veracruz 2008; INEGI 2009).

La precipitación media anual en el estado es de 1,484 milímetros, prácticamente el doble de la media nacional que es de $772 \mathrm{~mm}$. El potencial hídrico superficial del 
estado de Veracruz es de los más altos del país, al tener un escurrimiento superficial anual medio de 121 mil millones de $\mathrm{m}^{3}$, que representa el 33\% de todo el escurrimiento superficial del país (39,930 millones de $\mathrm{m}^{3}$ ), sin embargo la disponibilidad del agua se ve limitada por variaciones espaciales (topografía) y estacionales a lo largo del año (CSVA 2006).

Método de estudio. Se recurrió a la consulta de las colecciones entomológicas mexicanas especializadas del INECOL (IEXA) y la Colección de Artrópodos de Importancia Médica del InDRE (CAIM). Se examinaron los ejemplares del estado de Veracruz correspondientes a las fases de larva, pupa y adultos, así como ejemplares de otros estados de la República, con el fin de seleccionar los mejor preservados o montados para fines de descripción e ilustración. Los adultos examinados están preservados en seco en alfileres entomológicos, mientras que los terminalia del macho, las pupas y las larvas se encuentran preservados en laminillas permanentes para microscopio compuesto.

Para proporcionar la diagnosis se realizó la consulta de varios trabajos previos, estandarizando la nomenclatura morfológica y quetotáxica con la propuesta por Harbach \& Knight (1980). Las ilustraciones finales de cada especie se elaboraron partiendo de los dibujos obtenidos a través de microscopios estereoscópico y compuesto mediante el empleo de cámara lúcida. El microscopio compuesto fue requerido para la observación de detalles estructurales de las larvas, las pupas y los terminalia de machos, mientras que los ejemplares hembra fueron revisados por medio del microscopio estereoscópico. Las escalas de los dibujos se espresan en milímetros. Debido a que algunas especies o estados de desarrollo no pudieron ser revisados, algunas de las láminas fueron redibujadas de trabajos anteriores, lo cual se indica en el pie de figura.

Para obtener la distribución geográfica conocida y potencial de las especies de anofelinos de Veracruz se compiló una base de datos en el programa Excel Office ${ }^{\circledR}$. Los datos se obtuvieron de la Colección de Artrópodos de Importancia Médica del InDRE y de la colección del INECOL, así como de la totalidad de registros geográficos existentes para cada especie en trabajos anteriores (Lassman 1948, Heinemann \& Belkin 1977, Vargas \& Martínez-Palacios 1956). Las localidades se georreferenciaron con la base de datos del INEGI (disponible en: http://mapserver.inegi.org.mx/ mgn2k/?s=geo\&c=1223) y de las bases de Falling Rain Genomics, Inc. (disponible en: http://www.fallingrain.com/world/MX/30/) y Pueblosamerica (disponible en: http://mexico.pueblosamerica.com/ veracruz-de-ignacio-de-la-llave/). Los mapas se obtuvieron a través del sistema de información geográfica ARC VIEW versión 3.2 y la aplicación Desktop GARP versión 1.1.0.6 (disponible en www.nhm.ku.edu/ desktopgarp) y se siguió el procedimiento común para su implementación referido por Scachetti-Pereira (2003). 
El algoritmo genético GARP (Genetic Algorithm for Rule-Set Prediction), describe las condiciones ambientales bajo las cuales la especie puede sobrevivir, relacionando las características ambientales de los lugares de presencia de la especie con lugares tomados al azar de la región considerada, a través de una serie de reglas (Stockwell \& Peters 1999). Por ello se tomaron en cuenta las diecinueve variables climáticas generadas en el proyecto WorldClim: temperatura promedio anual, temperatura promedio diurna, isotermalidad, temperatura por temporada, temperatura máxima del mes más cálido, temperatura mínima del mes más frío, rango de temperaturas anuales, temperatura promedio del cuatrimestre más cálido, temperatura promedio del cuatrimestre más frío, precipitación anual, precipitación del mes más húmedo, precipitación del mes más seco, precipitación del cuatrimestre más cálido y precipitación del cuatrimestre más frío (Hijmans et al. 2005) (disponibles en: http://www.worldclim.org/) y tres coberturas topográficas: elevación, pendiente e índice topográfico, tomadas del U.S. Geological Survey’s HYDRO 1K ( http://edc.usgs.gov/products/elevation/gtopo30/hydro/namerica.html). En el caso de las especies con más de 25 registros se utilizaron el $50 \%$ de las localidades como puntos de entrenamiento y el $50 \%$ como puntos de prueba; para las especies con menor número de registros se utilizó el 100\% de los datos como puntos de entrenamiento. En todos los casos se estableció un límite de convergencia de 0.01 y un máximo de 1000 interacciones. Se desarrollaron 100 modelos por especie, de los cuales se tomaron en cuenta los mejores, seleccionados por el GARP, mismos que se promediaron para obtener el mapa final.

\section{RESULTADOS}

La subfamilia Anophelinae tiene especies distribuidas en casi todo el mundo, excepto Micronesia y Polinesia. Se considera que está representada por 522 especies descritas pertenecientes a tres géneros Anopheles, Bironella Theobald 1905 y Chagasia Cruz 1906. Para el caso concreto de México se tienen registradas 27 especies pertenecientes al género Anopheles y una al género Chagasia (Ibáñez-Bernal et al. 1996).

Las especies pueden ser reconocidas mediante las características morfológicas de todas las etapas de desarrollo. En el caso de las larvas se utilizan comúnmente las de cuarto estadio ya que algunas de sus características y en especial el patrón de sedas es variable en los estadios previos, motivo por el cual resulta difícil su determinación taxonómica y la diferenciación de las especies. Para identificar las pupas también se recurre a la quetotaxia y a otras particularidades como la forma de las trompetas ventiladoras. En los adultos son de gran importancia taxonómica los patrones de manchas en las alas y en ocasiones aquellos de las patas y palpos maxilares. En el caso particular de los machos, los genitales o terminalia (para incluir los segmentos postgenitales) resultan de gran valor para la distinción entre especies (Ibáñez-Bernal et al. 1996). Por ello, se presenta a continuación las particularidades morfológicas y la notación estructural que permiten la identificación de las especies. 
Larva (Figs. 1-4). Cabeza bien desarrollada, completamente esclerotizada y no retráctil. Antenas cilíndricas formadas por un solo segmento, en la parte apical se encuentran dos sedas en forma de sables ( 2 y 3-C), útiles para la determinación taxonómica. Tórax más ancho que los otros dos tagmata; protórax, mesotórax y metatórax distinguibles por los grupos de sedas particulares de cada segmento. Abdomen

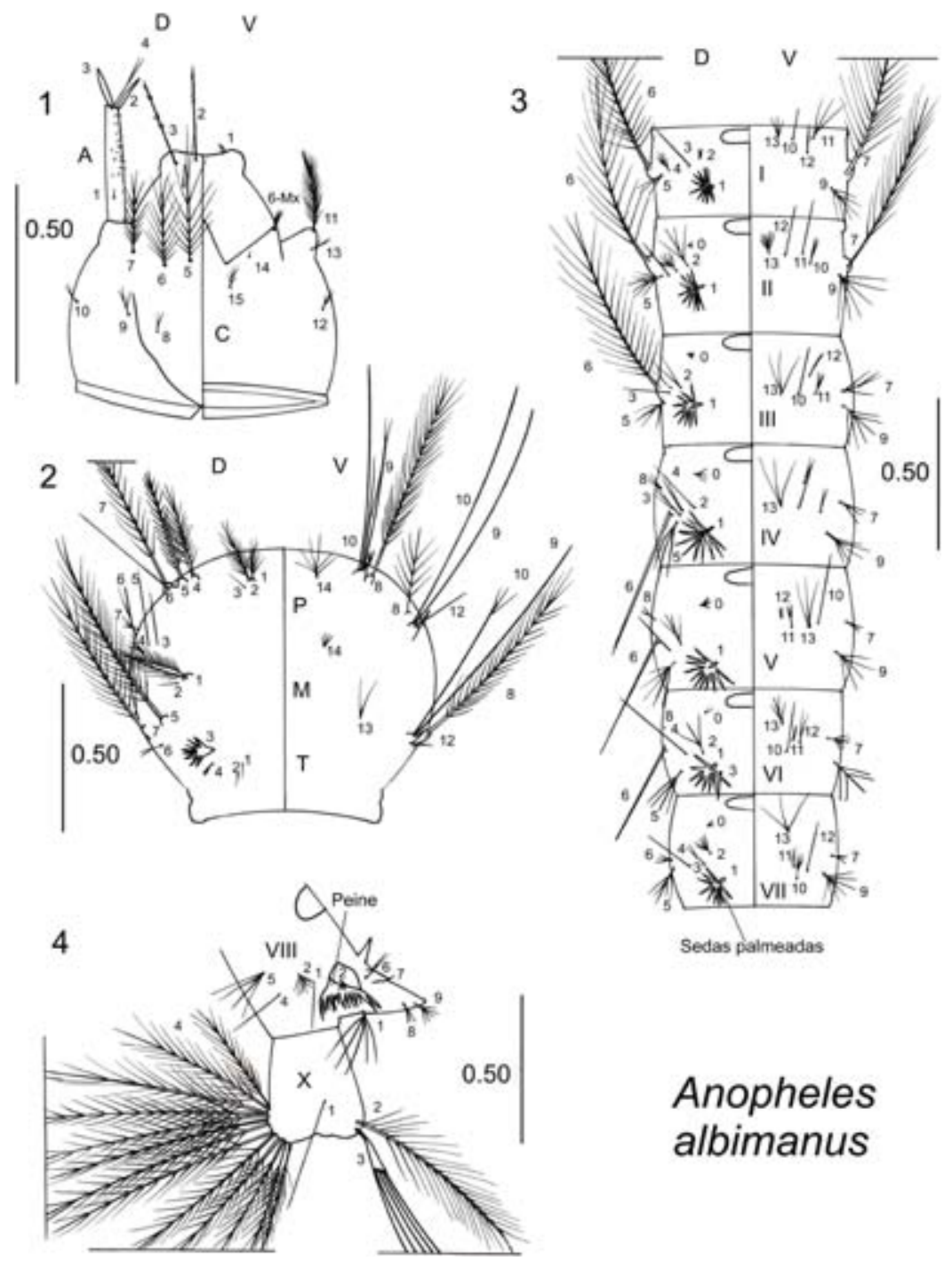

Figuras 1-4. Características morfológicas. Larva de Anopheles (Nyssorhynchus) albimanus. 1: Cabeza. 2: Tórax. 3: Segmentos abdominales I-VII. 4: Segmentos abdominales VIII-X vista lateral. 
conformado por 10 segmentos, aún cuando el noveno no se distingue plenamente; algunos segmentos presentan sedas palmeadas dorsales que pueden variar en forma y grado de desarrollo. En la parte dorsal del octavo segmento se encuentra el aparato ventilador el cual está constituido por una placa compuesta sobre la que se encuentran los estigmas o espiráculos que le permiten a la larva ventilarse con aire atmosférico. Al lado de este aparato se encuentran dos estructuras quitinosas triangulares con dientes llamadas peines. Las sedas de todo el cuerpo de la larva son imprescindibles para la determinación taxonómica de las especies y existe un sistema nomenclatural estandarizado para referirse a ellas (quetotaxia) referida gráficamente en las figuras 1-4 (Vargas \& Martínez-Palacios 1956, Williams \& Feltmate 1992).

Pupa (Figs. 5-7). La pupa es móvil pero no se alimenta. Es fácil reconocerla por su forma de "coma". Cabeza y tórax fusionados en un cefalotórax. En la parte dorsal del cefalotórax se encuentra un par de estructuras con forma de trompeta a través de las cuales se ventila, pudiendo tener forma laticorne (corta y ancha) o angusticorne (larga y delgada) y puede presentar surcos y proyecciones, lo que se utiliza para diferenciar las especies. Abdomen formado por nueve segmentos visibles, algunos con una seda espiniforme en las esquinas posteriores; noveno segmento más pequeño que los demás, observable en posición ventral y en la porción posterior se encuentra el lóbulo genital cuyas diferencias permiten distinguir el sexo, ya que en el macho es más largo y parcialmente bilobulado; el último segmento presenta en su extremo posterior un par de paletas natatorias que son casi planas, de forma ovoidal, con un engrosamiento cuticular en la parte media conocido como vena media y pueden presentar el borde aserrado o aciculado. En esta etapa la quetotaxia también se utiliza para la determinación taxonómica de las especies (Harbach \& Knight 1980, Vargas \& Martínez-Palacios 1956, Williams \& Feltmate 1992).

Adultos (Figs. 8-10). Con cuerpo delgado midiendo entre 4 y $10 \mathrm{~mm}$ de longitud. Cabeza sin ocelos, con probóscide larga, tanto como la longitud de la cabeza y tórax combinados, formada por el labio que envuelve seis estiletes (labro-epifaringe, mandíbulas, maxilas e hipofaringe) con los que la hembra atraviesa la piel y succiona la sangre. Los palpos maxilares están conformados por cinco segmentos, el patrón de coloración de éstos tienen importancia para la determinación taxonómica; en los dos sexos tienen longitud similar a la de la probóscide pero en los machos los últimos segmentos se encuentran ensanchados. Las antenas presentan un escapo poco visible, un pedicelo globular, también conocido como toro, y un flagelo dividido en 13 flagelómeros. Los machos pueden distinguirse de las hembras por sus antenas densamente plumosas y por las diferencias en forma y tamaño de los palpos maxilares (en machos son más largos o con los últimos segmentos expandidos), además de que en éstos los estiletes están menos desarrollados. Tórax cubierto lateral y dorsalmente por esca- 

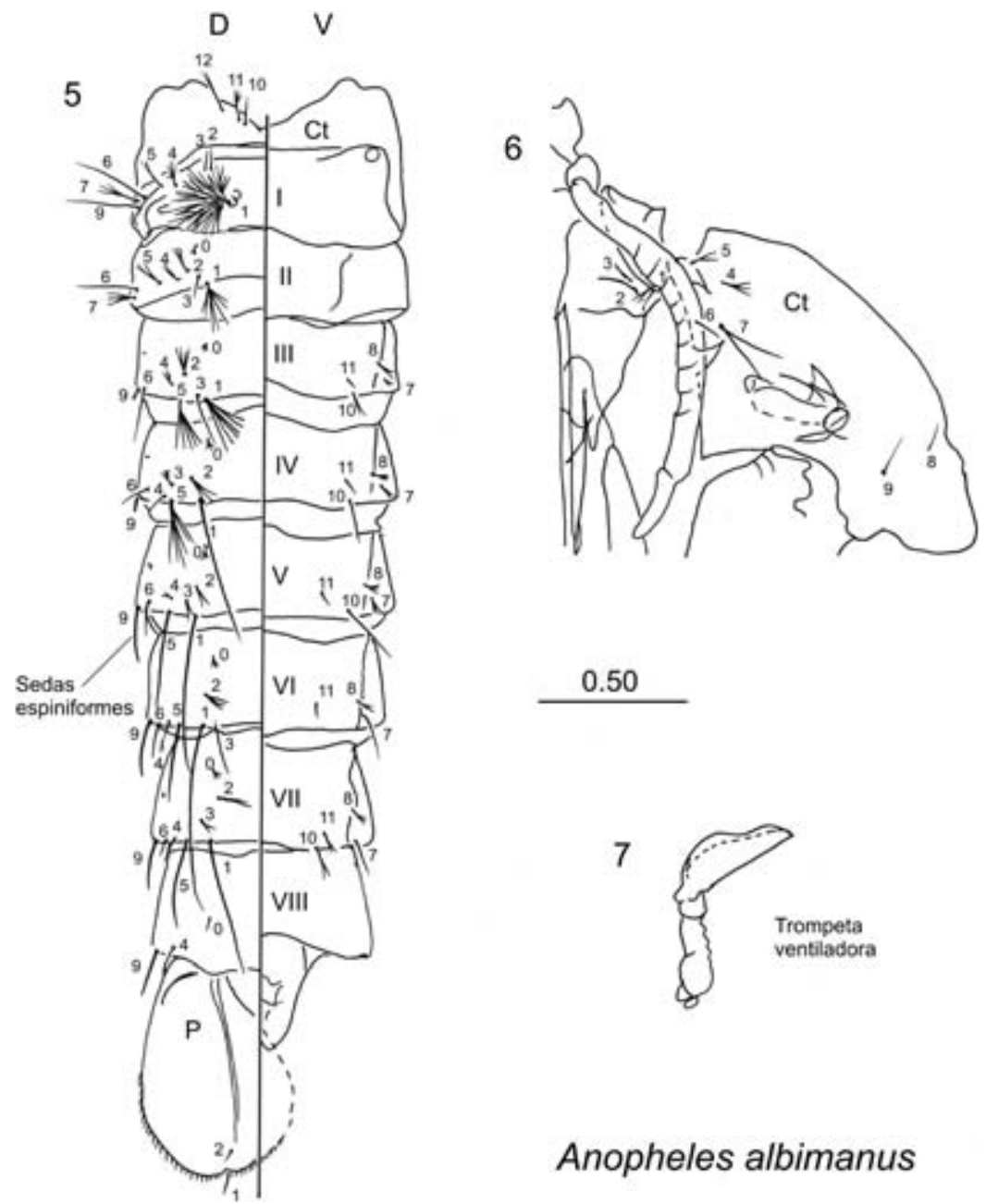

\section{Anopheles albimanus}

Figuras 5-7. Características morfológicas. Pupa de Anopheles (Nyssorhynchus) albimanus. 5: Abdomen. 6: Cefalotórax. 7: Trompeta ventiladora.

mas, de las que el patrón y color son de importancia taxonómica; los tres segmentos torácicos (protórax, mesotórax y metatórax) se encuentran fusionados, sin embargo el mesotórax predomina en tamaño y dorsalmente forma una placa llamada escudo, detrás de este se encuentra otra placa más pequeña llamada escudete; el patrón de coloración del integumento y las escamas son de importancia taxonómica. Como la mayoría de los dípteros, las alas mesotorácicas están bien desarrolladas y su venación es característica de la familia; además poseen sobre las venas escamas oscuras y en 


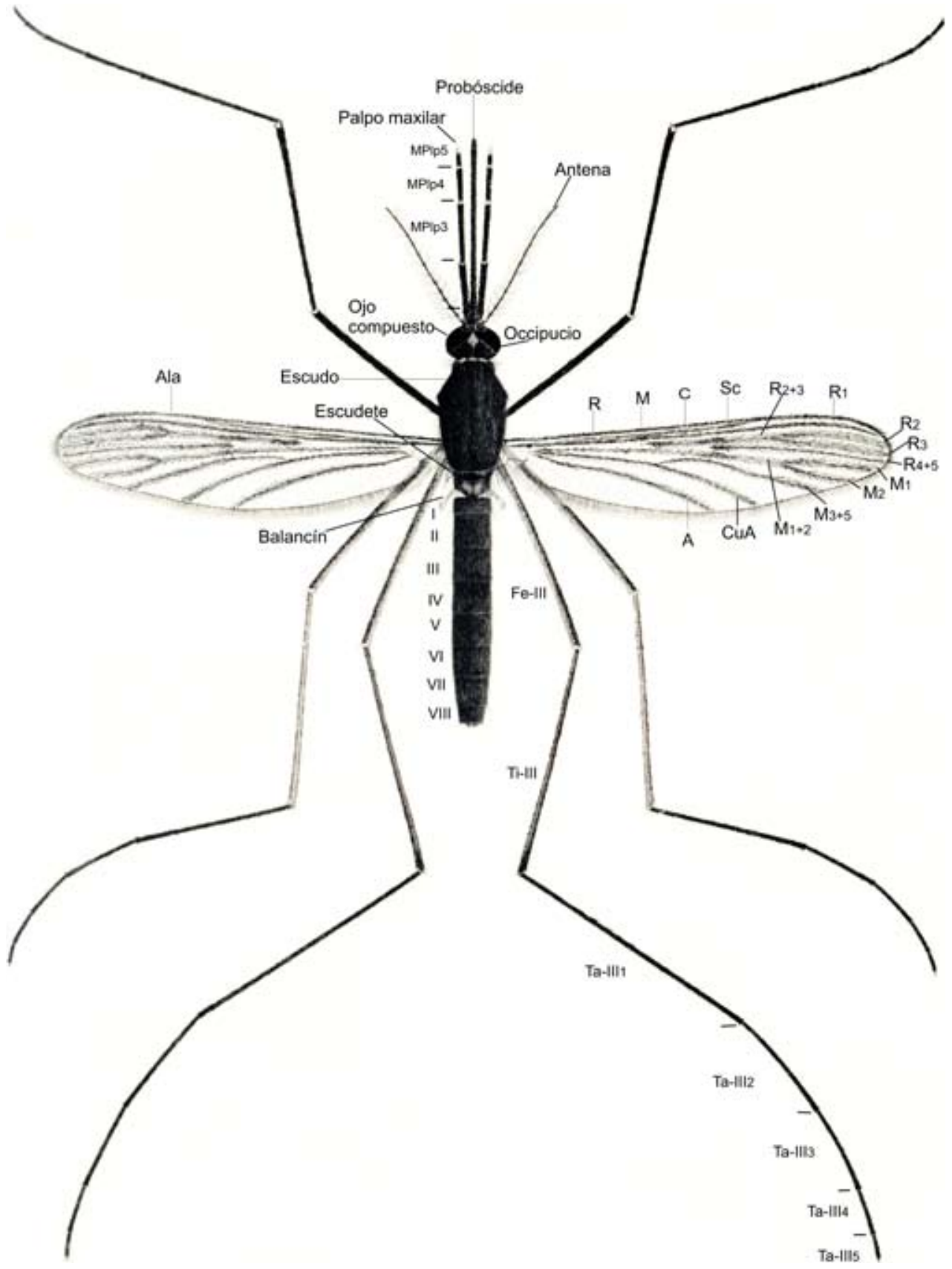

Figura 8. Características morfológicas. Adulto hembra de Anopheles (Anopheles) walkeri vista dorsal (tomado de Carpenter y LaCasse, 1955). 


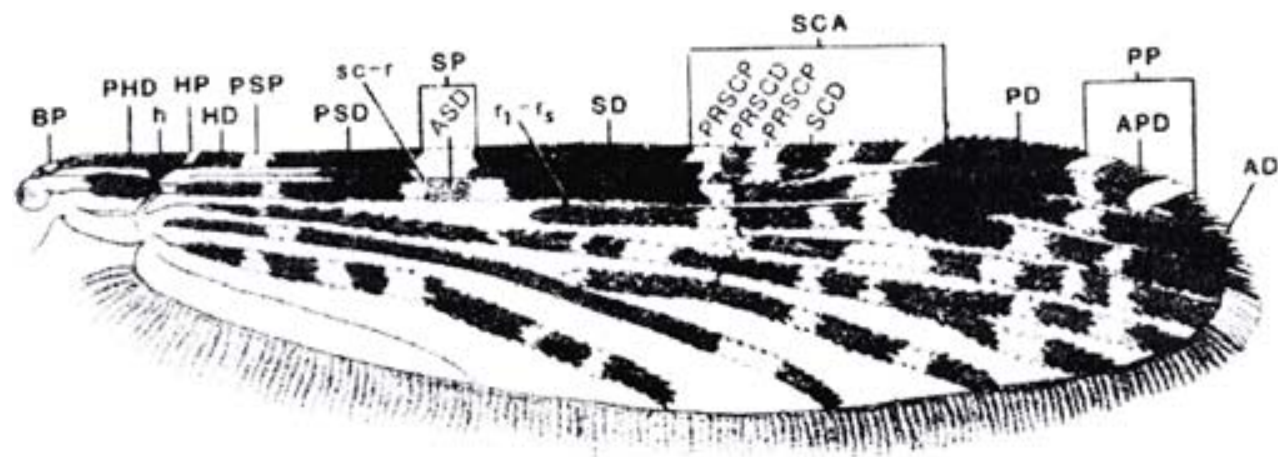

Figura 9. Manchas del Ala de Anopheles (Anopheles) apicimacula (tomada de Wilkersonet al., 1993).

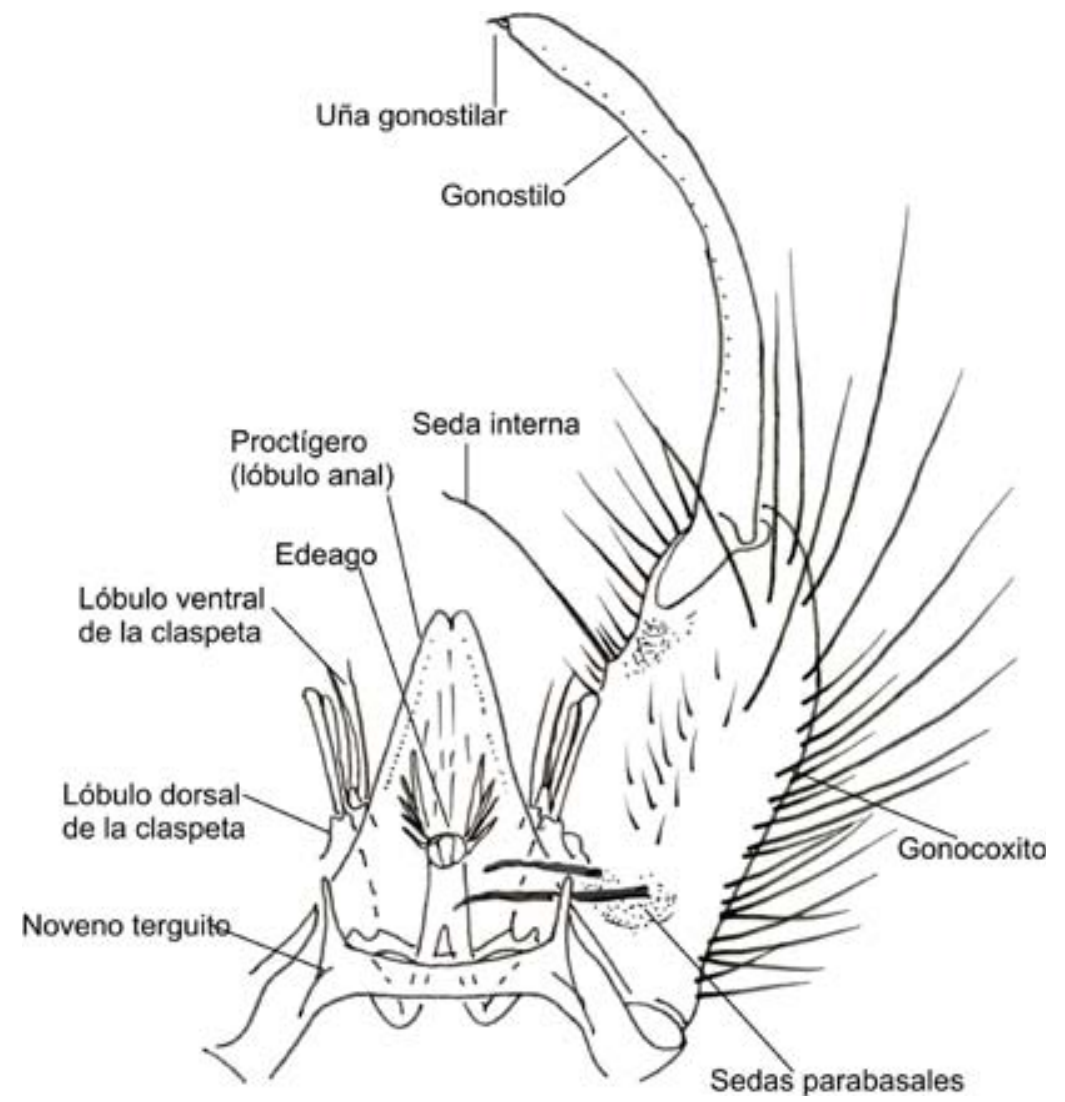

Figura 10. Características morfológicas de la subfamilia Anophelinae. Macho: Terminalia de Anopheles (Anopheles) walkeri (redibujado de Carpenter y LaCasse, 1955). 
muchos casos también claras que forman un patrón de manchas sumamente útil para la diferenciación entre especies (Fig. 9). En el metatórax se encuentran los balancines, que tienen forma capitada y cumplen la función de órganos del equilibrio durante el vuelo. Las patas son largas y delgadas formadas por la coxa, el trocánter, fémur y tibia y un tarso formado por cinco artejos o tarsómeros, el quinto tarsómero termina en dos uñas; el patrón de coloración de las escamas de recubrimiento también es útil para la distinción de las especies. Abdomen formado por 10 segmentos, los primeros ocho son muy evidentes y están poco modificados. Los dos últimos están relacionados con las funciones sexuales. En la hembra el décimo lleva un par de cercos, mientras que en el macho el noveno y décimo conforman los terminalia (Fig. 10). El décimo segmento consiste en un falosoma o edeago, rodeado por los parámeros y otras estucturas del décimo esternito, en posición ventral y a los lados se encuentra un par de gonocoxitos a los que se articula un gonostilo que termina en una uña; en el gonocoxito se presentan sedas espiniformes de gran importancia taxonómica por su forma y posición; el esternito consiste en un paraprocto sobre el que se encuentra el lóbulo anal o proctígero membranoso (Wilkerson et al.1993, Williams \& Feltmate 1992).

Taxa de la Subfamilia Anophelinae presentes en Veracruz. A la fecha se han registrado en el estado de Veracruz un total de dos géneros, Chagasia con una especie y Anopheles con tres subgéneros y 17 especies, lo que representa el 64\% de la totalidad de especies conocidas en la República Mexicana (Cuadro 1).

\section{Claves para la identificación de las especies de anofelinos conocidas de Veracruz}

\section{LARVAS DE CUARTO ESTADIO}

1. Abdomen consifón ventilador; segmentos abdominales sinsedas palmeadas ... Subfamilia Culicinae (incluyendo la tribu Toxorhynchitini)

1a. Abdomen sin sifón ventilador (Fig. 4); varios segmentos abdominales con sedas palmeadas (1-III-VII, al menos) (Fig. 3). . . . . . Subfamilia

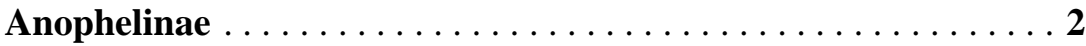

2 (1a). Abdomen con las sedas palmeadas presentando sus ramas en forma de raqueta en los segmentos III-V (1-III-V) (Fig. 187); aparato ventilador con el lóbulo anterior presentando un proceso largo que termina en una seda larga (Fig. 188) . . . . . . . . . . . . . . . . Chagasia

2a. Abdomen con las sedas palmeadas (1-III-VII) presentando sus ramas fusiformes en distintos segmentos abdominales (Figs. 13, 148 y 165); aparato ventilador con el lóbulo anterior variable, pero nunca con un proceso largo o seda larga apical como el descrito en el punto anterior ........................ Anopheles ....... 3 
Cuadro 1. Géneros, subgéneros y especies conocidos en el estado de Veracruz, México

\begin{tabular}{|c|c|c|}
\hline Género & Subgénero & Especie \\
\hline \multirow[t]{17}{*}{ Anopheles Meigen, 1818} & Anopheles Meigen, 1818 & apicimacula Dyar y Knab, 1906 \\
\hline & & bradleyi King, 1939 \\
\hline & & crucians Wiedemann, 1828 \\
\hline & & eiseni Coquillett, 1902 \\
\hline & & gabaldoni Vargas, 1941 \\
\hline & & neomaculipalpus Curry, 1931 \\
\hline & & parapunctipennis Martini, 1932 \\
\hline & & pseudopunctipennis Theobald, 1901 \\
\hline & & punctimacula Dyar y Knab, 1906 \\
\hline & & punctipennis (Say, 1823) \\
\hline & & quadrimaculatus Say, 1824 \\
\hline & & vestitipennis Dyar y Knab, 1906 \\
\hline & & walkeri Theobald, 1901 \\
\hline & Kerteszia Theobald 1905 & $\begin{array}{l}\text { neivai Howard, Dyar y Knab, } 1912 \\
\text { (1913) }\end{array}$ \\
\hline & Nyssorhynchus Blanchard, 1902 & albimanus Wiedemann, 1820 \\
\hline & & argyritarsis Robineau-Desvoidy, 1827 \\
\hline & & strodei Root, 1926 \\
\hline Chagasia Cruz, 1906 & - & bathana (Dyar, 1928) \\
\hline
\end{tabular}

3 (2a). Cabeza con las sedas frontales (5 y 6-C) sencillas, sin ramas (Fig. 146). Abdomen con las sedas palmeadas (1-III-VII) presentando sus ramas con el ápice truncado (Fig. 148) . . . . . Anopheles (Kerteszia) neivai

3a. Cabeza con las sedas frontales (5 y 6-C) presentando ramas laterales en toda su longitud (Fig. 11). Abdomen con las sedas palmeadas (1-IIIVII) presentando sus ramas con el ápice puntiagudo (Fig. 13) . . . . 4

4 (3a). Abdomen con las sedas palmeadas (1-III-VII) presentando las ramas anchas y sus bordes irregulares ....... Anopheles (Anopheles). . . 5

4a. Abdomen con las sedas palmeadas (1-III-VII) presentando las ramas angostas y los bordes lisos. . . . . Anopheles (Nyssorhynchus). . . 16

5 (4). Antena con las sedas apicales (2 y 3-A) a manera de sables puntiagudos (Fig. 23). Protórax con las sedas pleurales (9-12-P) sencillas (Fig.

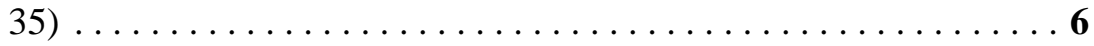

5a. Antena con las sedas apicales (2 y 3-A) a manera de sables, uno puntiagudo (3-A) y el otro truncado con el ápice deshilachado (2-A) (Fig. 11). Protórax con las sedas pleurales (9-12-P) sencillas o con ramas. . . 13 

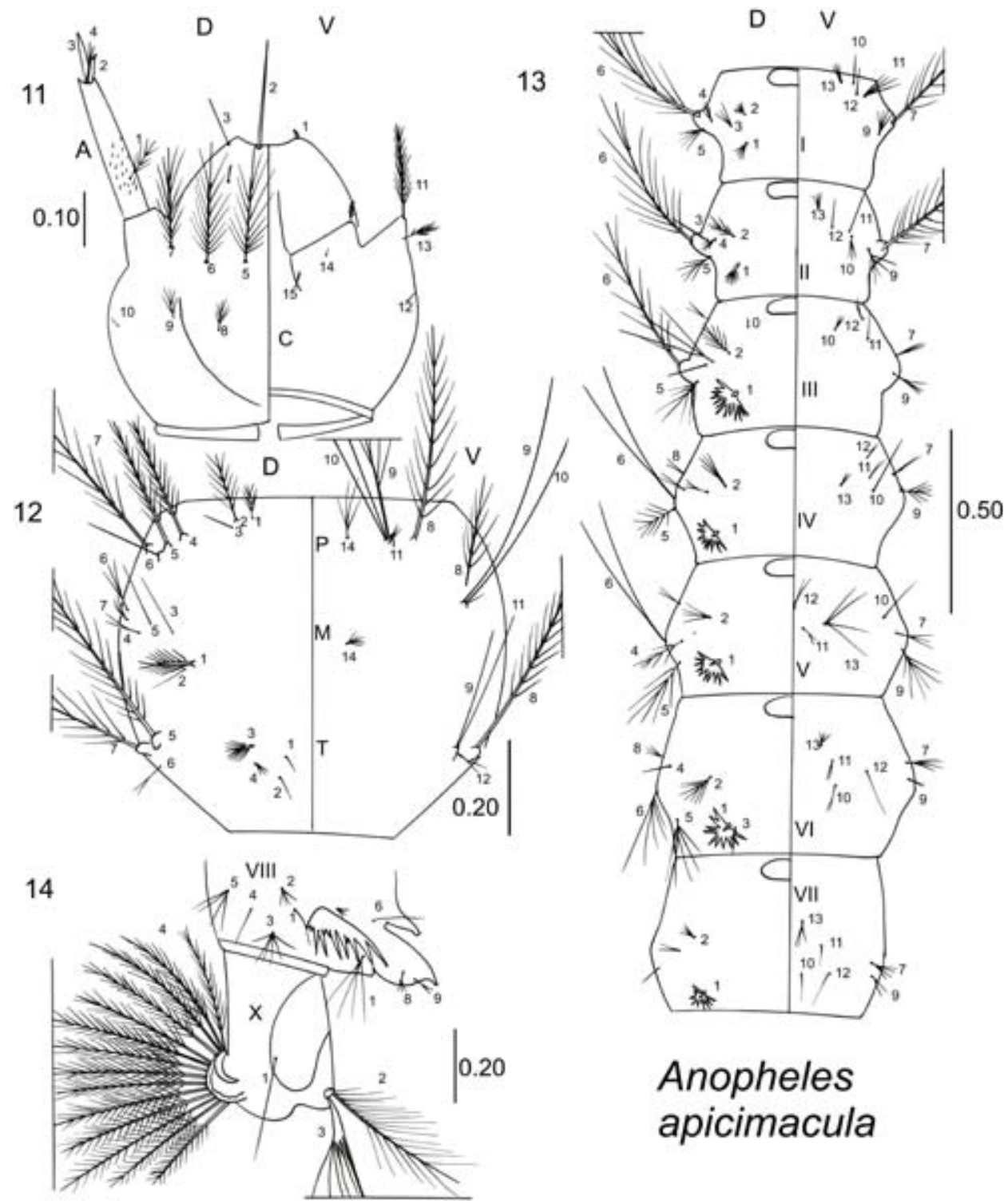

Figuras 11-14. Larva de Anopheles (Anopheles) apicimacula. 11: Cabeza. 12: Tórax. 13: Segmentos abdominales I-VII. 14: Segmentos abdominales VIII-X vista lateral.

6 (5). Cabeza con las sedas clipeales (2-3-C) simples (Fig. 44) . . . . . 7

6a. Cabeza con las sedas clipeales externas (3-C) ramificadas dicotómicamente y con más de 25 ramas terminales (Fig. 34) . . . . . . . . 9 


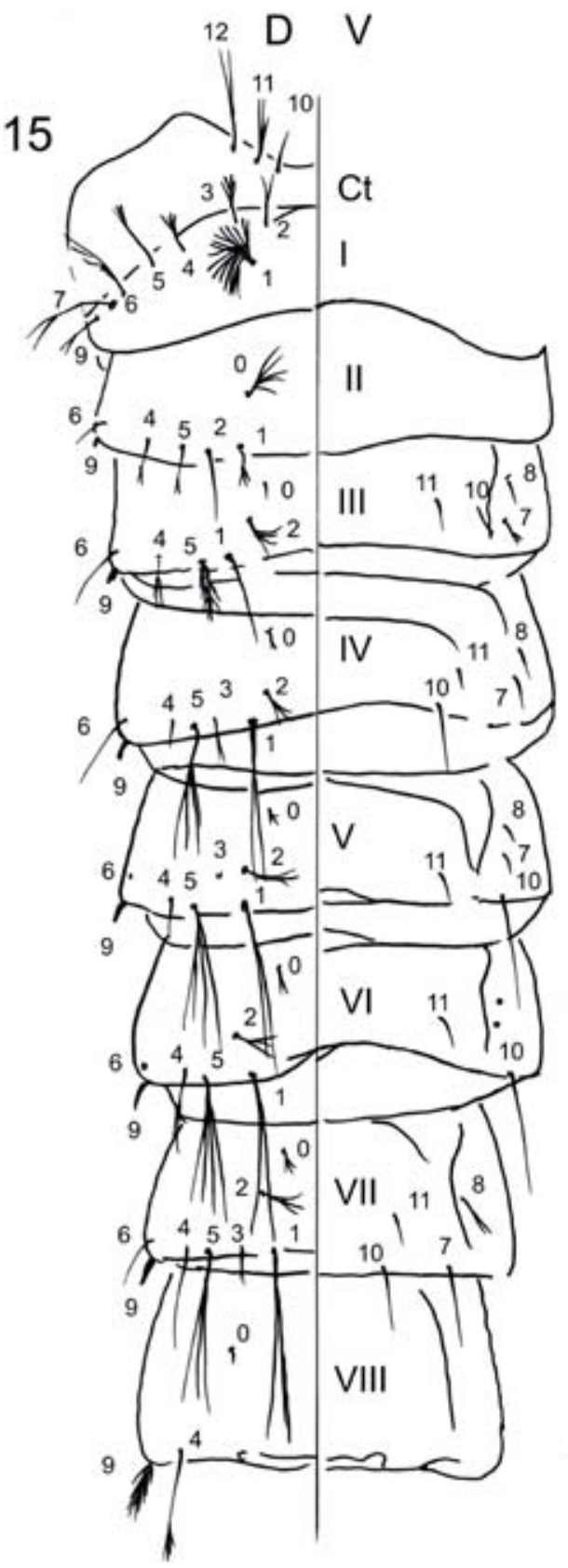

\section{Anopheles apicimacula}

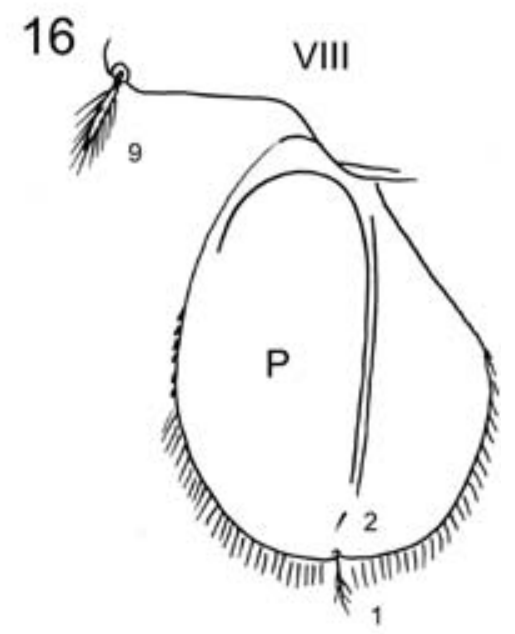

Figuras 15-16. Pupa de Anopheles (Anopheles) apicimacula (redibujada de Senevet, 1931). 15: Segmentos abdominales I-VIII.16: Paleta natatoria vista dorsal. 
7 (6). Abdomen con las sedas 1-II-VII palmeadas (Fig. 78). Cabeza con las sedas clipeales internas (2-C) muy juntas entre sí, tanto que sus alveolos casi se tocan (Fig. 76). Protórax con la seda 1-P con varias ramas fuertes (Fig. 45) y aparato ventilador nunca con filamento posterior lar-

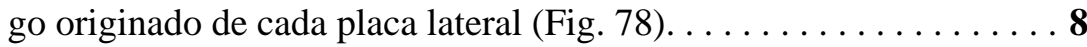

7a. Abdomen con las sedas 1-III-VII palmeadas (Fig. 90). Cabeza con las sedas clipeales internas (2-C) con sus alveolos alejados entre sí. Protórax con la seda 1-P corta, sencilla o la sumo con tres ramas (Fig. 89). Aparato ventilador con un par de filamentos largos, cada uno originado de la porción posterior de cada placa lateral (Fig. 90).

\section{Anopheles (Anopheles) pseudopunctipennis}

8 (7). Abdomen con la seda 6-III sencilla, sin ramas (Fig. 78). Protórax con la seda 1-P presentando el tronco largo y ramas laterales (Fig. 77) .............. Anopheles (Anopheles) parapunctipennis

8a. Abdomen con la seda 6-III con ramas (Fig. 46). Protórax con la seda 1-P presentando el tronco corto y ramas irradiadas (Fig. 45) ..................... Anopheles (Anopheles) eiseni

9 (6a). Abdomen con la seda $0-\mathrm{IV}-\mathrm{V}$ desarrollada y hasta con nueve ramas

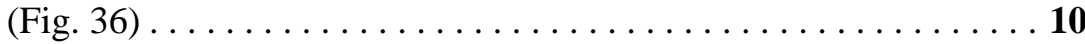

9a. Abdomen con la seda $0-\mathrm{IV}-\mathrm{V}$ pequeña y sencilla, difícil de observar (Fig. 25) .............................. 11

10 (9). Cabeza con las sedas $2-C$ con ramas pequeñas en los 0.33 apicales (Fig. 140). Abdomen con la seda 2-IV-V sencilla (Fig. 142). .

Anopheles (Anopheles) walkeri

10a. Cabeza con las sedas 2-C sencillas (Fig. 34). Abdomen con la seda 2IV-V compuestas por cuatro a diez ramas (Fig. 36) ...........

Anopheles (Anopheles) crucians

11 (9a). Cabeza con las sedas 2-C débiles, con sus troncos paralelos y con sus alvéolos separados entre sí por una distancia similar a dos diámetros de uno de sus alveolos (Fig. 120). Abdomen con la seda 1-I-II rudimentaria y la seda 2-IV-V sencilla (Fig. 122) . . . . . . . . . . . . . .

Anopheles (Anopheles) quadrimaculatus

11a. Cabeza con las sedas $2-C$ débiles o fuertes, con sus alvéolos separados entre sí por una distancia similar o menor al diámetro de un alveolo (Fig. 111). Otras características variables ............. 12

12 (11a). Antena de color pardo oscuro, con las espículas del tallo cortas pero robustas con sus bases muy anchas. Abdomen con la seda 2-IV-V sencilla (Fig. 25) . . . . . . . . . . . Anopheles (Anopheles) bradleyi

12a. Antena de color pardo claro o amarillento, con las espínulas del tallo largas y delgadas con sus bases angostas. Abdomen sin placas esclero- 
tizadas accesorias, con la seda 2-IV-V compuesta, casi siempre con tres ramas (Fig. 113). . . . . . . . Anopheles (Anopheles) punctipennis

13 (5a). Cabeza con las sedas 3-C sencillas o presentando cuando mucho cuatro

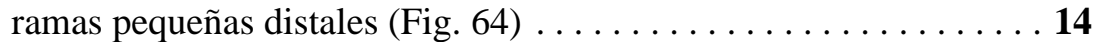

13a. Cabeza con las sedas 3-C ramificadas dicotómicamente con alrededor de diez ramas dispuestas a manera de abanico (Fig. 99) . . . . . . 15

14 (13). Protórax con las sedas 9, 10, 12-P sencillas; seda 1-P débil con pocas ramas finas (Fig. 65) .... . Anopheles (Anopheles) neomaculipalpus

14a. Protórax con las seda 9-P con alrededor de diez ramas; seda 1-P fuerte con muchas ramas largas (Fig. 12)

Anopheles (Anopheles) apicimacula

15 (13a). Protórax con todas las sedas pleurales (9-12-P) sencillas (Fig. 100) . Anopheles (Anopheles) punctimacula

15a. Protórax con la seda pleural anterior dorsal (9-P) presentando de tres a cinco ramas laterales (Fig. 56). . Anopheles (Anopheles) vestitipennis Anopheles (Anopheles) gabaldoni

16 (4a). Abdomen con las sedas 1-II-VII bien desarrolladas (Fig. 165). Sedas 2-C con sus alvéolos muy juntos entre sí, casi tocándose (Fig. 163) Anopheles (Nyssorhynchus) argyritarsis

16a. Abdomen con las sedas 1-I-VII bien desarrolladas (Fig. 177). Sedas 2-

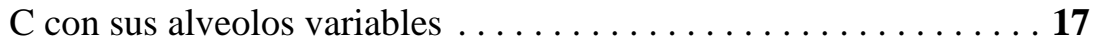

17 (16a). Protórax con la seda 1-P de tipo palmeado con ramas lanceoladas (Fig. 176). Sedas 2-C con sus alveolos muy juntos entre sí...........

. Anopheles (Nyssorhynchus) strodei

17a. Protórax con la seda 1-P de tipo setiforme, grande, con el tronco ancho y aplanado (Fig. 2). Sedas 2-C con sus alveolos tan alejados entre sí como de las sedas 3-C del lado respectivo (Fig. 1).

. Anopheles (Nyssorhynchus) albimanus

Pupas

1. Abdomen con la seda 9-III-VI espiniforme y situada en la esquina posterior del segmento respectivo (Fig. 5) . .................

Subfamilia Anophelinae ...... 3

1a. Abdomen con la seda 9-III-VI simple o ramificada, nunca espiniforme, situada lejos de la esquina posterior del segmento respectivo .................... Subfamilia Culicinae. . ....2

2 (1a). Paletilla caudal con la porción externa extendiéndose hacia atrás a manera de lóbulo y alcanzando más allá del nivel de la punta de la quilla ........................ Tribu Toxorhynchitini 


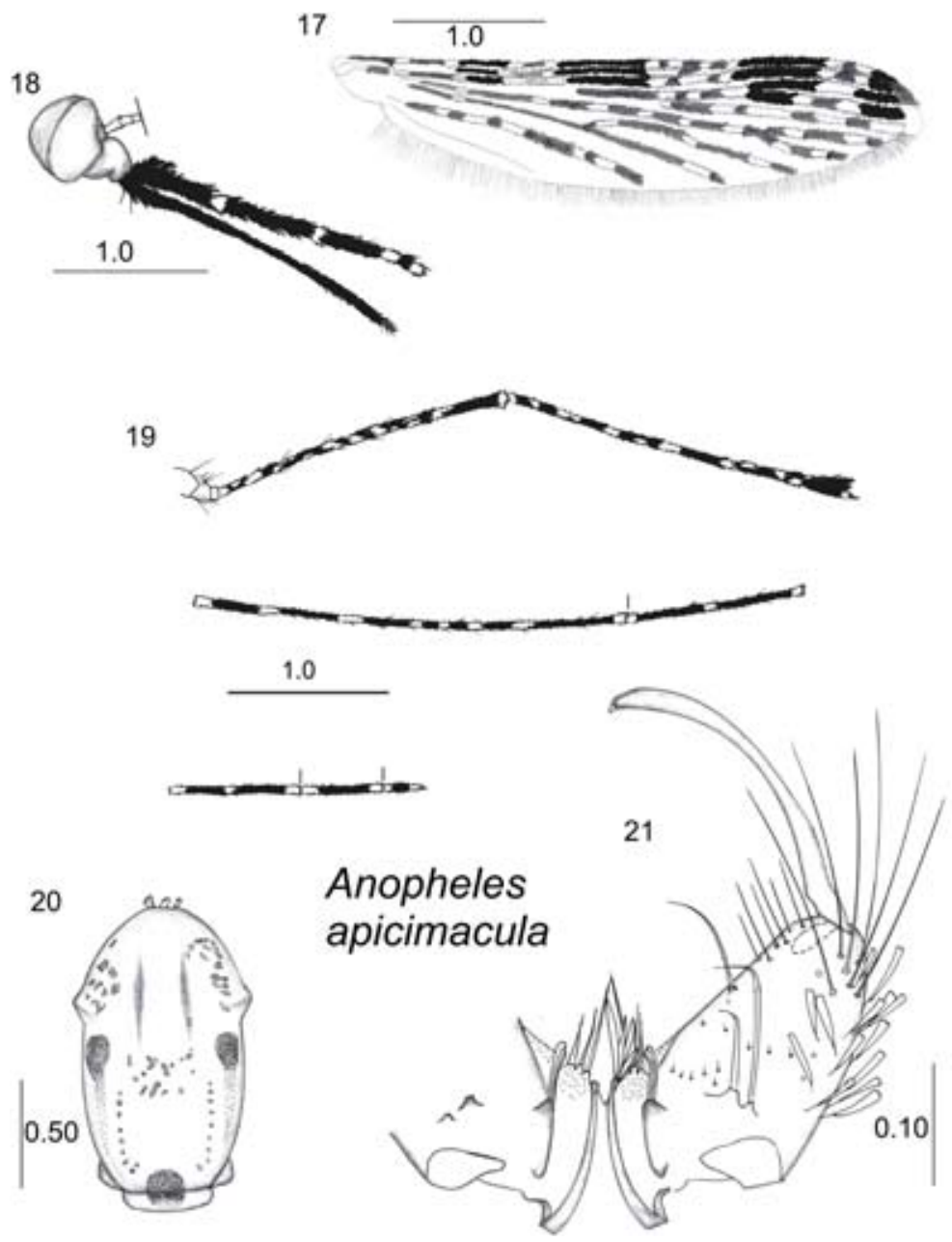

Figuras 17-21. Adultos de Anopheles (Anopheles) apicimacula. Hembra. 17: Ala. 18: Palpo maxilar. 19: Pata posterior. 20: Escudo y escudete. Macho. 21: Terminalia.

2a. Paletilla caudal con la porción externa nunca extendiéndose más allá del nivel de la punta de la quilla media o del margen posterior de la porción interna....................tribus restantes

3 (1). Abdomen con la seda 2-III-VII espiniforme, corta, gruesa y oscura; segmentos abdominales posteriores a partir del VI considerablemente delgados en comparación con los segmentos anteriores (Fig. 189) 
3a. Abdomen con la seda 2-III-VII setiforme y delicada, frecuentemente ramificada (Fig. 5) . . . . . . . . . . . . . Anopheles. . . . 4

4 (3a). Abdomen con la seda 9-IV-VII presentando ramas laterales cortas. Paleta natatoria con hilera de sedas largas y onduladas en la porción preapical (Fig. 150). .Anopheles (Kerteszia) neivai

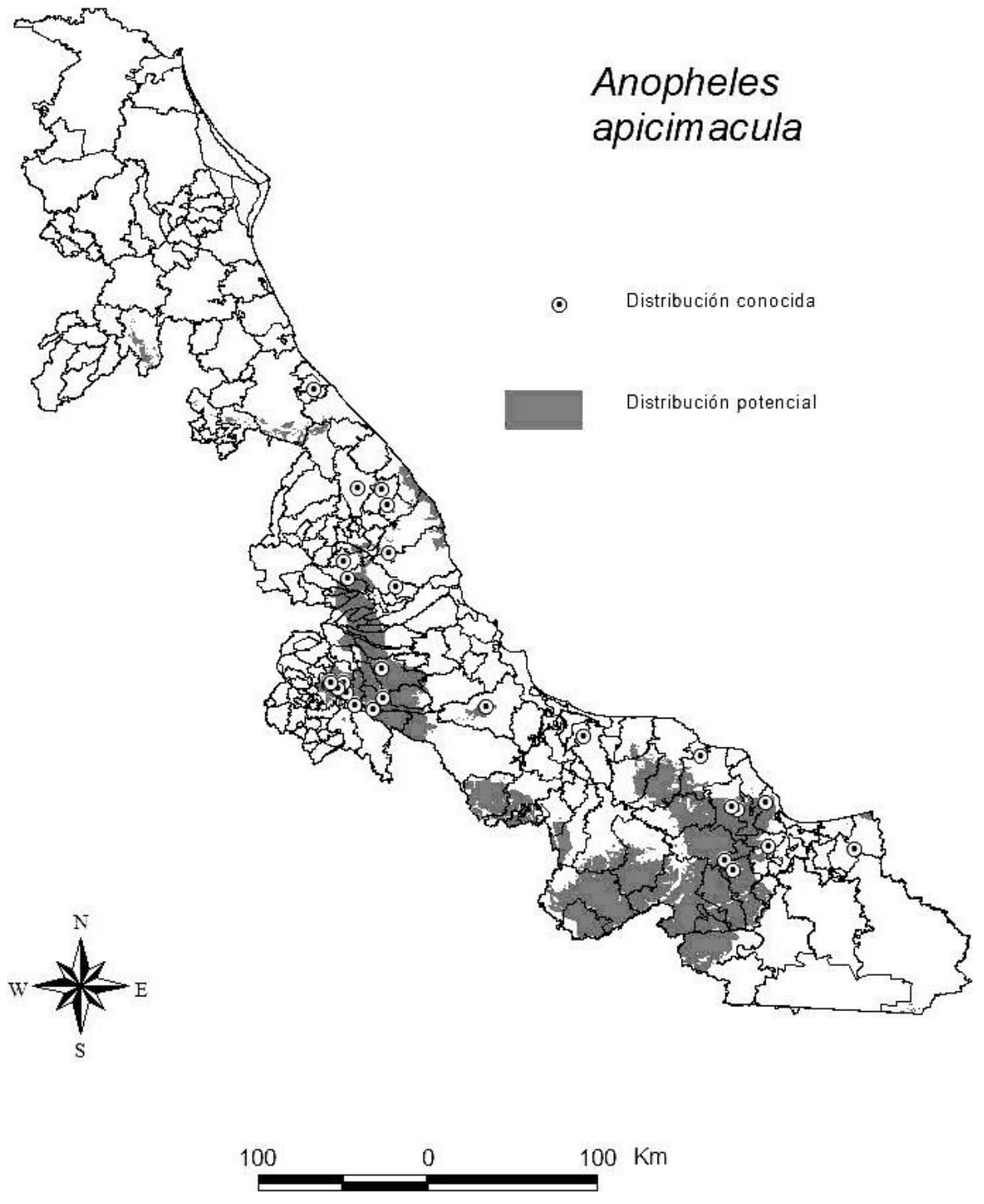

Figura 22. Mapa de la distribución conocida y potencial de Anopheles (Anopheles)apicimacula. 
4a. Abdomen con la seda 9-IV-VII careciendo de ramas laterales. Paleta natatoria sin hilera de sedas largas y onduladas en la porción preapical

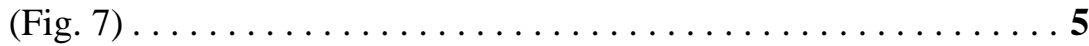

5 (4a). Abdomen con la seda 9-VIII con ramas, aunque sean pocas y cortas (Figs. 15, 145) ........................... 9

5a. Abdomen con la seda 9-VIII carente de ramas (Fig. 91) . . . . . 6

6 (5a). Abdomen con la seda 9-IV puntiaguda similar a la misma seda de los siguientes segmentos; seda 1-P a manera de gancho (Fig. 91) .............. Anopheles (Anopheles) pseudopunctipennis

6a. Abdomen con la seda 9-IV roma, diferente a la misma seda de los siguientes segmentos; seda 1-P recta o a manera de gancho (Figs. 5, 166) . . . . . . . . . . Anopheles (Nyssorhynchus). . . . 7

7 (6a). Paleta natatoria con la seda 1-P grande y a manera de gancho (Fig. 166) .............. Anopheles (Nyssorhynchus) argyritarsis

7a. Paleta natatoria con la seda 1-P relativamente pequeña, recta u ondula-

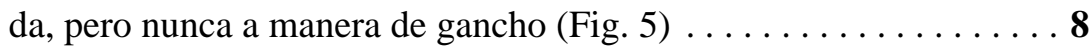

8 (7a). Longitud de la seda 9-V menor a 2.3 veces la longitud de la seda 9-IV; seda 9-VI relativamente corta, 9-VII con 1.4 a 2.0 veces la longitud de 9-VI (Fig. 178); seda 7-Ct bifurcada con una de las ramas más larga que la otra . . . . . . . . . . . Anopheles (Nyssorhynchus) strodei

8a. Longitud de la seda $9-\mathrm{V}$ igual o mayor que 2.3 veces la longitud de la seda 9-IV, aunque en raras ocasiones puede ser tan larga como 2.0; seda 9-VI larga, 9-VII con 1.0 a 1.5 veces la longitud de 9-VI (Fig. 5); seda 7-Ct bifurcada con las ramas de longitud similar (Fig. 6) ..........

\section{Anopheles (Nyssorhynchus) albimanus}

9 (5). $\quad$ Sedas 1-VII y 5-VII sencillas; seda 1-P con hasta 4 ramas distales aunque en ocasiones es sencilla, la 2-P ramificada (Fig. 123) .........

Anopheles (Anopheles) quadrimaculatus

9a. Alguna o las dos sedas 1-VII y 5-VII ramificada (Fig. 132), otras características variables ...................... 10

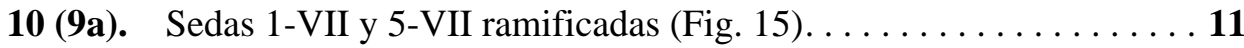

10a. Seda 1-VII sencilla, la seda 5-VII ramificada (Fig. 132) . . . . . . 15

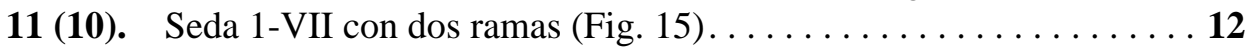

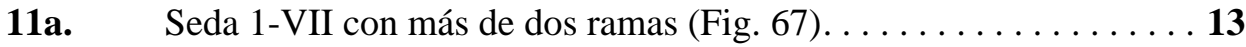

12 (11). Sedas 1-IV-VII con dos ramas; seda 1-P comúnmente con ramas distales; Abdomen con los segmentos III-VII careciendo de espículas en el borde posterior (Figs. 15-16) . . . Anopheles (Anopheles) apicimacula

12a. Sedas 1-IV-VI con más de dos ramas; seda 1-P sencilla; Abdomen con la seda 5-III con menos de siete ramas, seda 2-I con menos de cuatro 
ramas (Figs. 27 y 29); cefalotórax con la seda 10-Ct presentando más de dos ramas. ...............Anopheles (Anopheles) bradleyi

13 (11a). Trompeta ventiladora con el borde distal presentando una proyección puntiaguda e incisión secundaria grande (Fig. 69); seda 2-II- VII sencilla; seda 1-P con ramas (Fig. 67)

13a. Trompeta ventiladora con el borde distal careciendo de proyecciones largas y sin incisión secundaria (Fig. 38); en general la seda 2-II-VII con dos o más ramas (Fig. 37); seda 1-P sencilla (Fig. 39) . . . . . 14

14 (13a). Sedas 1- y 5-III-VII con más de cuatro ramas (Fig. 37)

Anopheles (Anopheles) crucians

14a. Sedas 1- y 5-III-VII con menos de cuatro ramas (Fig. 143)

Anopheles (Anopheles) walkeri

15 (10a). Trompeta ventiladora con una proyección larga digitiforme en su borde distal (Fig. 133). Abdomen con los segmentos IV-VII careciendo de espículas en el borde lateral. ... Anopheles (Anopheles) vestitipennis

15a. Trompeta ventiladora sin la proyección larga digitiforme (Figs. 60, 103); otras características variables. . . . . . . . . . 16

16 (15a). Trompeta ventiladora corta y ancha con tres lóbulos cortos redondeados en su borde distal (Fig. 103). Abdomen con los segmentos IV-VII presentando espículas en el borde lateral. ................

Anopheles (Anopheles) punctimacula

16a. Trompeta ventiladora más larga que ancha, sin los lóbulos descritos (Figs. 49, 60); otras características variables............ 17

17 (16a). Trompeta ventiladora con dos hendiduras: la normal y otra accesoria (Fig. 60). Abdomen con los segmentos III-VII presentando espículas en el borde posterior y segmentos IV-VII careciendo de espículas en el borde lateral . . . . . . . . . . . Anopheles (Anopheles) gabaldoni

17a. Trompeta ventiladora con una sola hendidura (Fig. 49). Otras características variables. ..................... 18

18 (17a). Abdomen con la seda 5-VII doble (Fig. 79) . . . . . . . . . 19

18a. Abdomen con la seda 5-VII con más de dos ramas; Seda 1- VI-VII sencilla; paletilla sin espículas cortas en la parte media del margen externo (Fig. 47) . . . . . . . . . . . . . Anopheles (Anopheles) eiseni

19 (18). Seda 1- V-VI doble (Fig. 114); paletilla con espículas cortas en la parte media del margen externo (Fig. 116).

\section{Anopheles (Anopheles) punctipennis}

19a. Seda 1- V-VI sencilla; paletilla sin espículas cortas en la parte media del margen externo (Fig. 79) 

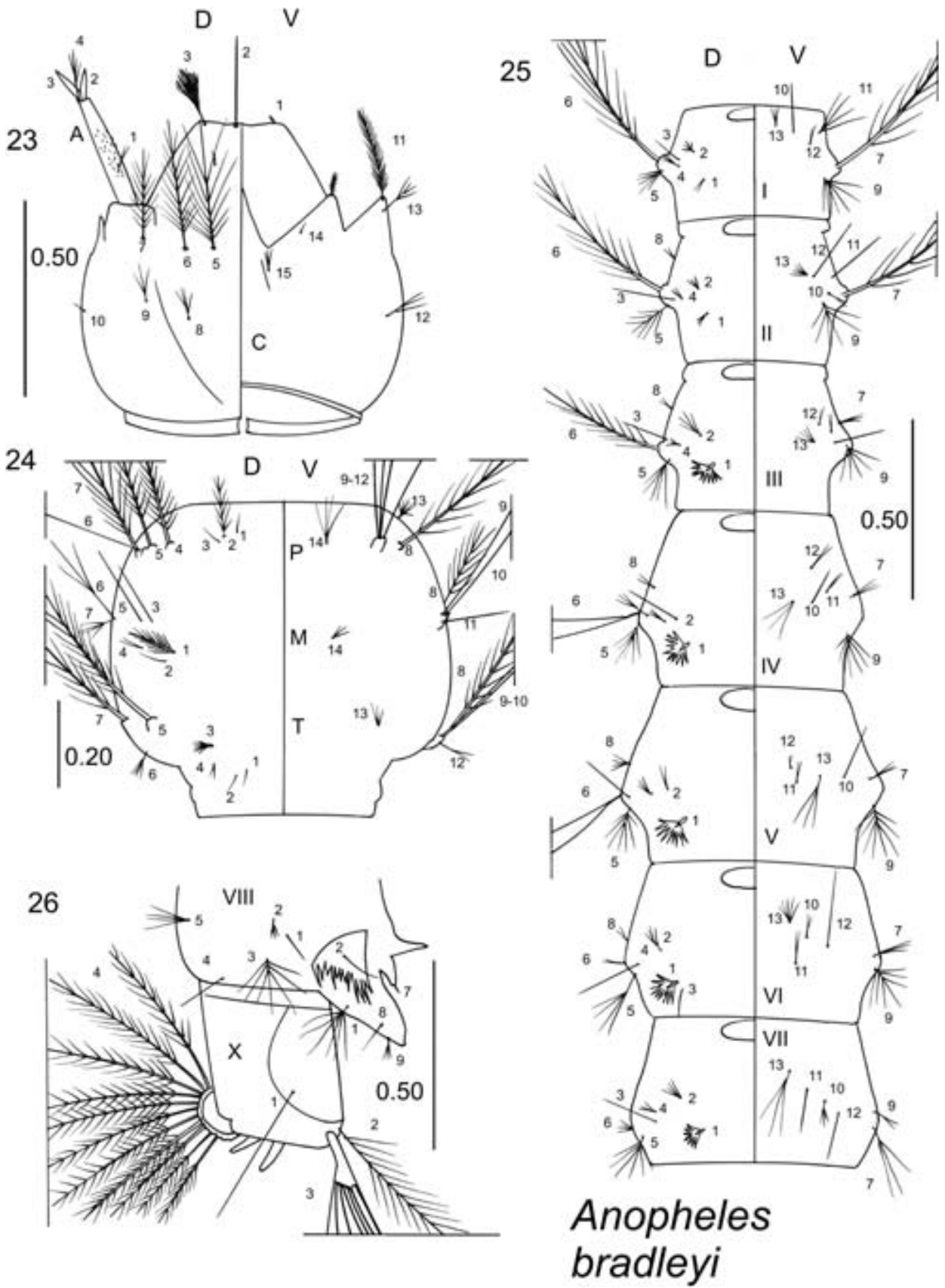

24

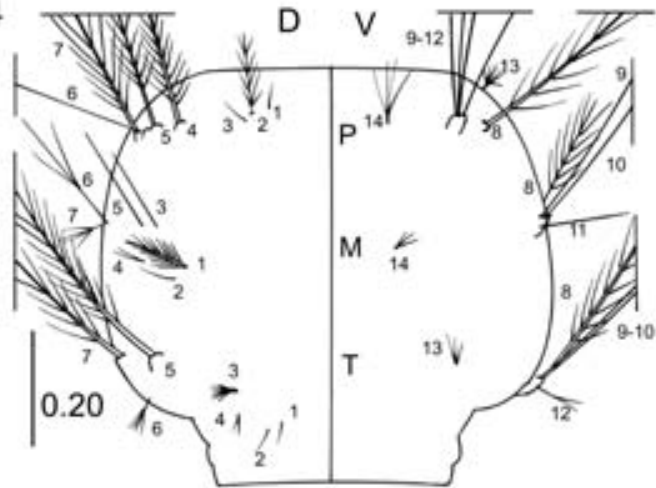

26

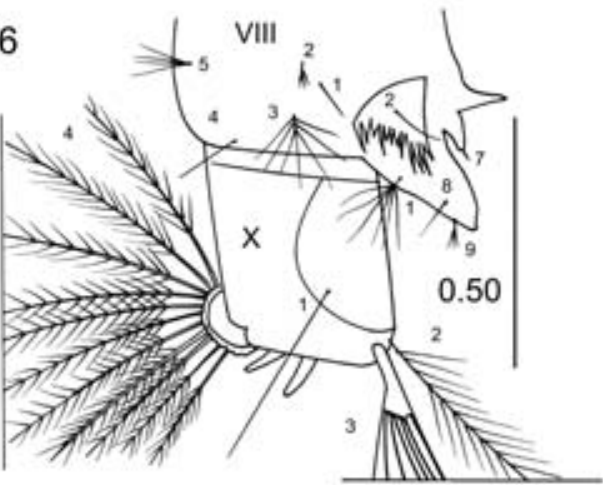

\section{Anopheles bradleyi}

Figuras 23-26. Larva de Anopheles (Anopheles) bradleyi. 23: Cabeza. 24: Tórax. 25: Segmentos abdominales I-VII. 26: Segmentos abdominales VIII-X vista lateral. 

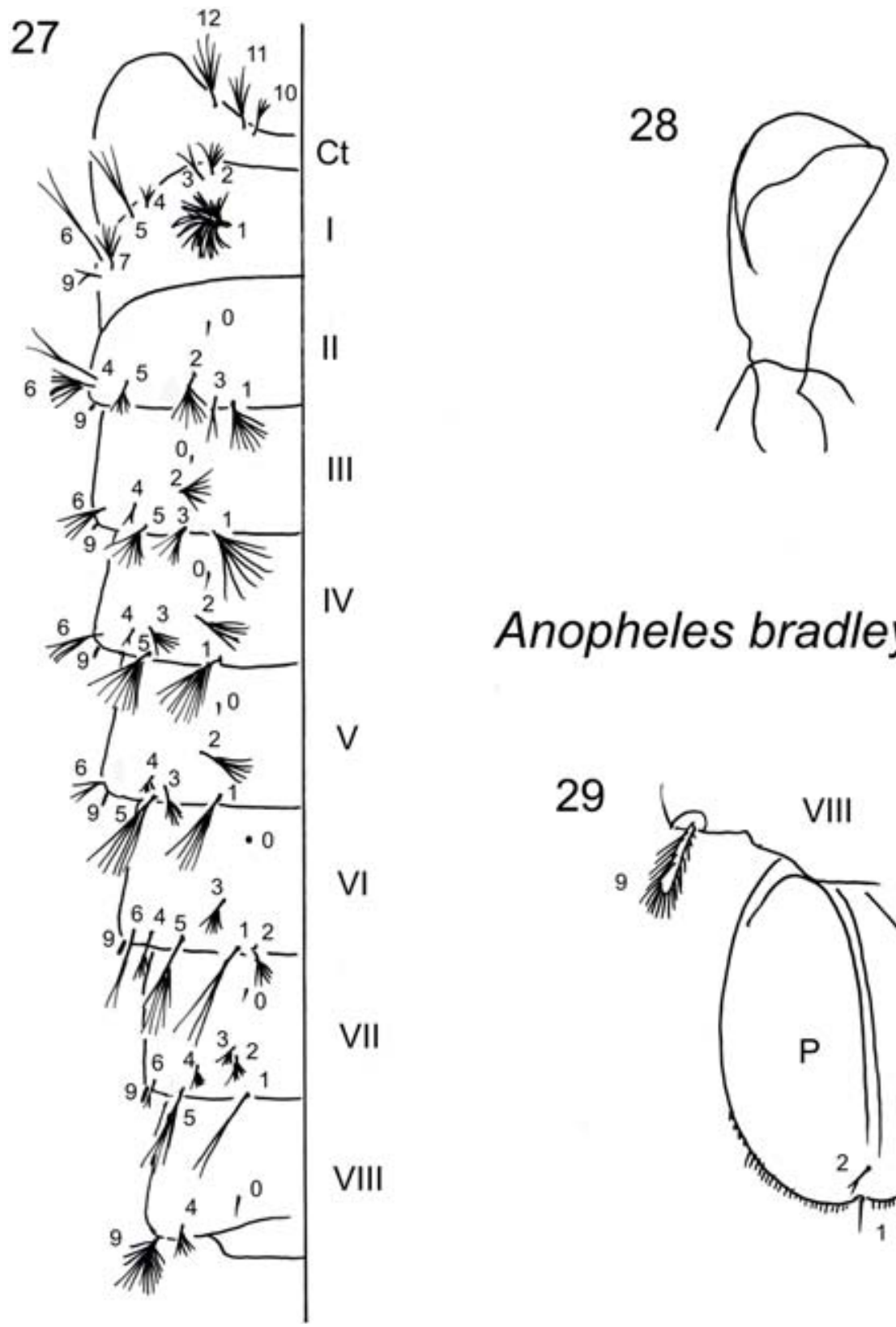

\section{Anopheles bradleyi}

Figuras 27-29. Pupa de Anopheles (Anopheles) bradleyi (redibujada de Penn, 1949). 27: Segmentos abdominales I-VIII vista dorsal. 28: Trompeta ventiladora. 29: Paleta natatoria izquierda vista dorsal. 


\section{HEMBRAS}

1. Probóscide arqueada con el ápice dirigido hacia atrás; mosquitos grandes con coloración metálica.....................

\section{Subfamilia Culicinae, Tribu Toxorhynchitini}

1a. Probóscide recta o con curvaturas sutiles; mosquitos generalmente de tamaño pequeño en comparación con el grupo anterior y con coloración variable. ............................... 2

2 (1a). Palpo tan largo como la probóscide; abdomen con los esternitos y terguitos sin o con muy pocas escamas (Fig. 8)...............

Subfamilia Anophelinae .... . . 3

2a. Palpo mucho más corto que la probóscide; abdomen con los esternitos y terguitos densa y uniformemente recubiertos con escamas................... Subfamilia Culicinae (en parte)

3 (2). Escudete trilobulado, con tres grupos de sedas separados entre sí; con dos mechones de escamas espatuladas largas en posición anterior a la inserción del ala; postpronoto con sedas y escamas (Figs. 191-

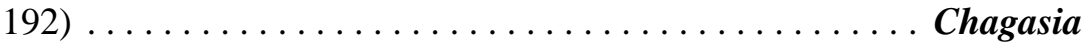

Chagasia bathana

3a. Escudete redondeado con sedas distribuidas homogéneamente sin que formen grupos (Fig. 20); sin mechones de escamas espatuladas anteriores a la inserción del ala; postpronoto sin sedas ni escamas (Fig. 108)

Anopheles. .... 4

4 (3a). Patas con los fémures y las tibias de un solo color o con pocas manchas oscuras pequeñas (Figs. 8, 52). Ala con la vena costal (C) en el tramo cercano a la unión de la vena subcostal (Sc) oscura o presentando una sola mancha clara (Figs. 50, 82). Si está presente sobre la vena costal la mancha clara del sector, ésta no está interrumpida por una mancha oscura (Fig. 153) . . . . . . . . . . . . . . . . . . . . 5

4a. Patas con los fémures y las tibias con gran número de manchas claras grandes (Fig. 19). Ala con la vena costal (C) en el tramo cercano a la unión de la vena subcostal (Sc) con una mancha oscura pequeña o grande, flanqueada por una o más manchas claras y oscuras. Mancha clara del sector interrumpida por una mancha oscura accesoria (Fig. 17) ................Anopheles (Anopheles), en parte. . . 7

5 (4). Pata posterior con los tarsómeros presentando bandas apicales claras o algunos de ellos con estas bandas y otros completamente claros (Figs. 154, 159). Alas con la vena costal (C) casi siempre presentando ocho manchas claras (Fig. 181) . . . . . . . . . . . . . . . 6

5a. Pata posterior con los tarsómeros careciendo de bandas apicales claras (Fig. 52) o, cuando mucho, algunos pueden presentar manchas claras o bandas muy angostas en la base (Fig. 19). Alas con la vena costal (C) 
casi siempre oscura o con una a cinco manchas claras (Figs. 30, 94, 126) ................. Anopheles (Anopheles), en parte. . 11

6 (5). Escudo con cuatro franjas oscuras longitudinales (Fig. 155). Pata posterior con los tarsómeros presentando bandas claras apicales conspicuas (Fig. 154). Ala con la vena costal presentando la mancha clara que se encuentra al nivel del origen del sector radial, cerca de la parte media del ala y dispuesta a una distancia similar entre la manchas claras previa y siguiente (Fig. 153). Pata posterior con el segundo tarsómero presentando una banda basal oscura no mayor a la mitad del artejo (Fig. 154) . . . . . . . . . . . . . . Anopheles (Kerteszia) neivai

6a. Escudo diferente. Pata posterior con los tarsómeros 3 y 4 completamente claros (Fig. 159). Ala con la vena costal presentando la mancha clara que se encuentra al nivel del origen del sector radial antes de la parte media del ala y dispuesta más cerca de la mancha clara que le precede que con respecto a la mancha clara siguiente (Fig. 157). Pata posterior con el segundo tarsómero variable.

Anopheles (Nyssorhynchus) . . . . 18

7 (4a). Escudo con tres manchas polinosas oscuras acentuadas por la presencia de polinosidad plateada, un par lateral por delante de la inserción de las alas y una sola central posterior que también ocupa el disco del escudete (Fig. 20). Ala con predominio de escamas claras, en particular la vena $\mathrm{R}_{4+5}$ (Figs. 17, 70) ................... 9

7a. Escudo sin las tres manchas polinosas mencionadas en el dilema anterior. Ala con predominio de escamas oscuras, en particular la vena $\mathrm{R}_{4+5}$

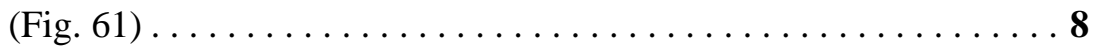

8 (7a). Abdomen con los terguitos presentando mechones de escamas posterolaterales, los esternitos con numerosas escamas claras y oscuras.................. Anopheles (Anopheles) gabaldoni

8a. Abdomen con los terguitos careciendo de mechones de escamas posterolaterales, los esternitos con escamas claras y oscuras esparcidas ................. Anopheles (Anopheles) vestitipennis

9 (7). Ala con la vena cubital $(\mathrm{Cu})$ revestida de escamas oscuras, pequeñas en comparación con las escamas de otras venas cercanas y aplicadas estrechamente a la superficie. Margen anterior del ala con cuatro manchas de escamas muy oscuras, ya que existe una mancha apical (formada por las escamas del ápice de la $\mathrm{R}_{1} \mathrm{y}$ de la $\mathrm{R}_{2}$ ) (Fig. 17). . . . . . . . .

\section{Anopheles (Anopheles) apicimacula}

9a. Ala con la vena cubital $(\mathrm{Cu})$ revestida en su mayor parte con escamas claras o con una mezcla de claras y oscuras, similares en tamaño a las escamas de otras venas cercanas y frecuentemente no aplicadas es- 


\section{0}

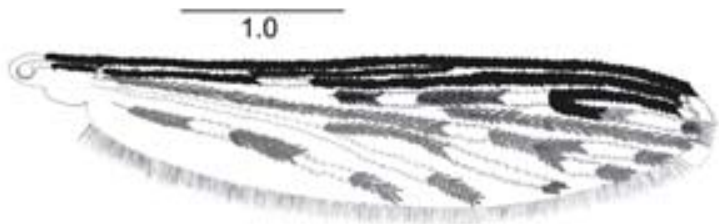

31
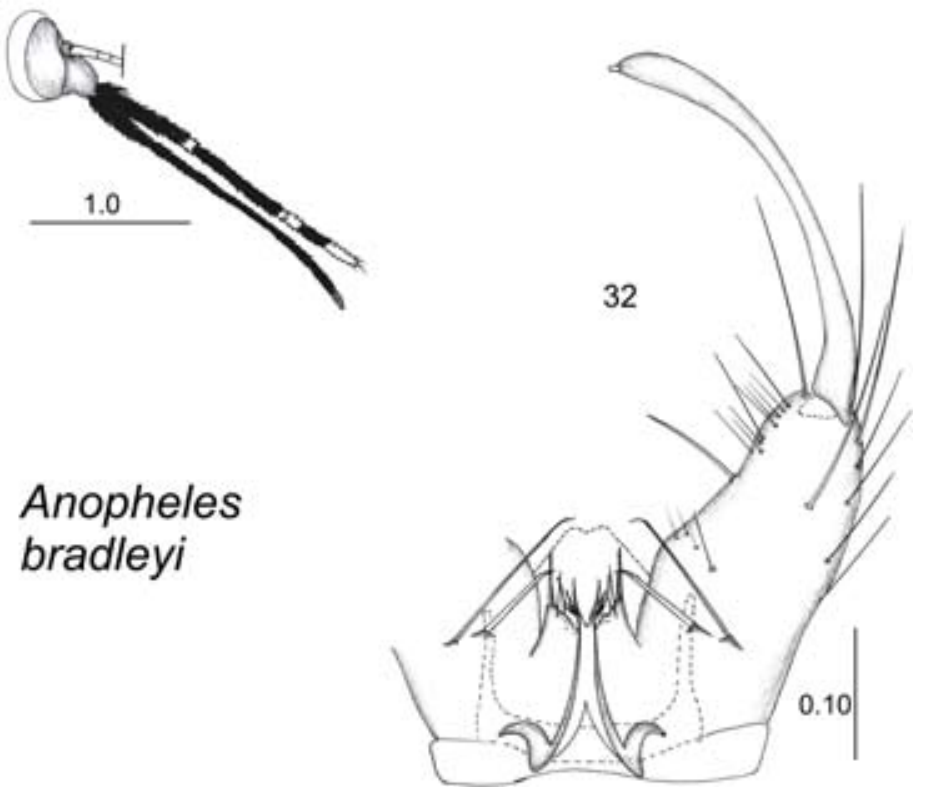

Anopheles bradleyi

Figuras 30-32. Adultos de Anopheles (Anopheles) bradleyi. Hembra. 30: Ala. 31: Palpo maxilar. Macho. 32: Terminalia.

trechamente a la superficie. Margen anterior del ala con tres o cuatro manchas de escamas muy oscuras, ya que existe una mancha apical (formada por las escamas del ápice de la $\mathrm{R}_{1} \mathrm{y}$ de $\mathrm{la}_{2}$ ), pero esta última puede ser difícil de observar (Fig. 105) . . . . . . . . . . . 10

10 (9a). Ala con la mancha oscura preapical pequeña (Fig. 70). Abdomen con el esternito I presentando pocas escamas claras posterolaterales.............. Anopheles (Anopheles) neomaculipalpus 


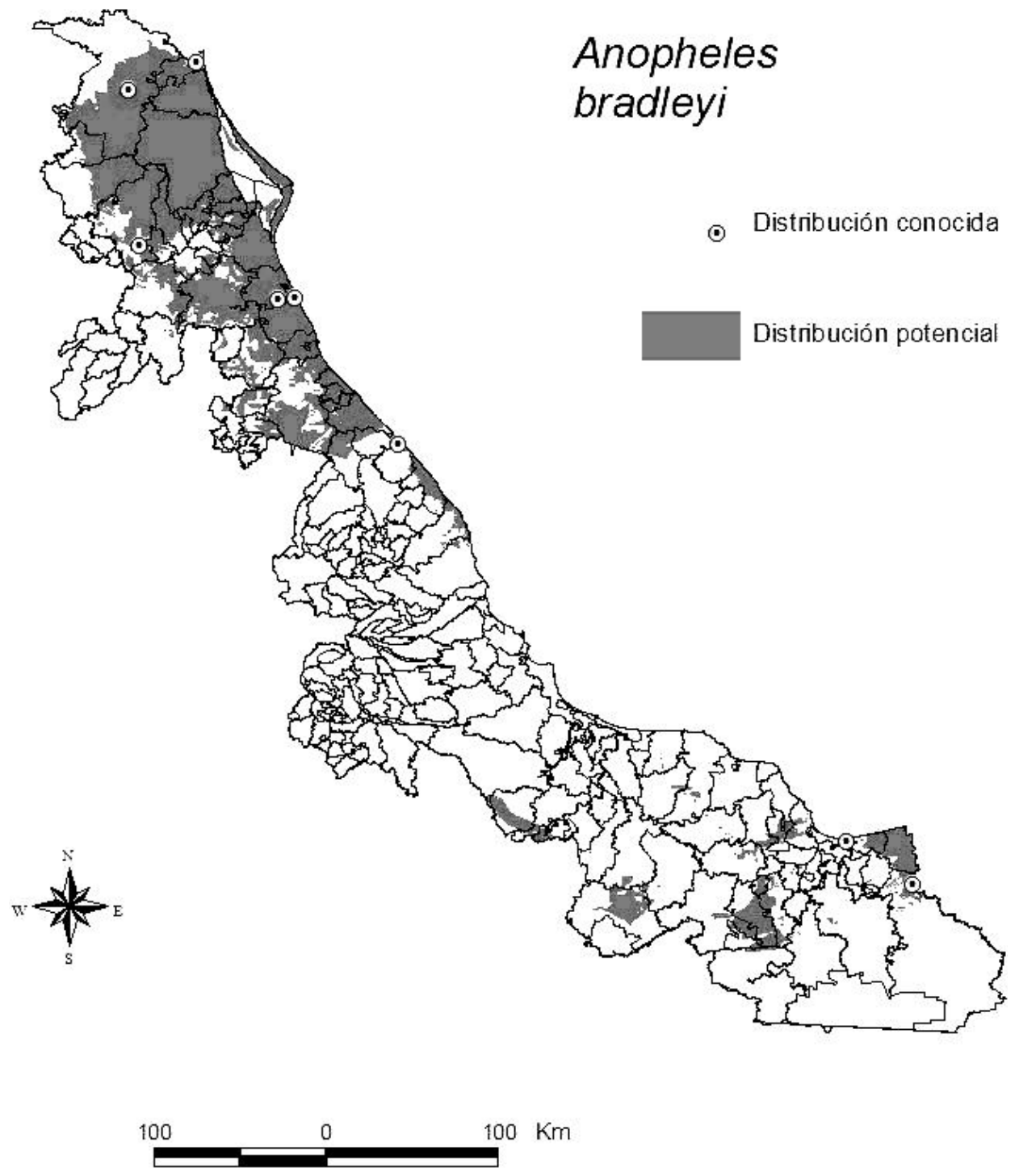

Figura 33. Mapa de la distribución conocida y potencial de Anopheles (Anopheles) bradleyi.

10a. Ala con la mancha oscura preapical grande (Fig. 105). Abdomen con el esternito I desnudo. Mesepimerón sin escamas superiores claras (Fig. 108). Pata posterior con el tarsómero 5 con escamas claras y una banda o mancha oscura central (Fig. 107) .................... 
11 (5a). Ala totalmente revestida con escamas oscuras (Fig. 126) . . . . 12

11a. Ala con una o más manchas de escamas claras (Figs. 29, 50) . . . 13

12 (11). Palpo con escamas claras en las articulaciones de los palpómeros 2-3, 3-4, 4-5 y en el ápice del 5 (Fig. 8) . . Anopheles (Anopheles) walkeri

12a. Palpo enteramente con escamas oscuras .

13 (11a). Pata posterior con la tibia presentando una banda apical ancha y el fémur con pocas escamas claras (Fig. 52). Ala con la vena costal (C) revestida con escamas oscuras excepto por algunas claras que forman una mancha preapical que involucra el ápice de la vena $\mathrm{R}_{1}$ (Fig. $50) \ldots \ldots \ldots \ldots \ldots \ldots$. . . . . . . . . . . Anopheles (Anopeles) eiseni

13a. Sin la combinación de características del dilema anterior. . . . . . 14

14 (13a). Ala con la vena costal presentando una sola mancha clara apical (Fig. 30) ........................... 15

14a. Ala con la vena costal presentando al menos dos manchas claras, la

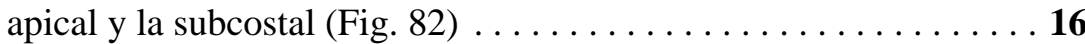

15 (14). Ala con la vena cubital presentando frecuentemente escamas claras hasta el nivel de la vena transversal m-cu (Fig. 30).

\section{.Anopheles (Anopheles) bradleyi}

15a. Ala con la vena cubital presentando frecuentemente escamas oscuras hasta el nivel de la vena transversal m-cu (Fig. 40)...............

Anopheles (Anopheles) crucians

16 (14a). Ala con la base de la costa con escamas oscuras, sin manchas clara prehumeral y clara humeral (Fig. 94). Palpo y escudo con patrón de coloración diferente....................... 17

16a. Ala con la base de la costa presentando manchas clara prehumeral y clara humeral; sin mancha pálida del sector (Fig. 82). Escudo con el borde anterior de la franja plateada mediodorsal con escamas delgadas fusiformes de color blanco (Fig. 85). Palpo casi completamente con escamas oscuras, excepto por el ápice del palpómero 3, y la base del palpómero 4 y 5 que presentan escamas claras (Fig. 83). Balancín con el capitelo oscuro (Fig. 84)

\section{Anopheles (Anopheles) parapunctipennis}

17 (16). Ala con la vena cubital recubierta con escamas oscuras; vena Rs y $\mathrm{R}_{1}$ con escamas oscuras, excepto por las manchas claras subcostal y apical (Fig. 117). Palpo únicamente con escamas oscuras (Fig. 118) .................Anopheles (Anopheles) punctipennis

17a. Ala con la vena cubital recubierta predominantemente con escamas claras; vena Rs y $\mathrm{R}_{1}$ con escamas claras, excepto por las manchas oscuras del presector, del sector y preapical; vena medial recubierta predomi- 
nantemente con escamas claras (Figura 94). Palpo con escamas claras en las articulaciones y el palpómero 5 recubierto completamente por escamas claras (Fig. 95).

\section{Anopheles (Anopheles) pseudopunctipennis}

18 (6a). Pata posterior con el tarsómero 5 presentando una banda basal de escamas oscuras (Fig. 159). . . . . . . . . . . . . . . . . 19

18a. Pata posterior con el tarsómero 5 revestido en su totalidad con escamas claras (Fig. 171). Ala con la vena costal presentando la mancha clara humeral más larga que la mancha oscura prehumeral; las escamas claras de la porción anterior del ala blancas (Fig. 169). Abdomen con el terguito II careciendo un mechón de escamas oscuras postero-laterales................ Anopheles (Nyssorhynchus) argyritarsis

19 (18). Abdomen con el terguito II presentando mechones de escamas oscuras postero-laterales. Palpo con el palpómero 4 presentando por lo menos algunas escamas claras (Fig. 182). Pata anterior con el tarsómero 5 variable .................. Anopheles (Nyssorhynchus) strodei

19a. Abdomen con el terguito II careciendo de mechones de escamas oscuras postero-laterales. Palpo con el palpómero 4 con escamas oscuras o cuando mucho con algunas escamas claras de color amarillo en la parte lateral (Fig. 170). Pata anterior con el tarsómero 5 completamente oscuro ................ Anopheles (Nyssorhynchus) albimanus

\section{TERMiNALIA MASCULINOS}

1. Proctígero membranoso casi en su totalidad. Paraprocto no distinguible. Edeago largo y cilíndrico con excepción de su base, su ápice con hojillas o un par de procesos largos y delgados con puntas divididas ......................... 3

1a. Proctígero con desarrollo variable pero al menos presenta esclerotizaciones evidentes. Paraprocto visible, generalmente con hilera transversal de espinas, con dentículos o con espínulas. Edeago variable pero nunca presentando hojillas o procesos largos y delgados con puntas divididas en su ápice . . . . . . . . . . Subfamilia Culicinae. ... . 2

2 (1a). Segmentos abdominales VII y VIII con mechones de escamas lineares largas, terguito IX largo y no dividido con sedas restringidas a las porciones laterales. ................. Tribu Toxorhynchitini

2a. Segmentos abdominales VII y VIII y terguito IX diferentes a lo descrito en el dilema contrario ....... Subfamilia Culicinae, tribus restantes

3 (1). Gonocoxito con sedas espiniformes parabasales y carente de lóbulo subbasal (Fig. 21). . . . . . . . . . . . . . . . Anopheles. . . . 4 
34

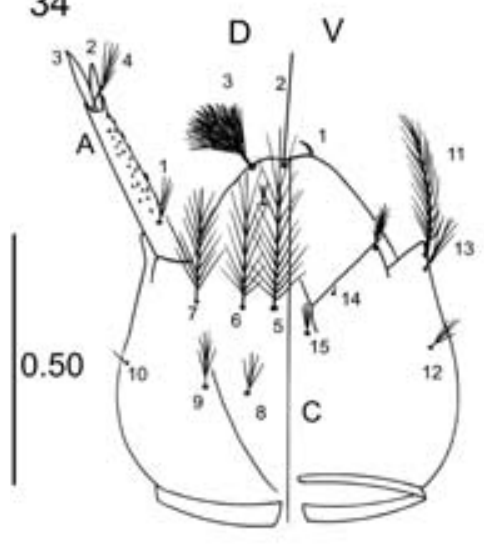

Anopheles crucians
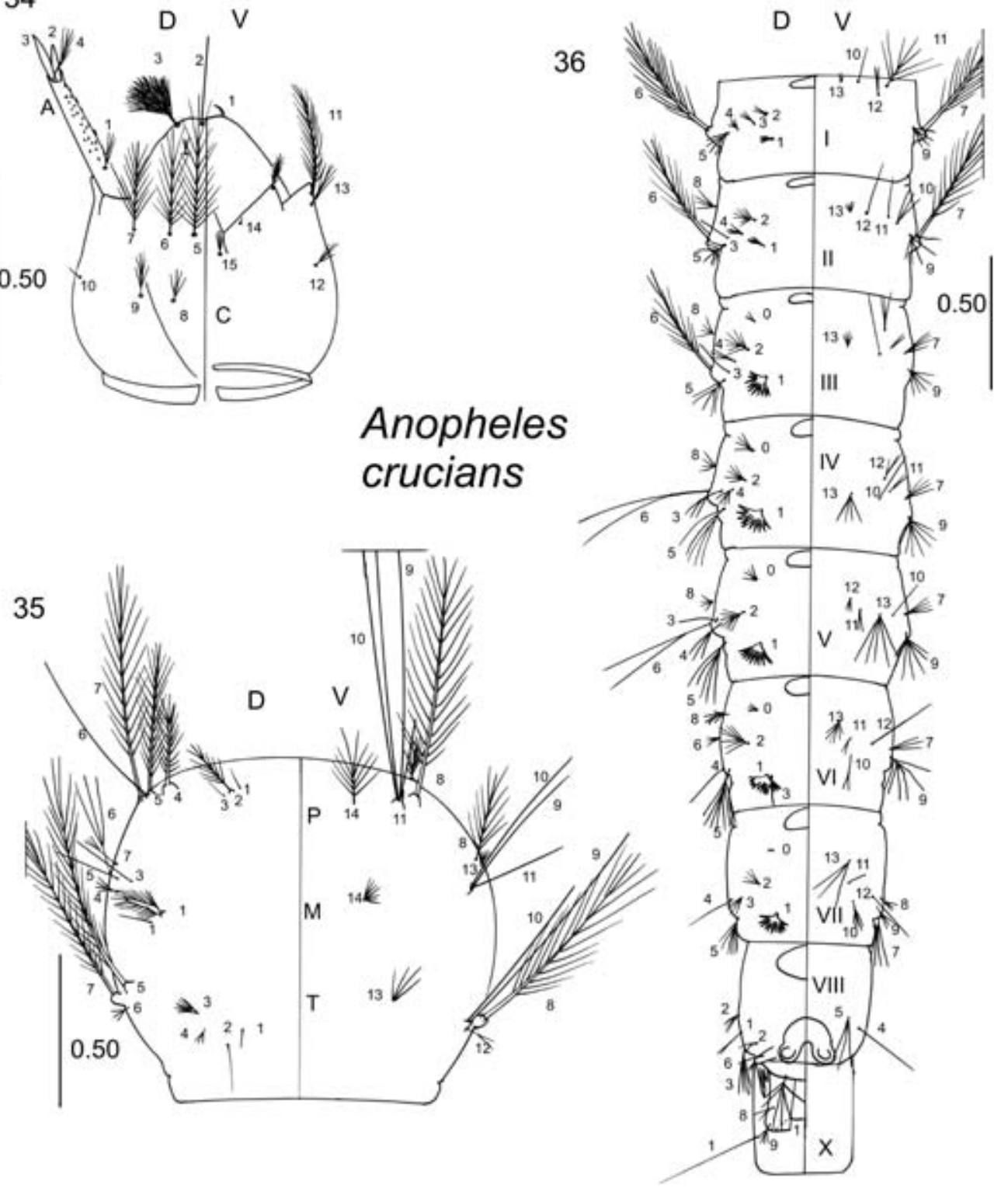

Figuras 34-36. Larva de Anopheles (Anopheles) crucians. 34: Cabeza. 35: Tórax. 36: Abdomen. 

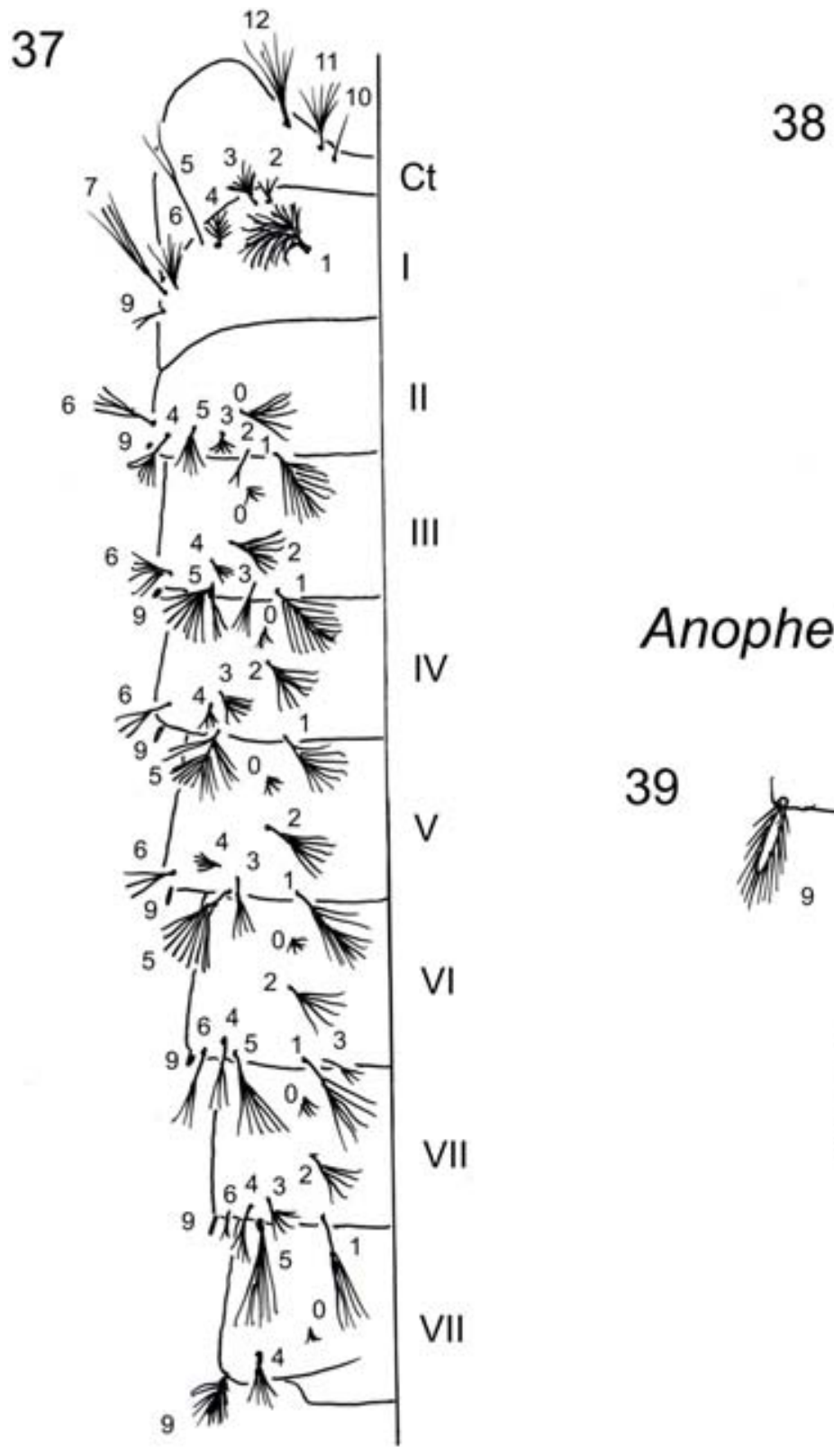

\section{Anopheles crucians}

39

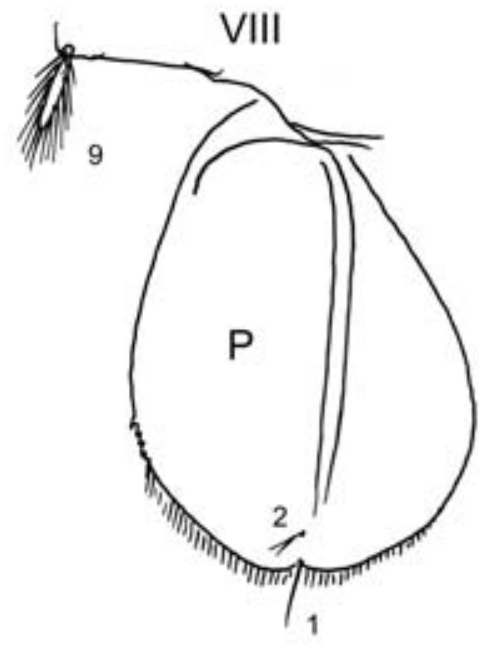

Figuras 37-39. Pupa de Anopheles (Anopheles) crucians (redibujada de Penn, 1949). 37: Segmentos abdominales I-VIII vista dorsal. 38: Trompeta ventiladora. 39: Paleta natatoria izquierda vista dorsal. 
3a. Gonocoxito sin sedas espiniformes parabasales pero con un lóbulo subbasal que lleva de ocho a diez sedas espiniformes (Fig. 193) .............................. Chagasia

Chagasia bathana

4 (3). Gonocoxito con dos sedas espiniformes parabasales y una seda espiniforme interna, sin sedas espiniformes accesorias (Fig. 10)

\section{Anopheles (Anopheles) ..... 5}

4a. Gonocoxito con una seda espiniforme parabasal, una seda espiniforme interna y dos sedas espiniformes accesorias (Fig. 173) . . . . . . 17

5 (4). Edeago con las hojillas presentando escotaduras en sus márgenes (Fig.

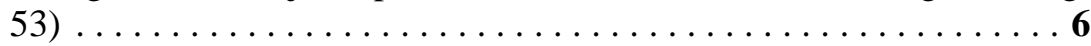

5a. Edeago con las hojillas careciendo de escotaduras en sus márgenes . 9

6 (5). Claspeta con el lóbulo dorsal presentando cuatro sedas a manera de espátulas con la punta roma y engrosada. Gonocoxito con abundantes escamas ................ Anopheles (Anopheles) gabaldoni

6a. Claspeta con el lóbulo dorsal presentando menos de cuatro sedas con forma variable. Gonocoxito con o sin escamas . . . . . . . . . 7

7 (6a). Gonocoxito con abundantes escamas. Claspeta con el lóbulo dorsal casi siempre presentando una sola seda espiniforme de punta roma a manera de espátula (Fig. 86). . . . . Anopheles (Anopheles) parapunctipennis

7a. Gonocoxito sin escamas. Claspeta con el lóbulo dorsal presentando dos o tres sedas espiniformes (Figs. 53, 97) . . . . . . . . . . 8

8 (7a). Claspeta con el lóbulo dorsal presentando sedas espiniformes cilíndricas, el lóbulo ventral con una sola seda recta. Edeago con sus lados paralelos y con un par único de hojillas (Fig. 53)

\section{.Anopheles (Anopheles) eiseni}

8a. Claspeta con el lóbulo dorsal presentando sedas espiniformes aplanadas, el lóbulo ventral con dos o tres sedas curvas. Edeago con sus lados convergentes hacia el ápice, los brazos basales formando un ángulo agudo y con uno a seis pares de hojillas de los cuales el par distal es el más grande (Fig. 97) . . . Anopheles (Anopheles) pseudopunctipennis

9 (5a). Gonocoxito con las sedas espiniformes parabasales similares en grosor aun cuando una sea más larga. Claspeta con el lóbulo ventral corto (Fig.

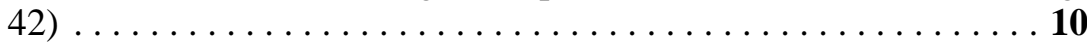

9a. Gonocoxito con la seda espiniforme parabasal externa más delgada y más larga que la interna. Claspeta con el lóbulo ventral largo . . . . 14

10 (9). Claspeta con el lóbulo dorsal y el lóbulo ventral fusionados por lo que no se distinguen. Terguito IX con los lóbulos largos tanto como 6-7X

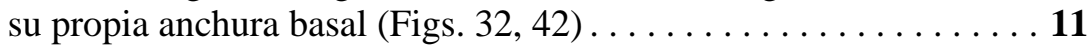

10a. Claspeta con el lóbulo dorsal y el lóbulo ventral separados al menos en su ápice. Terguito IX con los lóbulos generalmente cortos (Fig. 119) 
11 (10). Claspeta con tres sedas, una distal ventral más gruesa que las dos dorsales laterales ................Anopheles (Anopheles) bradleyi

11a. Claspeta con cuatro sedas aplanadas acomodadas en pares, el par dorsal (lateral) casi igual en tamaño y forma y el par ventral con la seda distal más larga y gruesa que la otra ..... Anopheles (Anopheles) crucians

12 (10a). Claspeta con el lóbulo dorsal presentando sedas espiniformes romas............................. 13

12a. Claspeta con el lóbulo dorsal presentando una o dos sedas espiniformes puntiagudas. Gonostilo sin parche de sedas muy cortas en la porción basal. Terguito IX con los lóbulos anchos, tanto como 3 o 4X su anchura basal (Fig. 119) . . . . . . . . Anopheles (Anopheles) punctipennis

13 (12). Gonostilo con un parche de sedas muy cortas en la porción basal. Terguito IX con los lóbulos anchos pero de ápice estrecho (Fig. 10) ................... Anopheles (Anopheles) walkeri

13a. Gonostilo sin parche de sedas muy cortas en la porción basal. Terguito IX con los lóbulos anchos pero de ápice dilatado (Fig. 127) .............. Anopheles (Anopheles) quadrimaculatus

14 (9a). Edeago con un solo par de hojillas lanceoladas largas, tan largas como 0.75 veces la longitud del edeago

Anopheles (Anopheles) vestitipennis

14a. Edeago con tres o cuatro pares de hojillas.............. 15

15 (14a). Edeago con el primer par de hojillas con una anchura menor que 2.0 veces la anchura del siguiente par. Lóbulo ventral de la claspeta con sedas largas (Fig. 21)........ Anopheles (Anopheles) apicimacula

15a. Edeago con el primer par de hojillas tan anchos como 4.0 veces la anchura del siguiente par. Lóbulo ventral de la claspeta con sedas cortas

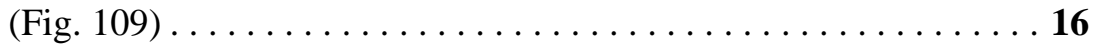

16 (15a). Edeago con el primer par de hojillas presentando un engrosamiento central a manera de nervadura y los bordes hialinos, las hojillas restantes paulatinamente reducidas en longitud (Fig. 109). . .

\section{Anopheles (Anopheles) punctimacula}

16a. Edeago con el primer par de hojillas careciendo de engrosamiento central a manera de nervadura y los bordes tan esclerotizados como el resto de la hojilla, las hojillas restantes con aproximadamente la misma longitud (Fig. 73) ......... Anopheles (Anopheles) neomaculipalpus

17 (4a). Gonocoxito con la seda espiniforme interna situada entre las sedas espiniformes accesorias y el ápice del gonocoxito. Edeago sin hojillas (Fig. 156) . . . . . . . . . . . . . Anopheles (Kerteszia) neivai

17a. Gonocoxito con la seda espiniforme interna situada entre las sedas espiniformes accesorias y la seda espiniforme parabasal. Edeago con o sin hojillas (Fig. 161). . . . . . . . Anopheles (Nyssorhynchus). . . 18 
40

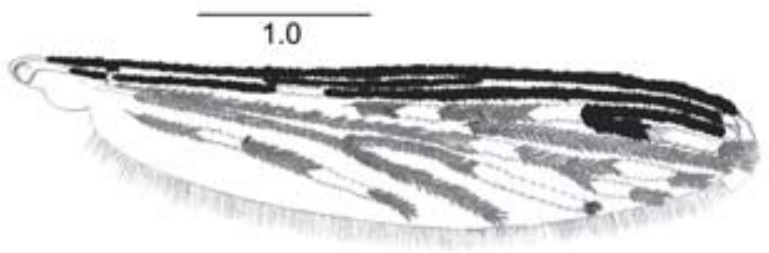

41

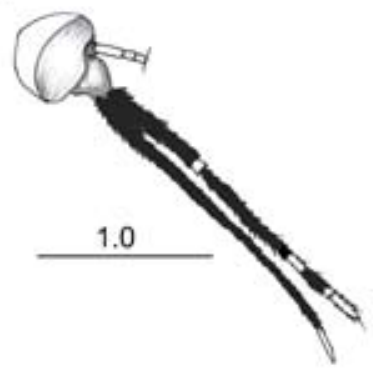

Anopheles crucians

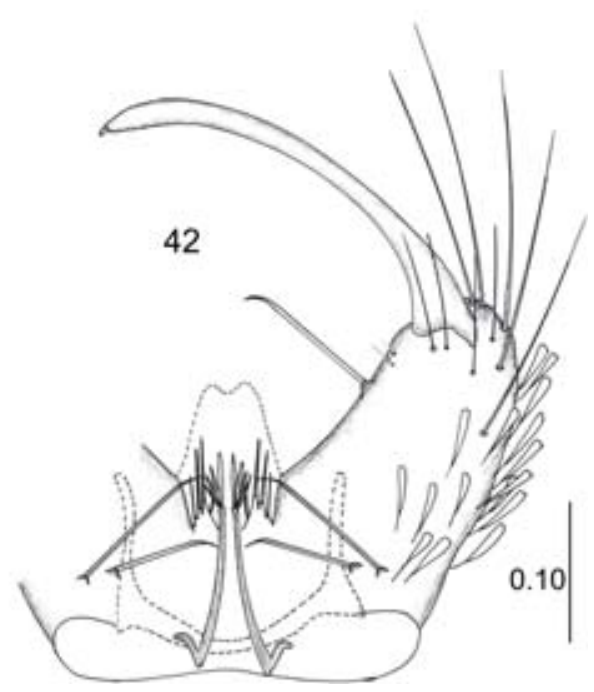

Figuras 40-42. Adultos de Anopheles (Anopheles) crucians. Hembra. 40: Ala 41: Palpo maxilar. Macho. 42: Terminalia.

18 (17a). Edeago con un par de hojillas; el ápice del edeago homogéneamente membranoso, tan ancho o más ancho que su propia longitud (Fig. 173) .............. Anopheles (Nyssorhynchus) argyritarsis

18a. Edeago sin hojillas y con otras características a las mencionadas en el dilema anterior (Fig. 161) . . . . . . . . . . . . . . 19

19 (18a). Claspeta con los lóbulos ventrales fusionados, con forma ovoide y unidos por el extremo distal por lo su forma es de herradura y con sedas evidentes (Fig. 184) . . . . . . . . Anopheles (Nyssorhynchus) strodei 


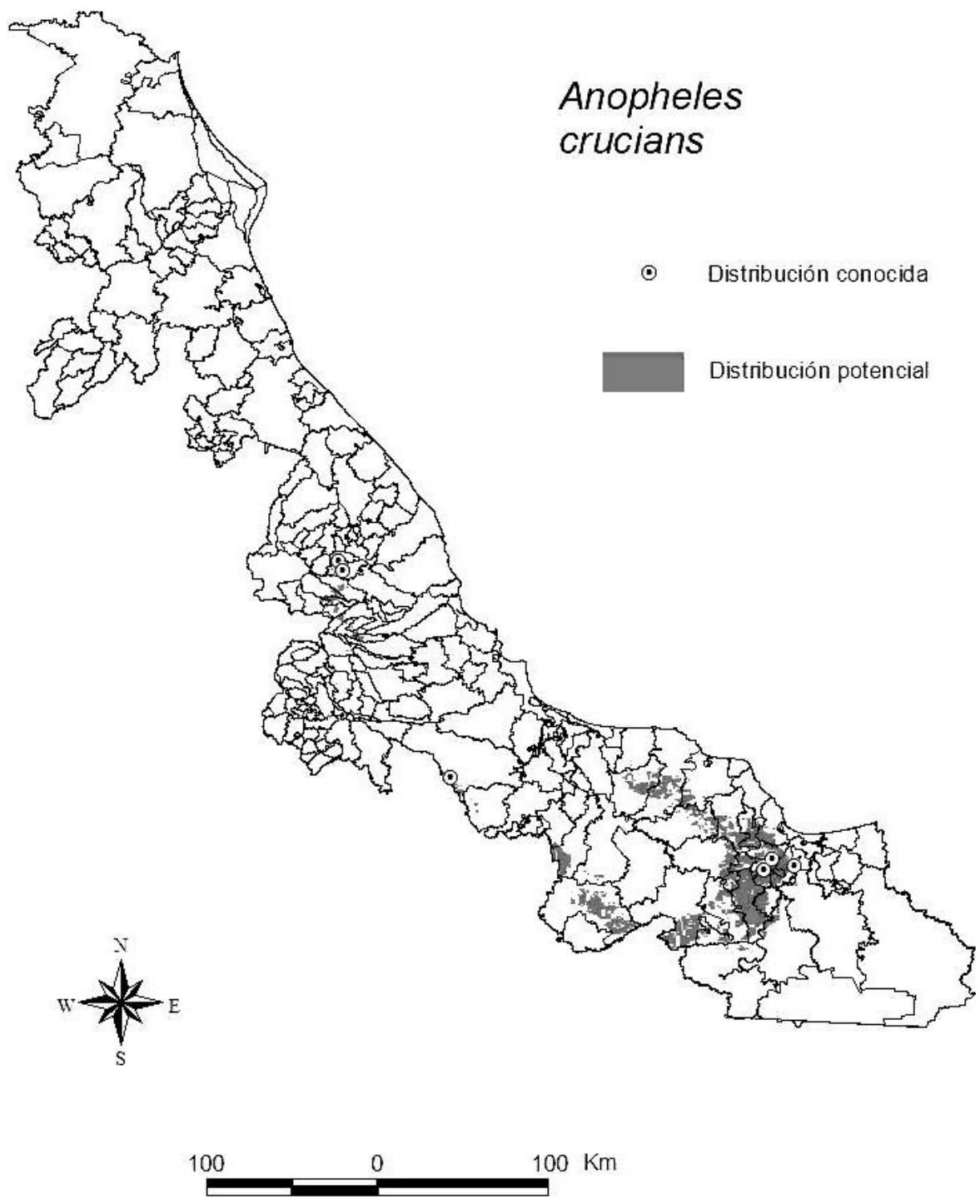

Figura 43. Mapa de la distribución conocida y potencial de Anopheles (Anopheles) crucians.

19a. Claspeta con los lóbulos ventrales fusionados, con forma más o menos cilíndrica, con hendidura apical, con dos estructuras ovoides en la parte basal y sin sedas evidentes (Fig. 161) . . . . . . . . . . . . 


\section{Elenco sistemático de los anofelinos de Veracruz \\ Subgénero Anopheles Meigen 1818}

Diagnosis. LARVA. Cabeza: sedas 5-6-C plumosas con numerosas ramas. Antena: seda 3-A puntiaguda, 2-A puntiaguda o con el ápice trunco y deshilachado. Abdomen: sedas 1-III-VII palmeadas, con el ápice puntiagudo y ramas con el borde aserrado. PUPA. Trompeta: laticorne o angusticorne, con uno o dos surcos, con o sin proyecciones. Abdomen: seda 9-IV-VIII espiniforme, la 9-VIII generalmente con ramas laterales (excepto en Anopheles pseudopunctipennis). HEMBRA. Cabeza: palpo maxilar con predominancia de escamas oscuras y un patrón de escamas claras variable. Tórax: escudo y escudete variables. Patas: tarsómeros de la pata posterior careciendo de bandas apicales claras o con manchas claras o bandas muy angostas en la base. Ala: con escamas oscuras en su totalidad o con la vena costal con una a cinco manchas pálidas, o bien la vena costal con la mancha clara del sector interrumpida por una mancha oscura accesoria. Abdomen: con o sin mechones de escamas posterolaterales (Wilkerson et al. 1993). MACHO. Terminalia: gonostilo delgado, uña gonostilar con la punta redondeada. Gonocoxito con dos sedas espiniformes parabasales y una seda espiniforme interna, sin sedas espiniformes accesorias. Lóbulos de la claspeta variables. Edeago variable, con hojillas apicales.

\section{Anopheles (Anopheles) apicimacula Dyar \& Knab 1906}

(Figs. 11-21, 22)

Anopheles apicimacula Dyar \& Knab 1906a: 136. Localidad tipo: Livingston, Guatemala. Referencias adicionales.- Senevet 1931: 96 (pupa); Cova-García 1939: 18 (larva), 25 (hembra); Vargas 1940a: 201 (claves hembra); Kumm 1941: 92 (huevo); Rozeboom 1941: 106 (distribución y bionomía); Komp 1942: 55 (hembra), 99 (pupa, larva), 144(macho); Levi-Castillo 1945: 68 (huevo, larva, pupa, hembra, macho); Cova-García 1946: 45 (macho, hembra, larva, huevo); Lassmann 1948: 11 (distribución en Veracruz); Darsie 1949: 525 (pupa); Lane 1953: 211 (hembra, macho, pupa, larva, huevo); Vargas \& Martínez-Palacios 1956: 54 (claves pupa), 99 (larva, hembra y macho); Vargas 1959: 385 (claves macho); Stojanovich et al. 1966: 8 (claves larva), 27 (claves hembra), 28 (bionomía); Gorham et al. 1973: 120 (calves hembra), 129 (claves larva), 141 (bionomía); Heinemman \& Belkin 1977: 504 (distribución en México); Rodríguez et al. 1996: 454 (huevo).

Diagnosis. LARVA (Figs. 11-14). Cabeza: sedas 2-C largas, convergentes, con cerdillas en la mitad distal; sedas 3-C divergentes, sencillas o con tres ramas distales, más cortas que las 2-C. Antena: seda 3-A puntiaguda y la 2-A truncada; seda 4-A débil, más corta que las 2-3-A, con pocas ramificaciones. Tórax: seda 1-P fuerte con siete a nueve ramas; 9-P larga con siete a diez ramas. Abdomen: seda 0-II-VI minúscula; sedas 1-III-VI palmeadas con las ramas anchas y pigmentadas, con el borde aserrado en 
la mitad distal (Vargas \& Martínez-Palacios 1956). PUPA (Figs. 15-16). Trompeta: laticorne, con un surco meatal profundo, con una proyección triangular en la pinna. Abdomen: segmentos abdominales III-VII sin espículas en el borde posterior; sedas 9- IV-VI sencillas y espiniformes, 9-VII sencilla, espiniforme y ligeramente curvada, seda 9-VIII con dos a tres ramas laterales cortas. Paletas natatorias: margen externo aserrado; parte distal del margen externo con acículas filamentosas que se continúan sobre el margen interno; seda 1-P con un tallo central grueso y de cinco a seis ramas laterales; seda 2-P bifurcada, de la misma longitud que la 1-P (Senevet 1931, Vargas \& Martínez -Palacios Op. cit.). HEMBRA (Figs.17-20). Cabeza: Palpo maxilar con predominancia de escamas negras, palpómero 3 con algunas escamas blancas sin formar un anillo, palpómero 4 con un anillo basal claro más angosto y palpómero 5 con algunas escamas blancas en su ápice y un anillo basal de escamas blancas. Tórax: escudo y escudete con tres manchas polinosas oscuras distinguibles, acentuadas por polinosidad plateada, dos manchas en la posición anterolateral con respecto a las bases de las alas y una mediana en el área prescutelar que se continúa sobre el escudete. Ala: porción media de la vena cubital con escamas oscuras, aplicadas estrechamente sobre la vena y más pequeñas que las que se observan en las venas cercanas; venas anteriores del ala con las manchas del presector, del sector, preapical y apical muy oscuras. Abdomen: integumento oscuro con algunas sedas amarillentas; esternitos con algunas escamas dispersas; segmentos II-VIII con mechones posterolaterales de escamas oscuras (Vargas \& Martínez -Palacios Op. cit., Wilkerson et al. 1993). MACHO. Terminalia (Fig. 21): gonostilo más largo que el gonocoxito, ligeramente adelgazado en la parte central; uña gonostilar corta y redondeada. Gonocoxito con numerosas escamas en la cara externa; con dos espinas parabasales y una espina interna; la parabasal externa más delgada y larga que la parabasal interna. Lóbulo dorsal de la claspeta con tres espinas planas curvas dirigidas hacia la parte media del cuerpo, de puntas redondeadas y ensanchadas. Lóbulo ventral de la claspeta largo, con sedas más largas que las que presentan otras especies similares; también con tres espinas puntiagudas en la parte apical del lóbulo, siendo la interna más larga. Edeago generalmente con cuatro pares de hojillas lanceoladas apicales; las del primer par están esclerotizadas uniformemente y carecen de vena central de una anchura menor que 2.0 veces la anchura del siguiente par; las demás hojillas son progresivamente más cortas. Noveno terguito estrecho en la parte central con los lóbulos laterales cortos (Vargas \& Martínez -Palacios 1956).

Material examinado. 30 ejemplares. México: Veracruz, Mpo. Acayucan, Acayucan, 10-05-1947 (2 L, CAIM CulH/lam-00109 y CAIM CulH/lam-00116); Mpo. Catemaco, Sontecomapan, 30-07-1963 (1 H, CAIM CulH/alf-00023), 05-08-1965 (1 H, CAIM CulH/alf-00017); Mpo. Chinameca, Chinameca, 01-02-1947 (5 L, CAIM CulH/lam-00110, CAIM CulH/lam-00111, CAIM CulH/lam-00112, CAIM CulH/ 

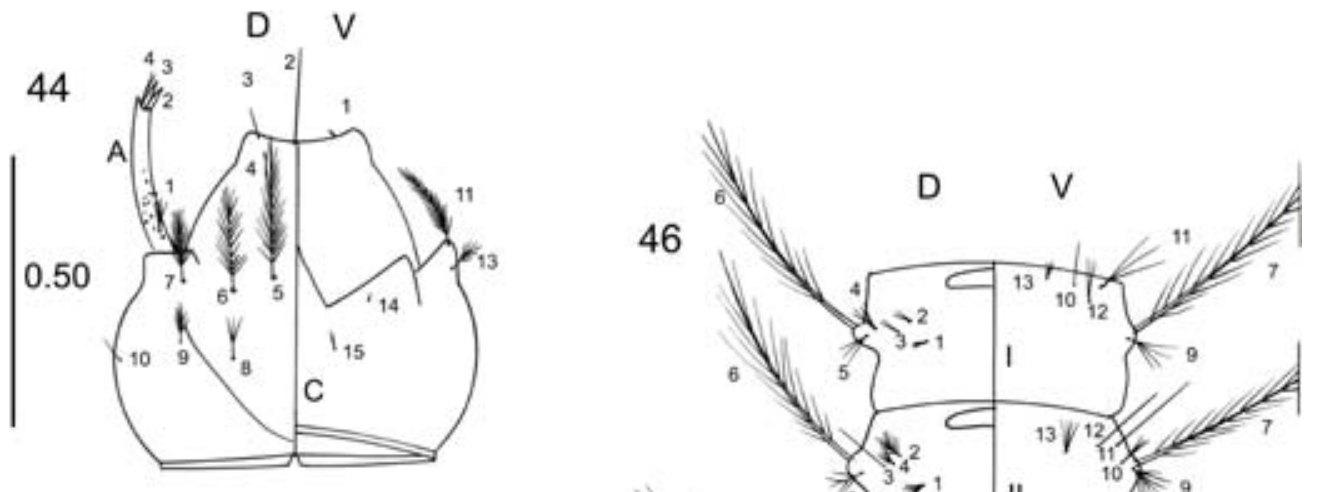

\section{Anopheles eiseni}
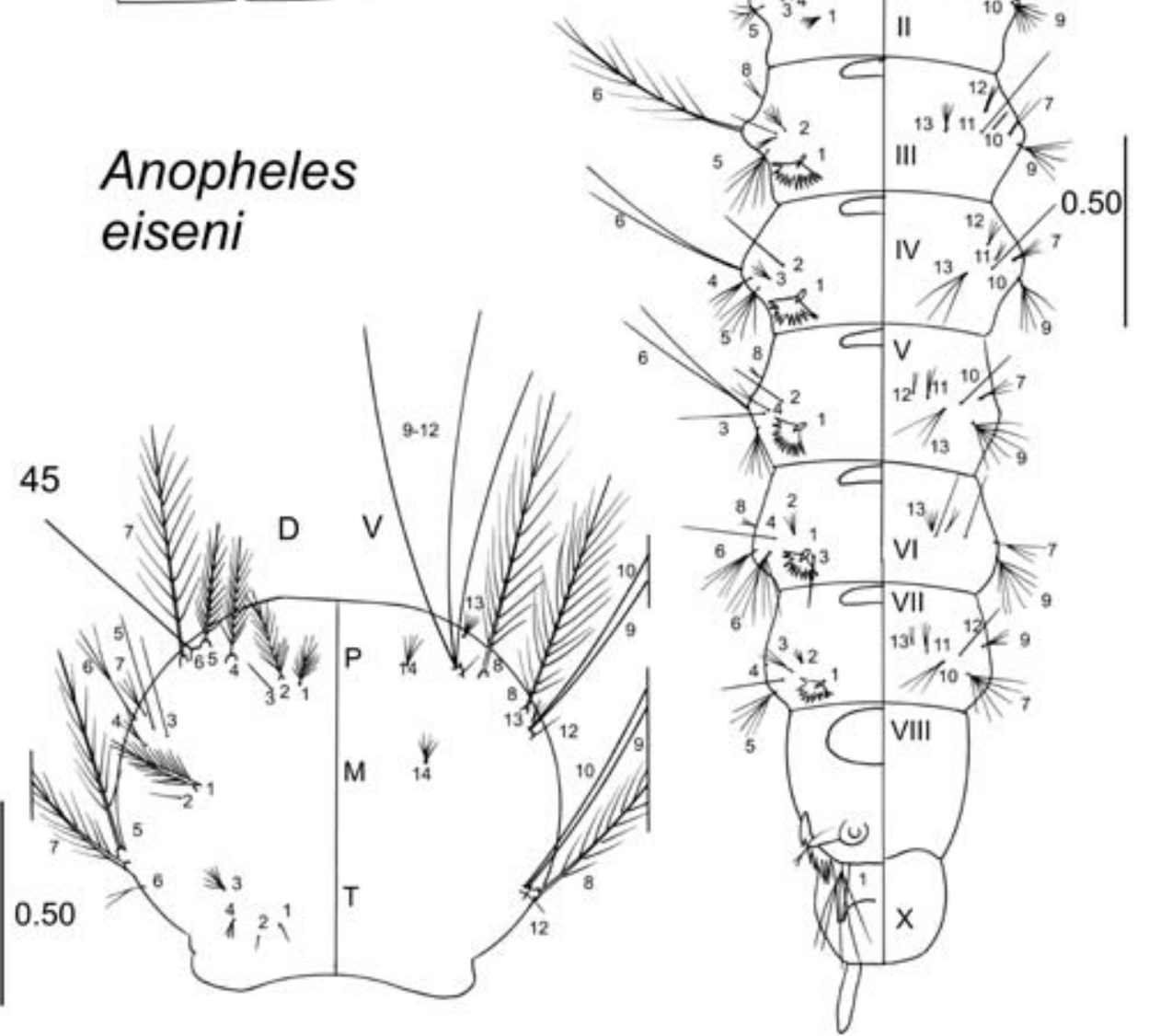

Figuras 44-46. Larva de Anopheles (Anopheles)eiseni. 44: Cabeza. 45: Tórax. 46: Abdomen. 


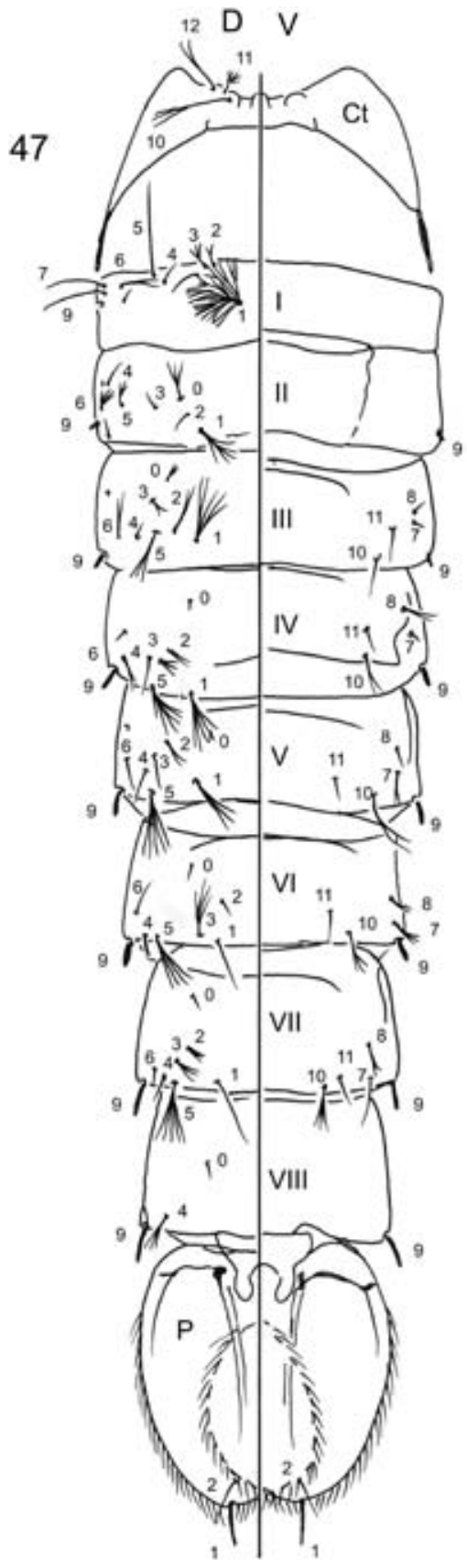

48

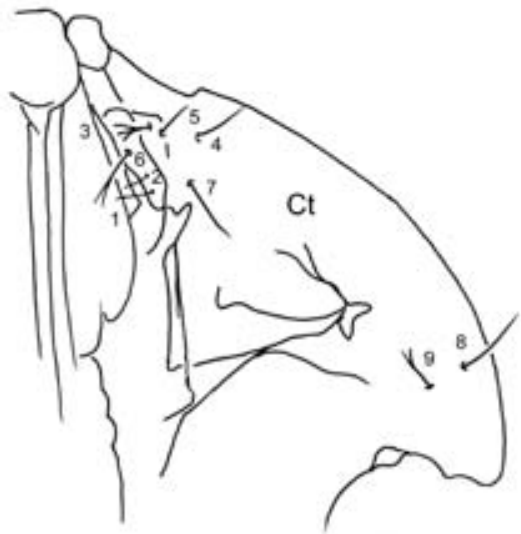

49

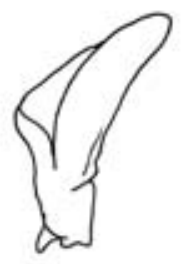

\section{Anopheles eiseni}

Figuras 47-49. Pupa de Anopheles (Anopheles) eiseni. 47: Abdomen. 48: Cefalotórax. 49: Trompeta ventiladora. 
lam-00113 y CAIM CulH/lam-00114); Mpo. Córdoba, La Providencia, 05-02-1948 (13 L, CAIM CulH/lam-00101, CAIM CulH/lam-00102, CAIM CulH/lam-00103, CAIM CulH/lam-00104, CAIM CulH/lam-00105, CAIM CulH/lam-00106, CAIM CulH/lam-00107, CAIM CulH/lam-00108, CAIM CulH/lam-00115, CAIM CulH/ lam-00117, CAIM CulH/lam-00118, CAIM CulH/lam-00119, CAIM CulH/lam00120; 2 P, CAIM CulH/lam-05215 y CAIM CulH/lam-05216); Mpo. Moloacan, Moloacan, 08-12-1959 (1 H, CAIM CulH/alf-00001); Chiapas, Mpo. Tapachula, Tapachula, 23-09-1941(1 H, CAIM CulH/alf-00021), 02-1942 (1 P, CAIM CulH/ lam-05212); Oaxaca, Mpo. Santiago Jamilitepec, Santiago Jamilitepec, 06-01-1954 (2 MT, CAIM CulH/lam-05214); Tabasco, Mpo. Tenosique, Tenosique, sin fecha (1 L, CAIM CulH/lam-00057).

Distribución conocida. Centroamérica, México, Colombia, Venezuela, Trinidad y Tobago, Guyana, Surinam, Ecuador, Bolivia (Knight \& Stone 1977). En México se ha informado para los estados de Chiapas, Michoacán, Quintana Roo, San Luis Potosí, Tabasco, Veracruz, Yucatán (Vargas \& Martínez -Palacios Op. cit.).

Distribución en Veracruz (Fig. 22). Mpo. Acayucan: Acayucan; Mpo. Alto Lucero: Blanca Espuma; Mpo. Amatlán de los Reyes: Amatlán de los Reyes; Mpo. Catemaco: Sontecomapan; Mpo. Chinameca: Chinameca; Mpo. Coatepec: Las Lomas; Mpo. Colipa: Colipa; Mpo. Córdoba: Córdoba, La Providencia, Veinte de Noviembre; Mpo. Cuichapa: Cuichapa, Ingenio la Providencia; Mpo. Cuitláhuac: Cuitláhuac; Mpo.Emiliano Zapata: Plan del Río; Mpo. Fortín: Coapichapan, Fortín; Mpo. Gutiérrez Zamora; Gutiérrez Zamora; Mpo. Juchique de Ferrer: Juchique de Ferrer, Mpo. Mecayapan: Mecayapan; Mpo. Minatitlán: Las Choapas, Mpo. Misantla: Misantla; Mpo. Moloacan: Moloacan; Mpo. Paso del Macho: Paso del Macho; Mpo. Texistepec: Ojapa; Mpo. Tlacotalpan: Tlacotalpan; Mpo. Tlalixcoyan: Piedras Negra; Mpo. Pajapan: Pajapan; Mpo. Soteapan: Soteapan.

Datos bionómicos. La larva se cría en cuerpos de agua claros, templados y con sombra, particularmente en pequeños arroyos, pozos y pantanos. Las hembras prefieren alimentarse de animales, más que del humano. Rara vez penetran al interior del domicilio humano (Rozeboom 1941).

Importancia médica. Desconocida.

Comentarios. Se distingue de otras especies por las siguientes características: Larva: seda 3-A puntiaguda y 2-A truncada, seda 9-P larga, con siete a diez ramas. Pupa: trompeta con un proyección triangular en el pinna y seda 1-P con cinco a seis ramas laterales. Hembra: escudo con tres manchas polinosas oscuras distinguibles, vena 
medio-cubital con escamas oscuras aplicadas estrechamente sobre la vena, más pequeñas que las que se observan en venas cercanas. Macho, Terminalia: lóbulo ventral de la claspeta largo, con sedas más largas que en otras especies similares, edeago con generalmente cuatro pares de hojillas apicales.

Anopheles apicimacula presenta varias similitudes con An. neomaculipalpus y An. punctimacula, sin embargo se puede diferenciar de estas por la combinación de las siguientes características. Larva: sedas 3-C sencillas, seda 1-P con ramas fuertes, 9-P ramificada con alrededor de diez ramas; Pupa: trompeta con una proyección triangular en la pinna, segmentos abdominales III-VII sin espículas en el borde posterior; Hembra: porción media de la vena cubital con escamas oscuras, aplicadas estrechamente sobre la vena y más pequeñas que las que se observan en las venas cercanas; Macho, terminalia: primer par de hojillas del edeago sin un engrosamiento central a manera de nervadura, con los bordes esclerotizados, con una anchura menor que 2.0 veces la anchura del siguiente par y el lóbulo ventral de la claspeta con sedas más largas que las de las otras dos especies.

Parece ser una especie abundante y ampliamente distribuida en el estado, ya que se ha informado desde localidades costeras, hasta los 1460 msnm en Xalapa. La distribución potencial de esta especie se encuentra hacia los climas cálidos con lluvias en verano, ya sea muy húmedos o con influencia de monzón.

A pesar de que no existen informes donde se incrimine como vector de algún patógeno causante de enfermedad, se recomienda que se tenga bajo vigilancia por su amplia distribución en Veracruz.

\section{Anopheles (Anopheles) bradleyi King 1939}

(Figs. 23-32, 33)

Anopheles (Ano.) bradleyi King 1939:468 (como variedad de Anopheles crucians). Localidad tipo: Río St. Johns, Condado de Brevard, Florida, Estados Unidos. Referencias adicionales.- King \& Bradley 1941: 65 (elevada a especie); Roth 1944: 99 (macho); Darsie 1949: 526 (pupa); Penn 1949: 64 (pupa); Carpenter \& LaCasse 1955: 34 (macho, hembra, larva, bionomía); Vargas \& Martínez-Palacios 1956: 54 (claves pupa), 68 (hembra, macho y larva); Kreutzer \& Kitzmiller 1971: 195 (cromosomas y taxonomía); Floore et al. 1976: 30 (macho, hembra, pupa, larva).

Anopheles crucians, raza de agua salobre; Root 1924: 449 (larva); Bradley 1936: 859 (larva); Dozier 1936: 148 (hembra, larva).

Anopheles crucians, costero, variedad de agua salobre; Bradley 1932: 41 (larva), King et al. 1939: 34 (hembra, pupa, larva); Stearns 1940: 143 (hembra, larva); Mulhern 1941: 72 (hembra), 1942: 60 (hembra), 1943: 133 (hembra).

Anopheles crucians var. bradleyi King 1939: 468 (hembra, macho, pupa, larva); Vargas 1940a: 202 (claves hembra), 1940b: 66 (claves larva); Vargas 1941c: 112 (claves huevo). 


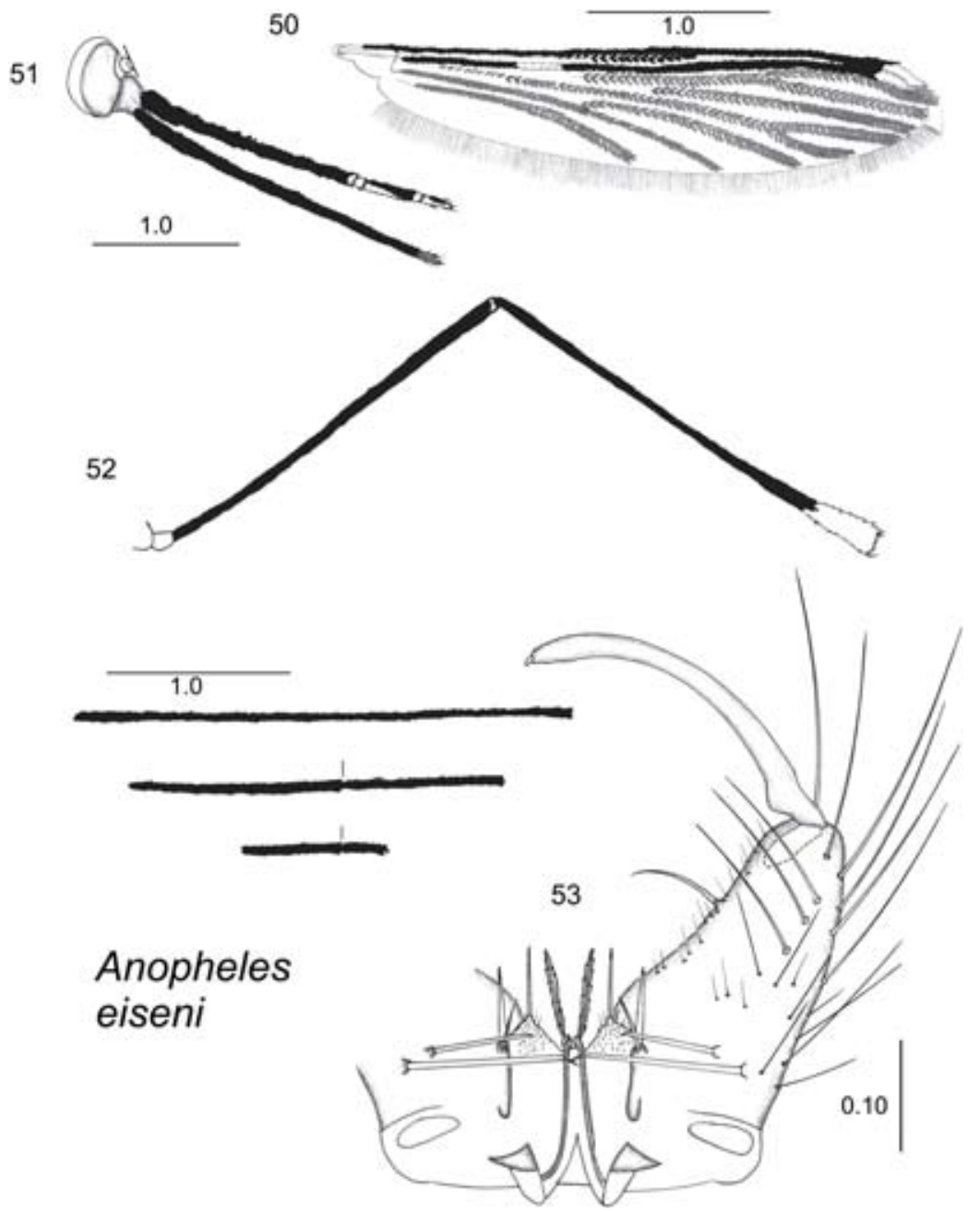

Figuras 50-53. Adultos de Anopheles (Anopheles) eiseni. Hembra. 50: Ala. 51: Palpo maxilar. 52: Pata posterior. Macho. 53: Terminalia.

Anopheles crucians bradleyi: Ross \& Roberts 1943: 22 (hembra y larva); Russell et al. 1943: 19, 21(hembra), 28, 29 (larva); Carpenter et al. 1946: 58 (hembra, macho, larva); Lassmann 1948: 9 (distribución en Veracruz); Yamaguti 1952: 5 (claves hembra), 6 (claves macho); Vargas 1959: 373 (claves macho).

Diagnosis. LARVA (Figs. 23-26). Cabeza: sedas 2-C largas y simples, separadas por un espacio igual o menor al diámetro de un alveolo que les da origen; seda 3-C 


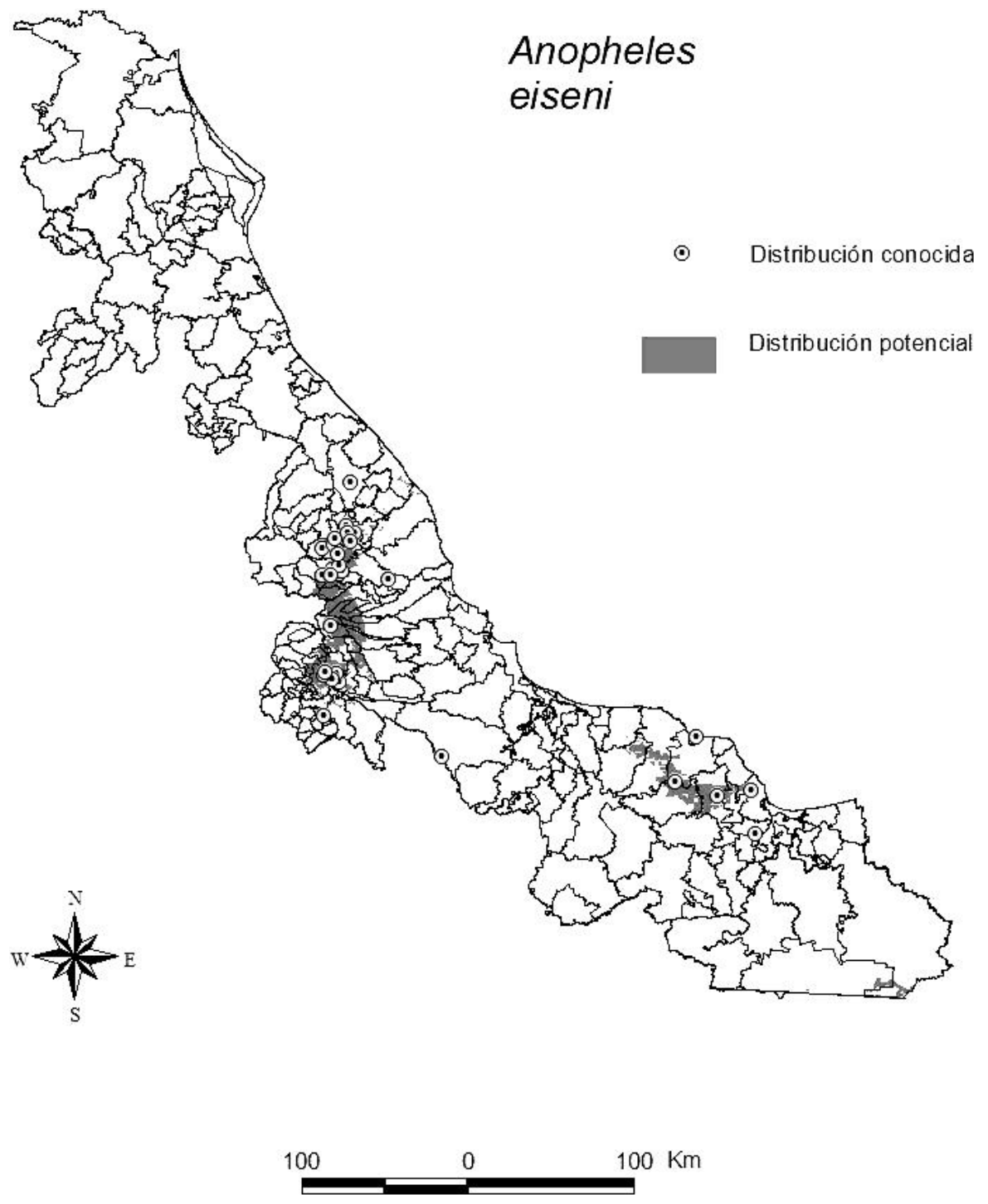

Figura 54. Mapa de la distribución conocida y potencial de Anopheles (Anopheles) eiseni.

ramificada dicotómicamente con veinte o más ramas. Antena: con las sedas 2-3-A puntiagudas, con un borde aserrado. Tórax: seda 1-P generalmente simple; sedas 9, 10, 11 y 10- P simples. Abdomen: sedas abdominales 0-III-VIII pequeñas, sencillas o bífidas; sedas 1-III-VII palmeadas, con hojas anchas y pigmentadas, el borde aserrado en la mitad distal (Floore et al. 1976, Vargas \& Martínez-Palacios 1956). PUPA 
(Figs. 27-29). Trompeta: fuertemente pigmentada, con un surco meatal del 0.33 veces la longitud de la trompeta, generalmente con una espina en la pinna. Abdomen: seda 0 -IV-VI generalmente simple o bífida; 1-IV con cinco a nueve ramas, 1-V con tres a seis ramas; 2-IV con tres a nueve ramas, 2-V-VII con de dos a cuatro ramas; 5-III con menos de siete ramas, 5-IV con cinco a diez ramas; seda 9-I generalmente simple, sedas 9-II-VIII espiniformes y fuertemente pigmentadas. Paletas natatorias: margen exterior aserrado y con acículas filamentosas; seda 1-P simple o bífida, 2-P simple o con dos a tres ramas distales (Floore et al. 1976, Vargas \& Martínez -Palacios 1956). HEMBRA (Figs. 30-31). Cabeza: palpo maxilar con predominancia de escamas negras, palpómero 3 con escamas claras en su base, palpómero 4 con escamas claras basales y apicales, palpómero 5 totalmente claro. Ala: costa negra, excepto por la mancha clara apical; y la vena anal uno con tres manchas claras, una basal, una media y una apical; cúbito comúnmente con escamas claras hasta la vena transversal mediocubital. Patas: fémures y tibias casi totalmente oscuros, excepto por algunas escamas claras en el ápice del fémur y en la base de la tibia. Abdomen: con numerosas escamas oscuras (Floore et al. Op. cit., Wilkerson et al. 1993). MACHO. Terminalia (Fig. 32): gonostilo ligeramente más largo que el gonocoxito, con la parte central adelgazada; uña gonostilar corta, con la punta redondeada. Gonocoxito sin escamas, con dos espinas parabasales y una espina interna. Lóbulos de la claspeta fusionados con generalmente tres sedas, una distal ventral, más gruesa que las otras, y dos dorsales (laterales). Edeago con seis a ocho hojillas atenuadas. Noveno terguito con los lóbulos largos y delgados (Floore et al. Op. cit., Vargas \& Martínez-Palacios Op. cit.).

Material examinado. 15 ejemplares. México: Veracruz, Mpo. Tuxpan, Barra de Tuxpan, 23-01-1951 (6 H, CAIM CulH/alf-00325, CAIM CulH/alf-00326, CAIM CulH/alf-00327 y CAIM CulH/alf-00328; 2 M, CAIM CAIM CulH/alf-0324 y CAIM CulH/alf-00329); Quintana Roo, Mpo. Benito Juárez, Cancún, 07-01-1976 (1 H, CAIM CulH/alf-00321); Tabasco, Mpo. Tenosique, Tenosique, 01-06-1941 (1 L, CAIM CulH/lam-00180); Tamaulipas, Mpo. Matamoros, La Reforma, 23-07-1971 (1 H, CAIM CulH/alf-00322); Mpo. Tampico, Tampico, 01-01-1949 (2 P, CAIM CulH/ lam-05262 y CAIM CulH/lam-05264), 18-04-1938 (1 MT, CAIM CulH/lam-05261); Yucatán, Mpo. Progreso, Progreso, 22-04-1942 (1 MT, CAIM CulH/lam-05267).

Distribución conocida. Costa del Atlántico Estados Unidos (Carpenter \& LaCasse 1955). En México se distribuye por toda la costa del Golfo de México y el Caribe, en los estados de Tamaulipas, Veracruz, Tabasco, Campeche, Yucatán y Quintana Roo (Floore et al Op. cit., Vargas \& Martínez-Palacios Op. cit.).

Distribución en Veracruz (Figura 33). Mpo. Coatzacoalcos: Agua Dulce, Coatzacoalcos; Mpo. Nautla: Nautla; Mpo. Pánuco: Pánuco; Mpo. Pueblo Viejo: Pueblo 
Viejo, Villa Cuauhtémoc; Mpo. Tantoyuca: San Jerónimo; Mpo. Tuxpan: Barra Norte de Tuxpan, Tuxpan; Mpo. Las Choapas: Las Choapas.

Datos bionómicos. Las larvas se encuentran en agua salobre a lo largo de la costa del Atlántico y el Golfo de México, y no tan comúnmente en cuerpos de agua dulce. (Floore et al. 1976), asociado a Chara y otros pastos acuáticos (Carpenter \& LaCasse 1955).

Importancia médica. En un estudio lograron infectar a An. bradleyi con Plasmodium falciparum bajo condiciones de laboratorio, pero no se sabe de su participación natural en la transmisión de Plasmodium spp. causantes de malaria (Boyd et al. 1936, Carpenter \& LaCasse Op. cit., WRBU 2008).

Comentarios. Esta especie es muy similar a Anopheles crucians, lo que en muchas ocasiones dificulta la determinación de los adultos. La única diferencia es que An. bradleyi comúnmente presenta el cúbito con escamas claras hasta la vena transversal mediocubital, y en la terminalia del macho que los lóbulos de la claspeta poseen generalmente tres sedas, una distal ventral, más gruesa que las otras, y dos dorsales (laterales). Esta especie se puede diferenciar de An. crucians únicamente en las fases de larva y pupa por las siguientes características: Larva: sedas abdominales 0-IIIVIII minúsculas y generalmente sencillas o bífidas; Pupa: seda 0-IV-VI generalmente simple o bífida, 1-IV con cinco a nueve ramas.

No parece ser una especie abundante en Veracruz, habiendo sido informada en pocas localidades y con una distribución restringida a zonas costeras, ya que la larva se cría en agua salobre; sin embargo se recomienda tenerla bajo vigilancia debido a que se ha logrado infectar con plasmodios experimentalmente.

La distribución potencial de esta especie se ubica hacia la zona de la planicie costera del norte, sin embargo no se tienen suficientes datos para hacer una buena predicción distributiva, ya que no se tienen puntos de colecta del sur de Veracruz y la distribución informada para An. bradleyi abarca hasta el Caribe. Dicha ausencia aparente en esos sitios puede ser el resultado de colectas inadecuadas de anofelinos.

\section{Anopheles (Anopheles) crucians Wiedemann 1828}

(Figs. 34-42, 43)

Anopheles crucians Wiedemann 1828: 12. Localidad tipo: Nueva Orleans, Louisiana, Estados Unidos. Referencias adicionales.- Rozeboom 1941: 104 (distribución y bionomía); Komp 1942: 48 (hembra), 89 (larva), 137 (macho); Ross \& Roberts 1943: 19 (hembra, macho y larva); Darsie 1949: 525 (pupa); Freeborn In: Boyd 1949: 388 (revisión); Penn 1949: 63 (pupa); Vargas 1959: 373 (macho); Bellamy \& Repass 1950: 84 (huevo); Breeland 1951: 224 (larva); Carpenter \& LaCasse 1955: 35 (ma- 


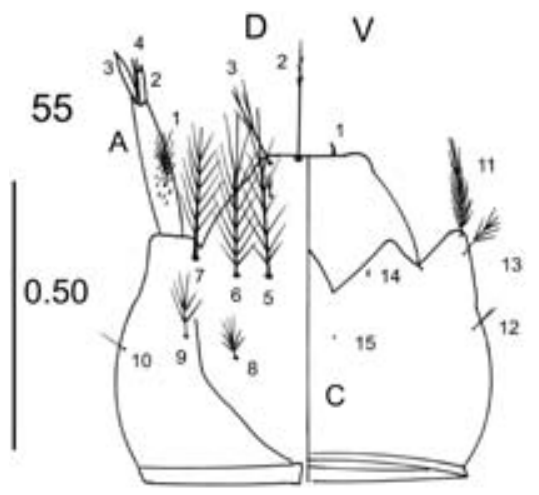

\section{Anopheles gabaldoni}

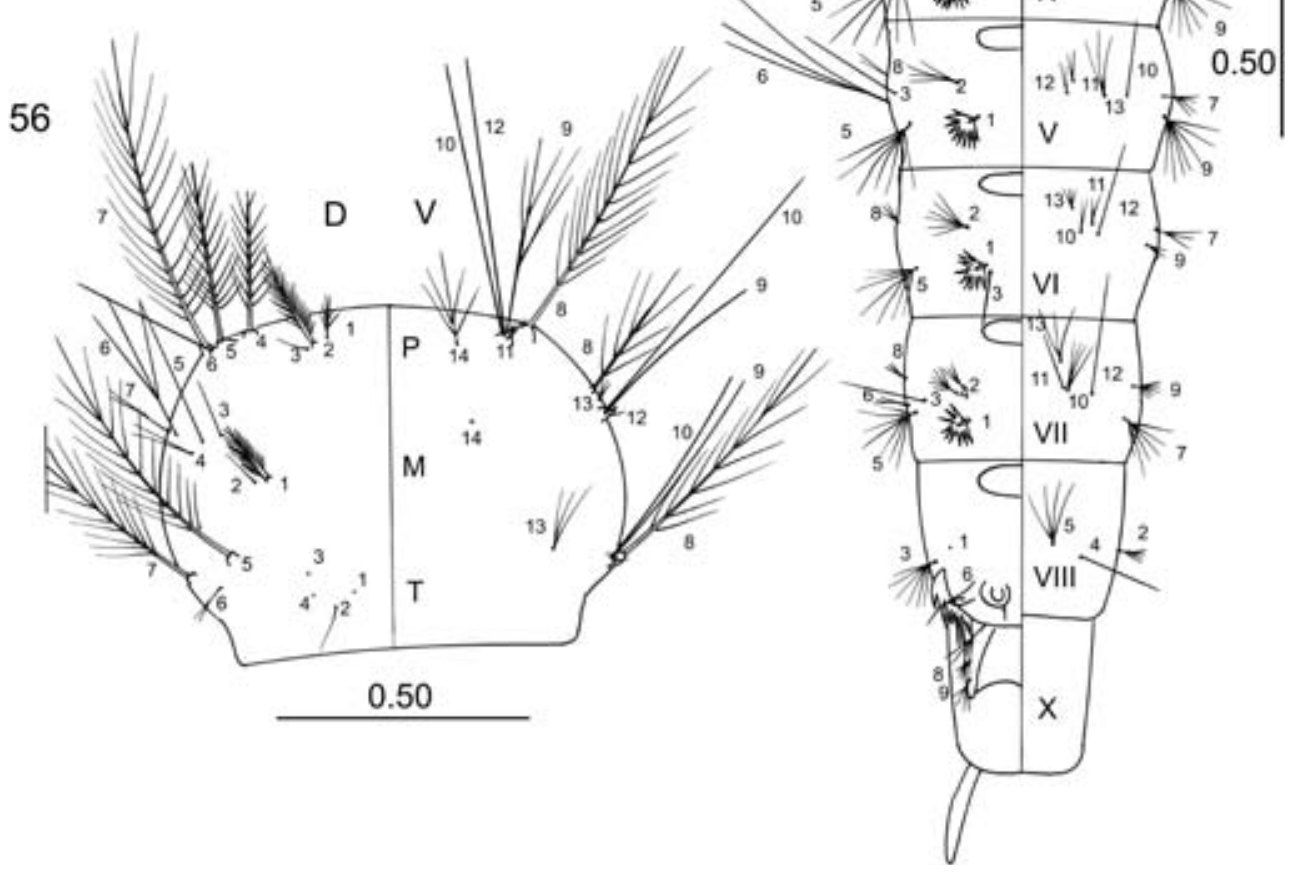

Figuras 55-57. Larva de Anopheles (Anopheles) gabaldoni. 55: Cabeza. 56: Tórax.57: Abdomen. 
58

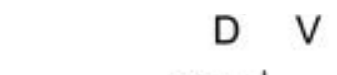

.
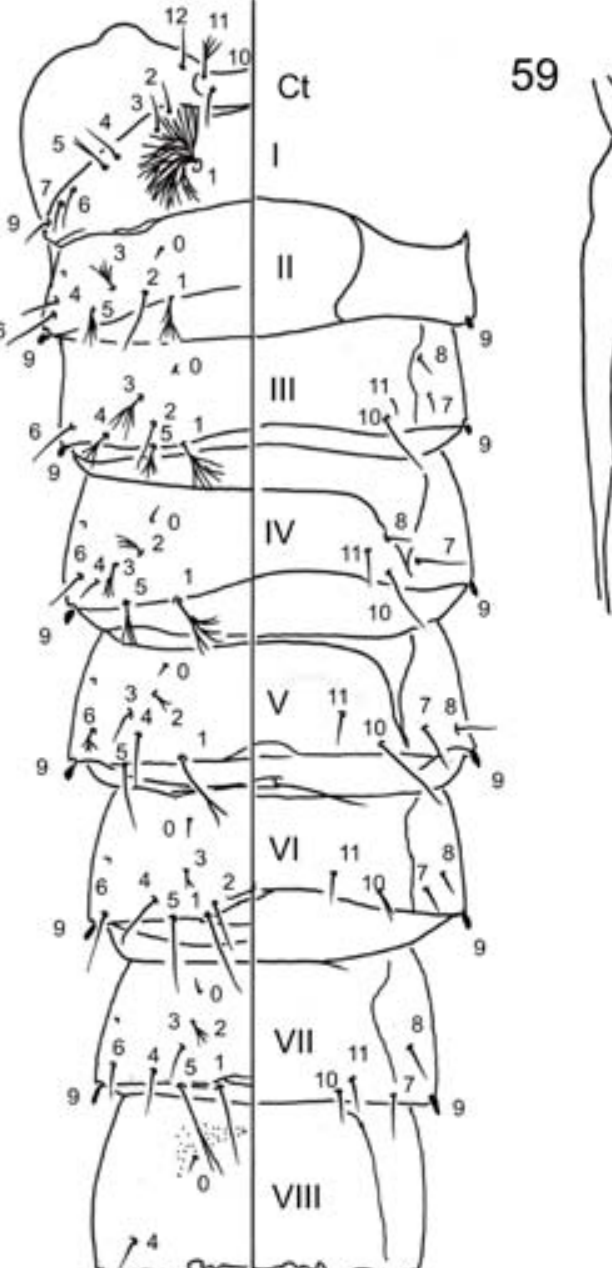

9

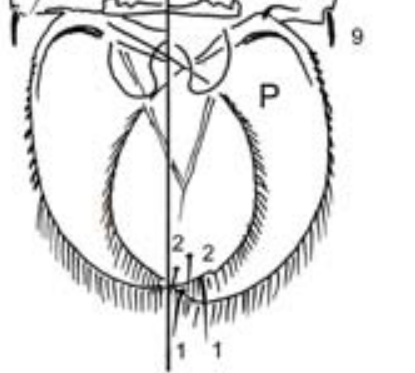

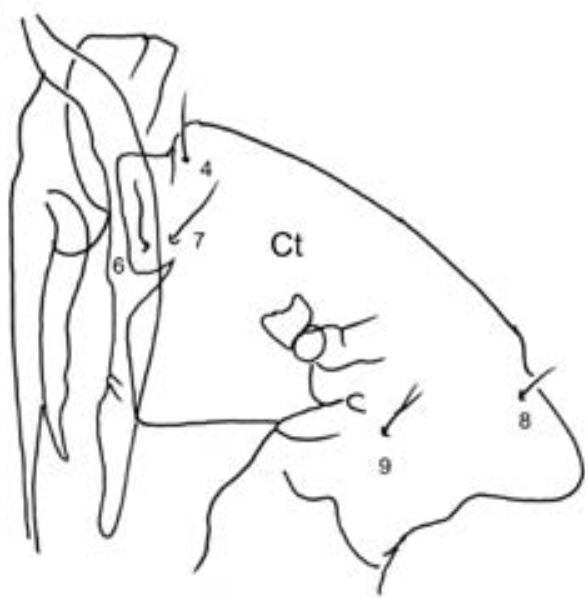

60

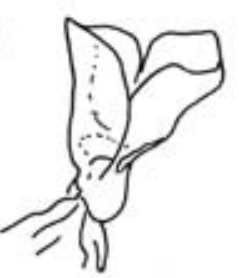

\section{Anopheles gabaldoni}

Figuras 58-60. Pupa de Anopheles (Anopheles) gabaldoni. 58: Abdomen. 59: Cefalotórax. 60 Trompeta ventiladora. 
cho, hembra, larva, bionomía); Horsfall 1955: 75 (distribución y bionomía); Vargas \& Martínez-Palacios 1956: 53 (claves pupa), 69 (hembra, macho, larva); Stojanovich et al. 1966: 5 (claves larva), 23 (claves hembra), 32 (bionomía); Belkin 1968: 9 (diseño del lectotipo); Belkin et al. 1970: 17 (macho, hembra, pupa, larva); Kreutzer \& Kitzmiller 1971:195 (cromosomas y taxonomía); Vargas M. 1975: 77 (distribución); Floore et al. 1976: 15 (macho, hembra, pupa, larva).

Anopheles crucians raza de agua dulce: Root 1924: 449 (larva); Root 1929: 476 (larva); Bradley 1936: 859 (larva); Dozier 1936: 148 (hembra, adulto); Herms \& Gray 1940 (hembra).

Anopheles crucians variedad de agua dulce: Bradley 1932: 41 (larva); King et al. 1939: 34 (hembra, pupa, larva).

Anopheles crucians var. crucians King 1939:470 (hembra, macho, larva, pupa); Vargas 1940a: 202 (claves hembra), 1940b: 66 (claves larva).

Anopheles crucians crucians: Ross \& Roberts 1943: 19 (hembra, macho, larva); Russell et al. 1943: 19, 21(hembra), 28, 29 (larva); Carpenter et al. 1946: 60 (hembra, macho, larva); Lassmann 1948: 9 (distribución en Veracruz); Yamaguti 1952: 5 (claves hembra), 6 (claves macho); Vargas 1959: 373 (claves macho).

Diagnosis. LARVA (Figs. 34-36). Cabeza: Sedas 2-C largas y simples, separadas entre sí por menos del diámetro de un alveolo que les da origen; seda 3-C ramificada dicotómicamente con más de veinte ramas. Antena: las sedas 2-3-A puntiagudas, con un borde aserrado. Tórax: seda 1-P simple, bífida o trífida; sedas 9-12-P sencillas. Abdomen: sedas 0-III-V con cuatro a trece ramas, casi del mismo tamaño que la seda 2-III-V; sedas 1-III-VIII palmeadas, con las ramas anchas y pigmentadas, con el borde aserrado en la mitad distal (Floore et al. 1976, Vargas \& Martínez -Palacios 1956). PUPA (Figs. 37-39). Trompeta: fuertemente pigmentada con un surco meatal profundo y a menudo con una espina pequeña en el borde lateral de la pinna; seda 8-CT casi siempre simple. Abdomen: seda 0-IV-V larga, 0-IV generalmente con dos a seis ramas, $0-\mathrm{V}$ con tres a once ramas, seda 1-IV con ocho a veintiún ramas; seda 2IV generalmente con más de siete ramas; seda 9-III-VIII espiniformes y fuertemente pigmentadas. Paletas natatorias: margen externo aserrado y con acículas finas; 1-P simple o bífida; 2-P simple, bífida o trífida (Floore et al. 1976). HEMBRA (Figs. 40-41). Cabeza: palpo maxilar con predominancia de escamas negras, palpómero 3 con escamas claras en su base, palpómero 4 con escamas claras basales y apicales, palpómero 5 totalmente claro. Ala: costa negra, excepto por la mancha clara apical; la vena anal uno con tres manchas claras, una basal, una media y una apical; cúbito comúnmente con escamas oscuras hasta la vena transversal medio-cubital. Patas: fémures y tibias casi totalmente oscuros, excepto por algunas escamas claras en el ápice del fémur y en la base de la tibia. Abdomen: con numerosas escamas oscuras (Floore et al. Op. cit., Wilkerson et al. 1993). MACHO (Fig. 42). Terminalia: go- 
nostilo ligeramente más largo que el gonocoxito, con la parte central adelgazada; uña gonostilar corta, con la punta redondeada. Gonocoxito con pocas escamas y sedas ventral y lateralmente. Dos espinas parabasales en un tubérculo adelgazadas apicalmente. Espina interna insertada a 0.5 basal del gonocoxito, más larga que el diámetro del gonocoxito. Lóbulos de la claspeta fusionados generalmente con cuatro sedas aplanadas acomodadas en pares, el par dorsal (lateral) casi igual en tamaño y forma, el par ventral con la seda distal más larga y gruesa que la otra. Edeago con seis a ocho hojillas delgadas; lóbulos del noveno terguito largos y delgados (Belkin et al. 1970, Floore et al. Op. cit., Vargas \& Martínez-Palacios 1956).

Material examinado. 11 ejemplares. México: Veracruz, Mpo. Banderilla, Banderilla, sin fecha (2 L, CAIM CulH/lam-00207 y CAIM CulH/lam-00208); Mpo. Chinameca, Chinameca, sin fecha (1 L, CAIM CulH/lam-00206); Mpo. Xalapa de Enríquez, Xalapa, sin fecha (1 MT, CAIM CulH/lam-05265); Quintana Roo, Mpo. Cozumel, Cozumel, 12-08-1970 (5 H, CAIM CulH/alf-00391, CAIM CulH/alf-00395, CAIM CulH/alf-00399, CAIM CulH/alf-00405 y CAIM CulH/alf-00406); Mpo. Benito Juárez, Cancún, 03-12-1975 (1 H, CAIM CulH/alf-00477); Yucatán, Mpo. Progreso, Progreso, 04-1942 (1 H, CAIM CulH/alf-00342).

Distribución conocida. Estados Unidos, México, Guatemala, Honduras, Nicaragua, Cuba, Jamaica, Bahamas, República Dominicana. (Knight \& Stone 1977). En México se ha informado para los estados de Nuevo León, San Luis Potosí, Tamaulipas, Veracruz, Yucatán y Quintana Roo (Floore et al. 1976, Vargas \& Martínez-Palacios 1956).

Distribución en Veracruz (Figura 43). Mpo. Banderilla: Banderilla; Mpo. Chinameca: Chinameca; Mpo. Minatitlán: Minatitlán; Mpo. Tierra Blanca: Tierra Blanca; Mpo. Jaltipan: Jaltipan de Morelos; Mpo. Xalapa: Xalapa-Enríquez.

Datos bionómicos. Las larvas y pupas se desarrollan en charcos permanentes o semipermanentes de agua dulce, pozos, arroyos, pantanos y en los márgenes lagos, en agua ácida o alcalina ( $\mathrm{pH}$ entre 4.0 y 8.6), aunque se ha observado que prefiere un ambiente ácido. Generalmente están asociadas a vegetación acuática, ya sea flotante o emergente, bajo la condición de media sombra. Las hembras se alimentan del hombre, aunque prefieren hacerlo de animales domésticos (Belkin et al. 1970, Carpenter \& LaCasse 1955, Floore et al. Op. cit.).

Importancia médica. Experimentalmente es susceptible a Plasmodium falciparum (Boyd et al. 1936), En la naturaleza esta especie ha sido encontrada infectada con plasmodios de malaria humana con tasas de infección de 3.28\%, por lo que podría ser un vector importante de malaria (WRBU 2008). 

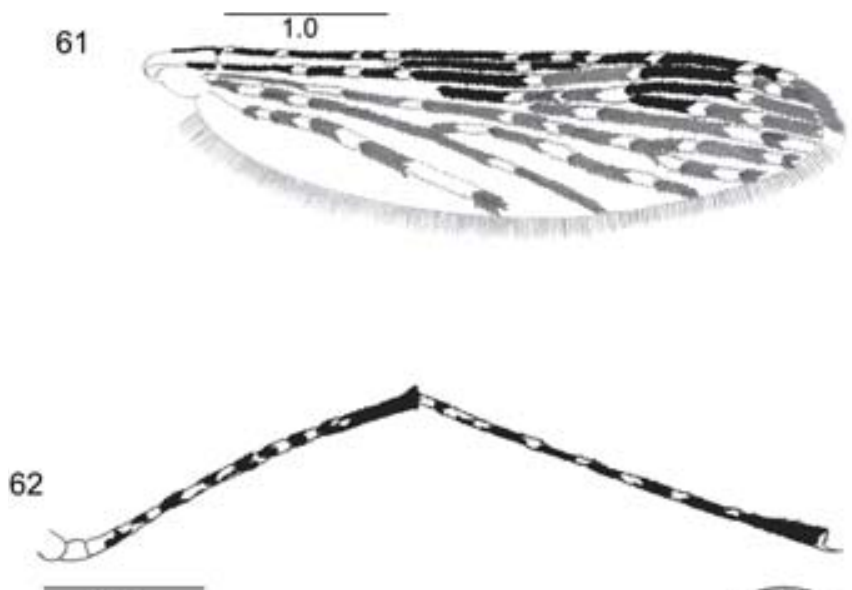

1.0
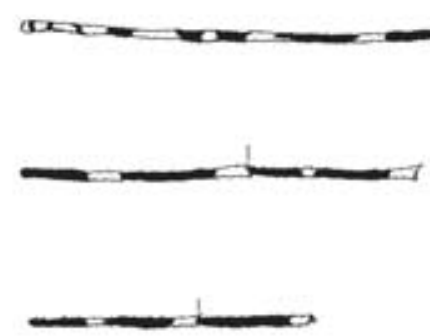

63

\section{Anopheles gabaldoni}

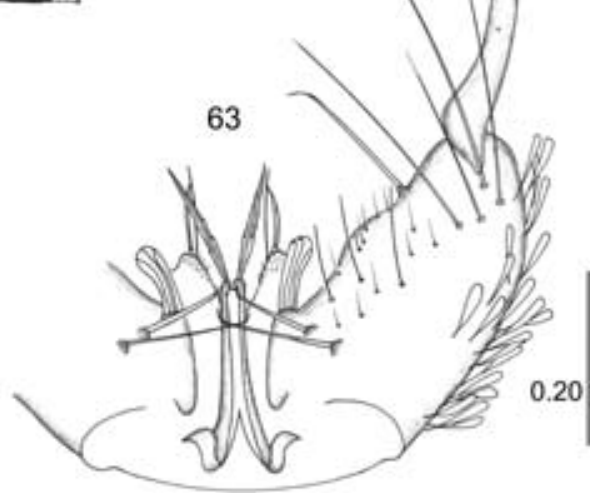

Figuras 61-63. Adultos de Anopheles (Anopheles) gabaldoni. Hembra. 61: Ala. 62: Pata posterior. Macho. 63: Terminalia.

Comentarios. Como se comentó anteriormente, las únicas diferencias con An. bradleyi son que An. crucians presenta las siguientes características. Larva: sedas 0-III-V con cuatro a trece ramas, casi del mismo tamaño que la seda 2-III-V. Pupa: seda 1-IV con ocho a veintiuna ramas, seda $0-\mathrm{V}$ con tres a once ramas. Hembra: comúnmente presenta el cúbito con escamas oscuras hasta la vena transversal medio-cubital. Macho, terminalia: lóbulos de la claspeta con generalmente cuatro sedas aplanadas aco- 


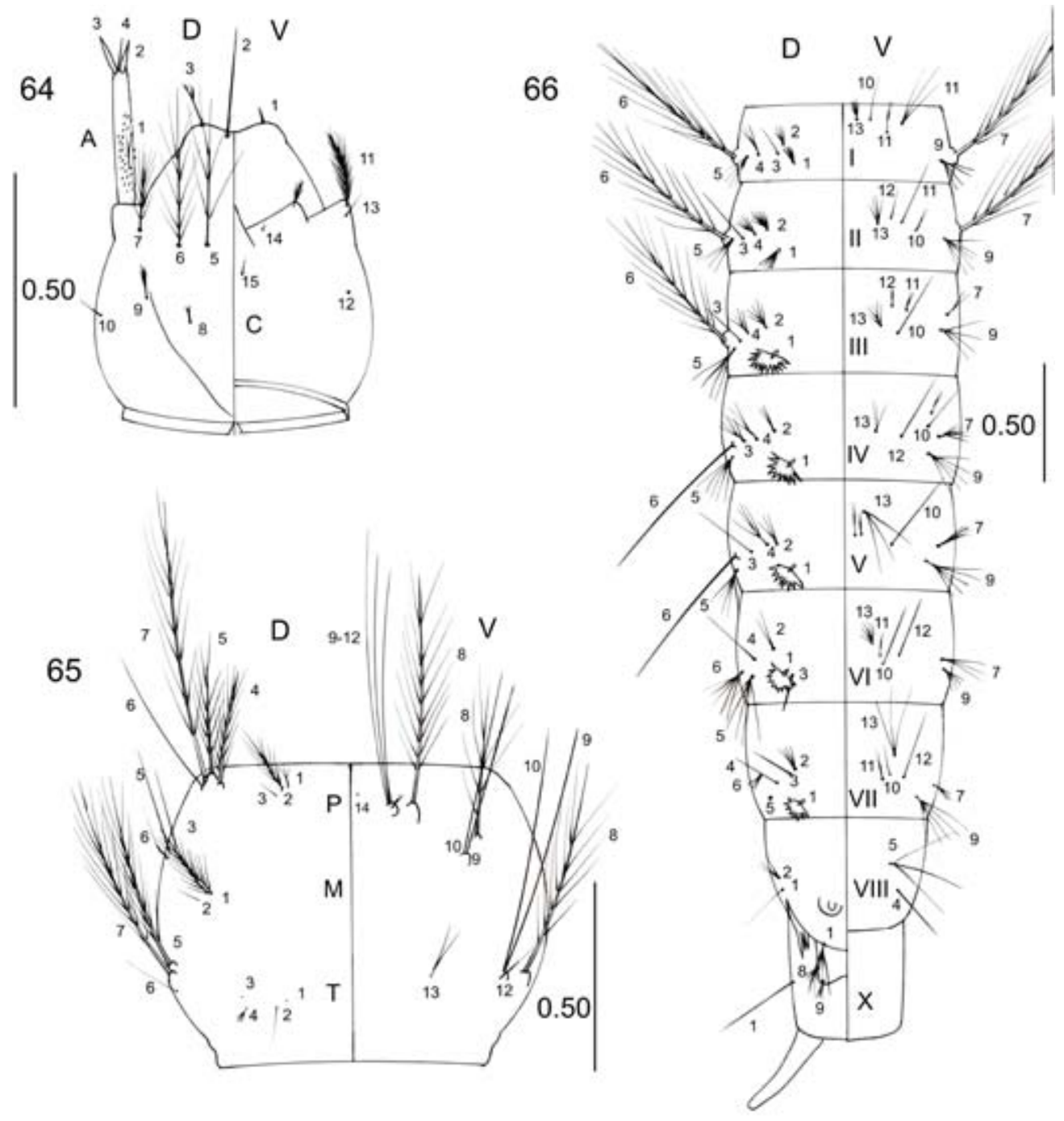

\section{Anopheles neomaculipalpus}

Figuras 64-66. Larva de Anopheles (Anopheles) neomaculipalpus. 64: Cabeza. 65: Tórax. 66: Abdomen. 
modadas en pares, el par dorsal (lateral) casi igual en tamaño y forma, el par ventral con la seda distal más larga y gruesa que la otra.

Se tienen muy pocos registros de esta especie en el estado, por lo que no se puede obtener una distribución potencial acertada, ni reconocer algún patrón de su distribución conocida. Como se mencionó para An. bradleyi, esto puede deberse a la falta de colecta en Veracruz y al hecho de que muchas identificaciones pudieron ser erradas.

Aunque no se considera una especie abundante en el estado, se recomienda tenerla bajo vigilancia debido a que se ha logrado infectar con plasmodios experimentalmente y se ha encontrado infectada naturalmente.

\section{Anopheles (Anopheles) eiseni Coquillett 1902}

(Figs. 44-53, 54)

Anopheles eiseni Coquillett 1902: 192 (macho y hembra). Localidad tipo: Aguna, Guatemala. Referencias adicionales.- Cova- García 1939: 18 (larva), 25 (hembra); Rozeboom 1941: 104 (distribución y bionomía); Correa 1942: 25 (pupa, larva, huevo); Komp 1942: 51 (hembra), 91 (larva), 139 (macho); Levi-Castillo 1945: 47 (huevo, larva, hembra, macho); Lassmann 1948: 10 (distribución en Veracruz); Lane 1953: 168 (hembra, macho, larva, huevo); Horsfall 1955: 80 (distribución y bionomía); Vargas \& Martínez-Palacios 1956: 52 (claves pupa), 72 (hembra, macho, larva); Vargas 1959: 384 (claves macho); Gorham et al. 1973: 115 (claves hembra), 132 (claves larva), 149 (bionomía).

Anopheles (Myzomia) tibiamaculata Neiva 1906: 3 (hembra). Localidad tipo: Oliveira, Estado de Minas Geraes, Brasil. Referencias adicionales.- Edwards 1932: 38 (sinonimia).

Anopheles niveopalpis Ludlow 1919: 166 (hembra). Localidad tipo: Reserva Comacho, Panamá. Referencias adicionales: Edwards 1932: 38 (sinonimia).

Diagnosis. LARVA (Figs. 44-46). Cabeza: sedas 2-C largas, delgadas y sencillas, tan juntas que sus alvéolos casi se tocan; sedas 3-C sencillas, como 0.4 del tamaño de las 2-C. Antena: sedas 2-3-A puntiagudas. Tórax: seda 1-P con siete a once ramas, con el tronco corto, sedas 9-12-P sencillas. Abdomen: sedas 1-II-VII con ramas anchas, pigmentadas, con el borde aserrado en la mitad distal; las sedas 1-II y 1-VII más pequeñas que las sedas 1-III-VI; seda 6-III ramificada (Vargas \& Martínez -Palacios 1956). PUPA (Figs. 47-49). Trompeta: laticorne, tan larga como su anchura máxima, la pinna alcanzando la base. Abdomen: seda 1-IV-VII con dos o tres ramas; seda 5-IV-VII con cinco o más ramas, 9-IV-VII sin ramas laterales, 9-VIII ramificada distalmente con menos de seis ramas. Paletas natatorias: seda 1-P débil, más corta que la seda 9-V (Vargas \& Martínez -Palacios Op. cit.). HEMBRA (Figs. 50-52). Cabeza: palpo maxilar con predominancia de escamas oscuras, palpómero 3 negro con un anillo delgado apical de escamas blancas, palpómero 4 negro en su parte dor- 
sal y blanco en la ventral y su base y punta blancas, palpómero 5 con una pequeña mancha dorsal negra. Tórax: Escudo con una línea central ancha de pruinosidad gris. Ala: costa con escamas oscuras, excepto por una mancha clara preapical distinguible en la costa y la vena radial uno. Patas: tibia de la pata posterior con una banda apical blanca conspicua; ápice del fémur de la pata posterior con unas pocas escamas claras. Abdomen: integumento negro; con sedas oscuras; sin escamas (Vargas \& MartínezPalacios 1956, Wilkerson et al. 1993). MACHO. Terminalia (Fig. 53): gonostilo ligeramente más largo que el gonocoxito, adelgazado en la parte central; uña gonostilar corta y redondeada en la punta. Gonocoxito sin escamas. Con dos espinas parabasales de grosor similar, la basal exterior más larga. Una espina interna. Lóbulo dorsal de la claspeta con dos espinas apicales, una grande y vertical y la otra que encorvada en dirección interna. Lóbulo ventral de la claspeta con una sola seda apical recta, mucho más tenue que las del lóbulo dorsal. Edeago muy largo, casi recto con un solo par de hojillas apicales toscas, largas y moderadamente anchas, con numerosas escotaduras en los bordes laterales. Noveno terguito estrecho en la parte central, con lóbulos laterales cortos y redondeados (Vargas \& Martínez-Palacios Op. cit.).

Material examinado. 28 ejemplares. México: Veracruz, Mpo. Catemaco, La Chorrera, 24-07-1964 (7 H, CAIM CulH/alf-00531, CAIM CulH/alf-00533, CAIM CulH/ alf-00534, CAIM CulH/alf-00535, CAIM CulH/alf-00536, CAIM CulH/alf-00537 y CAIM CulH/alf-00538; 1 M, CAIM CulH/alf-00532), La Selva, 26-07-1961 (1 H, CAIM CulH/alf-00528); Mpo. Naolinco, La Raya, 27-06-1956 (5 L, CAIM CulH/ lam-00304, CAIM CulH/lam-00306, CAIM CulH/lam-00307, CAIM CulH/lam00308 y CAIM CulH/lam-00309; 1 H, CAIM CulH/alf-00540; 1 M, CAIM CulH/ alf-00539), Naolinco de Victoria, 01-08-1945 (3 L, CAIM CulH/lam-00299, CAIM CulH/lam-00305 y CAIM CulH/lam-00311), San Marcos Atexquilapan, 01-08-1956 (3 L, CAIM CulH/lam-00303 y (2)CAIM CulH/lam-00310), Tenampa, 01-08-1945 (3 L, CAIM CulH/lam-00300, CAIM CulH/lam-00301 y CAIM CulH/lam-00302); Mpo. Pajapan, Pajapan, 24-11-1954 (1 M, CAIM CulH/alf-00542) Mpo. Tierra Blanca, Tierra Blanca, 02-04-1957 (1 M, CAIM CulH/alf-00530); San Luis Potosí, Mpo. Tlapexhuacan, 04-1942 (1 MT, CAIM CulH/lam-005281).

Distribución conocida. Centroamérica, México, Colombia, Trinidad y Tobago, Surinam, Guyana Francesa, Brasil, Bolivia y Ecuador (Knight \& Stone 1977). En México se ha colectado en los estados de Chiapas, Durango, Guerrero, Hidalgo, Michoacán, Morelos, Oaxaca, San Luis Potosí, Tabasco y Veracruz (Vargas \& Martínez-Palacios Op. cit.).

Distribución en Veracruz (Figura 54). Mpo. Acajete: El Sedeño; Mpo. Amatlán de los Reyes: Amatlán de los Reyes; Mpo. Banderilla: Banderilla; Mpo. Catemaco: La 


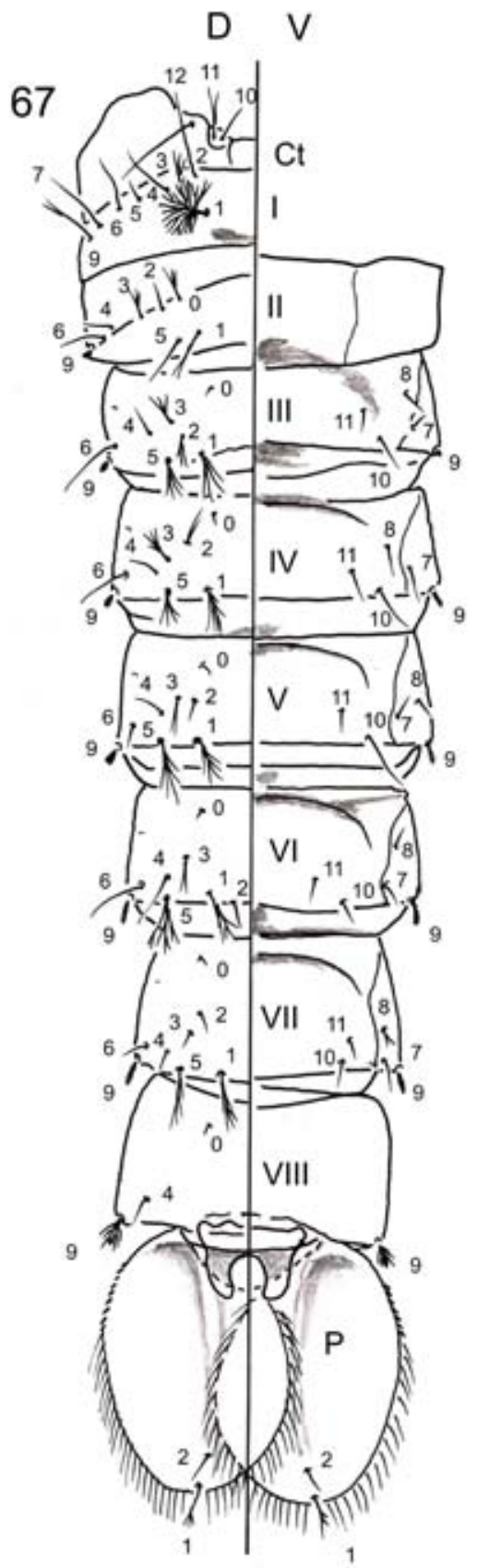

68
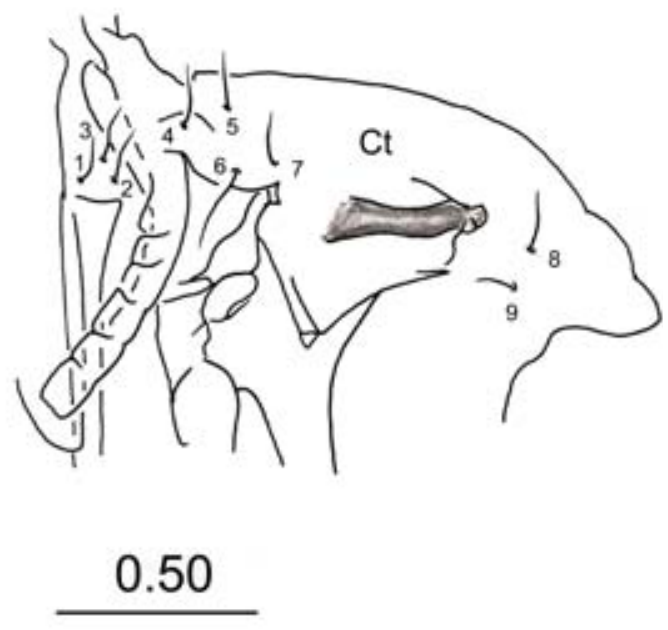

69

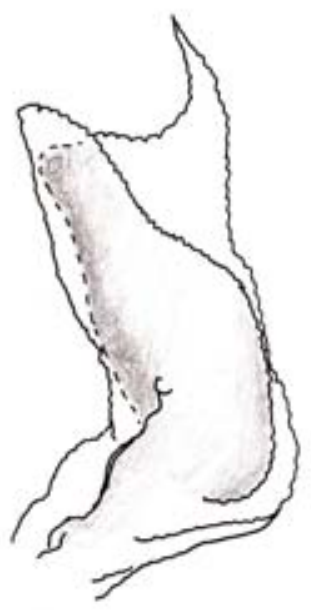

Figuras 67-69. Pupa de Anopheles (Anopheles) neomaculipalpus. 67: Abdomen. 68: Cefalotórax. 69: Trompeta ventiladora. 


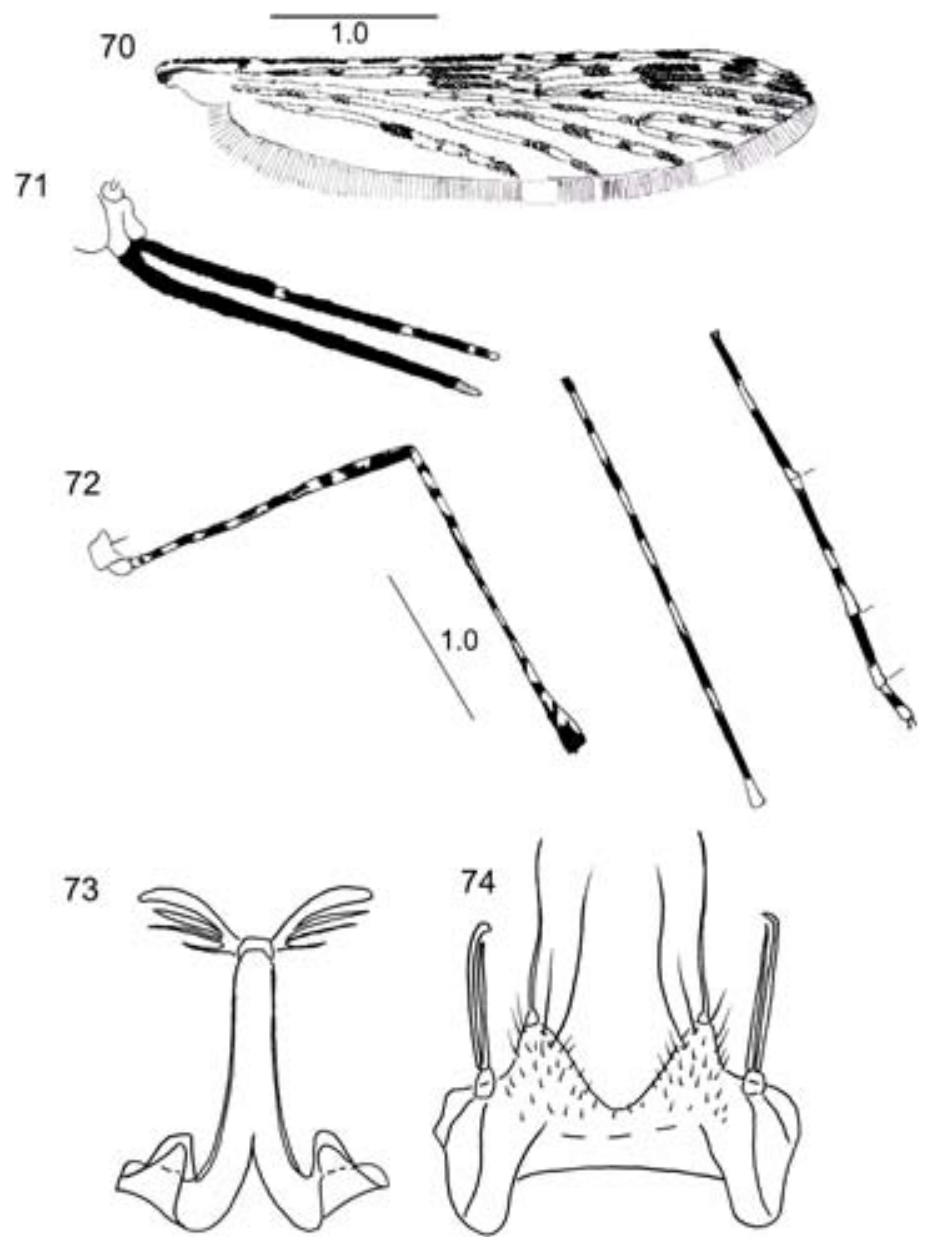

Figuras 70-74. Adultos de Anopheles (Anopheles) neomaculipalpus. Hembra. 70: Ala. 71: Palpo maxilar. 72: Pata posterior. Macho (redibujado de Lane, 1953). 73: Edeago. 74: Lóbulos de la claspeta.

Chorrera, La Selva; Mpo. Coatepec: Coatepec, El Grande, Las Lomas, Pacho Viejo; Mpo. Córdoba: Córdoba, Río Tiburcio, Veinte de Noviembre; Mpo. Chinameca: Chinameca; Mpo. Emiliano Zapata: Plan del Río; Mpo. Fortín: Cuapichapan, Fortín; Mpo. Huatusco: Huatusco; Mpo. Xalapa: Xalapa-Enríquez; Mpo. Xico: San Marcos; Mpo. Jilotepec: Esquilón; Mpo. Misantla: Misantla; Mpo. Naolinco: La Raya, San Marcos Atesquinapan, Naolinco de Victoria, Tenampa; Mpo. Pajapan: Pajapan; Mpo. Tierra Blanca: Tierra Blanca; Mpo. Soteapan: Soteapan; Mpo. Zongolica: Zongolica; Mpo. Indeterminado: Los Reyes. 
Datos bionómicos. Las larvas se crían en cuerpos de agua dulce limpia con mucha sombra, como pequeños arroyos y pozos. Se han colectado larvas en agua acumulada en cáscaras de coco, en huecos de los árboles y en bromelias. Las hembras parecen no ser atraídas por el humano y rara vez entran a las casas (Rozeboom 1941).

\section{Importancia médica. Desconocida.}

Comentarios. Se puede distinguir de otras especies por las siguientes características. Larva: sedas 3-C sencilla, 1-P con siete a once ramas, 6-III ramificada; Pupa: trompeta laticorne, seda 1-IV-VII con dos o tres ramas, 5-IV-VII con cinco o más ramas, 9-VIII ramificada, 1-P débil, más corta que 9-V. Hembra: palpómero 5 con una mancha dorsal de escamas oscuras, pata posterior con la tibia presentando una banda apical ancha y el fémur con pocas escamas claras. Macho, terminalia: lóbulo dorsal de la claspeta con dos espinas apicales, lóbulo ventral con una sola seda apical recta, edeago muy largo, casi recto con un solo par de hojillas apicales toscas, largas y moderadamente anchas, con numerosas escotaduras en los bordes.

Esta especie no se encuentra ampliamente distribuida en el estado; sin embargo, se puede considerar abundante en los municipios de Naolinco, Catemaco y Banderilla, aunque ha sido reportada para una gama amplia de altitudes, desde los 20 hasta los $1800 \mathrm{msnm}$. Debido a esto se recomienda vigilar sus poblaciones, a pesar de que hasta el momento su importancia médica es desconocida.

La distribución potencial de esta especie se limita a zonas altas del centro del estado, a una altitud de entre los 800 y $2000 \mathrm{msnm}$, asociado al bosque mesófilo de montaña; y en otra zona de la Sierra de los Tuxtlas. Se observa claramente que algunos de los puntos de colecta quedan fuera del área predicha; sin embargo, estos se encuentran cerca de dicha área, lo que podría deberse a la capacidad de vuelo de estos mosquitos.

\section{Anopheles (Anopheles) gabaldoni Vargas 1941}

(Figs. 55-63)

Anopheles (Ano.) gabaldoni Vargas 1941a: 389 (macho, hembra). Localidad tipo: Tenosique, Tabasco, México. Referencias adicionales: Peláez 1945: 74 (hembra); Vargas \& Martínez-Palacios 1946: 19 (pupa, larva, huevo); Lane 1953: 207 (hembra, macho, larva); Vargas \& Martínez-Palacios 1956: 54 (claves pupa), 103 (macho, hembra, larva); Vargas 1959: 379 (claves macho); Stojanovich et al. 1966: 7 (claves larva), 25 (claves hembra), 32 (bionomía).

Diagnosis. LARVA (Figs. 55-57). Cabeza: sedas 2-C sencillas, convergentes, separadas entre sí por un espacio del doble del diámetro de uno de los alvéolos que les da origen; sedas 3-C más cortas que las 2-C, ramificadas dicotómicamente, con siete a 
catorce ramas. Antena: seda 3-A puntiaguda, y la 2-A truncada. Tórax: seda 1-P con cuatro a seis ramas finas, seda 9-P con cuatro a cinco ramas. Abdomen: sedas 1-IIIVII palmeadas, con ramas pigmentadas y con el borde aserrado en la mitad distal (Stojanovich et al. 1966, Vargas \& Martínez-Palacios 1946). PUPA (Figs. 58-60). Trompeta: laticorne, con un surco meatal profundo y un surco secundario; pinna con una proyección digitiforme conspicua. Abdomen: borde posterior de los segmentos III-VII con algunas pequeñas espículas, seda 9-VIII con un tallo grueso y alrededor de catorce ramas. Paletas natatorias: fuertemente pigmentadas, contrastando con el abdomen de color más claro; margen exterior con acículas filamentosas; margen interno con serraciones en la mitad basal y acículas filamentosas en la mitad apical; seda 1-P gruesa, bifurcada; 2-P sencilla y delgada (Vargas \& Martínez-Palacios 1941, 1956). HEMBRA (Figs. 61-62). Cabeza: Palpo maxilar con escamas negras erectas; palpómeros 3, 4 y 5 con escamas blancas en la parte basal, sin que formen anillos. Tórax: escudo pruinoso gris con puntos pequeños de escamas negras y una mancha negra en la zona prescutelar más o menos marcada que se continúa en el escudete. Ala: con escamas oscuras y claras en todas las venas; costa con la mancha pálida preapical interrumpida por la mancha oscura preapical accesoria; vena radial $4+5$ con predominancia de escamas oscuras. Abdomen: terguitos con mechones de escamas posterolaterales y esternitos con numerosas escamas claras y oscuras (Vargas \& Martínez-Palacios 1956, Wilkerson et al. 1993). MACHO. Terminalia (Fig. 63): gonostilo tan largo como 1.2X la longitud del gonocoxito; uña gonostilar corta y con la punta redondeada. Gonocoxito con sedas y escamas. Gonocoxito con una espina interna que nace en la mitad distal y dos espinas parabasales implantadas en lóbulos separados. Lóbulo ventral de la claspeta con una espina fuerte y otras más o menos gruesas. Lóbulo dorsal de la claspeta con tres espinas delgadas con el ápice redondeado y no ensanchado. Edeago con dos hojillas largas y delgadas, con el borde aserrado, con una vena central claramente marcada (Vargas 1941a).

Material examinado: 7 ejemplares. México: Veracruz, Mpo. Indeterminado, F. Reyes 20 de Nov., 16-05-1948 (1 H, CAIM CulH/alf-00664); Chiapas, Mpo. Salto del Agua, Salto del Agua, 09-1945 (1 H, CAIM CulH/alf-00732), sin fecha (3 P, CAIM CulH/lam-05292); Tabasco, Mpo. Teapa, San Joaquín, 16-10-1954 (1 MT, CAIM CulH/lam-05302); Mpo. Villa Hermosa, Centro, 26-10-1954 (1 MT, CAIM CulH/ lam-05301).

Distribución conocida. México y Guatemala (Knight \& Stone 1977). En México se encuentra en las regiones húmedas de Veracruz, Tabasco y Chiapas (Vargas \& Martínez-Palacios 1956).

Distribución en Veracruz. Mpo. Chapopotla: Nanchital; Mpo. Indeterminado: F. Reyes. 


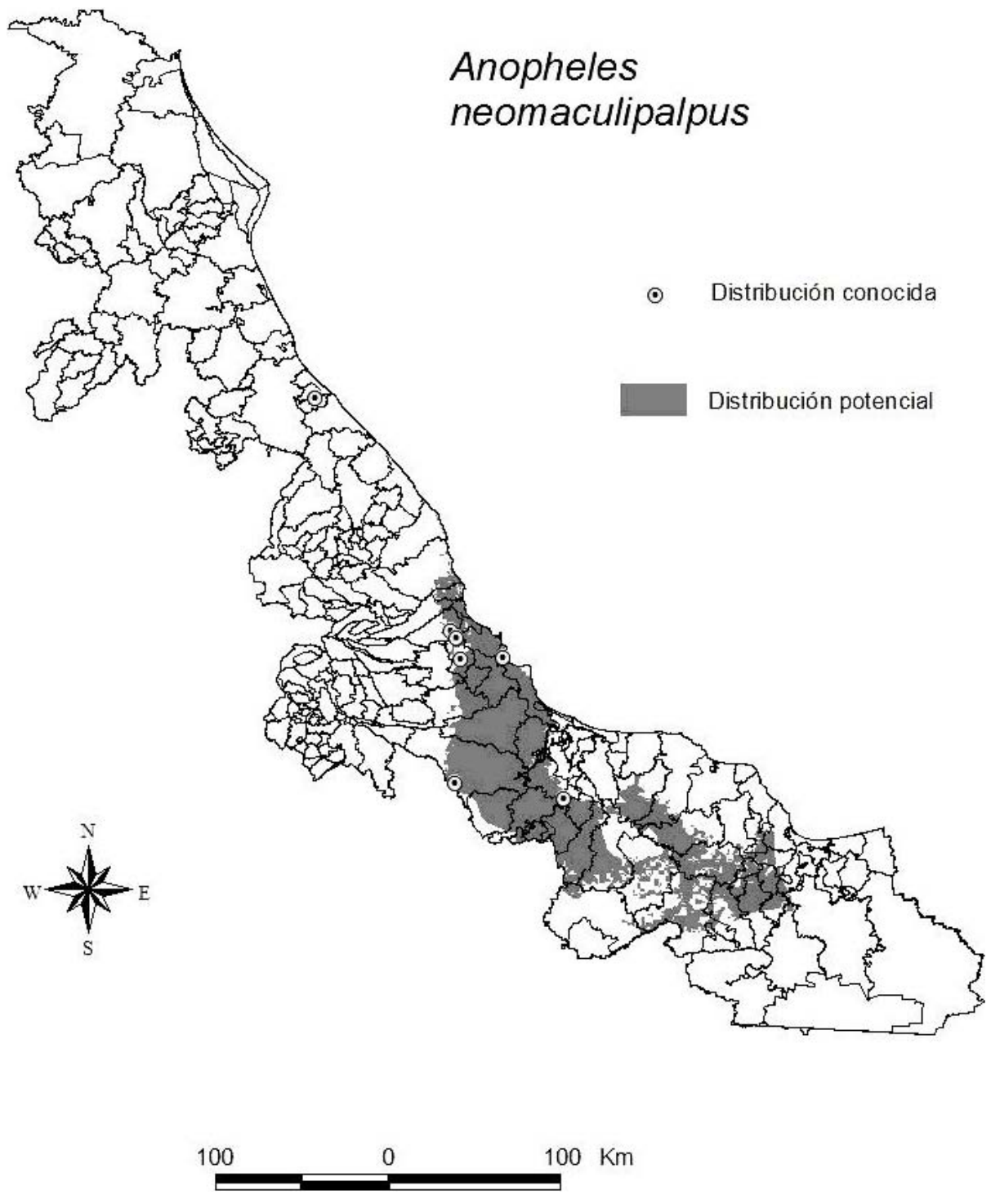

Figura 75. Mapa de la distribución conocida y potencial de Anopheles (Anopheles) neomaculipalpus.

Datos bionómicos. En 1946 encontraron que la larva se cría en charcos pequeños de agua de lluvia con poca profundidad, con sombra, entre la vegetación y asociada con An. punctimacula. Se informó que las hembras prefirieron alimentarse de caballos, antes que del humano (Vargas \& Martínez-Palacios 1946). 

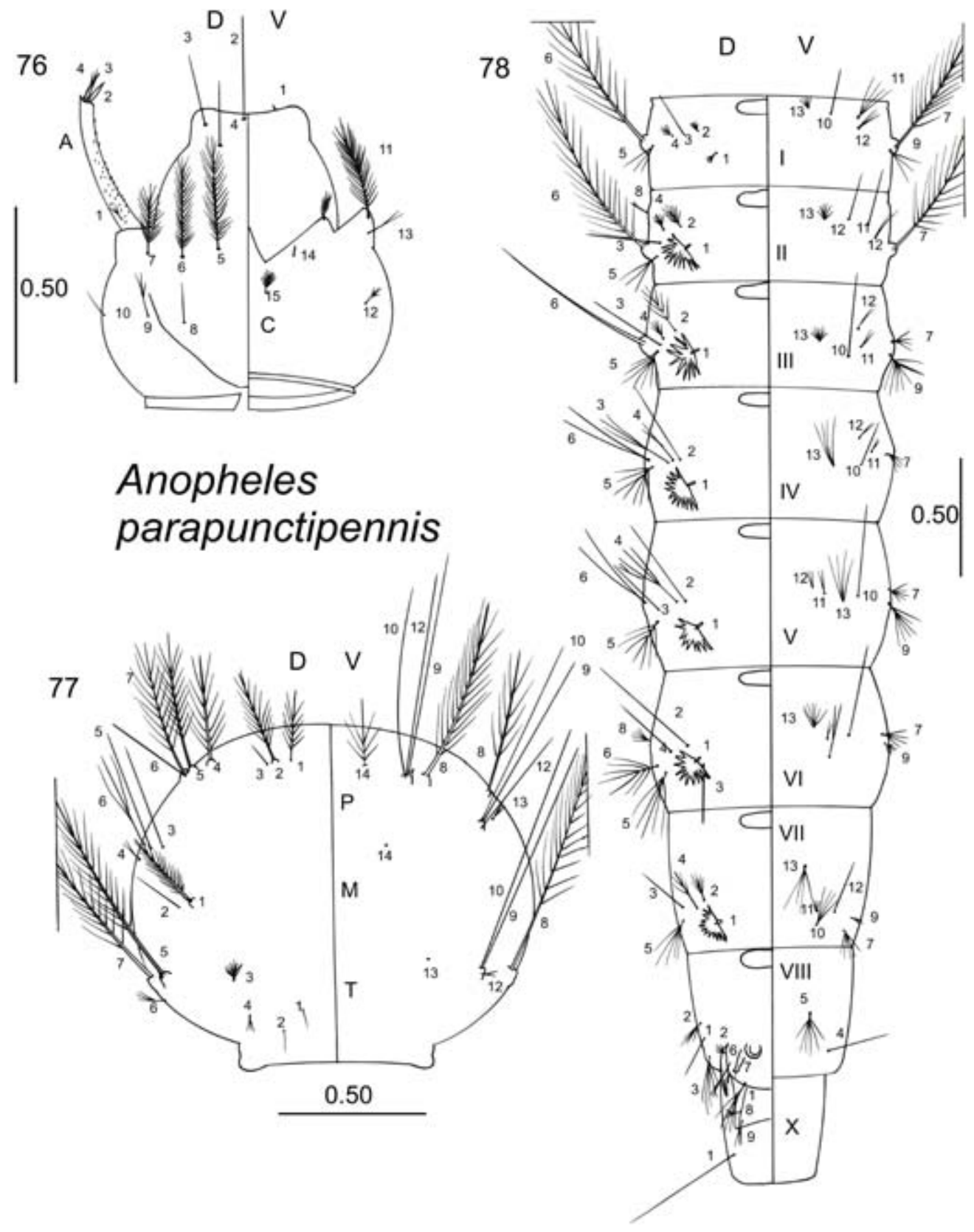

Figuras 76-78. Larva de Anopheles (Anopheles) parapunctipennis. 76: Cabeza. 77: Tórax. 78: Abdomen. 


\section{Importancia médica. Desconocida.}

Comentarios. Se puede distinguir de otras especies (excepto de la larva de An. vestitipennis) por las siguientes características. Larva: sedas 2-C sencillas, convergentes, separadas entre sí por un espacio del doble del diámetro de uno de los alvéolos que les da origen, sedas 3-C más cortas que las 2-C, ramificadas dicotómicamente, con siete a catorce ramas; Pupa: trompeta laticorne con un lóbulo caudal conspicuo, paletas fuertemente pigmentadas, contrastando con el abdomen de color más claro; Hembra: palpómeros 3, 4 y 5 con escamas blancas en la parte basal, sin que formen anillos, costa con la mancha pálida preapical interrumpida por la mancha oscura preapical accesoria; vena radial 4+5 con predominancia de escamas oscuras; Macho, terminalia: lóbulo ventral de la claspeta con una espina fuerte y otras más o menos gruesas, lóbulo dorsal de la claspeta con tres espinas delgadas con el ápice redondeado y no ensanchado, edeago con dos hojillas largas y delgadas, con el borde aserrado, con una vena central claramente marcada.

La larva de An. gabaldoni es prácticamente indistinguible de la de An. vestitipennis.

Su distribución es incierta ya que las únicas dos localidades dónde se ha colectado, no se encuentran dentro de las bases de datos utilizadas para georreferenciar los puntos de colecta. Por esta razón, no se pudo obtener un mapa de su distribución conocida y potencial.

Es una especie poco estudiada, debido a que es una especie rara en todo el mundo (en México se ha informado en zonas muy húmedas de solo tres estados); como consecuencia, nunca ha sido incriminada como vector de malaria, por lo que su importancia médica hasta el momento es desconocida.

\section{Anopheles (Anopheles) neomaculipalpus Curry 1931}

(Figs. 64-74, 75)

Anopheles (Ano.) neomaculipalpus Curry 1931: 643 (macho, hembra, pupa y larva). Localidad tipo: Gatun, al este de la ciudad de Panamá, Panamá. Referencias adicionales.- Senevet 1934: 33 (pupa); Cova- García 1939: 18 (larva), 25 (hembra); Kumm 1941: 91 (huevo); Komp 1942: 59 (hembra), 104 (pupa, larva), 145 (hembra); Pelaez 1945: 74 (hembra); Cova-García 1946: 48 (hembra, larva); Lassmann 1948: 11 (distribución en Veracruz); Lane 1953: 215 (hembra, macho, larva); Horsfall 1955: 118 (distribución y bionomía); Vargas \& Martínez Palacios 1956: 53 (claves pupa), 105 (macho, hembra, larva); Vargas 1959: 379 (claves macho); Stojanovich et al. 1966: 7 (claves larva), 26 (claves hembra), 33 (bionomía); Gorham et al. 1973: 119 (claves hembra), 129 (claves larva), 147 (bionomía); Heinemann \& Belkin 1977:414 (distribución). 
Diagnosis. LARVA (Figs. 64-66). Cabeza: sedas 2-C convergentes, sencillas, más gruesas que las 3-C, separadas entre sí por un espacio del diámetro de uno de los alvéolos que les da origen; sedas 3-C divergentes, simples. Antena: seda 3-A puntiaguda y 2-A truncada. Tórax: seda 1-P con tres a seis ramas finas, seda 11-P ramificada, sedas 9, 10, 12-P sencillas. Abdomen: sedas 1-III-VII palmeadas, con ramas pigmentadas, con el borde aserrado en la mitad distal (Komp 1942, Stojanovich et al. 1966, Vargas \& Martínez-Palacios 1956). PUPA (Figs. 67-69). Trompeta: con un surco meatal profundo y un surco secundario; pinna con una proyección puntiaguda corta en su margen distal. Abdomen: sedas 9-IV-VII sencillas, espiniformes, 9-VIII gruesa, con tres a cuatro ramas finas y cortas en su mitad distal. Paletas natatorias: margen externo con serraciones que decrecen en tamaño hacia la parte media de la paleta; seda 1-P corta y gruesa, con cuatro a cinco ramas, 2-P simple (Senevet 1934, Vargas \& Martínez -Palacios Op. cit.). HEMBRA (Figs. 70-72). Cabeza: palpo maxilar con predominancia de escamas oscuras, palpómero 3 con escamas claras en su base; palpómero 4 con un anillo basal de escamas claras; palpómero 5 con un anillo de escamas en su base y escamas claras en su ápice. Tórax: escudo pruinoso gris con puntos pequeños de escamas negras y tres manchas grandes, dos en posición anterolateral con respecto a las bases de las alas y una tercera en el área prescutelar que se continúa en el escudete. Patas: tarsómero 5 de la pata posterior con una banda oscura; articulaciones de los tarsómeros de la pata posterior blancas. Ala: con escamas claras blancas; mancha oscura preapical pequeña, tan larga como 0.06-0.12 la longitud del ala. Abdomen: esternitos I-VIII comúnmente con pocas escamas claras postero-laterales (Vargas \& Martínez-Palacios 1956, Wilkerson et al. 1993). MACHO. Terminalia (Figs. 73-74): gonostilo más largo que el gonocoxito, con la parte central adelgazada; uña gonostilar corta y de punta redondeada. Gonocoxito con el extremo apical muy redondeado; con numerosas escamas en la parte externa. Dos espinas parabasales (una más larga y delgada que la otra) y una espina interna. Edeago con cuatro pares de hojillas, las del primer par cuatro veces más anchas que las demás, esclerosadas de aspecto estriado. Lóbulo dorsal de la claspeta con tres espinas apicales, planas, rectas, de puntas obtusas, ligeramente ensanchadas. Lóbulo ventral de la claspeta moderadamente con sedas cortas, dos espinas puntiagudas de longitud similar y una tercera espina muy débil. Noveno terguito ancho en la parte central con lóbulos laterales cortos, de puntas redondeadas (Vargas \& Martínez -Palacios Op. cit.).

Material examinado. 9 ejemplares. México: Veracruz, Mpo. Boca del Río, Boca del Río, 10-1941 (4 H, CAIM CulH/alf-00861, CAIM CulH/alf-00862; CAIM CulH/alf-00863 y CAIM CulH/alf-00864), 01-10-1941 (2 P CAIM CulH/lam-05325 y CAIM CulH/lam-05326); Mpo. Tierra Blanca, Tierra Blanca, sin fecha (1 L, CAIM CulH/lam-00536); Chiapas, Mpo. Tapachula, Tapachula, 01-10-1941 (1 L, CAIM CulH/lam-00474); Mpo. Indeterminado, Finca la Esperanza, 01-03-1947 (1 P, CAIM CulH/lam-05324). 

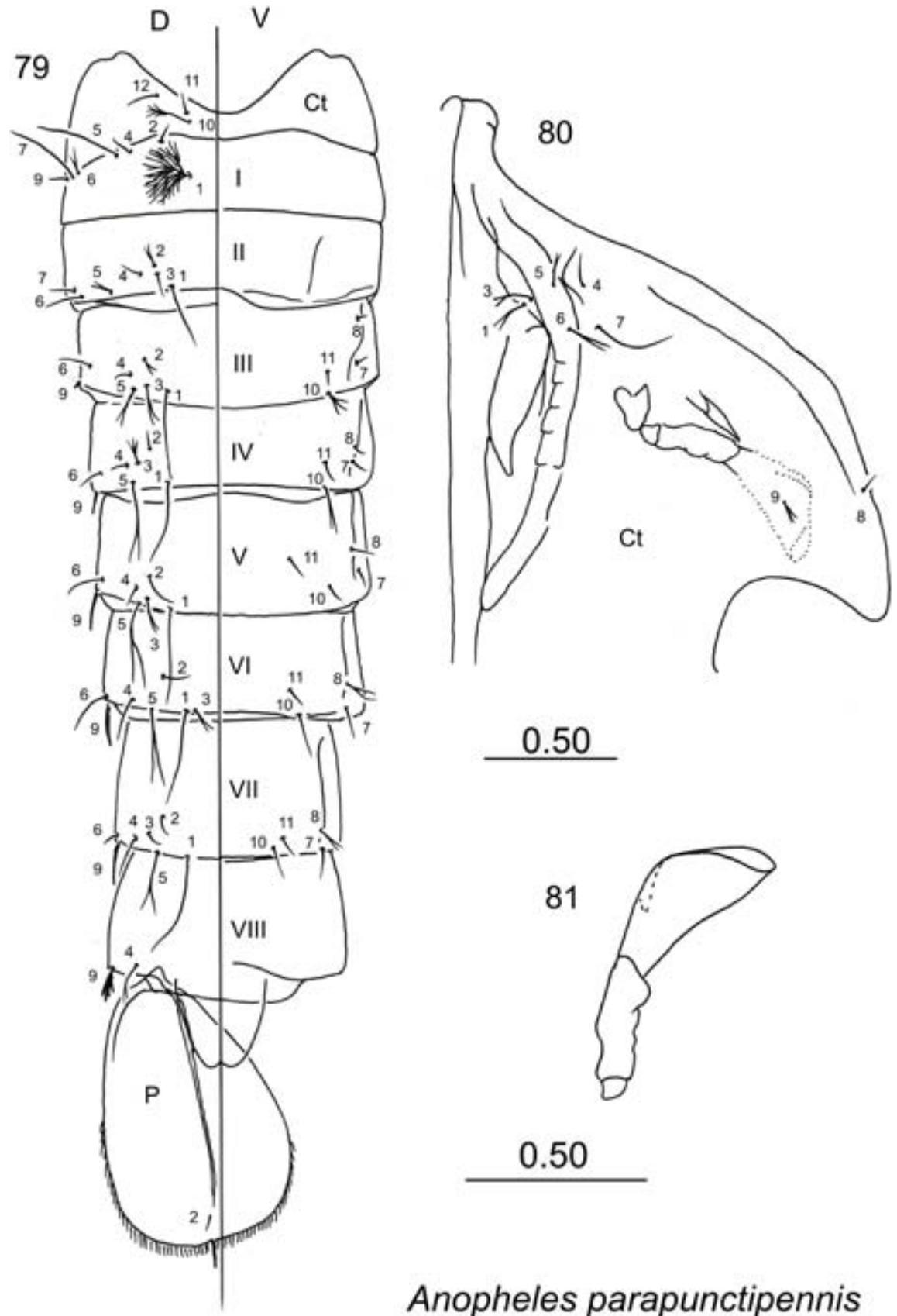

\section{Anopheles parapunctipennis}

Figuras 79-81. Pupa de Anopheles (Anopheles) parapunctipennis. 79: Abdomen.80: Cefalotórax. 81: Trompeta ventiladora. 

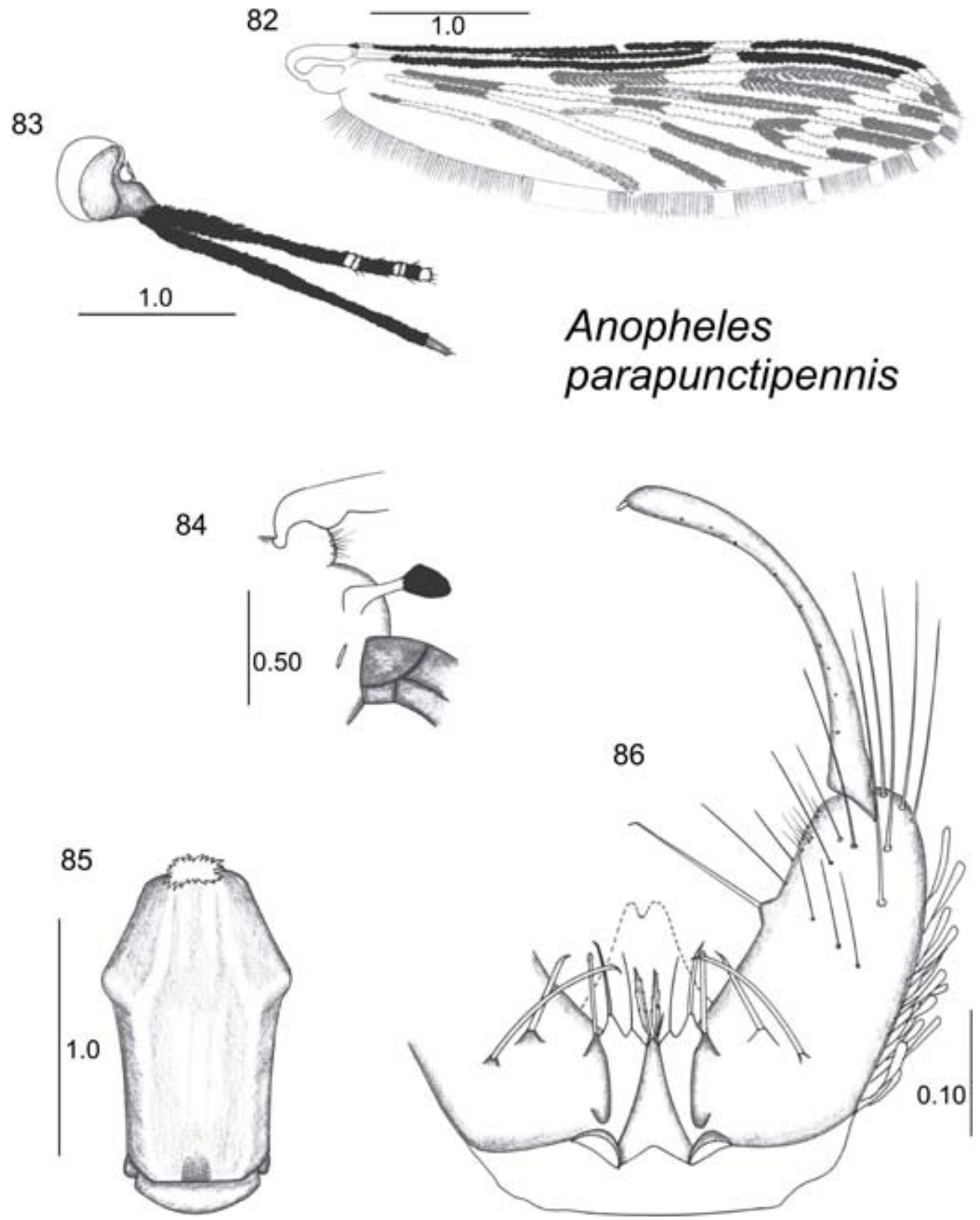

Figuras 82-86. Adultos de Anopheles (Anopheles) parapunctipennis. Hembra.82: Ala. 83: Palpo maxilar. 84: Balancín. 85: Escudo y escudete. Macho. 86: Terminalia. 
Distribución conocida. Panamá, Costa Rica, El Salvador, México, Trinidad y Tobago, Colombia, Venezuela, Paraguay, Argentina, Brasil (Knight \& Stone 1977).

Distribución en Veracruz (Figura 75). Mpo. Boca del Río: Boca del Río; Mpo. Cosamaloapan: Vista Hermosa; Mpo. Manlio Fabio Altamirano: Manlio Fabio Altamirano; Mpo. Gutiérrez Zamora, Gutiérrez Zamora; Mpo. Paso de Ovejas: Cerro de Guzmán, Puente de Jula; Mpo. Tierra Blanca: Tierra Blanca.

Datos bionómicos. Las larvas se desarrollan en agua acumulada en huellas, marcas de llantas, charcos con pastos, con plena exposición al sol. Pueden tolerar agua sucia con heces de ganado (Komp 1942). En cuanto a las hembras se ha mencionado que son altamente antropófilas (Moreno et al. 2005).

Importancia médica. En un estudio realizado en municipio de Sifontes, en el estado de Bolívar, Venezuela (parte del Amazonas) encontraron a esta especie infectada con Plasmodium vivax, con una tasa de esporozooitos de 0.84 , por lo que sugieren que es un vector secundario de la malaria en zonas recientemente colonizadas por el hombre (Moreno et al. Op. cit.).

Comentarios. Se distingue de otras especies por las siguientes características. Larva: sedas 3-C divergentes, simples, seda 1-P con tres a seis ramas finas, seda 11-P corta, ramificada. Pupa: trompeta laticorne, con proyección puntiaguda en la pinna, seda 1P corta y gruesa, con cuatro a cinco ramas. Hembra: palpómero 3 con escamas claras en su base; palpómero 4 con un anillo basal de escamas claras; palpómero 5 con un anillo de escamas en su base y escamas claras en su ápice, ala con escamas blancas (no amarillentas); Macho, terminalia: Edeago con cuatro pares de hojillas, las del primer par cuatro veces más anchas que las demás, esclerosadas de aspecto estriado, lóbulo dorsal de la claspeta con tres espinas apicales, planas, rectas, de puntas obtusas, ligeramente ensanchadas. La hembra de esta especie es similar a la de Anopheles punctimacula, sin embargo se puede distinguir por las siguientes características que presenta An. neomaculipalpus: ala con escamas claras blancas; mancha oscura preapical pequeña, tan larga como 0.06-0.12 la longitud del ala, abdomen con los esternitos I-VIII comúnmente con pocas escamas claras postero-laterales. Los terminalia del macho de esta especie son similares a los de An. apicimacula y An. punctimacula; sin embargo, An. neomaculipalpus presenta el primer par de hojillas del edeago sin un engrosamiento central a manera de nervadura, con los bordes esclerotizados, al igual que el resto de la hojilla.

En Veracruz esta especie ha sido colectada en localidades a muy baja altitud (menor a $100 \mathrm{~m} \mathrm{snm}$ ) y no parece ser abundante ni tampoco parece estar ampliamente distribuida en el estado. 
La distribución conocida de esta especie se encuentra cerca de cuerpos de agua, por el tipo de vegetación presente en la zona (manglar y vegetación halófila).

En el mapa de la distribución potencial se observa que los hábitats adecuados para el desarrollo de esta especie son el clima cálido húmedo con lluvias en verano (el de mayor humedad en el estado), a baja altitud.

Se recomienda que esta especie esté bajo vigilancia considerando que ha sido incriminada como vector de malaria humana en zonas recientemente colonizadas y que algunos de los criaderos de las larvas suelen estar asociados a los asentamientos humanos (agua acumulada en huellas de llantas y animales), aun cuando no esté ampliamente distribuida en el estado.

\section{Anopheles (Anopheles) parapunctipennis Martini 1932}

(Figs. 76-86, 87)

Anopheles parapunctipennis Martini 1932:101 (macho y hembra). Localidad tipo: San Cristóbal de las Casas, Chiapas, México. Referencias adicionales.- Komp 1941: 95 (claves larva); Rozeboom 1941: 106 (distribución); Vargas 1949: 233 (pupa); Stojanovich et al. 1966: 8 (claves larva), 24 (claves hembra), 35 (bionomía); Wilkerson 1989: 180 (neotipo).

Anopheles (Anopheles) chiriquiensis guatemalensis De León 1938: 416 (larva, pupa, hembra, macho); Hoffman 1939: 347 (taxonomía).

Anopheles parapunctipennis var. guatemalensis De León 1938; Vargas 1940a: 202 (claves hembra); Vargas 1959: 378 (claves macho).

Anopheles parapunctipennis parapunctipennis Martini 1932 In: Russell et al. 1943: 26 (claves macho), 33 (claves larva); Lassmann 1948: 10 (distribución en Veracruz); Vargas 1949: 233 (pupa); Lane 1953:163 (hembra, macho, larva); Vargas \& Martínez-Palacios 1956: 52 (claves pupa), 80 (macho, hembra, larva); Vargas 1959: 378 (claves macho).

Diagnosis. LARVA (Figs. 76-78). Cabeza: sedas 2-4-C sencillas; las 2-C tan juntas que los alvéolos que les dan origen casi se tocan. Antena: sedas 2-3-A puntiagudas. Tórax: seda 1-P larga, con nueve a catorce ramas; sedas 9-12-P sencillas. Abdomen: sedas abdominales 1-II-VI palmeadas, con ramas anchas, pigmentadas y con el borde aserrado en la mitad distal; seda 6-III sencilla y larga (Stojanovich et al. 1966, Vargas \& Martínez-Palacios 1956, Wilkerson 1989). PUPA (Figs. 79-81). Trompeta: angusticorne. Abdomen: seda 1-IV-VII sencilla; seda 5-IV-VII bifurcada; seda 9-IV-VII sencilla, 9-VIII ramificada distalmente con dos a seis ramas gruesas. Paletas natatorias: margen externo sin serraciones, con acículas filamentosas largas en el tercio inferior, sin llegar a la seda 1-P; seda 1-P espiniforme, recta (Vargas 1949, Vargas \& Martínez-Palacios Op. cit.). HEMBRA (Figs. 82-85). Escamas claras del ala, tórax 


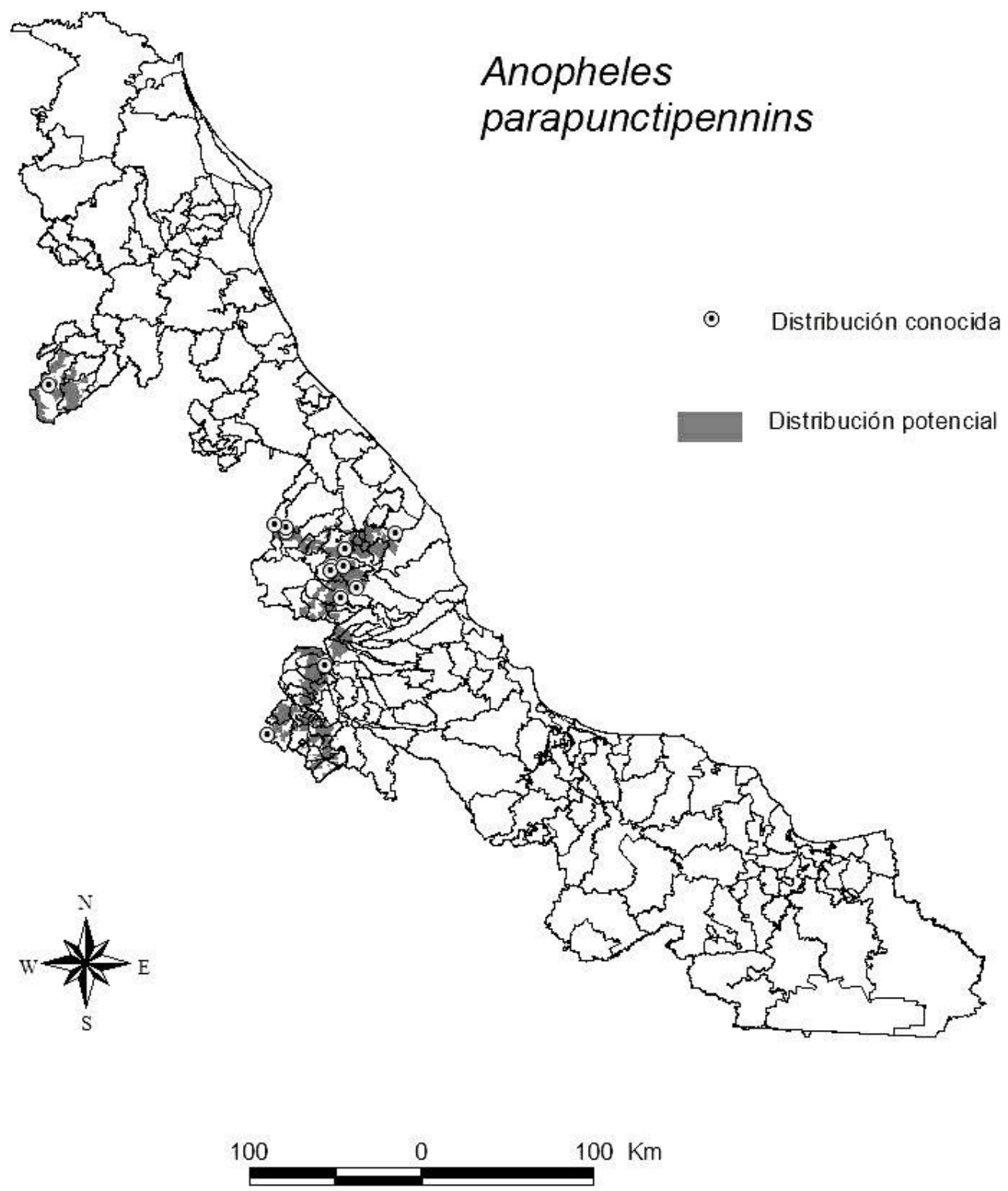

Figura 87. Mapa de la distribución conocida y potencial de Anopheles (Anopheles) parapunctipennis. 


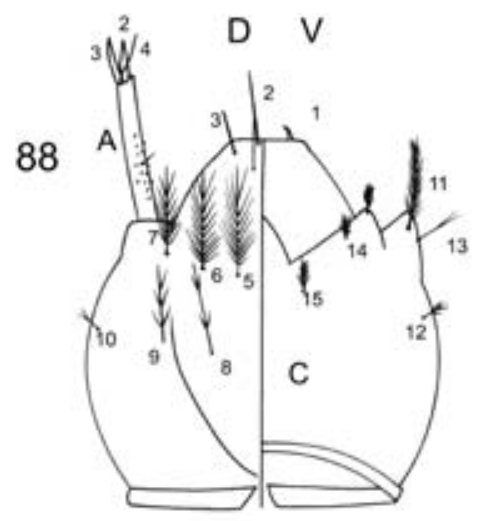

Anopheles pseudopunctipennis

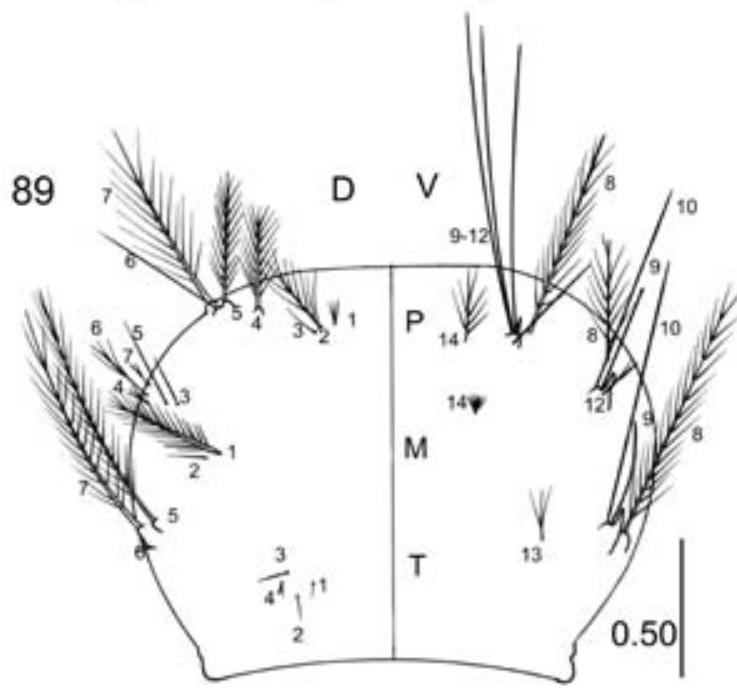

90

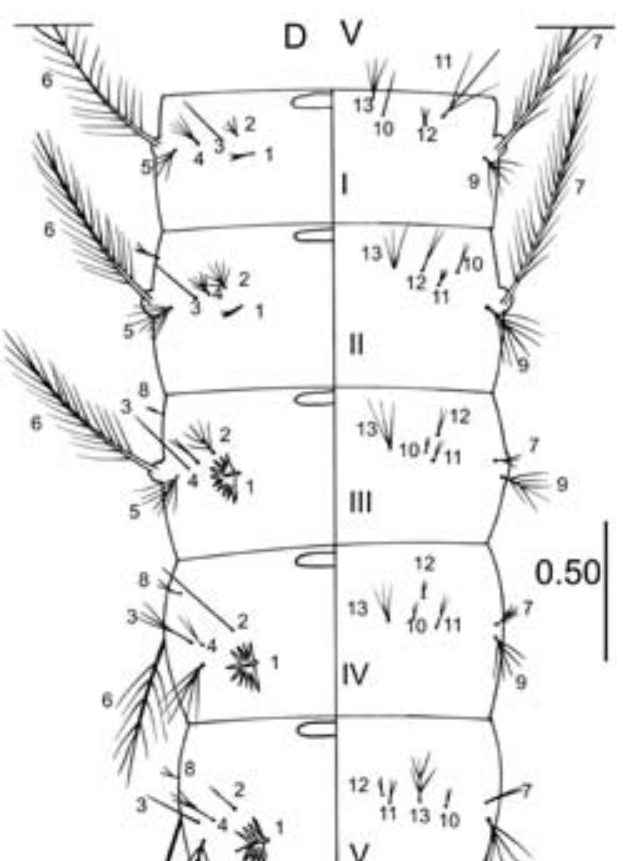

Figuras 88-90. Larva de Anopheles (Anopheles) pseudopunctipennis. 88: Cabeza. 89: Tórax. 90: Abdomen. 
y palpo maxilar de color blanco amarillento. Cabeza: palpo maxilar en su mayoría negro, palpómero 4 con la base y el ápice claros y palpómero 5 claro con una banda media de escamas oscuras. Tórax: pedicelo del balancín amarillo pálido y capítelo marrón con escamas negras. Ala: mancha pálida del sector ausente; escamas claras y manchas pálidas del fleco presentes en el ápice de las venas radial $4+5$, medial, medial 1, medial 2 y medial 3+4. Abdomen: Integumento marrón y en los esternitos y a veces los terguitos II-VIII de color amarillento pálido; con sedas amarillentas, sin escamas (Wilkerson Op. cit.). MACHO. Terminalia (Fig. 86): Gonostilo más largo que el gonocoxito, con la parte central adelgazada; uña gonostilar corta, con la punta redondeada. Gonocoxito con numerosas escamas en la parte externa. Dos espinas parabasales del mismo grosor, una más larga que la otra. Una espina interna. Lóbulo dorsal de la claspeta con una espina apical de forma de espatulada con una incisión no muy profunda en la punta. Lóbulo ventral de la claspeta con una prominencia apical esclerosada sobre la que nace una espina de igual grosor que la del lóbulo dorsal, en posición interna a ésta, hay una seda débil, subapical. Edeago con un par de hojillas de bordes aserrados (como hojas de encino) y otro par detrás de éstas. Noveno terguito estrecho en la parte central; lóbulos laterales largos, como cuatro o seis veces más largos que el ancho de sus bases y con las puntas redondeadas (Vargas \& MartínezPalacios 1956).

Material examinado. 20 ejemplares. México: Veracruz, Mpo. Acajete, Acajete, 17-10-1956 (4 L, CAIM CulH/lam-00534, CAIM CulH/lam-00535, CAIM CulH/ lam-00536 y CAIM CulH/lam-00537), 18-10-1956, (1 M, CAIM CulH/alf-00929; $1 \mathrm{H}$, CAIM CulH/alf-00957), 10-1956 (3 H, CAIM CulH/alf-00930, CAIM CulH/ alf-00931 y CAIM CulH/alf-00936; 5 M, CAIM CulH/alf-00932, CAIM CulH/alf00933, CAIM CulH/alf-00934, CAIM CulH/alf-00935 y CAIM CulH/alf-00937); Mpo. Coscomatepec, Coscomatepec de Bravo, 12-11-1947 (2 P, CAIM CulH/lam05347 y CAIM CulH/lam-05348); Chiapas, Mpo. San Cristóbal de las Casas, 07-1940 (2 H, CAIM CulH/alf-00891 y CAIM CulH/alf-00899), 01-08-1940 (1 MT, CAIM CulH/lam-05338); Oaxaca, Mpo. Ixtlán de Juárez, Ixtlán de Juárez, 01-09-1942 (1 P, CAIM CulH/lam-05342).

Distribución conocida. México, Guatemala, Costa Rica y Panamá (Knight \& Stone 1977; WRBU 2008). En México se conoce en los estados de Morelos, Veracruz, Oaxaca, Chiapas y Puebla, con una interrupción amplia en el Istmo de Tehuantepec (Vargas \& Martínez -Palacios Op. cit.).

Distribución en Veracruz (Fig. 87). Mpo. Acajete: Acajete, El Sedeño; Mpo. Acultzingo: Las Cumbres; Mpo. Altotonga: Altotonga; Mpo. Atzalan: Atzalan; Mpo. Banderilla: Banderilla; Mpo. Coatzintla: Chapultepec; Mpo. Coscomatepec: Cosco- 
matepec; Mpo. Jalacingo: Jalacingo; Mpo. Xico: San Marcos; Mpo. Juchique de Ferrer: Plan de las Hayas; Mpo. Emiliano Zapata: Pacho Nuevo; Mpo. Huayacocotla: Huayacocotla; Mpo. Perote: Ximonoco.

Datos bionómicos. Las larvas se encuentran en cuerpos de agua fría a grandes altitudes. Las hembras descansan en los huecos de los árboles (Stojanovich et al. 1966).

\section{Importancia médica. Desconocida.}

Comentarios. Se puede distinguir de otras especies por las siguientes características: Larva: sedas 2-4-C sencillas, 1-P larga, con nueve a catorce ramas, sedas abdominales 1-II-VI palmeadas; Pupa: seda 1-IV-VII sencilla; seda 5-IV-VII bifurcada, 9-VIII ramificada distalmente con dos a seis ramas gruesas; Hembra: escamas claras del ala, tórax y palpo maxilar de color blanco amarillento, palpómero 4 con la base y ápice claros y palpómero 5 claro con una banda media de escamas oscuras, escamas claras y manchas pálidas del fleco presentes en el ápice de las venas radial 4+5, medial, medial 1, medial 2 y medial 3+4; Macho, terminalia: lóbulo dorsal de la claspeta con una espina apical de forma de espatulada con una incisión no muy profunda en la punta, Edeago con un par de hojillas de bordes aserrados (como hojas de encino) y otro par detrás de éstas.

No parece ser una especie ampliamente distribuida en el estado, estando restringida a localidades que se encuentran por encima de los $1000 \mathrm{~m}$ snm hasta Acultzingo a $2340 \mathrm{~m} \mathrm{snm}$.

En el mapa de la distribución potencial se observa que los hábitats adecuados para esta especie se encuentran a altitudes entre los 1000 y los 2500 msnm, asociada a bosque mesófilo de montaña, bosque de pino y bosque de pino-encino.

No se encontraron trabajos en los que se le haya incriminado como vector de malaria humana, por lo que su importancia médica hasta el momento es desconocida.

\section{Anopheles (Anopheles) pseudopunctipennis Theobald 1901}

(Figs. 88-97, 98)

Anopheles (Ano.) pseudopunctipennis Theobald 1901: 305 (macho y hembra). Localidad tipo: Granada. Referencias adicionales.- Senevet 1934: 29 (pupa); Rozeboom 1941: 105 (distribución y bionomía); Cova-García 1939: 18 (larva), 25 (hembra); Komp 1942: 49 (hembra), 93 (larva), 140 (macho); Ross \& Roberts 1943: 23 (hembra, macho, larva); Freeborn In: Boyd, 1949: 391; Horsfall 1955: 123 (distribución y bionomía); Vargas \& Martínez Palacios 1956: 54 (claves pupa), 83 (hembra, macho, larva); Vargas 1959: 378 (macho); Stojanovich et al. 1966: 6 (larva), 24 (hembra), 35 (bionomía); Gorham et al. 1973: 122 (hembra), 131 (larva), 149 (bionomía); Heinemman \& Belkin 1977: 486, 488, 494, 495, 501, 505 (distribución); Zimmerman 


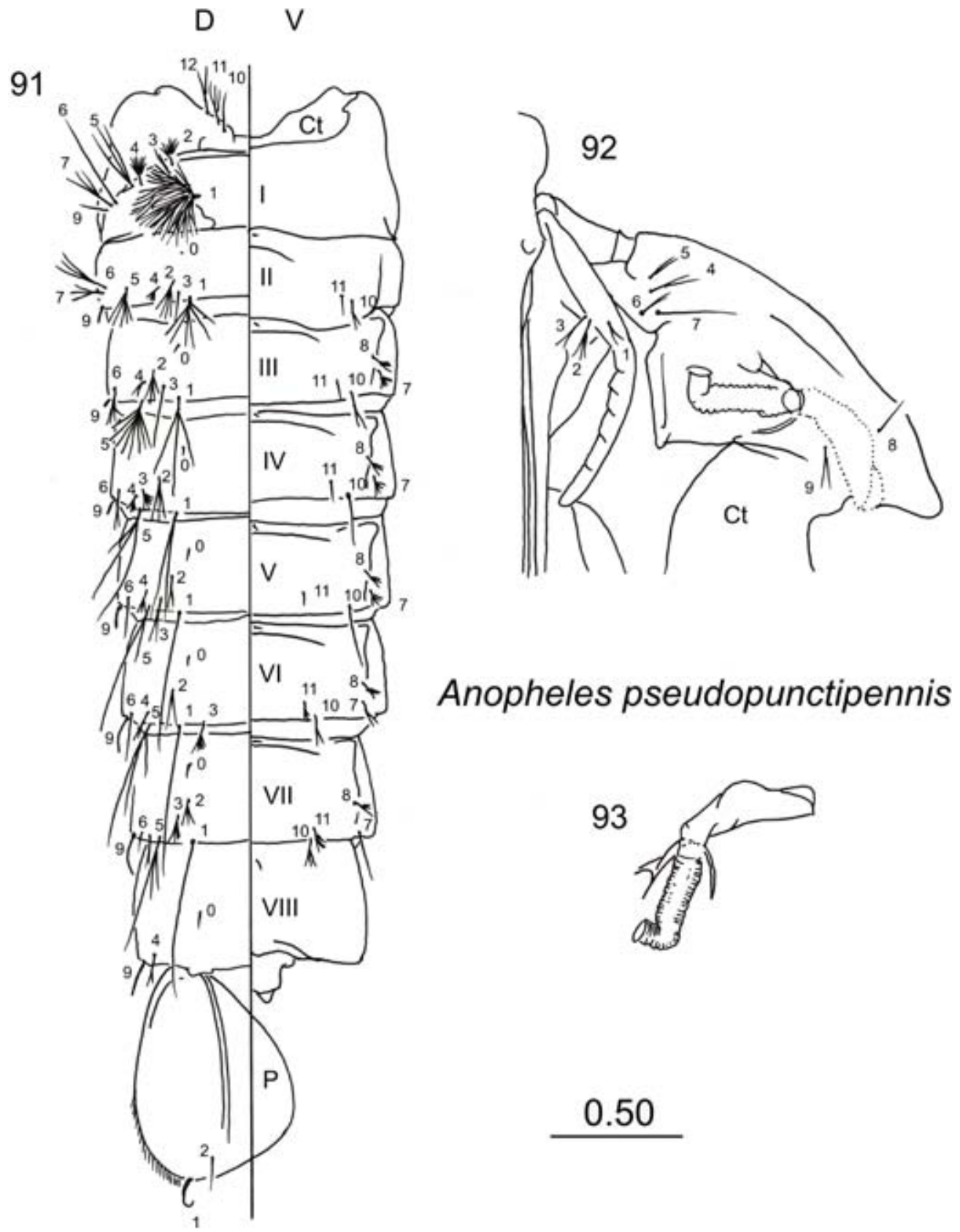

Figuras 91-93. Pupa de Anopheles (Anopheles) pseudopunctipennis. 91: Abdomen.92: Cefalotórax. 93: Trompeta ventiladora. 

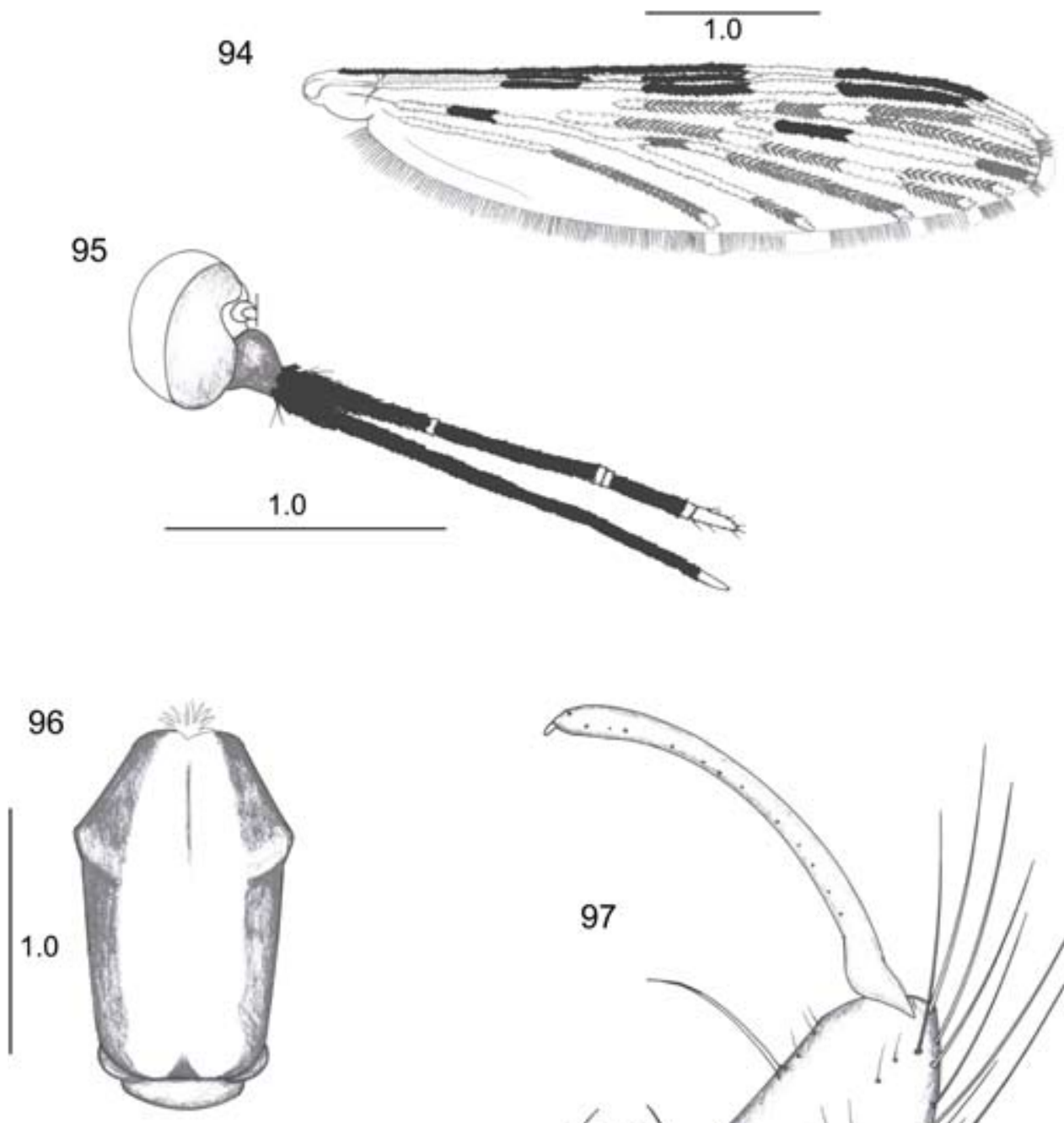

\section{Anopheles pseudopunctipennis}

Figuras 94-97. Adultos de Anopheles (Anopheles) pseudopunctipennis. Hembra. 94: Ala. 95: Palpo maxilar. 96: Escudo y escudete. Macho. 97: Terminalia. 
1992: 376 (bionomía); Estrada-Franco et al. 1993a: 26 (genética); Estrada-Franco et al. 1993b: 746 (genética); Manguin et al. 1995: 362 (genética); Manguin et al. 1996: 619 (bionomía); Villareal et al. 1998: 369 (cultivo); Coetzee et al. 1999: 649 (genética); Rueda et al. 2004: 13 (macho, hembra, larva, pupa; designación del neotipo; Localidad neotipo: Estado de Chambord ( $12^{\circ} 12^{\prime}$ N, 61 $37^{\prime}$ W), Río Sallee, Granada); Harbach \& Howard 2007: 39 (exclusión de la ssp. bifoliata).

Anopheles peruvianus Tamayo 1907 In: Tamayo \& Gargia 1907: 35 (hembra, macho, pupa, larva). Localidad tipo: Huacachina, San Pedro de Lloc, Lima, Otono, Chanchamayo, Perú. Referencias adicionales.- Lane 1953: 160 (sinonimia).

Proterorhynchus argentinus Brèthes 1912: 15 (macho, hembra). Localidad tipo: Tucuman, Salta, Jujuy, Santiago del Estero, Argentina. Referencias adicionales.Howard et al. 1917: 1015 (sinonimia); Casal In: Belkin et al. 1968: 9 (designación de lectotipo).

Anopheles tucumanus Lahille 1912: 253 (hembra). Localidad tipo: Río Sali, Argentina. Referencias adicionales.- Howard et al. 1912-1917: 1015 (sinonimia).

Anopheles pseudopunctipennis pseudopunctipennis Theobald In: Levi-Castillo 1944: 1 (macho, huevo); Aitken 1945: 327 (macho, hembra, pupa, larva y huevo, taxonomía, biología); Carpenter et al. 1946: 66 (macho, hembra, larva); Freeborn In: Boyd 1949: 391; Lane 1953: 160 (macho, hembra, pupa, larva, huevo); Carpenter \& LaCasse 1955: 46 (macho, hembra, larva, bionomía); Vargas 1959: 378 (claves macho).

Anopheles pseudopunctipennis var. boydi Vargas 1939: 361 (huevo); Vargas 1941c: 116 (huevo); Vargas 1959: 373 (claves macho).

Anopheles pseudopunctipennis var. willardi Vargas 1941d: 48 (huevo, larva, hembra, macho); Vargas 1941c: 116 (huevo); Vargas 1959: 373 (claves macho).

Anopheles pseudopunctipennis levicastillo Levi-Castillo 1944: 1 (macho y huevo como variedad). Locallidad tipo: Guayasa, Ecuador. Referencias adicionales.- LeviCastillo 1945: 41 (macho, hembra, pupa, larva, huevo); Lane 1953: 160 (sinonimia con Anopheles pseudopunctipennis pseudopunctipennis).

Anopheles pseudopunctipennis rivadeneirai Levi-Castillo 1945: 33 (macho, hembra, pupa, larva, huevo). Localidad tipo: provincias de Carchi, Imbabura, Pichincha, Cotopaxi, Tungurahua, Chimborazo, Cañar, Azuay y Loja, Ecuador. Referencias adicionales.- Lane 1953: 160 (sinonimia con Anopheles pseudopunctipennis pseudopunctipennis).

Anopheles pseudopunctipennis var. pattersoni Alvarado \& Heredia 1947: 73 (huevo). Localidad tipo: Tucumán, Argentina. Referencias adicionales.- Lane 1953: 161 (elevada a especie).

Anopheles pseudopuctipennis var. bifoliata Osorno-Mesa \& Muñoz-Sarmiento 1948: 105 (macho, hembra, larva). Localidad tipo: Florida, Valle del Cauca, Colombia. Referencias adicionales.- Vargas 1959: 378 (claves macho). 
Anopheles pseudopunctipennis neghmei Mann 1950: 34 (macho, hembra, larva, huevo). Localidad tipo: Quebrada de Minemine, Tarapacá, Chile.

Anopheles pseudopunctipennis noei Mann 1950: 37 (macho, hembra, larva, huevo). Localidad tipo: Oasis de Suca, Tarapacá, Chile.

Diagnosis. LARVA (Figs. 88-90). Cabeza: sedas 2-4-C largas y sencillas; las 2-C separadas, pero más cerca entre ellas que de las 3-C. Antena: sedas 2-3-A puntiagudas. Tórax: seda 1-P sencilla o doble; sedas 9-12-P sencillas. Abdomen: seda abdominal 1-I con dos a cuatro ramas; 1 -II sencilla o con dos a seis ramas; sedas 1-III-VII palmeadas con las ramas bien desarrolladas, cada rama con un filamento corto; las dos placas espiraculares posteriores con una proyección delgada, esclerotizada, a manera de "cola”, en el margen interno caudal (Rueda et al. 2004, Stojanovich et al. 1966). PUPA (Figs. 91-93). Trompeta: angusticorne, con un surco meatal profundo, pinna redondeada distalmente. Abdomen: seda 1-II-VII bien desarrollada; seda 6-I sencilla y delgada; 7-I con una a cinco ramas; 8-II ausente; sedas 9-I-II sencillas y delgadas, 9-III fuerte y puntiaguda de 0.41-1.00 la longitud de 9-II, 9-IV gruesa y puntiaguda, sedas 9-V-VIII espiniformes, largas. Paletas natatorias: con espículas en el margen externo (Rueda et al. Op. cit.). HEMBRA (Figs. 94-96). Cabeza: palpo maxilar con predominancia de escamas oscuras, base del palpómero 3 y ápice del 4 con una banda delgada de escamas claras; palpómero 5 con escamas claras casi en su totalidad. Tórax: integumento del escutelo oscuro con una franja longitudinal de polinosidad plateada. Ala: costa con escamas oscuras de la base hasta la mancha clara del sector; base de la vena radial con escamas claras; vena media con predominancia de escamas claras; vena anal con una mancha pálida en su base y otra en el ápice; fleco del ala con manchas claras en la porción distal de cada vena. Abdomen: integumento oscuro con polinosidad gris; terguitos y esternitos con escamas doradas (Rueda et al. 2004). MACHO. Terminalia (Fig. 97): gonostilo 1.06 a 1.48 veces la longitud de la gonocoxito; con muchas sedas minúsculas en la parte dorsal; uña gonostilar corta y con la punta redondeada. Gonocoxito 1.08 a 1.83 veces tan largo como ancho; superficie dorsal con sedas largas y cortas, sedas muy largas distalmente y numerosas espículas muy pequeñas. Dos espinas parabasales, una gruesa con la punta curvada, naciendo en una base ligeramente levantada y otra más larga y delgada que la anterior. Lóbulo dorsal de la claspeta con tres filamentos apicales sobrepuestos con forma de hojillas; lóbulo ventral de la claspeta con dos sedas apicales largas y delgadas y una seda subapical corta y débil. Edeago cilíndrico, ancho y bifurcado en la base; con dos pares de hojillas en el ápice, ligeramente curvadas y aserradas. Lóbulos del noveno terguito gruesos, tan largos como anchos (Rueda et al Op. cit.).

Material examinado. 36 ejemplares. México: Veracruz, Mpo. Actopan, Soyacuautla, 07-02-2008 (1 H); Mpo. Córdoba, Córdoba, 07-09-1958 (1 L, CAIM CulH/lam- 


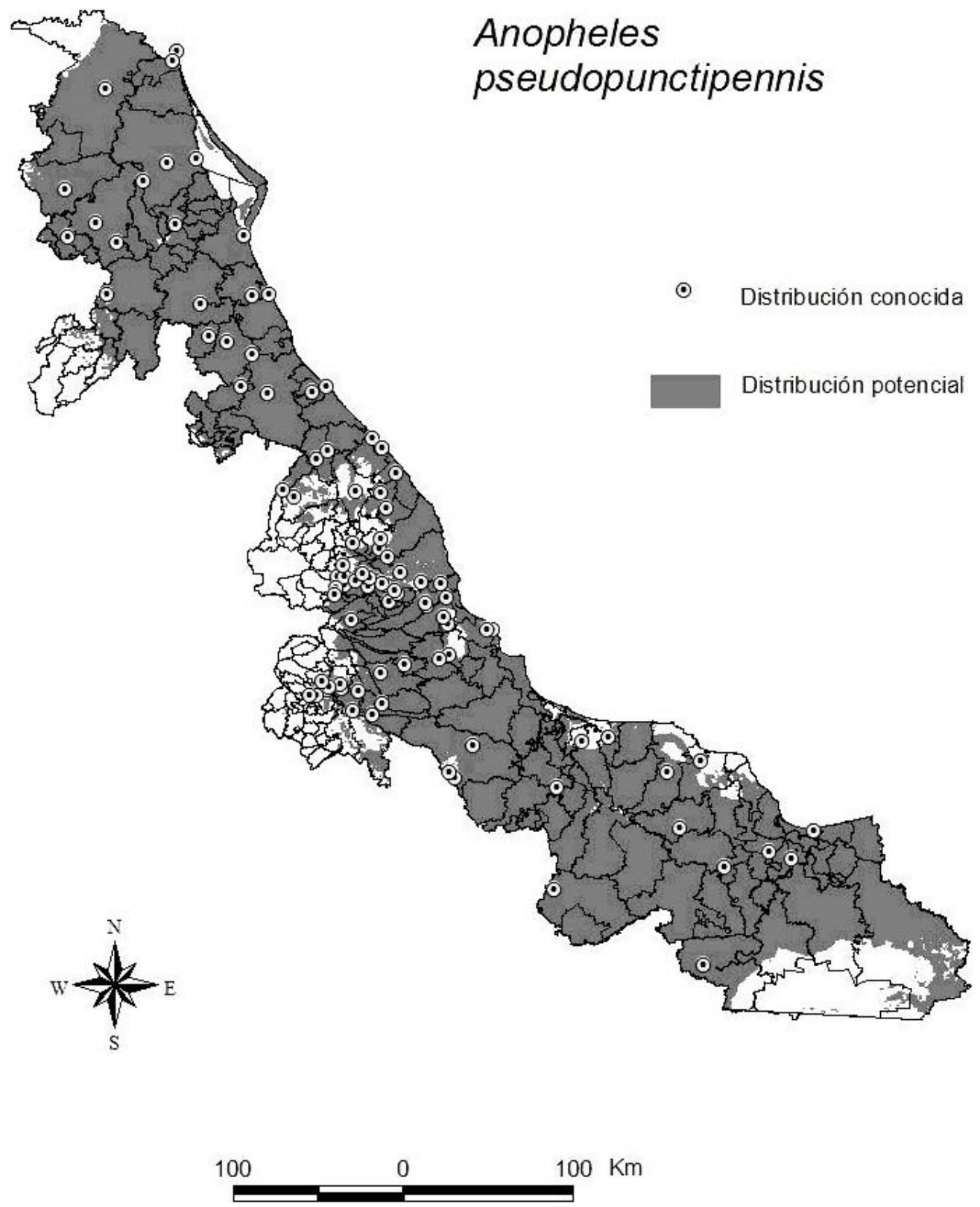

Figura 98. Mapa de la distribución conocida y potencial de Anopheles (Anopheles) pseudopunctipennis. 

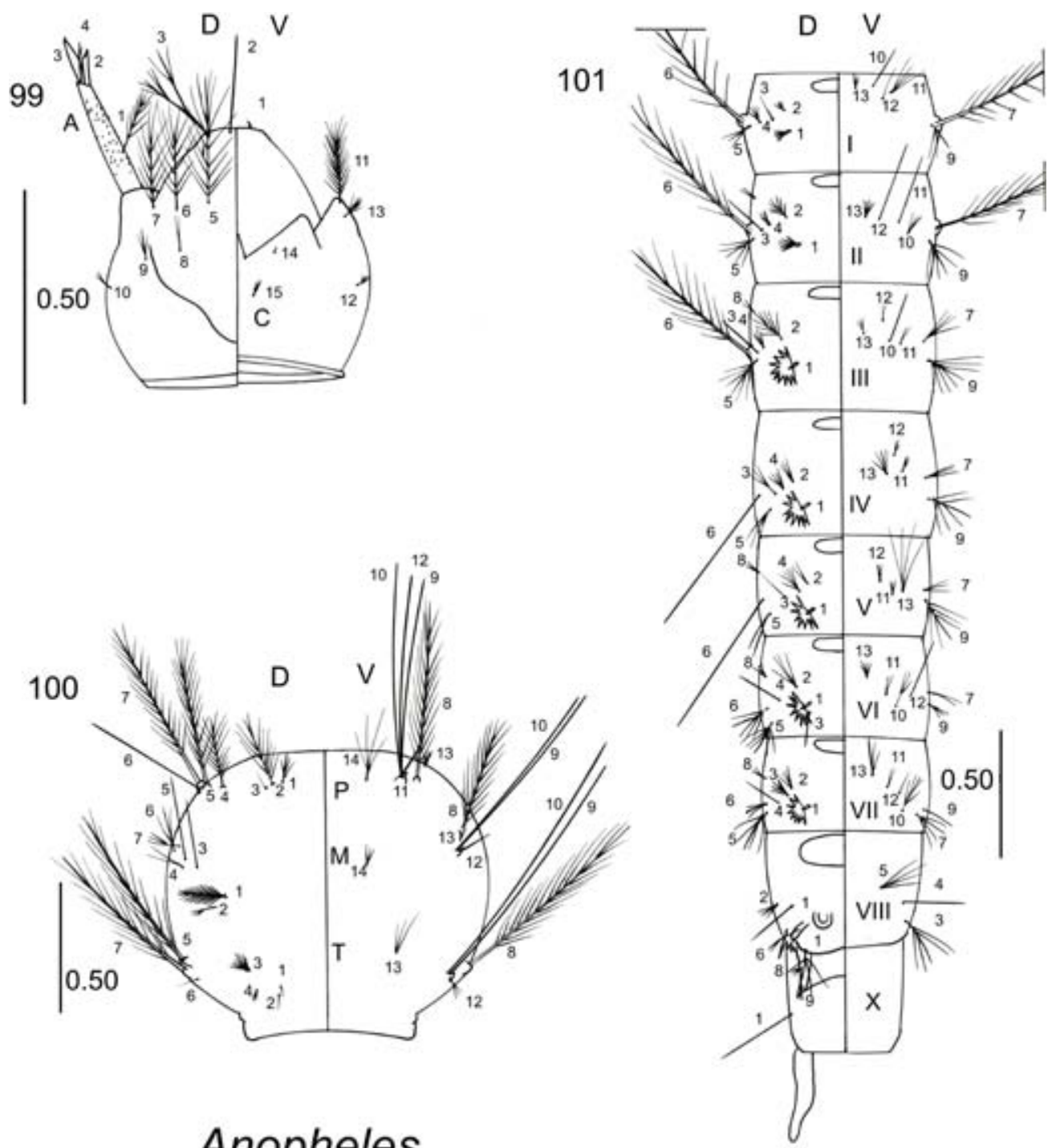

\section{Anopheles punctimacula}

Figuras 99-101. Larva de Anopheles (Anopheles) punctimacula. 99: Cabeza. 100: Tórax. 101: Abdomen. 
01221); Mpo. Hueyapan de Ocampo, Hueyapan de Ocampo, 07-03-1958 (1 L, CAIM CulH/lam-01215); Mpo. Jesús Carranza, Jesús Carranza, 01-10-1939 (1 MT, CAIM CulH/lam-05445); Mpo. Manlio Fabio Altamirano, Rancho San Andrés, 10-04-1959 (1 L, CAIM CulH/lam-01214); Mpo. Martínez de la Torre, La Unión Paso Largo, 1510-1956 (1 L, CAIM CulH/lam-01230); Mpo. Pánuco, Pánuco, 01-02-1942 (1 MT, CAIM CulH/lam-05443), sin fecha (4 MT, CAIM CulH/lam-05439, CAIM CulH/ lam-05440, CAIM CulH/lam-05441 y CAIM CulH/lam-05442); Mpo. Naolinco, Naolinco de Victoria, 01-08-1945 (2 L, CAIM CulH/lam-01226 y CAIM CulH/lam01232); Mpo. Veracruz, Veracruz, 11-04-1956 (3 L, CAIM CulH/lam-01211, CAIM CulH/lam-01218 y CAIM CulH/lam-01219); Mpo. Xalapa, Xalapa-Enríquez, 10-121937 (1 MT, CAIM CulH/lam-05446); Mpo. Indeterminado, Álamo, 22-09-1979 (1 L, CAIM CulH/lam-01229), 23-09-1979 (5 L, CAIM CulH/lam-01213, CAIM CulH/ lam-01216, CAIM CulH/lam-01217, CAIM CulH/lam-01223 y CAIM CulH/lam01227); Mpo. Indeterminado, Finca Coyoacán, 09-10-1956 (2 L, CAIM CulH/lam01224 y CAIM CulH/lam-01225); Mpo. Indeterminado, Ojo de Agua Cruz Verde, 22-09-1945 (1 L, CAIM CulH/lam-01231); Mpo. Indeterminado, Paso Real, 25-061956 (1 L, CAIM CulH/lam-01228) Mpo. Indeterminado, Río Chapopoapan, 05-031958 (2 L, CAIM CulH/lam-01212 y CAIM CulH/lam-01222); Mpo. Indeterminado, Tuxpango, 19-06-1956 (2 L, CAIM CulH/lam-01220 y CAIM CulH/lam-01223); Hidalgo, Mpo. Huichapan, San Miguel, 01-04-1949 (4 P, (2) CAIM CulH/lam-05379 y (2) CAIM CulH/lam-05380); Tabasco, Mpo. Tenosique, Tenosique, 01-04-1942 (1 L, CAIM CulH/lam-01179).

Distribución conocida. Se encuentra desde el sur de Estados Unidos, hasta el norte de Argentina (Manguin et al. 1996). Se encuentra prácticamente en todo México, desde la costa, hasta los 2270 msnm (Distrito Federal) (Vargas \& Martínez-Palacios 1956).

Distribución en Veracruz (Fig. 98). Mpo. Acayucan: Acayucan; Mpo. Actopan: Actopan, La Esperanza; Mpo. Alto Lucero: Alto Lucero, Blanca Espuma, Xomotla; Mpo. Amatlán de los Reyes: Potrero Viejo; Mpo. Ángel R. Cabada: El Mesón; Mpo. La Antigua: José Cardel; Mpo. Apazapan: Chahuapa; Mpo. Atzalan: Cuazapotitlán; Mpo. Catemaco: Sontecomapan; Mpo. Coatepec: Cosolapan, El Grande, Pacho Viejo; Mpo. Coatzacoalcos: Coatzacoalcos; Mpo. Coatzintla: Coatzintla, Poza Rica de Hidalgo; Mpo. Colipa: Colipa; Mpo. Córdoba: Córdoba, Los Filtros, San Francisco, San Miguelito; Mpo. Cosamaloapan: Cosamaloapan; Mpo. Cuichapa: Cuichapa, Ingenio la Providencia; Mpo. Cuitláhuac: Cuitláhuac; Mpo. Chicontepec: Chicontepec; Mpo. Chinameca: Chinameca; Mpo. Chontla: Magosal; Mpo. Emilliano Zapata: Cerro Gordo, Corral Falso, Chavarrillo, Dos Ríos, La Estanzuela, Mata de Caña, Miradores del Mar, Palo Gacho, Plan del Río, La Venta del Encero; Mpo. Fortín: 
Cuapichapan, Fortín; Mpo. Gutiérrez Zamora: Gutiérrez Zamora; Mpo. Hueyapan de Ocampo: Hueyapan de Ocampo; Mpo. Ixtaczoquitlán: Ixtaczoquitlán, Ojo de Agua; Mpo. Jalacingo: El Arco; Mpo. Xalapa: Escuela Modelo, Xalapa-Enríquez; Mpo. Jesús Carranza: Jesús Carranza; Mpo. Xico: San Marcos; Mpo. Juchique de Ferrer: Juchique de Ferrer; Mpo. Lerdo de Tejada: Lerdo de Tejada; Mpo. Manlio Fabio Altamirano, Martínez de la Torre, Paso Largo, San Rafael, Rancho San Andrés; Mpo. Martínez de la Torre: La Unión Paso Largo; Mpo. Minatitlán: Minatitlán; Mpo. Misantla: Misantla; Mpo. Naolinco: Naolinco de Victoria; Mpo. Nautla: Nautla, El Raudal; Mpo. Orizaba: Orizaba, Planta de la Cervecería Cuauhtémoc; Mpo. Ozulama: La Laja, Ozulama; Mpo. Pánuco: Pánuco; Mpo. Papantla: Papantla; Mpo. Paso de Ovejas: Cerro de Guzmán, Plan del Manantial, Tierra Colorada, Tolomé; Mpo. Paso del Macho: Paso del Macho; Mpo. Platón Sánchez: Platón Sánchez; Mpo. Playa Vicente: Playa Vicente; Mpo. Pueblo Viejo: Bella Vista, Mata Redonda, Villa Cuauhtémoc; Mpo. Puente Nacional: Puente Nacional, Tamarindo; Mpo. San Andrés Tuxtla: San Andrés Tuxtla; Mpo. Soledad de Doblado: Soledad de Doblado; Mpo. Tamalín: Tamalín; Mpo. Tamiahua: Tamiahua; Mpo. Tantoyuca: San Jerónimo, Tantoyuca; Mpo. Teayo: Castillo de Teayo; Mpo. Tecolutla: Tecolutla; Mpo. Temapache: Álamo; Mpo. Tempoal: Tempoal; mpo. Tenampa: Tenampa; Mpo. Teocelo: Teocelo; Mpo. Tepezintla: Cerro Azul; Mpo. Tierra Blanca: Moreno Norte, Palma Sola, Tierra Blanca; Mpo. Tihuatlán: Concepción, Tihuatlán; Mpo. Tlacotalpan: Tlacotalpan; Mpo. Tuxpan: Barra Norte de Tuxpam, Tuxpan; Mpo. Temaxcal-Camarón: Villa Tejada; Mpo. Úrsulo Galván: Zempoala; Mpo. Vega de Alatorre: Vega de Alatorre; Mpo. Veraruz: La Forestal, Tembladeras, Veracruz, Vergara; Mpo. Zongolica: Pocitos; Mpo. Indeterminado: El Raudal; Mpo. Indeterminado: San Nicolás; Mpo. Indeterminado: Ojo de Agua; Mpo. Indeterminado: Río Chapopoapan; Mpo. Indeterminado: Álamo; Mpo. Indeterminado: Tuxpango; Mpo. Indeterminado: Finca Coyoacán; Mpo. Indeterminado: Paso Real; Mpo. Indeterminado: Ojo de Agua Cruz Verde; Mpo. Indeterminado: Santa Rosa.

Datos bionómicos. En un estudio informaron que las larvas de An. pseudopunctipennis se desarrollan en pozas con poca profundidad, con preferencia por el agua estancada, en sitios con plena exposición al sol o con media sombra, con valores de $\mathrm{pH}$ entre 4.5 y 8.8 y con presencia de algas verdes filamentosas del tipo Spirogyra y en ocasiones con otras algas verdes como Cladophora y Enteromorpha, y también con vegetación emergente, sumergida y flotante (Manguin et al. 1996). Los hábitos de las hembras parecen variar de una región a otra. En el caso del sureste de México, las hembras son domésticas, entran a las casas y se alimentan de sangre humana, aunque la mayoría de las ocasiones el ataque se produce fuera de la casa. Se alimentan de ganado bovino, caballos, burros y del ser humano (Carpenter \& LaCasse 1955). 

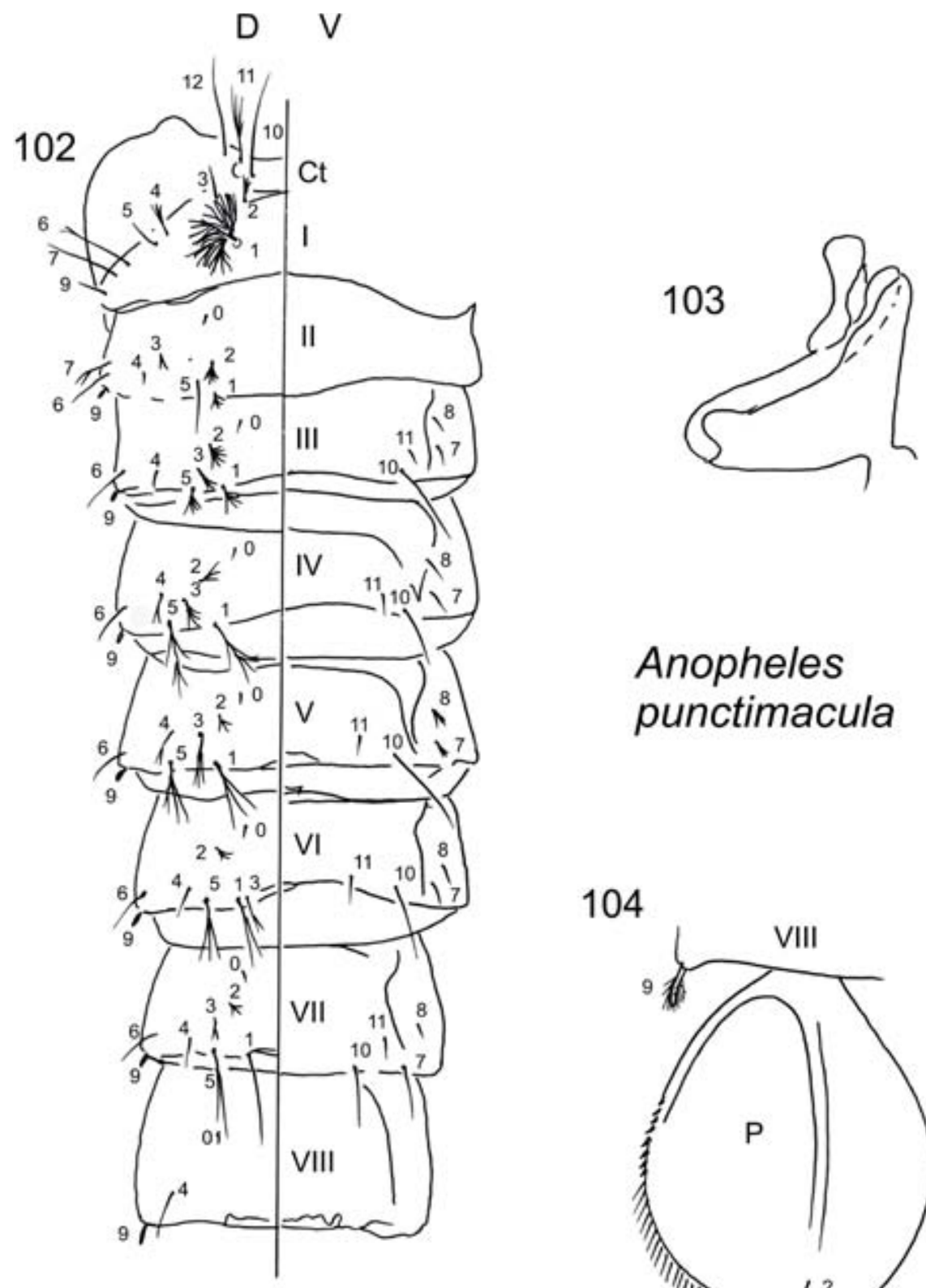

\section{Anopheles punctimacula}

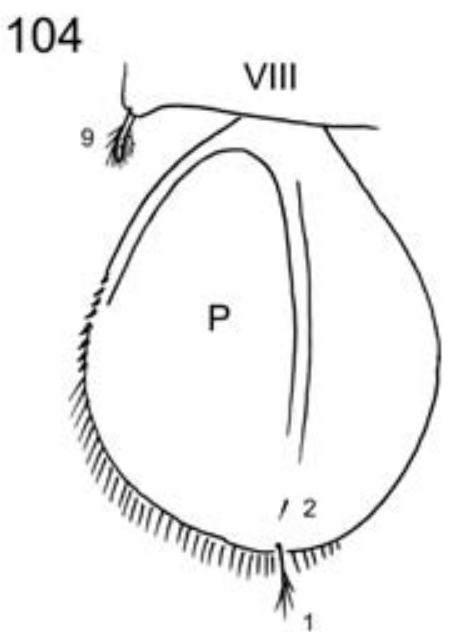

Figuras 102-104. Pupa de Anopheles (Anopheles) punctimacula (redibujada de Senevet, 1934). 102: Segmentos abdominales I-VIII. 103: Trompeta ventiladora. 104: Paleta natatoria izquierda vista dorsal. 


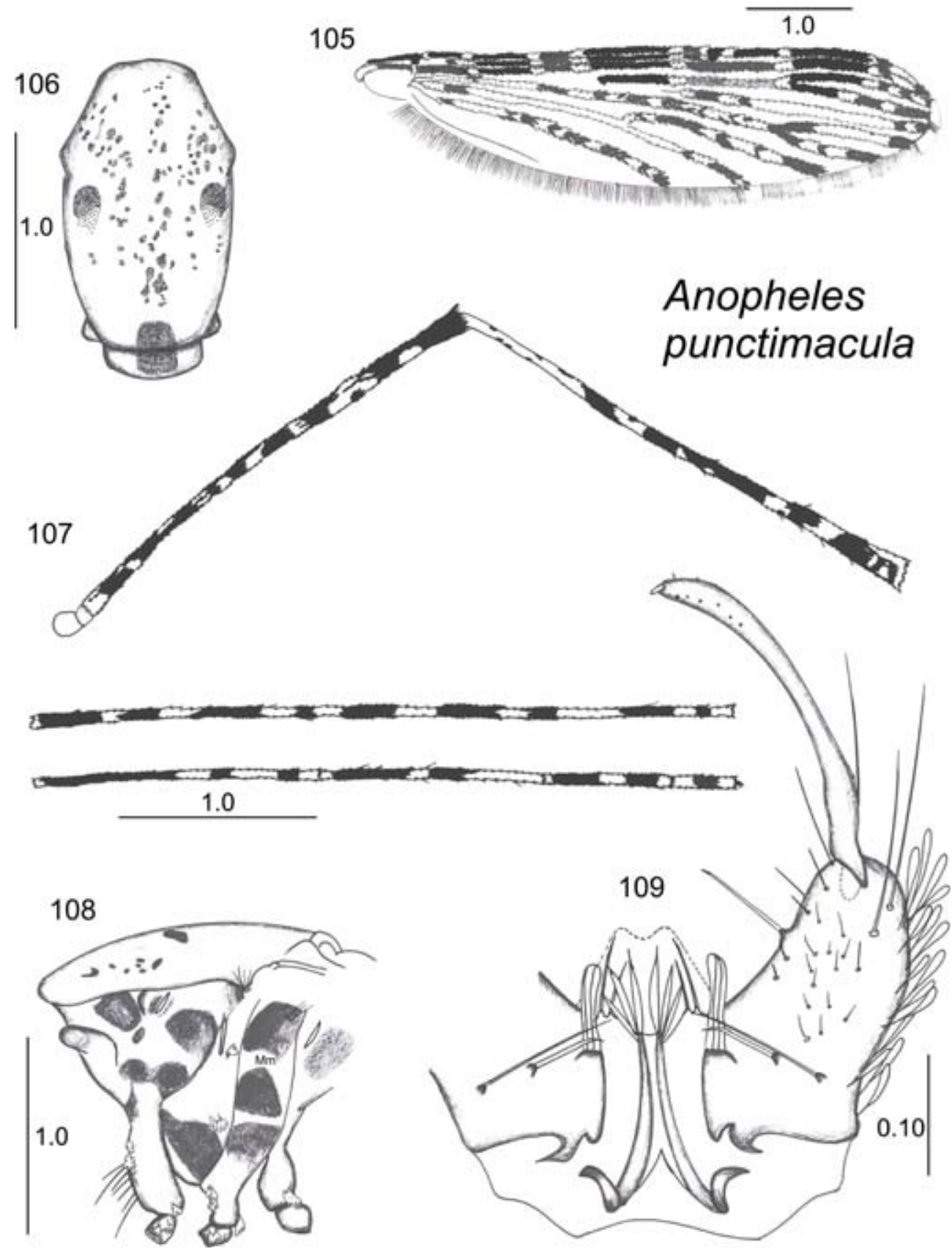

Figuras 105-109. Adultos de Anopheles (Anopheles)punctimacula. Hembra. 105: Ala. 106: Escudo y escudete. 107: Pata posterior. 108: Tórax vista lateral. Macho. 109: Terminalia. 
Importancia médica. Debido a su amplia distribución, preferencias por la sangre humana, endofilia y capacidad de infectarse con Plasmodium spp., es el vector de malaria dominante en siete de los diecinueve países con malaria endémica, incluyendo México (Manguin et al. 1996). Transmite la malaria en las regiones montañosas durante la época de secas, hasta en áreas elevadas de los Andes a más de 2800 m snm (Gorham et al. 1973).

Comentarios. Se puede distinguir de otras especies por las siguientes características: Larva: sedas 2-4-C largas y sencillas, las dos placas estigmales posteriores con una proyección delgada, esclerotizada, a manera de "cola”, en el margen interno caudal; Pupa: trompeta angusticorne, seda 9-VIII espiniforme, sencilla; Hembra: palpómero 5 con escamas claras casi en su totalidad, integumento del escutelo oscuro con una franja longitudinal de polinosidad plateada, vena media con predominancia de escamas claras; vena anal con una mancha pálida en su base y otra en el ápice; fleco del ala con manchas claras en la porción distal de cada vena; Macho, terminalia: lóbulo dorsal de la claspeta con tres filamentos apicales sobrepuestos con forma de hojillas, edeago cilíndrico, ancho, con dos pares de hojillas en el ápice, ligeramente curvadas y aserradas.

La pupa de An. pseudopunctipennis es muy similar a la del subgénero Nyssorhynchus, pero se puede distinguir fácilmente de estas por presentar la seda 9-IV puntiaguda.

En Veracruz esta especie se encuentra ampliamente distribuida y parece ser abundante, desde la costa hasta los $1540 \mathrm{~m}$ snm en Naolinco. Al igual que en otras especies, la mayoría de las localidades donde se ha colectado se encuentran cerca de cuerpos de agua, ríos principalmente.

En el mapa de la distribución potencial se aprecia que los hábitats adecuados para An. pseudopunctipennis son muy diversos, abarcando lugares desde la costa hasta aproximadamente los 2000 m snm y en cuanto al tipo de vegetación desde los manglares, hasta el bosque mesófilo de montaña.

Se han hecho numerosos estudios sobre la importancia médica de esta especie considerándose el vector primario de la malaria humana en áreas montañosas, en México se considera el vector dominante, por consiguiente su vigilancia debe ser constante.

\section{Anopheles (Anopheles) punctimacula Dyar \& Knab 1906}

(Figs. 99-109, 110)

Anopheles (Ano.) punctimacula Dyar \& Knab 1906a: 136. Localidad tipo: Colón, Panamá. Referencia adicionales.- Senevet 1934: 36 (pupa); Simmons 1937: 191 (hembra); Cova- García 1939: 18 (larva), 25 (hembra); Kumm 1941: 91 (huevo); Komp 1942: 57 (hembra), 102 (larva), 143 (macho); Ross \& Roberts 1943: 25 (hembra, ma- 
cho, larva); Levi-Castillo 1945: 56 (huevo, larva, pupa, hembra, macho); Lassmann 1948: 11 (distribución en Veracruz); Lane 1953: 208 (hembra, macho, pupa, larva, huevo); Horsfall 1955: 125 (distribución y bionomía); Vargas \& Martínez-Palacios 1956: 54 (pupa), 107 (hembra, macho, larva); Vargas 1959: 385 (claves macho); Gorham et al. 1973: 118 (hembra), 129 (larva), 149 (bionomía); Panday 1975: 143 (distribución); Heinemman \& Belkin 1977: 488, 489, 499 (distribución); Wilkerson 1990: 226 (redescripción); Rodríguez et al. 2002: 1 (huevo).

Anopheles stringimacula Dyar \& Knab 1906a: 136 (hembra). Localidad tipo: Córdoba, Veracruz, México.

Anopheles malefactor Dyar \& Knab 1907: 198 (hembra, macho). Referencias adicionales.- Wilkerson 1990: 225 (recuperado de la sinonimia con Anopheles punctimacula).

Anopheles (Arribalzagia) punctimacula; de Dyar 1918: 147 (claves, bionomía, taxonomía, recuperado de la sinonimia con Anopheles apicimacula).

Anopheles venezuelae Evans 1922: 214 (hembra). Localidad tipo: La Cabrera, Carabobo, Venezuela. Referencias adicionales: Belkin 1968: 11 (Holotipo)

Anopheles punctimacula var. strigimacula Christophers 1924: 35 (taxonomía), 89 (claves hembra).

Diagnosis. LARVA (Figs. 99-101). Cabeza: seda 2-C larga, generalmente con cerdillas a lo largo de la mitad 0.33 ; seda $3-\mathrm{C}$ de 0.5 la longitud de la 2-C, con tres a ocho ramas. Antena: seda 3-A puntiaguda, 2-A truncada. Tórax: seda 1-P con cuatro a siete ramas; sedas 9-12-P sencillas. Abdomen: seda 1-III-VII palmeada con ramas bien desarrolladas, pigmentadas y aserradas en el borde de la mitad distal; seda 6-IVV sencilla (Vargas \& Martínez-Palacios 1956, Wilkerson 1990). PUPA (Figs. 102104). Trompeta: laticorne, con un surco meatal y otro secundario, sin proyección en la pinna. Abdomen: seda 1-II bien desarrollada con seis a veinticuatro ramas; 1-VI con dos a siete ramas, $1-\mathrm{V}$ con una a cinco ramas, 1 -VI-VII generalmente sencilla; seda 2-I con una a cuatro ramas, 2-II bien desarrollada con tres a siete ramas; seda 3III por lo general simple, 3-VI de sencilla a triple, 3-VII con una a cuatro ramas; seda 4-I con una a seis ramas, generalmente doble o triple, 4-V con una a cuatro ramas; seda 5-I sencilla o doble, 5-IV con dos a cinco ramas, 5-V con dos a cuatro ramas; sedas 5-VI y 6-I de sencillas a triples; seda 8-III sencilla; sedas 9-IV-VII sencillas, espiniformes, seda 9-VIII a menudo con numerosas ramas largas. Paletas natatorias: con espículas marginales; seda 1-P ramificada; seda 2-P sencilla (Wilkerson 1990). HEMBRA (Figs. 105-108). Cabeza: palpo maxilar con predominancia de escamas oscuras, excepto por escamas claras en las articulaciones de los palpómeros 2-3, 3-4 y 4-5 y algunas dispersas en los palpómeros 3 y 5. Tórax: escudo pruinoso gris con puntos pequeños de escamas negras y tres manchas grandes, dos en posición anterolateral con respecto a las bases de las alas y una tercera en el área prescutelar que 


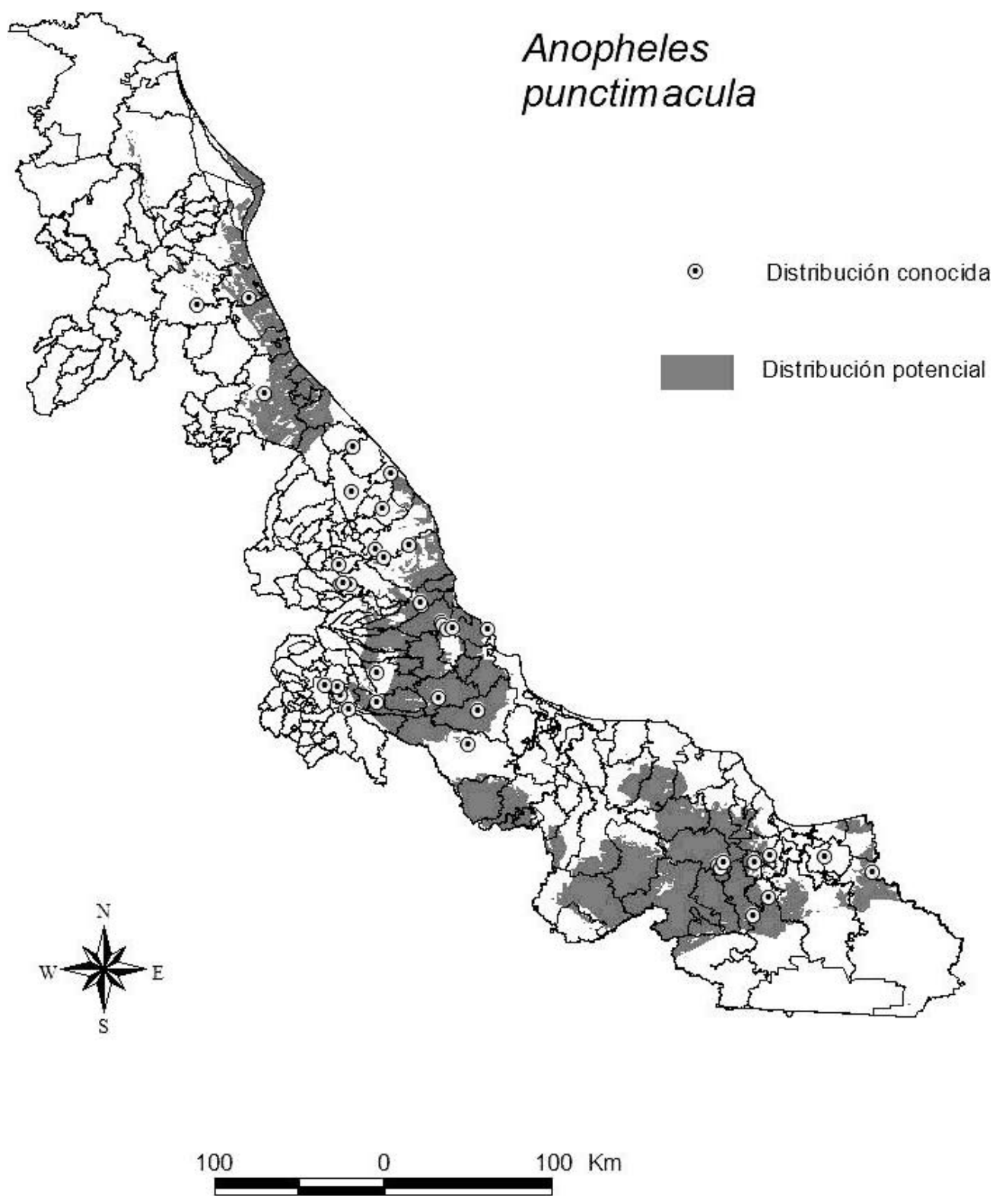

Figura 110. Mapa de la distribución conocida y potencial de Anopheles (Anopheles)punctimacula. 


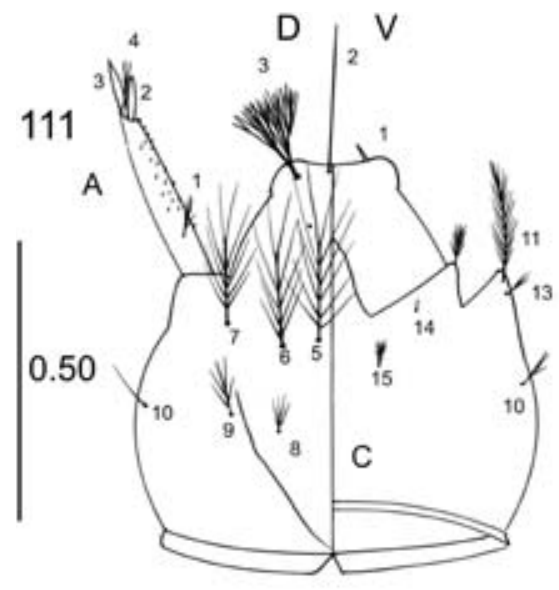

113

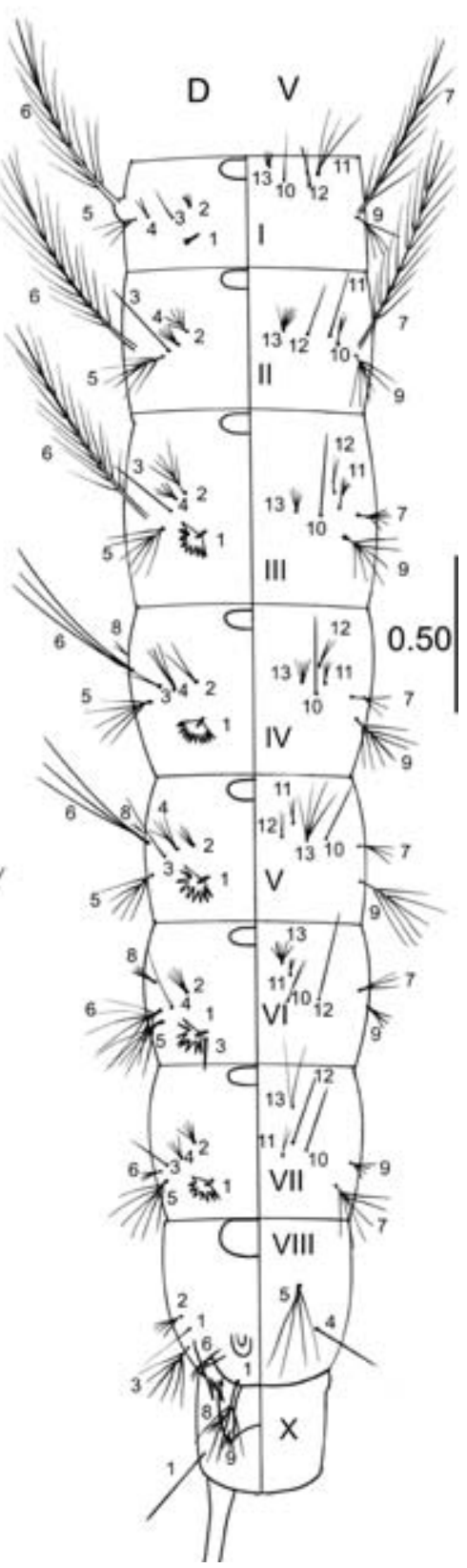

\section{Anopheles punctipennis}

Figuras 111-113. Larva de Anopheles (Anopheles) punctipennis. 111: Cabeza. 112: Tórax. 113: Abdomen. 
se continúa en el escudete; mesepímeron sin escamas. Patas: tarsómero 5 de la pata posterior con una banda oscura; articulaciones de los tarsómeros de la pata posterior blancas. Ala: escamas claras del ala en su mayoría color amarillo excepto por las escamas blancas contrastantes que se observan a cada lado de las manchas oscuras del presector, del sector y preapical; mancha oscura preapical tan larga como 0.110.23 la longitud del ala; escamas de la vena cubital en su mayoría claras. Abdomen: segmentos abdominales II al VIII con mechones posterolaterales de escamas oscuras; esternitos numerosas escamas de color marrón y blancas; terguitos y esternito VIII con numerosas escamas delgadas de color amarillo pálido (Wilkerson et al. 1993). MACHO. Terminalia (Fig. 109): gonostilo más largo que el gonocoxito, adelgazado en su parte central. Gonocoxito 2.0-3.0 veces tan largo como ancho, adelgazado a 0.33 de la base; superficie dorsal con varias sedas largas, y unas pocas sedas largas distalmente, con escamas delgadas fusiformes y espatuladas y numerosas espículas muy pequeñas. Dos espinas parabasales, una gruesa con la punta curvada, naciendo en una base ligeramente levantada y otra más larga y delgada. Una espina interna delgada, casi tan larga como la parabasal más corta. Lóbulo dorsal de la claspeta con tres (ocasionalmente dos o cuatro) sedas capitadas muy juntas que se pueden ver truncadas o chatas. Lóbulo ventral de la claspeta con dos (algunas veces tres) sedas apicales o subapicales. Edeago con hojillas variables, de dos a seis en cada lado, más comúnmente tres. Lóbulos del noveno terguito de 1.04-4.0 veces tan largo como ancho (Wilkerson Op. cit.).

Material examinado. 12 ejemplares. México: Veracruz, Mpo. Acayucan, Acayucan, 10-04-1947 (3 L, CAIM CulH/lam-01409, CAIM CulH/lam-01410 y CAIM CulH/ lam-01411; 1 MT, CAIM CulH/lam-05522); Mpo. Actopan, Soyacuautla, 07-02-2008 (1 H); Mpo. Las Choapas, Las Choapas, 14-11-1956 (1 L, CAIM CulH/lam-01412); Tabasco, Tenosique, Tenosique, 01-06-1946 (1 L, CAIM CulH/lam-01398), 01-061941 (1 L, CAIM CulH/lam-01405) 01-04-1942 (1 L, CAIM CulH/lam-01406, 1 MT CAIM CulH/lam-05520); Todos los datos indeterminados (2 MT, CAIM CulH/lam05521).

Distribución conocida. América Central, México, Venezuela, Trinidad y Tobago, Colombia, Brasil, Perú, Ecuador, Bolivia y Argentina (Knight \& Stone 1977). En México se ha encontrado en los estados de Campeche, Chiapas, Hidalgo, Michoacán, Nayarit, Oaxaca, Quintana Roo, San Luis Potosí, Sinaloa, Tabasco y Veracruz, desde la costa hasta lugares como Jalapa, Ver., con 1427 m snm (Vargas \& Martínez-Palacios 1956).

Distribución en Veracruz (Fig. 110). Mpo. Acayucan: Acayucan; Mpo. Alto Lucero: Alto Lucero, Blanca Espuma, El Rodeo; Mpo. Amatlán de los Reyes: Amatlán 
de los Reyes; Mpo. Coatepec: Col. Bella Esperanza, El Grande, Las Lomas; Mpo. Coatzintla: Poza Rica de Hidalgo; Mpo. Córdoba: Córdoba, Río de San Francisco, San Miguelito; Mpo. Cosoleacaque: Cosoleacaque; Mpo. Cotaxtla: Cotaxtla; Mpo. Cuichapa: Cuichapa; Mpo. Cuitláhuac: Cuitláhuac; Mpo. Emiliano Zapata: Plan de Nacaxtle; Mpo. Fortín: Fortín; Mpo. Hidalgotitlán: Hidalgotitlán; Mpo. Xalapa: Xalapa-Enríquez; Mpo. Jaltipan: Jaltipan de Morelos; Mpo. Juchique de Ferrer: Juchique de Ferrer; Mpo. Las Choapas: Las Choapas; Mpo. Manlio Fabio Altamirano: Martínez de la Torre, Paso Largo; Mpo. Misantla: Misantla; mpo. Moloacán: Moloacán; Mpo. Nautla: Jicaltepec; Mpo. Olutla: Olutla; Mpo. Papantla: Papantla; Mpo. Paso de Ovejas: Cerro de Guzmán, Plan de Manantial, Puente de Jula; Mpo. Paso del Macho: Paso del Macho; Mpo. Puente Nacional: Puente Nacional, Tamarindo; Mpo. Soconusco: Soconusco; Mpo. Temapache: Álamo; Mpo. Tepezintla: Cerro Azul; Mpo. Texistepec: Lázaro Cárdenas; Mpo. Tierra Blanca: Moreno Norte; Mpo. Tlalixcoyan: Piedras Negras; Mpo. Tuxpan: Tuxpan; Mpo. Temaxcal-Camarón: Villa Tejeda; Mpo. Vega de Alatorre: Vega de Alatorre; Mpo. Veracruz: Limones, Paso de San Juan, Veracruz.

Datos bionómicos. La larva de esta especie se desarrolla en agua clara y fresca de arroyos pequeños, charcas y pantanos, con sombra, con poca vegetación acuática pero con presencia de pastos, algas u hojas flotantes, comúnmente asociado a las especies Anopheles oswaldoi y An. aquasalis. Las hembras se han encontrado alimentándose de caballos y en trampas con cebo humano (Stojanovich et al. 1966, Wilkerson 1990).

Importancia Médica. Esta especie se ha encontrado infectada naturalmente con plasmodios de la malaria humana en Panamá y se logró infectar experimentalmente con Plasmodium vivax y P. falciparum. También se ha reportado que esta especie es el único vector de la malaria en ciertas regiones de Colombia, entre los 800 y los 1100 m snm; sin embargo, no se puede comprobar su condición real como vector del paludismo debido a que su identificación era dudosa y Anopheles malefactor estaba en sinonimia con esta especie (Wilkerson 1990).

Comentarios. Se puede distinguir de otras especies por las siguientes características: Larva: seda 3-C de 0.5 la longitud de la 2-C, con tres a ocho ramas, seda 1-P con cuatro a siete ramas, seda 6-IV-V sencilla; Pupa: trompeta laticorne, sin proyección en la pinna, seda 1-II bien desarrollada con seis a veinticuatro ramas, 1-VI-VII generalmente sencilla; Macho, terminalia: lóbulo dorsal de la claspeta con tres (ocasionalmente dos o cuatro) sedas capitadas muy juntas que se pueden ver truncadas o chatas, lóbulo ventral de la claspeta con dos (algunas veces tres) sedas apicales o subapicales, edeago con de dos a seis hojillas apicales en cada lado, más comúnmente tres. 

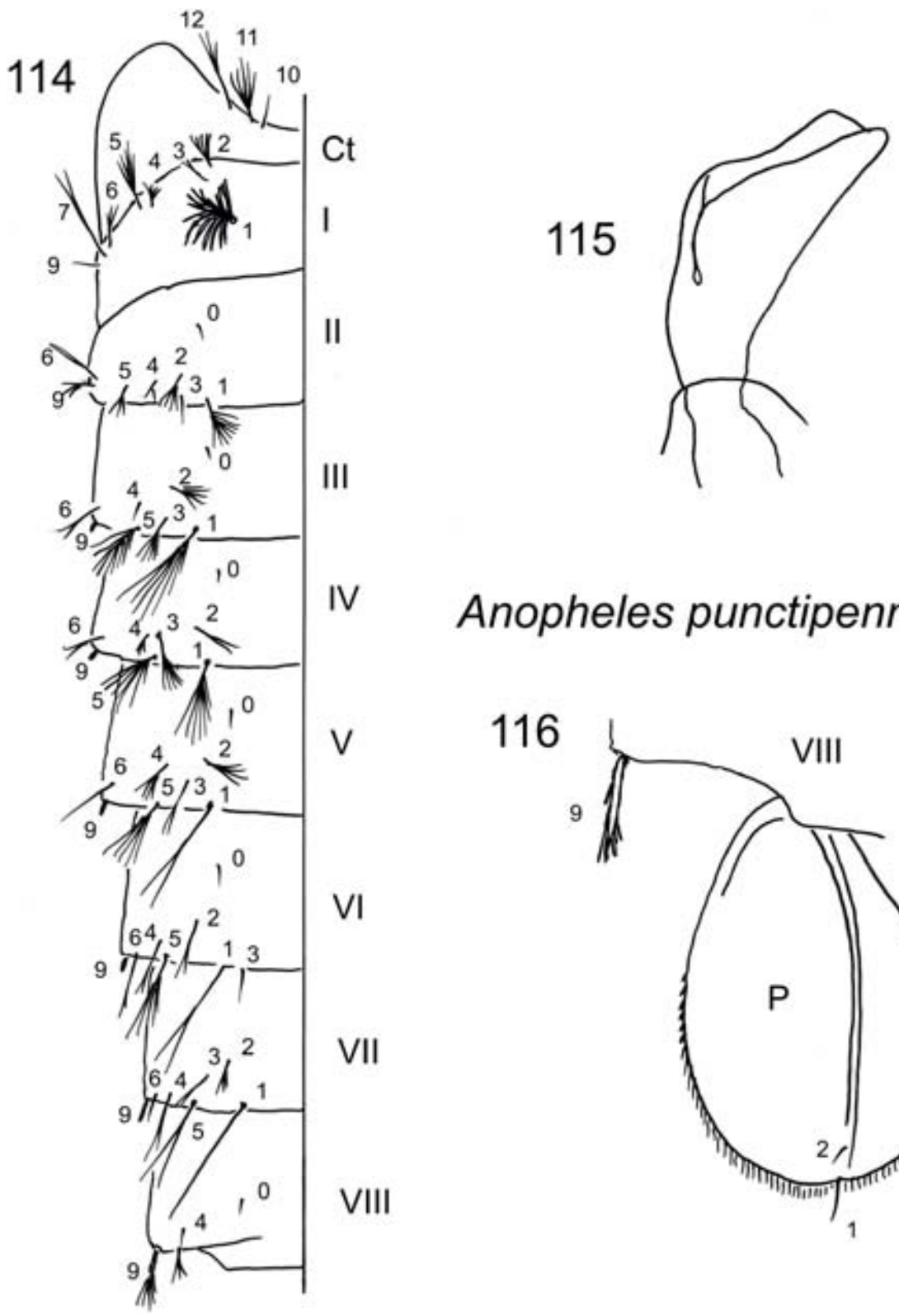

\section{Anopheles punctipennis}

116

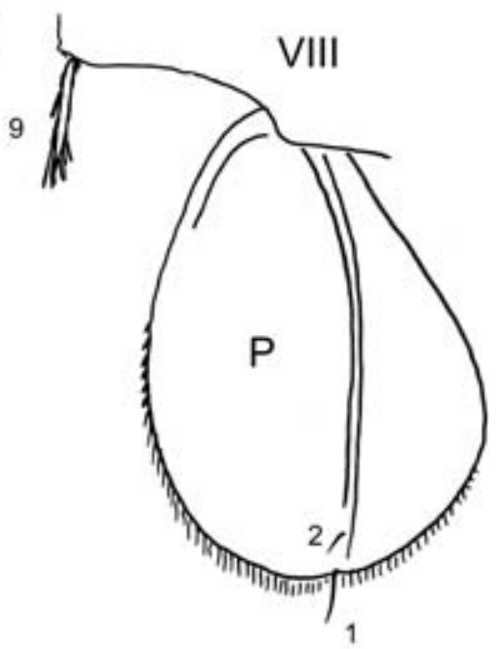

Figuras 114-116. Pupa de Anopheles (Anopheles) punctipennis (redibujada de Penn, 1949). 114:

Segmentos abdominales I-VIII vista dorsal. 115: Trompeta ventiladora. 116: Paleta natatoria izquierda vista dorsal. 

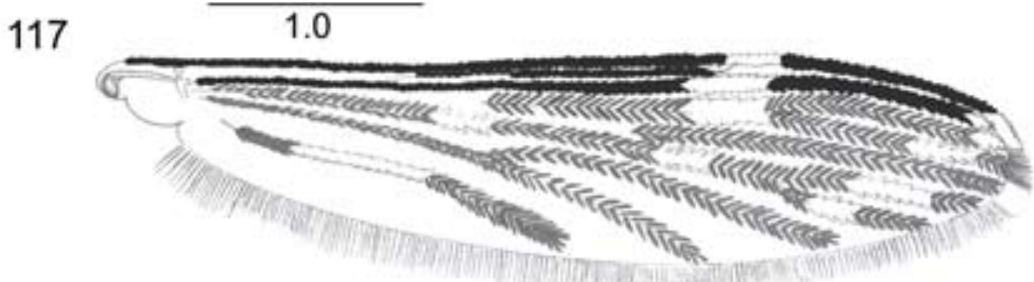

118

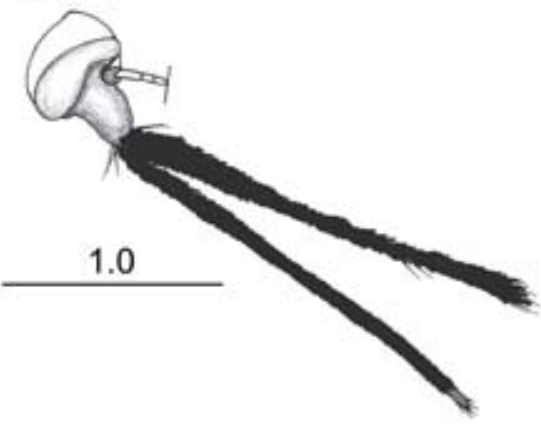

Anopheles punctipennis

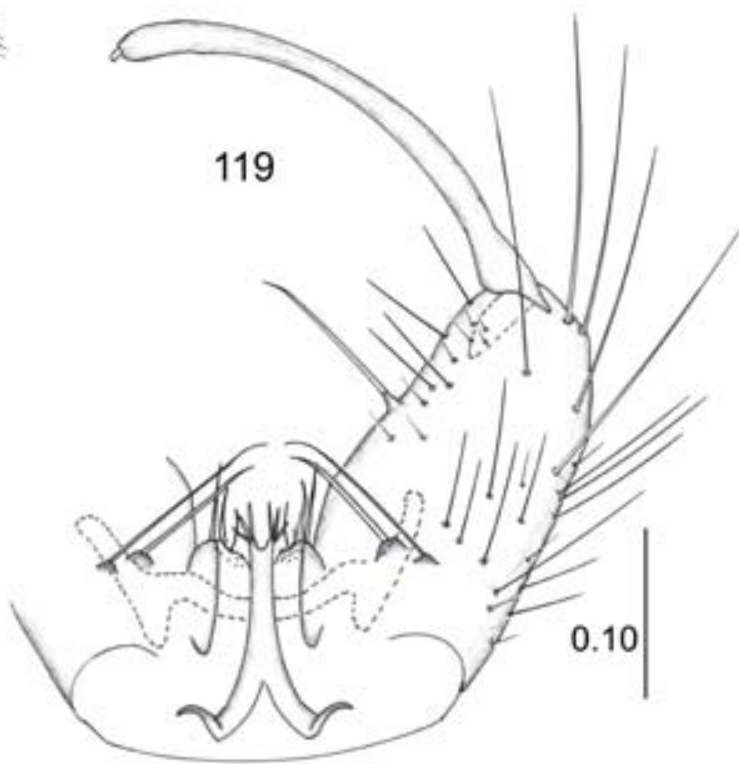

Figuras 117-119. Adultos de Anopheles (Anopheles) punctipennis. Hembra. 117: Ala. 118: Palpo maxilar. Macho. 119: Terminalia. 
La larva en esta especie es parecida a la de Anopheles apicimacula y An. neomaculipalpus, sin embargo se pueden distinguir fácilmente porque en A. punctimacula la sedas 9-12-P son sencillas y las sedas 3-C están ramificadas dicotómicamente con tres a ocho ramas.

La hembra de esta especie es similar a la de Anopheles neomaculipalpus, pudiéndose distinguir por las siguientes características que presenta An. punctimacula: escamas claras del ala en su mayoría color amarillo excepto por las escamas blancas contrastantes que se observan a cada lado de las manchas oscuras del presector, del sector y preapical, mancha oscura preapical tan larga como 0.11-0.23 la longitud del ala, pata posterior con el tarsómero 5 con una mancha o banda oscura central, esternito I sin mechones postero-laterales de escamas oscuras.

La terminalia del macho se puede confundir con la de An. neomaculipalpus; sin embargo, en An. punctimacula el primer par de hojillas del edeago presentan un engrosamiento central a manera de nervadura y los bordes hialinos.

Parece ser una especie de amplia distribución en Veracruz, ya que ha sido informada en un amplio rango de altitudes (desde la costa, hasta los $1140 \mathrm{msnm}$ ) y en el mapa de su distribución se observa que esta especie está asociada a la selva baja caducifolia y a la selva alta perennifolia, aunque también se ha colectado en pocas ocasiones en otros tipos de vegetación como los bosques de encino y mesófilo de montaña.

Se considera que esta especie puede tener importancia médica en Veracruz debido a su amplia distribución en el estado y a que ha sido encontrada infectada naturalmente con plasmodios que causan malaria humana, a pesar de que no se haya comprobado su condición real como vector de la enfermedad.

\section{Anopheles (Anopheles) punctipennis (Say 1823)}

(Figs. 111-119)

Culex punctipennis Say 1823: 9. Localidad tipo: Chestertown, Kent, Maryland, Estados Unidos.

Anopheles punctipennis (Say) 1824: 357; Rozeboom 1941: 104 (distribución y bionomía); Ross \& Roberts 1943: 13 (hembra, macho, larva); Aitken 1945: 345 (pupa, larva y huevo); Freeborn In: Boyd, 1949: 390 (taxonomía y biología); Darsie 1949: 514 (pupa); Penn 1949: 59 (pupa); Breeland 1951: 224 (larva); Carpenter \& LaCasse 1955: 48 (macho, hembra, larva, bionomía); Horsfall 1955: 126 (distribución y bionomía); Vargas \& Martínez-Palacios 1956: 53 (claves pupa), 87 (hembra, macho, larva); Vargas 1959: 378 (claves macho); Belkin et al. 1966: 2 (restricción de la localidad tipo); Kreutzer \& Kitzmiller 1971: 409; Kreutzer \& Kitzmiller 1972:191 (cromosomas); Kreutzer 1977: 265 (relación con el grupo maculipennis); Linley \& Kaiser 1994: 43 (huevo). 
Culex hyemalis Fitch 1847: 281 (macho, hembra) Localidad tipo: este de Nueva York, Estados Unidos.

Anopheles punctipennis var. stonei Vargas 1941b: 179 (macho, hembra). Localidad tipo: Monterrey, Nuevo León, México. Referencias adicionales.- Freeborn In: Boyd 1949: 390.

Diagnosis. LARVA (Figs. 111-113). Cabeza: sedas 2-C sencillas, separadas entre sí por una distancia menor al diámetro de uno de los alvéolos que les dan origen; sedas 3-C más cortas que las 2-C, densamente ramificadas dicotómicamente. Antena: sedas 2-3-A puntiagudas. Tórax: seda 1-P pequeña, con dos a siete ramas; sedas 9-12-P sencillas. Abdomen: seda 1-II palmeada, no pigmentada, con los bordes de las ramas lisos; sedas 1-III-VII palmeada con las ramas anchas, pigmentadas y con el borde aserrado en la mitad distal (Vargas \& Martínez-Palacios 1956). PUPA (Figs. 114-116). Trompeta: con un surco meatal profundo. Abdomen: seda 1-V-VIII sencilla; seda 7-II de la mitad de la longitud de la seda 6-II; sedas 9-IV-VII sencillas, espiniformes, 9-IV menor que la mitad de la longitud de la seda 9-VII, 9-VIII ramificada desde la base con más de diez ramas. Paletas natatorias: con espículas marginales; seda 1-P sencilla; 2-P corta, simple o bifurcada (Penn 1949, Vargas \& Martínez Palacios Op. cit.). HEMBRA (Figs. 117-118). Cabeza: palpo maxilar con escamas oscuras en su totalidad. Tórax: escudo oscuro en sus lados con una franja ancha medio-dorsal de polinosidad plateada. Ala: base de la costa con escamas oscuras; costa, radio y radial uno oscuros, excepto por con las manchas clara apical y subcostal; cúbito con predominancia de escamas oscuras. Abdomen: sin escamas (Vargas \& Martínez-Palacios 1956, Wilkerson et al. 1993). MACHO (Fig. 119). Terminalia: Gonostilo ligeramente más largo que el gonocoxito, adelgazado en la parte central, con la uña gonostilar corta y de punta redondeada. Gonocoxito sin escamas. Dos espinas parabasales del mismo grosor, una más larga que la otra. Una espina interna. Lóbulo dorsal de la claspeta con una o dos espinas apicales gruesas, puntiagudas. Lóbulo ventral de la claspeta con una espina apical muy fuerte y una espina subapical débil en el lado interno, y una pequeña intermedia, todas puntiagudas. Edeago con tres o cuatro pares de hojillas angostas, de bordes lisos; el par distal es más largo; algunas con sedas basales. Noveno terguito con la parte central estrecha, los lóbulos laterales anchos y cortos (Vargas \& Martínez-Palacios 1956).

Material examinado. 7 ejemplares. México: Hidalgo, Mpo. Ixmiquilpan, Ixmiquilpan, 01-10-1944 (2 P, CAIM CulH/lam-05505 y CAIM CulH/lam-05506); Guanajuato, Mpo. Allende, Villa de Santiago, 01-05-1927 (1 MT, CAIM CulH/lam-05501); Todos los datos (2 H, CAIM CulH/alf-01507 y CAIM CulH/alf-01567); Distrito Federal, Cultivo en insectario, 20-12-1957 (2 H, CAIM CulH/alf-01567 y CAIM CulH/ alf-01507). 


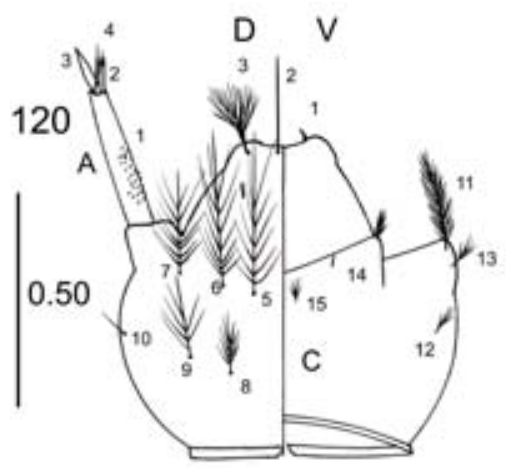

122
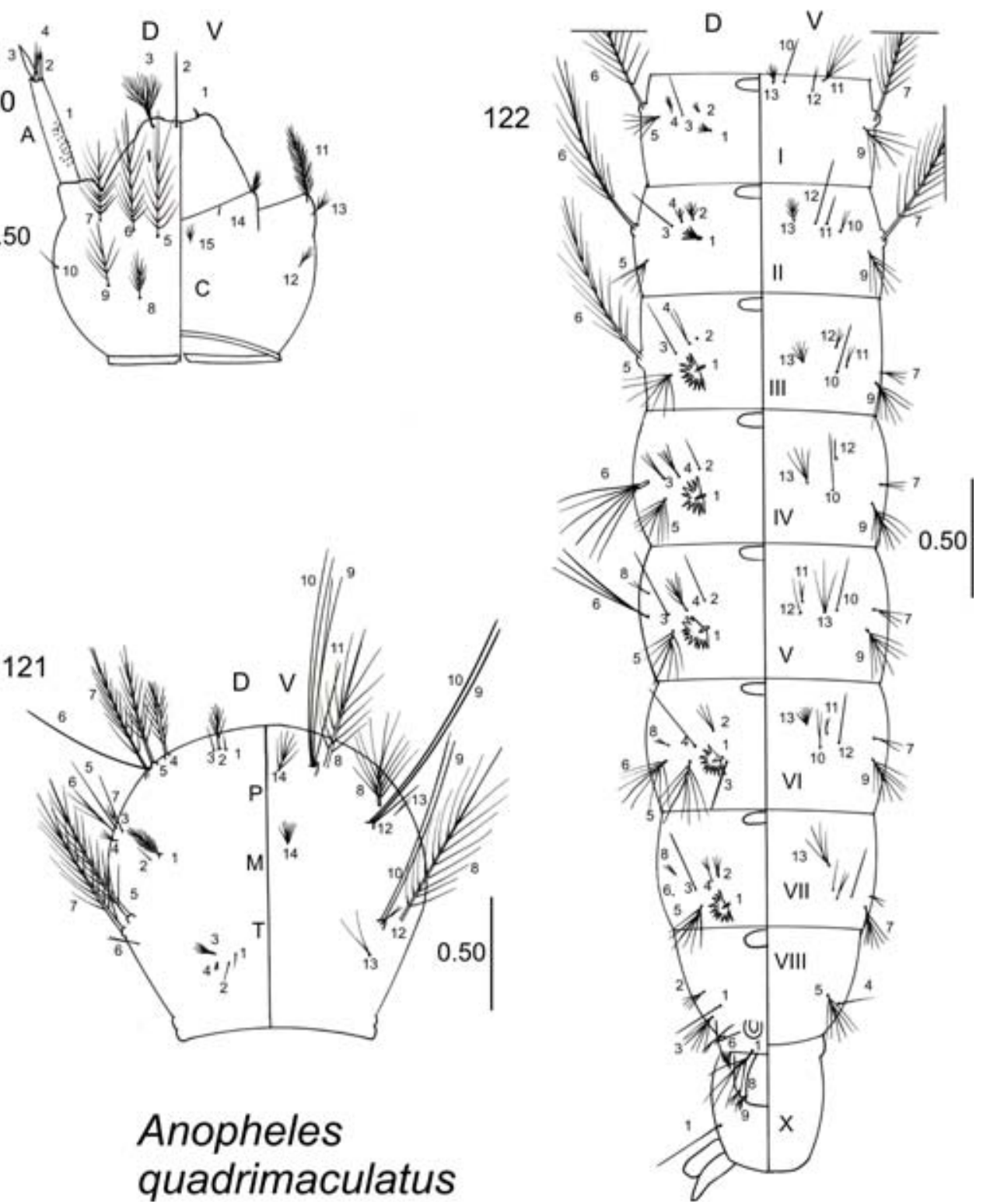

Figuras 120-122. Larva de Anopheles (Anopheles)quadrimaculatus. 120: Cabeza. 121: Tórax. 122: Abdomen. 

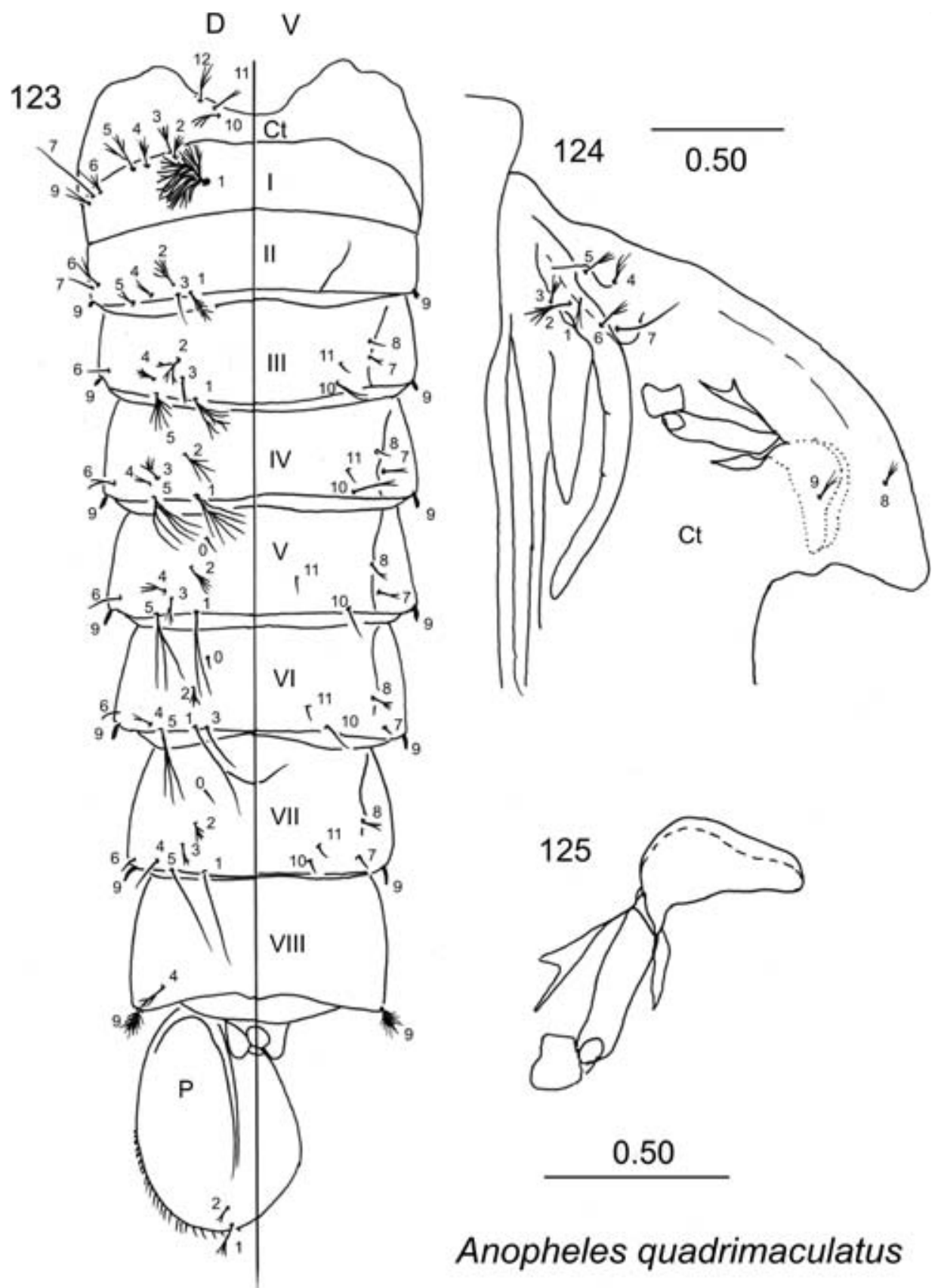

Figuras 123-125. Pupa de Anopheles (Anopheles)quadrimaculatus. 123: Abdomen. 124: Cefalotórax. 125: Trompeta ventiladora. 
Distribución conocida. Estados Unidos, sur de Canadá y México. (Knight \& Stone 1977). Para México: en los estados de Aguascalientes, Chihuahua, Coahuila, Durango, Guanajuato, Hidalgo, Michoacán, Nayarit, Nuevo León, Querétaro, Tamaulipas, Veracruz, principalmente en la Altiplanicie, pero también lugares bajos cerca de la costa (Vargas \& Martínez-Palacios Op. cit.).

Distribución en Veracruz. Mpo. Pueblo Viejo: Villa Cuauhtémoc.

Datos bionómicos. Las larvas se encuentran en una gran variedad de hábitats acuáticos incluyendo pozos, charcos temporales, manantiales en arroyos intermitentes, fosas artificiales, caminos fangosos, a las orillas de corrientes. Prefieren agua templada, particularmente en corrientes de montañas.

Las hembras se alimentan después del atardecer pero pueden atacar al hombre durante el día en bosques densos o en sus lugares de reposo. Se comporta en general como una especie del peridomicilio y rara vez entra a las habitaciones a alimentarse en grandes números (Carpenter \& LaCasse 1955).

Importancia médica. Aunque ha sido infectado con Palsmodium vivax y P. falciparum bajo condiciones de laboratorio, no se considera un vector importante de la malaria debido a sus hábitos mayormente zoófilos (Boyd \& Kitchen 1936).

Comentarios. Se puede distinguir de otras especies por las siguientes características: Larva: sedas 3-C más cortas que las 2-C, densamente ramificadas dicotómicamente, 1-P pequeña, con dos a siete ramas 1-II palmeada, no pigmentada, con los bordes de las ramas lisos; Pupa: seda 9-IV menor que la mitad de la longitud de la 9-VII, 1-V-VII sencilla; Hembra: palpo maxilar con escamas oscuras en su totalidad, escudo oscuro en sus lados con una franja ancha medio-dorsal de polinosidad plateada, cúbito con predominancia de escamas oscuras; Macho, terminalia: lóbulo dorsal de la claspeta con una o dos espinas apicales gruesas, puntiagudas, Edeago con tres o cuatro pares de hojillas angostas, de bordes lisos; el par distal es más largo.

La larva es parecida a la de Anopheles bradleyi, pudiéndose diferenciar por la seda abdominal 2-IV-V que es ramificada con generalmente tres ramas en An. punctipennis.

La pupa es similar a la de Anopheles bradleyi y An. crucians, no obstante se puede diferenciar por las siguientes características: seda 9-IV menor que la mitad de la longitud de la 9-VII, seda 1-V-VII sencilla.

La hembra tiene características similares a las de An. pseudopunctipennis; sin embargo, An. punctipennis se puede diferenciar fácilmente porque presenta el palpo maxilar con escamas oscuras en su totalidad.

En Veracruz solo se ha informado en una localidad del norte, por lo que no se considera que tenga importancia médica en el estado, aunque se debe tomar en cuenta 
si es que en un futuro se llega a registrar en otras localidades del estado, ya que se ha infectado con plasmodios bajo condiciones de laboratorio.

No se pudo obtener un mapa de su distribución potencial por falta de puntos de colecta.

\section{Anopheles (Anopheles) quadrimaculatus Say 1824}

(Figs. 120-127, 128)

Anopheles quadrimaculatus Say 1824: 356 (hembra). Localidad tipo: Wabasha, Minnesota, Estados Unidos. Referencias adicionales.- Dyar \& Knab 1906b: 159 (taxonomía); Howard, Dyar \& Knab 1912-1917 (huevo); Ross \& Roberts 1943: 11 (hembra, macho, larva); Rozeboom 1941: 107 (distribución); Aitken 1945: 280 (taxonomía); Lassmann 1948: 9 (distribución en Veracruz); Darsie 1949: 511 (pupa); Freeborn In: Boyd 1949: 380 (taxonomía y biología); Penn 1949: 56 (pupa); Breeland 1951: 224 (larva); Carpenter \& LaCasse 1955: 50 (macho, hembra, larva, bionomía); Horsfall 1955: 134 (distribución y bionomía); Vargas \& Martínez-Palacios 1956: 53 (claves pupa), 91 (hembra, macho, larva); Vargas 1959: 374 (claves macho); Weidhaas et al. 1965: 145 (biología); Belkin et al. 1966: 3 (restricción de la localidad tipo); Heinemman \& Belkin 1977: 495, 521, 522 (distribución); O’Malley 1992: 136 (biología); Linley et al. 1993: 124 (huevo); Reinert et al. 1997: 22 (macho, hembra, pupa, larva y huevo).

Anopheles annulimanus Van der Wulp 1867: 129 (macho). Localidad tipo: Wisconsin, Estados Unidos. Referencias adicionales.- Belkin et al. 1966: 3 (restricción de la Localidad tipo); Belkin 1968: 9 (taxonomía).

Diagnosis. LARVA (Figs. 120-122). Cabeza: sedas 2-C sencillas, separadas entre sí por una distancia del diámetro de dos alvéolos que les dan origen; sedas 3-C ramificadas dicotómicamente con once a treinta ramas. Antena: sedas 2-3-A puntiagudas. Tórax: seda 1-P sencilla o con dos a cuatro ramas, seda 9-P bifurcada o trifurcada; sedas 10-12-P sencillas. Abdomen: seda 1-II palmeada no pigmentada o moderadamente pigmentada y con los bordes de las hojas lisos o muy poco aserrados; sedas 1-III-VII palmeadas, con las ramas anchas, fuertemente pigmentadas pero con manchas claras, con el borde aserrado y un filamento terminal corto (Reinert et al. 1997). PUPA (Figs. 123-125). Trompeta: angusticorne con un surco meatal profundo. Abdomen: seda 1-VII ligeramente más larga que la longitud del segmento VIII; sedas 9-III-VII espiniformes, anchas, aplanadas y rectas, 9-VIII ramificada desde la base con de doce a veintiún ramas. Paletas natatorias: margen externo con serraciones y acículas cortas; parte apical de los márgenes interno y externo con acículas cortas y delgadas; seda 1-P generalmente con dos a seis ramas; 2-P con una a tres ramas (Darsie 1949, Reinert et al. Op. cit.). HEMBRA (Fig. 126). Cabeza: palpo maxilar negro en su 


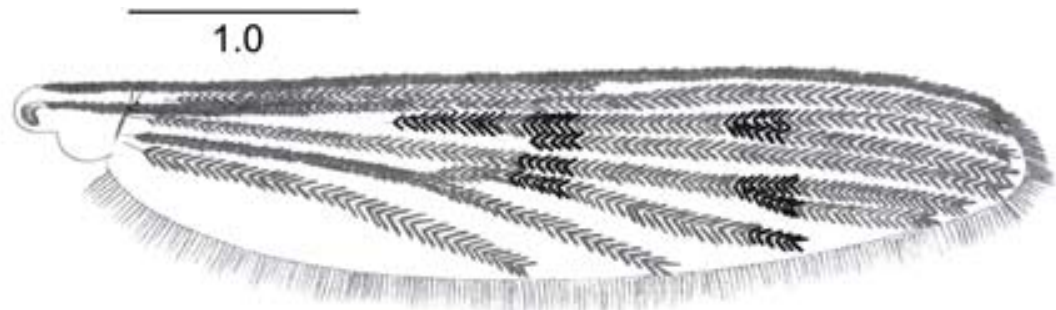

\section{Anopheles quadrimaculatus}

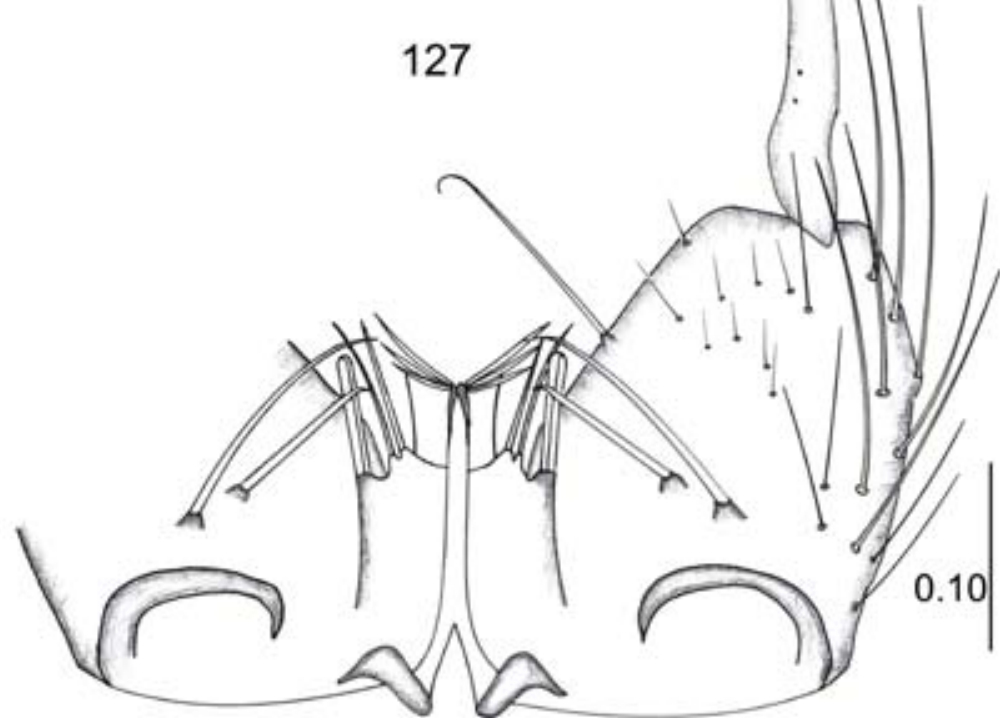

Figuras 126-127. Adultos de Anopheles (Anopheles) quadrimaculatus. Hembra. 126: Ala. Macho. 127: Terminalia. 


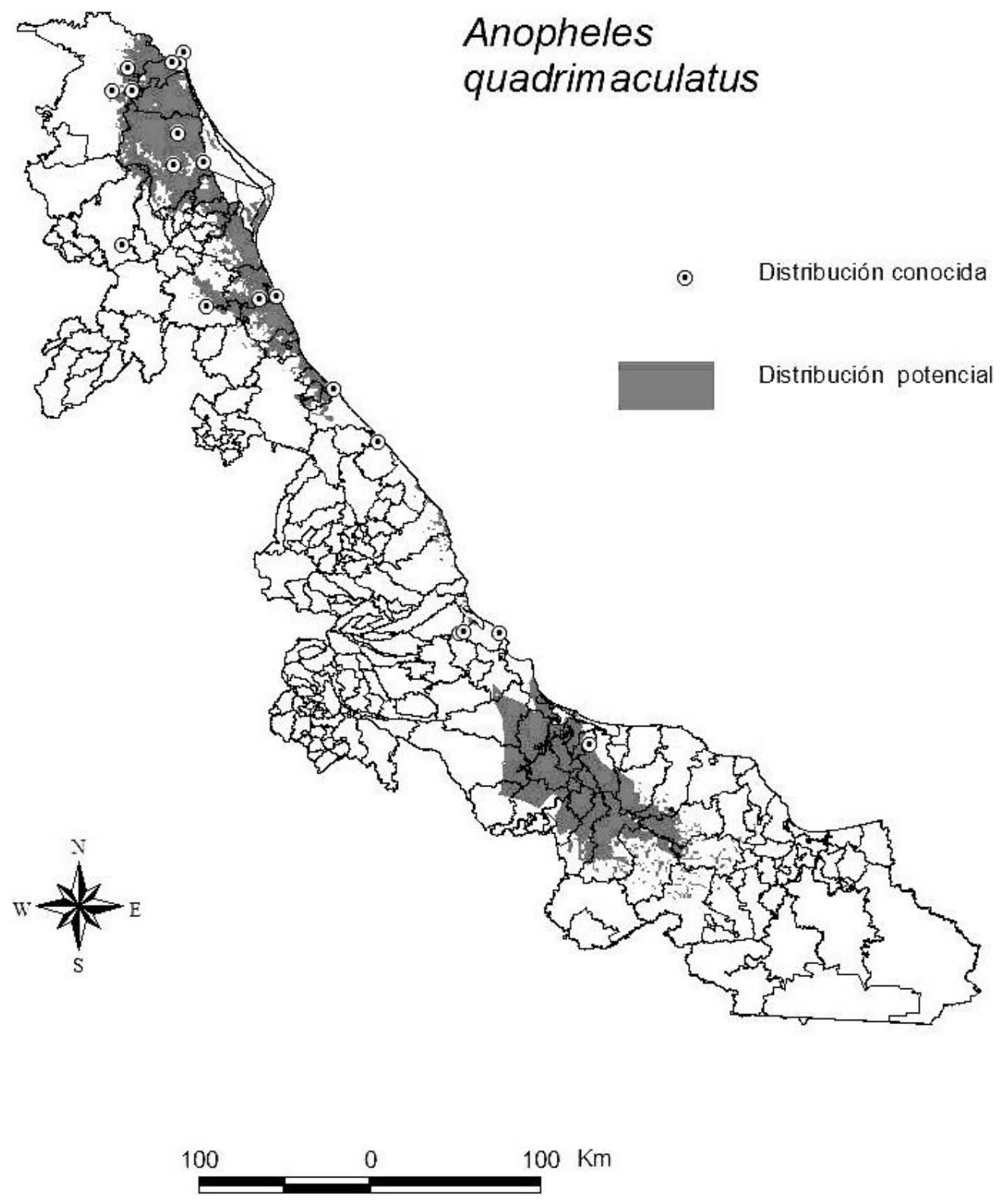

Figura 128. Mapa de la distribución conocida y potencial de Anopheles (Anopheles) quadrimaculatus. 
totalidad; escamas y sedas del espacio interocular de color blanco. Tórax: escudo y escudete oscuros, con numerosas sedas amarillentas y doradas. Patas: ápices de fémures con bandas apicales de escamas claras; tibias con una banda apical delgada a muy delgada de escamas claras. Ala: todas las venas y el fleco con escamas oscuras pero con cuatro áreas con escamas más oscuras que dan la apariencia de manchas (Reinert et al. 1997, Wilkerson et al. 1993). MACHO. Terminalia (Fig. 127): gonostilo más largo que el gonocoxito, adelgazado en su porción central, generalmente con once a diecinueve sedas diminutas; uña gonostilar gruesa y con la punta redondeada. Gonocoxito sin escamas. Dos espinas parabasales del mismo grosor, pero la exterior es más larga que la otra. Una espina interna. Lóbulo dorsal de la claspeta con de una a tres espinas moderadamente largas, aplanadas, fusionadas y expandidas apicalmente, que nacen de un proceso elevado. Lóbulo ventral de la claspeta con cinco sedas. Edeago largo, con de dos a cuatro hojillas delgadas, de bordes lisos, las del primer par más largas que las demás, algunas con espículas cortas basales. Noveno terguito estrecho, con los lóbulos laterales anchos y cortos y de puntas ensanchadas (Reinert et al. Op. cit., Vargas \& Martínez -Palacios 1956).

Material examinado. 25 ejemplares. México: Veracruz, Mpo. Pánuco, Pánuco, 0102-1942 (2 MT, CAIM CulH/lam-05555 y CAIM CulH/lam-05556), 01-1941 (1 H, CAIM CulH/alf-01638), sin fecha (1 MT, CAIM CulH/lam-05558); Mpo. Pueblo Viejo, Pueblo Viejo, 01-11-1940 (1 MT, CAIM CulH/lam-05557); Mpo. Indeterminado, Anáhuac, 10-10-1958 (5 H, CAIM CulH/alf-01672, CAIM CulH/alf-01673, CAIM CulH/alf-01674, CAIM CulH/alf-01697 y CAIM CulH/alf-01698); Mpo. Indeterminado, San Gerónimo, 01-03-1926 (2 P, CAIM CulH/lam-05553 y CAIM CulH/ lam-05554); Tamaulipas, Tampico, Tampico, 30-07-1936, (8 MT, CAIM CulH/lam05552), 01-08-1949 (2 P, CAIM CulH/lam-05549 y CAIM CulH/lam-05548), sin fecha (1 L, CAIM CulH/lam-01581), Distritito Federal, Cultivo en insectario, 10-021959 (1 H, CAIM CulH/alf-01662); 24-10-1960 (1 L, CAIM CulH/lam-01564).

Distribución conocida. Sur de Canadá, centro y este de Estados Unidos y México. (Knight \& Stone 1977). En México se ha reportado para los estados de Nuevo León, San Luis Potosí, Tamaulipas y Veracruz (Vargas \& Martínez -Palacios Op. cit.).

Distribución en Veracruz (Fig. 128). Mpo. Nautla: Nautla; Mpo. Ozuluama: La Mina, La Laja; Mpo. Pánuco: Calentadores, Topila; Mpo. Paso de Ovejas: Puente de Jula; Mpo. Pueblo Viejo: Mata Redonda, Pueblo Viejo, Villa Cuauhtémoc; Mpo. Tantoyuca: San Jerónimo; Mpo. Tecolutla: Tecolutla; Mpo. Temapache: Álamo; Mpo. Tepezintla: Cerro Azul; Mpo. Tlacotalpan: Tlacotalpan; Mpo. Tuxpan: Barra Norte, Tuxpan; Mpo. Veracruz: Paso de San Juan, Veracruz; Mpo. Indeterminado: San Gerónimo; Mpo. Indeterminado: Anáhuac. 
Datos bionómicos. Las larvas se desarrollan en cuerpos de agua dulce, en corrientes tranquilas, canales, pozos y lagos con vegetación flotante o emergente o con restos vegetales flotantes, y solo ocasionalmente en charcos temporales. Las hembras se alimentan activamente del hombre y de animales salvajes y domésticos. Los adultos son activos principalmente en la noche y por un corto periodo del atardecer (Carpenter \& LaCasse 1955).

Importancia médica. Se considera un vector primario de malaria humana, ya que se han realizado varios estudios sobre su susceptibilidad a los parásitos de la malaria y se reporta que es susceptible a la infección de Plasmodium vivax, $P$. falciparum y P. malariae. (Boyd \& Stratman 1934, Boyd et al. 1935, Boyd \& Kitchen 1936). Es también un posible vector del gusano del corazón de los perros (Dirofilaria immitis) (WRBU 2008).

Comentarios. El complejo Anopheles quadrimaculatus está formado por cinco especies, An. diluvialis Reinert 1997, An. inundatus Reinert 1997, An. maverlius Reinert 1997, An. smaragdinus Reinert 1997 y An. quadrimaculatus Say sensu stricto (Reinert et al. 1997); todas ellas, con la única excepción de An. quadrimaculatus s. s., tienen distribución en los Estados Unidos, con una disyunción muy amplia con el territorio mexicano (Reinert et al. 1997, Darsie \& Ward 2005). Anopheles quadrimaculatus se puede distinguir de otras especies mexicanas de Anopheles por las siguientes características. Larva: sedas 2-C débiles, con sus troncos paralelos, 3-C ramificadas dicotómicamente con once a treinta ramas, 9-P bifurcada o trifurcada, 1-II palmeada no pigmentada o moderadamente pigmentada y con los bordes de las hojas lisos; $\mathrm{Pu}-$ pa: trompeta angusticorne con un solo surco meatal profundo, seda 1-P generalmente con dos a seis ramas; 2-P con una a tres ramas; Hembra: palpo maxilar negro en su totalidad, ápices de fémures con bandas apicales de escamas claras, todas las venas y el fleco del ala con escamas oscuras pero con cuatro áreas con escamas más oscuras que dan la apariencia de manchas; Mecho, terminalia: Lóbulo dorsal de la claspeta con de una a tres espinas moderadamente largas, aplanadas, fusionadas y expandidas apicalmente, Edeago largo, con de dos a cuatro hojillas delgadas, de bordes lisos, las del primer par más largas que las demás.

La hembra y la terminalia del macho son similar a la de Anopheles walkeri, sin embargo se diferencian porque en la hembra de A. quadrimaculatus las escamas del palpo maxilar son todas oscuras; mientras que el macho presenta el gonostilo sin un parche de sedas muy cortas en la porción basal, el lóbulo dorsal de la claspeta presenta sedas espiniformes casi siempre fusionadas, con ápice romo pero no dilatado y el terguito IX con los lóbulos anchos pero de ápice dilatado.

En Veracruz, esta especie se encuentra distribuida en localidades a baja altitud, ya que la mayor altitud donde se ha informado está a $170 \mathrm{msnm}$. Se observa que 


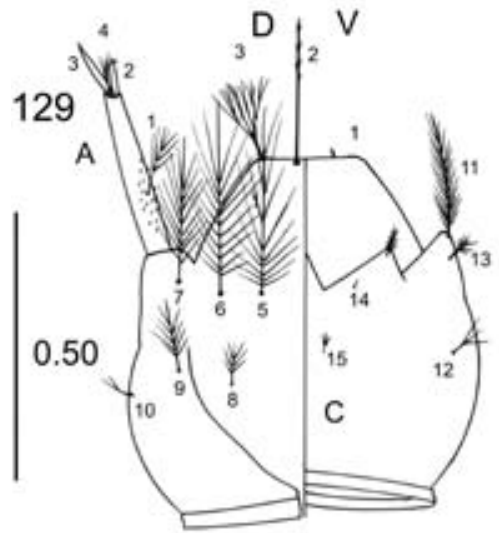

131
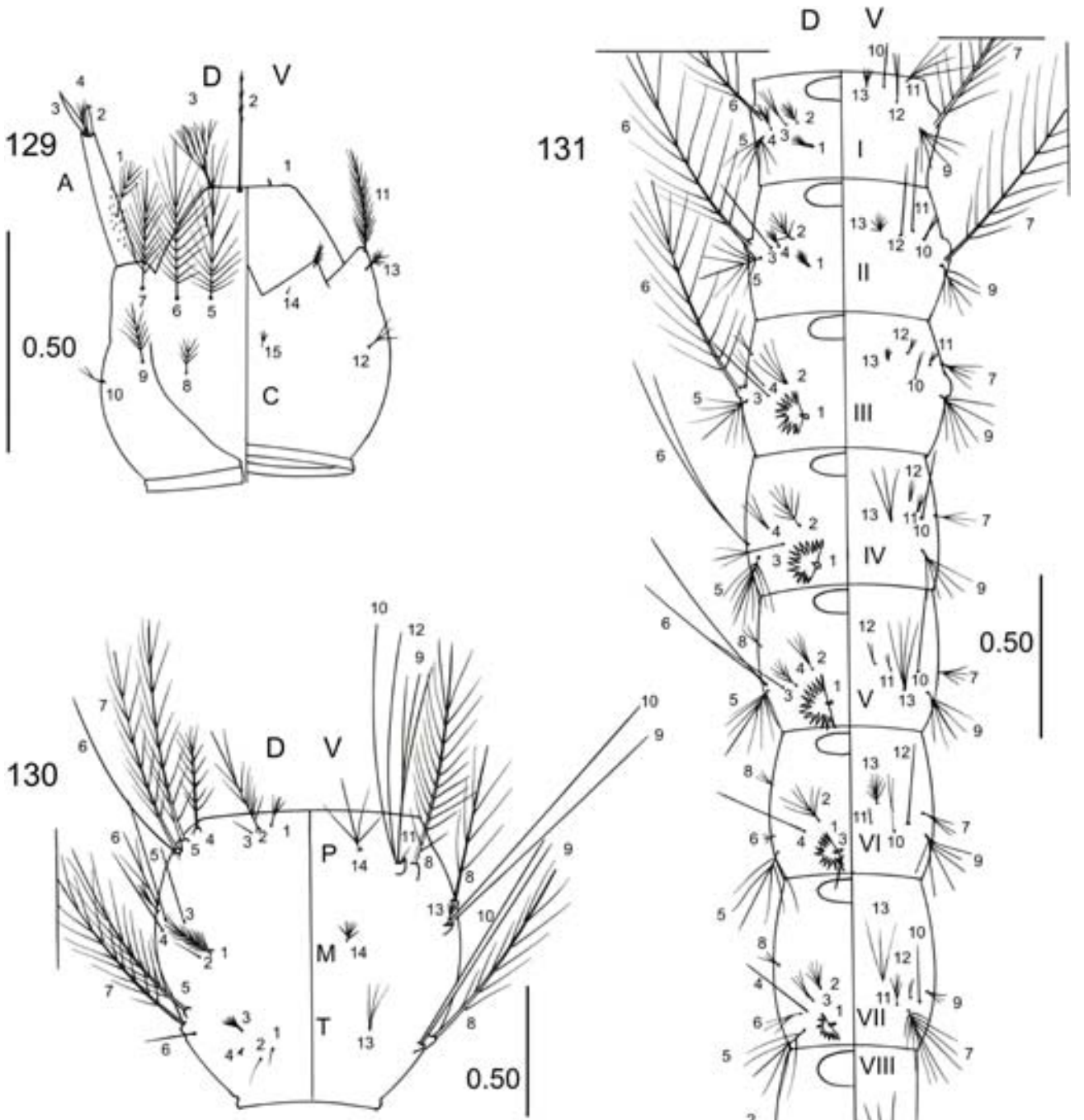

\section{Anopheles vestitipennis}

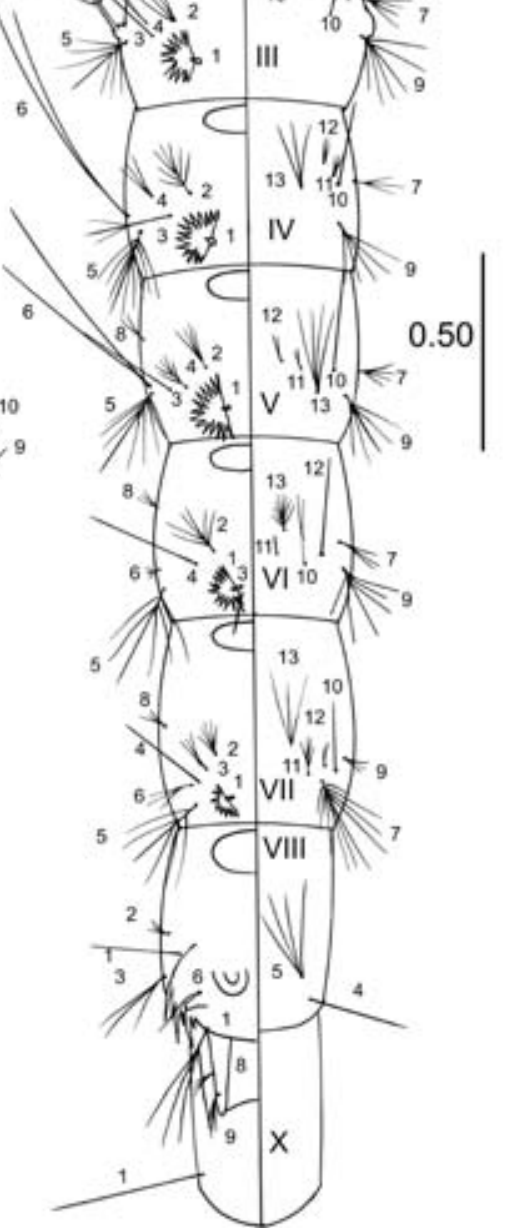

Figuras 129-131. Larva de Anopheles (Anopheles) vestitipennis. 129: Cabeza. 130: Tórax. 131: Abdomen. 
132
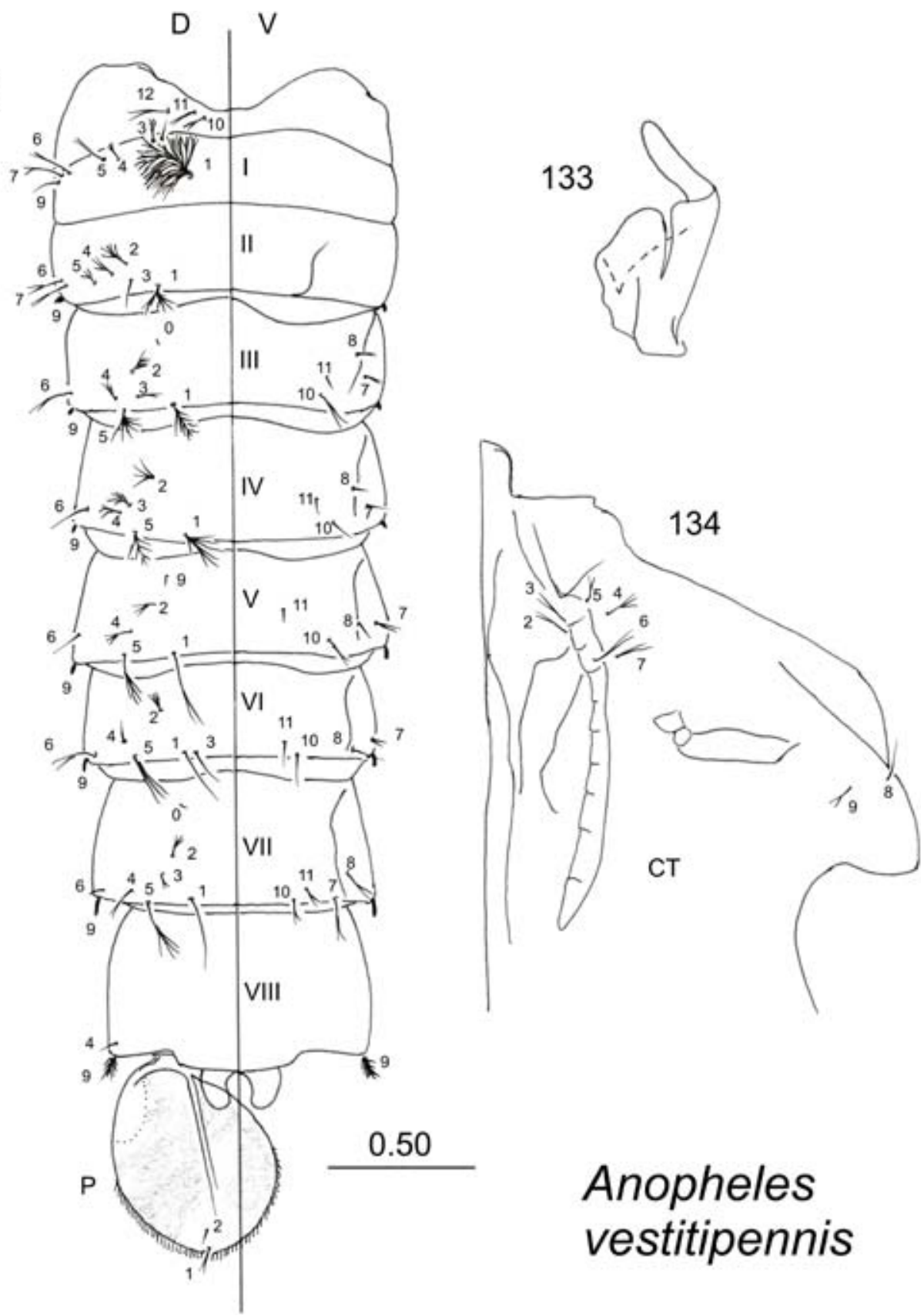

Figuras 132-134. Pupa de Anopheles (Anopheles) vestitipennis. 132: Abdomen. 133: Trompeta ventiladora. 134: Cefalotórax. 
varios de los sitios de colecta de esta especie se encuentran cerca de ríos importantes (Ríos Tuxpan, Tecolutla, Nautla y Tlacotalpan) y más concentrados hacia el norte del estado. En el mapa de la distribución potencial se observa que el hábitat donde esta especie podría estar presente se ubica en zonas de planicie costera (por debajo de los $200 \mathrm{msnm})$.

Aunque esta especie no se encuentra ampliamente distribuida en el estado ni parece ser abundante, resulta de importancia médica y veterinaria ya que es un vector primario de la malaria humana y también se le ha incriminado como vector de Dirofilaria immitis.

\section{Anopheles (Anopheles) vestitipennis Dyar \& Knab 1906}

(Figs. 129-138, 139)

Anopheles (Ano.) vestitipennis Dyar \& Knab 1906a:136. Localidad tipo: Cacao, Trece Aguas, Alta Vera Paz, Guatemala. Referencias adicionales.- Gerry 1932: 37 (hembra); Rozeboom 1941: 106 (distribución y bionomía); Vargas 1941c: 110 (huevo); Komp 1942: 53 (hembra), 97 (larva), 142 (macho); Pratt 1943: 1717 (larva); Lassmann 1948: 10 (distribución en Veracruz); Vargas 1949: 232 (pupa); Lane 1953: 172 (macho, hembra, pupa, larva); Vargas \& Martínez-Palacios 1956: 54 (claves pupa), 96 (hembra, macho, larva); Vargas 1959: 379 (claves macho); Stojanovich et al. 1966: 6 (claves larva), 20 (claves hembra), 36 (bionomía); Belkin, Heinemann \& Page 1970: 31 (macho, hembra, pupa, larva); Loyola et al. 1991: 171 (malaria); Zimmerman 1992: 376 (bionomía); Ulloa et al. 2005: 350 (biología).

Arribalzagia maculipes Theobald 1903: 13 (hembra). Localidad tipo: Sao Paulo, Brasil.

Anopheles maculipes Theobald In: Johnson 1919: 424.

Diagnosis. LARVA (Figs. 129-131). Cabeza: sedas 2-C generalmente convergentes, separadas entre sí por una distancia del diámetro de dos de los alvéolos que les dan origen; sedas 3-C ramificadas dicotómicamente con menos de 15 ramas. Antena: seda 3-A puntiaguda y la 2-A truncada. Tórax: seda 1-P con cinco a ocho ramas laterales; seda 9-P con tres a cinco ramas; Abdomen: sedas 1-I-II rudimentarias, palmeadas con pocas ramas aplanadas adelgazadas y no pigmentadas; sedas 1-III-VII palmeadas muy desarrolladas con hojas pigmentadas y el borde aserrado en la mitad distal; seda 6-IV-V generalmente doble o triple (Belkin et al. 1970, Vargas \& Martínez-Palacios 1956). PUPA (Figs. 132-134). Trompeta: laticorne, con un surco meatal y uno secundario; pinna con una proyección digitiforme conspicua. Abdomen: segmentos abdominales II-VII con espículas pequeñas y filosas en los márgenes caudales dorsales; seda 0 generalmente sencilla en todos los segmentos, raramente ramificada; sedas 9-II-III muy corta; 9-IV de una longitud poco menor a 3.0 la longitud de la seda 
9-VIII, con alrededor de quince ramas laterales; Paleta natatoria: pigmento fuerte e irregular; márgenes interno y externo con espículas filamentosas finas próximas entre sí y generalmente en doble fila, detal forma que parecen estar ramificadas; seda 1-P fuerte con tres o cuatro ramas distales; 2-P sencilla (Belkin et al. Op. cit.). HEMBRA (Figs. 135-137). Cabeza: palpo maxilar en su mayoría negro con escamas erectas y algunas escamas claras en las bases de los palpómeros 3, 4 y 5. Tórax: integumento marrón con sedas color cobrizo. Ala: con predominio de escamas oscuras, con manchas pequeñas de escamas claras en la superficie dorsal de todas las venas; mancha oscura del sector interrumpida por la mancha oscura accesoria del sector; vena anal con cinco puntos claros; fleco del ala completamente negro. Abdomen: esternitos con pocas escamas esparcidas (Belkin et al. 1970, Vargas \& Martínez-Palacios 1956, Wilkerson et al. 1993). MACHO (Fig. 138). Terminalia: gonostilo más largo que el gonocoxito; uña gonostilar corta y con la punta redondeada. Gonocoxito con escamas laterales. Dos espinas parabasales, ambas con el ápice adelgazado, la externa más larga y delgada y con el ápice más atenuado. Una espina interna con un largo de aproximadamente 1.4 del diámetro de la gonocoxito. Lóbulo dorsal de la claspeta con tres sedas aplanadas, dos de éstas con el ápice curvo y expandido y la otra redondeada apicalmente; lóbulo ventral de la claspeta con una seda larga y dos medianas cerca del ápice. Edeago largo y delgado; ápice con solo un par de hojillas muy largas. Noveno terguito no esclerotizado, pero largo y prominente; lóbulo lateral conspicuo, delgado con el ápice redondeado (Belkin et al. Op. cit., Vargas \& Martínez-Palacios Op. cit.).

Material examinado. 8 ejemplares. México: Veracruz, Mpo. Actopan, La Mancha, 05-11-2008 (1 H); Mpo. Indeterminado, Puerto México, 01-10-1939, (2 MT, CAIM CulH/lam-05568 y CAIM CulH/lam-05569); Tabasco, Mpo. Villa Hermosa, Centro, 20-01-1942 (1 MT, CAIM CulH/lam-05560); Mpo. Comacalco, Comacalco, 01-091946 (1 P y 1 L, CAIM CulH/lam-05565); Tamaulipas, Tampico, Tampico, 01-091938 (1 MT, CAIM CulH/lam-05567), 01-04-1941 (1 L, CAIM CulH/lam-01649).

Distribución. Su rango se extiende desde San Luis Potosí, en México, a lo largo de Centroamérica, Panamá y Colombia. Se sabe de su presencia en Cuba, Haití, República Dominicana, Jamaica y Puerto Rico (Belkin et. al. Op. cit.). En México se ha colectado en los estados de Campeche, Chiapas, Quintana Roo, San Luis Potosí, Tabasco, Tamaulipas, Veracruz y Yucatán (Vargas \& Martínez-Palacios Op. cit.).

Distribución en Veracruz (Fig. 139). Mpo. Agua Duce: Agua Dulce; Mpo. Catemaco: Sontecomapan; Mpo. Coatzacoalcos: Agua Dulce, Coatzacoalcos; Mpo. Coatzintla: Poza Rica de Hidalgo; Mpo. Cosamaloapan: Cosamaloapan, El Tinaco; Mpo. Cuichapa: Cuichapa; Mpo. Chapopotla: Nanchital; Mpo. Chinameca: Chinameca; 


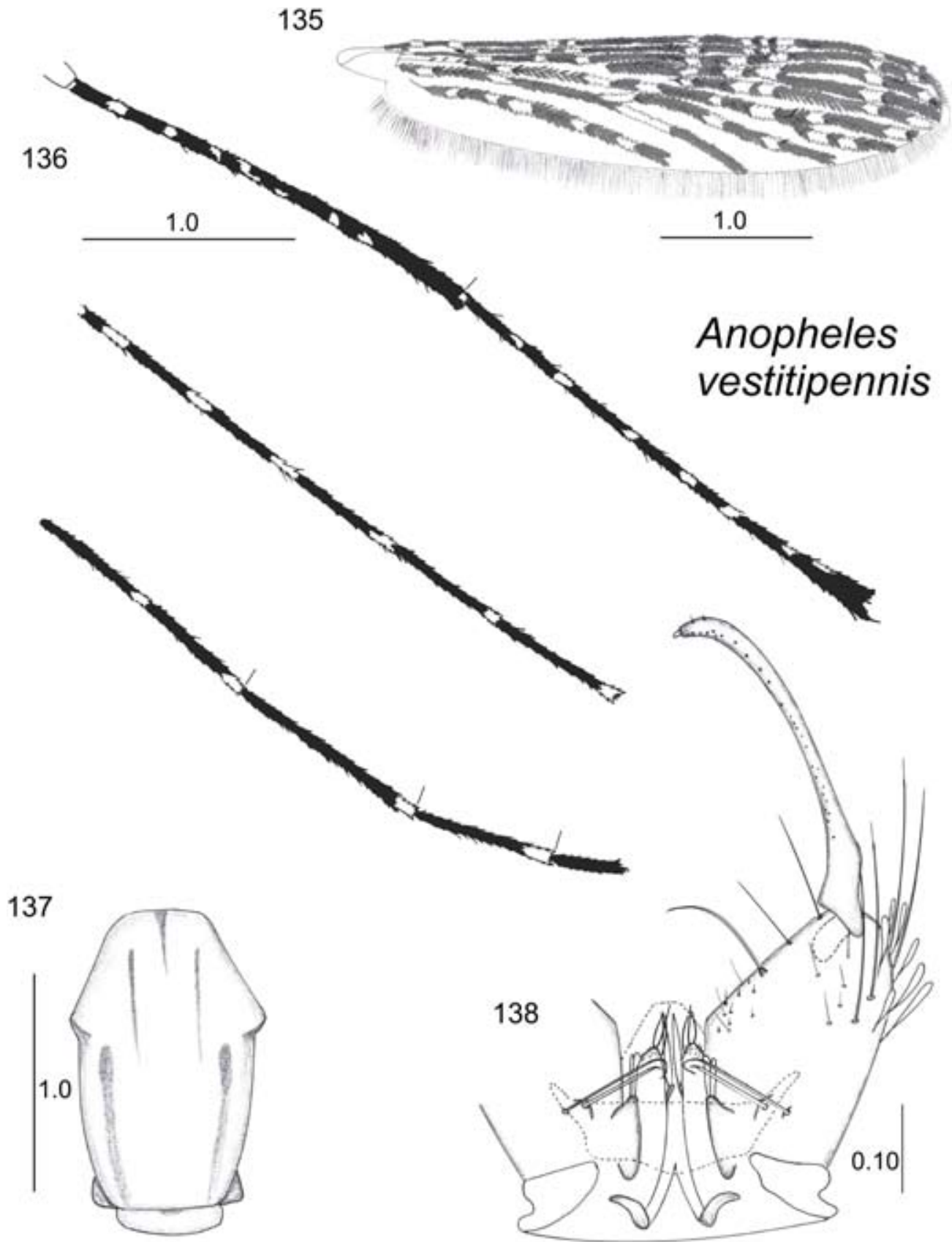

Figuras 135-138. Adultos de Anopheles (Anopheles) vestitipennis. Hembra.135: Ala. 136: Pata posterior. 137: Escudo y escudete. Macho. 138: Terminalia. 


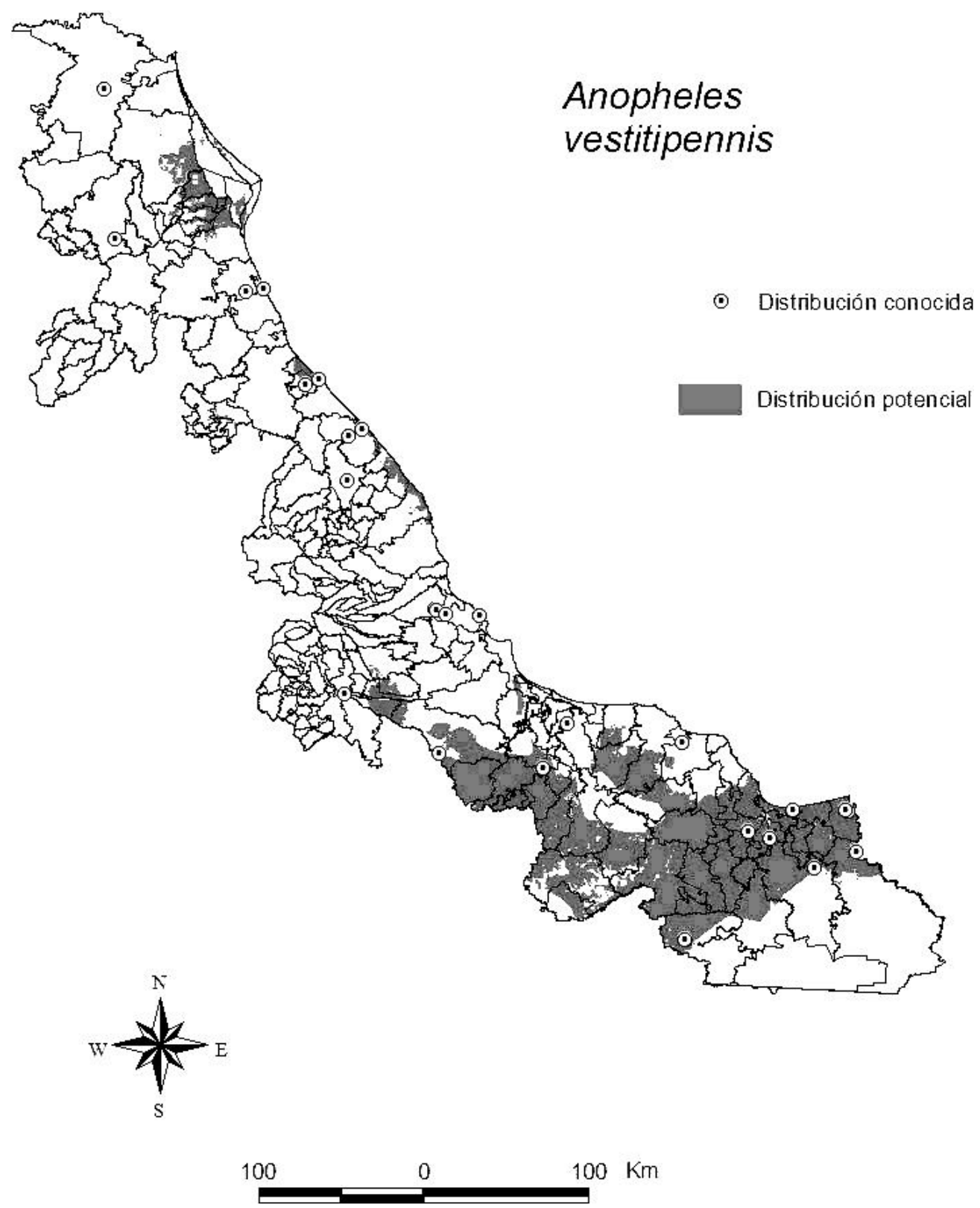

Figura 139. Mapa de la distribución conocida y potencial de Anopheles (Anopheles) vestitipennis. 
Mpo. Gutiérrez Zamora: Gutiérrez Zamora; Mpo. Jesús Carranza: Jesús Carranza; Mpo. Las Choapas: Las Choapas; Mpo. Minatitlán: Las Choapas, Francita, Minatitlán; Mpo. Misantla: Misantla; Mpo. Nautla: Jicaltepec, Nautla; Mpo. Pánuco: Pánuco; Mpo. Paso de Ovejas, Cerro de Guzmán, Puente de Jula, Tierra Colorada; Mpo. Tantoyuca: San Jerónimo; Mpo. Tecolutla: Tecolutla; Mpo. Tierra Blanca, Tierra Blanca; Mpo. Tlacotalpan: Tlacotalpan; Mpo. Tuxpan: Barra Norte; Tuxpan; Mpo. Veracruz: Paso de San Juan, Veracruz; Mpo. Indeterminado: Granja Pancho Villa; Mpo. Indeterminado: Puerto México; Mpo. Indeterminado: Boticaria; Mpo. Indeterminado: Guadalupe.

Datos bionómicos. La larva se desarrolla en cuerpos de agua dulce sombreados como arroyos, estanques y pozos de lluvia. Las hembras suelen picar al hombre al atardecer, o durante el día en días nublados, aunque prefieren alimentarse de animales como vacas, ovejas, cerdos, perros y caballos (Rozeboom 1941, Stojanovich et al. 1966)

Importancia médica. En un estudio Loyola y colaboradores (1991) sugieren que es un probable vector de malaria en la región de la Selva Lacandona en Chiapas, durante la época de lluvias.

Comentarios. Se puede distinguir de otras especies por las siguientes características: Larva: sedas 3-C ramificadas dicotómicamente con menos de 15 ramas, seda 1-P con cinco a ocho ramas laterales; seda 9-P con tres a cinco ramas, seda 6-IV-V generalmente doble o triple; Pupa: trompeta laticorne, con un surco meatal y uno secundario; pinna con un lóbulo caudal conspicuo, seda 1-P fuerte con tres o cuatro ramas distales, paleta pigmentada irregularmente; Hembra: palpo maxilar con escamas claras en las bases de los palpómeros 3, 4 y 5, ala con predominio de escamas oscuras, con manchas pequeñas de escamas claras en todas las venas; vena anal con cinco puntos claros; fleco del ala completamente negro; Macho, terminalia: lóbulo dorsal de la claspeta con tres sedas aplanadas, dos de éstas con el ápice curvo y expandido y la otra redondeada apicalmente, Edeago con solo un par de hojillas muy largas.

No se puede, diferenciar por características morfológicas de la larva y pupa, entre Anopheles vestitipennis y An. gabaldoni, por lo que su identificación sólo se puede realizar con ejemplares adultos.

Anopheles vestitipennis está ampliamente distribuida y parece ser abundante en las costas y en localidades por debajo de los $500 \mathrm{msnm}$. Su distribución potencial de esta especie se ubica en la planicie costera del sur del estado y en pequeñas zonas cercanas a la costa hacia el norte.

Esta especie se puede considerar de importancia médica en Veracruz por su distribución en el estado y debido a que se ha incriminado como vector de malaria humana en otras regiones. 


\section{Anopheles (Anopheles) walkeri Theobald 1901}

(Figs. 8, 10, 140-145)

Anopheles walkeri Theobald 1901: 199 (hembra). Localidad tipo: Lago Simcoe, Ontario, Canadá. Referencias adicionales.- Hurlbut 1938a: 149 (larva); Hurlbut 1938b: 521 (huevo); Rozeboom 1941: 107 (distribución); Ross \& Roberts 1943: 15 (hembra, macho, larva); Lassmann 1948: 9 (distribución en Veracruz); Darsie 1949: 520 (pupa); Penn 1949: 52 (pupa); Carpenter \& LaCasse 1955: 53 (macho, hembra, larva, bionomía); Horsfall 1955: 166 (distribución y bionomía); Vargas \& Martínez-Palacios 1956: 56 (claves pupa), 94 (hembra, macho, larva); Vargas 1959: 374 (claves macho); Belkin 1968: 11 (designación del lectotipo); Kitzmiller, Joslyn \& Kreutzer 1974: 22 (cromosomas).

Diagnosis. LARVA (Figs. 140-142). Cabeza: sedas 2-C largas, con cerdillas en la mitad distal, separadas entre sí por una distancia menor al diámetro de uno de los alvéolos que les da origen; sedas 3-C densamente ramificadas dicotómicamente, las ramificaciones comienzan cerca de la base de la seda. Antena: sedas 2-3-A puntiagudas. Tórax: seda 1-P con tres a cinco ramas; sedas 9-12-P sencillas. Abdomen: sedas 0-IV-V bien desarrolladas con tres a siete ramas; seda 1-III-VII palmeada con las ramas anchas, pigmentadas, con el borde aserrado en la mitad distal (Vargas \& Martínez-Palacios 1956). PUPA (Figs. 143-145). Trompeta: con un surco meatal profundo. Abdomen: sedas 1-II-V con cuatro a siete ramas, 1-VII con tres o cuatro ramas y 1-VII larga, bifurcada; seda 9-II pequeña, espiniforme y no pigmentada, sedas 9-II-VII sencillas, espiniformes y pigmentadas, 9- VIII ramificada desde la base con doce a dieciséis ramas laterales. Paletas natatorias: margen externo aserrado, parte apical con acículas finas; vena media estriada, sin llegar al margen; seda 1-P sencilla; seda 2-P muy pequeña, bifurcada o trifurcada (Darsie 1949, Penn 1949, Vargas \& Martínez-Palacios Op. cit.). HEMBRA (Fig. 8). Cabeza: palpo maxilar con escamas claras en las articulaciones de los palpómeros 2-3, 3-4, 4-5 y en el ápice del 5; escamas y sedas del espacio interocular de color blanco. Tórax: escudo con integumento marrón oscuro a negro, con sedas doradas cortas y otras más largas oscuras. Patas: Ápices de fémures y tibias con escamas blancas, fuertemente contrastantes con las escamas pardo oscuro de las patas. Ala: únicamente con escamas negras, con cuatro zonas más o menos distinguibles de escamas más oscuras. Abdomen: integumento marrón oscuro a negro, con numerosas sedas de color amarillento a marrón (Carpenter \& LaCasse 1955, Wilkerson et al. 1993). MACHO. Terminalia (Fig. 10): gonostilo ligeramente más largo que el gonocoxito; uña gonostilar corta y con la punta redondeada. Gonocoxito con sedas cortas y largas y pocas o ninguna escama. Dos espinas parabasales y una espina interna. Lóbulo dorsal de la claspeta con uno o dos espinas largas, redondeadas en el ápice o ligeramente capitadas. Lóbulo ventral de la claspeta con una espina apical larga y puntiaguda y una espina 

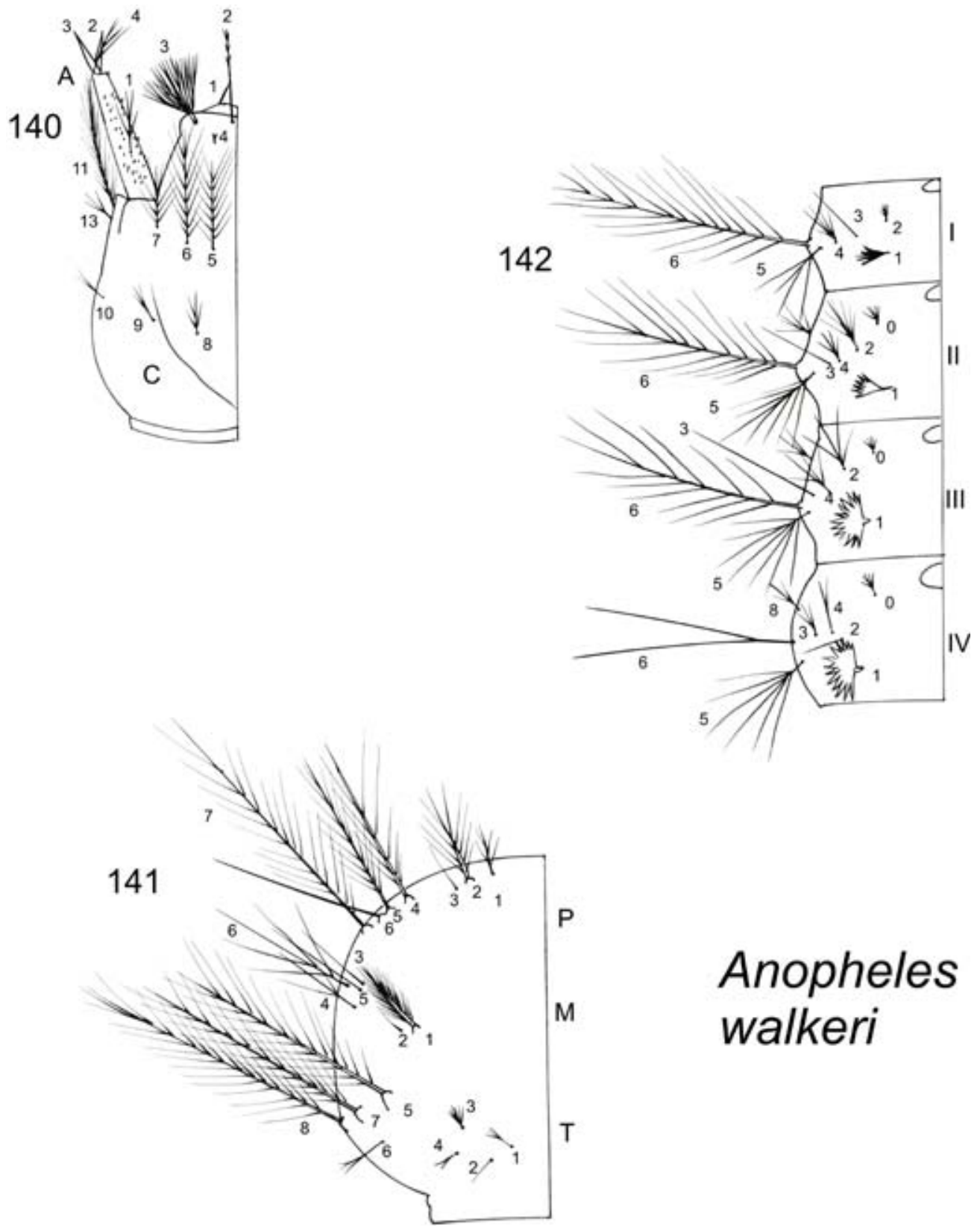

\section{Anopheles walkeri}

Figuras 140-142. Larva de Anopheles (Anopheles) walkeri (redibujada de Carpentery LaCasse, 1955). 140: Cabeza vista dorsal. 141: Tórax vista dorsal. 142: Segmentos abdominales I-IV vista dorsal. 

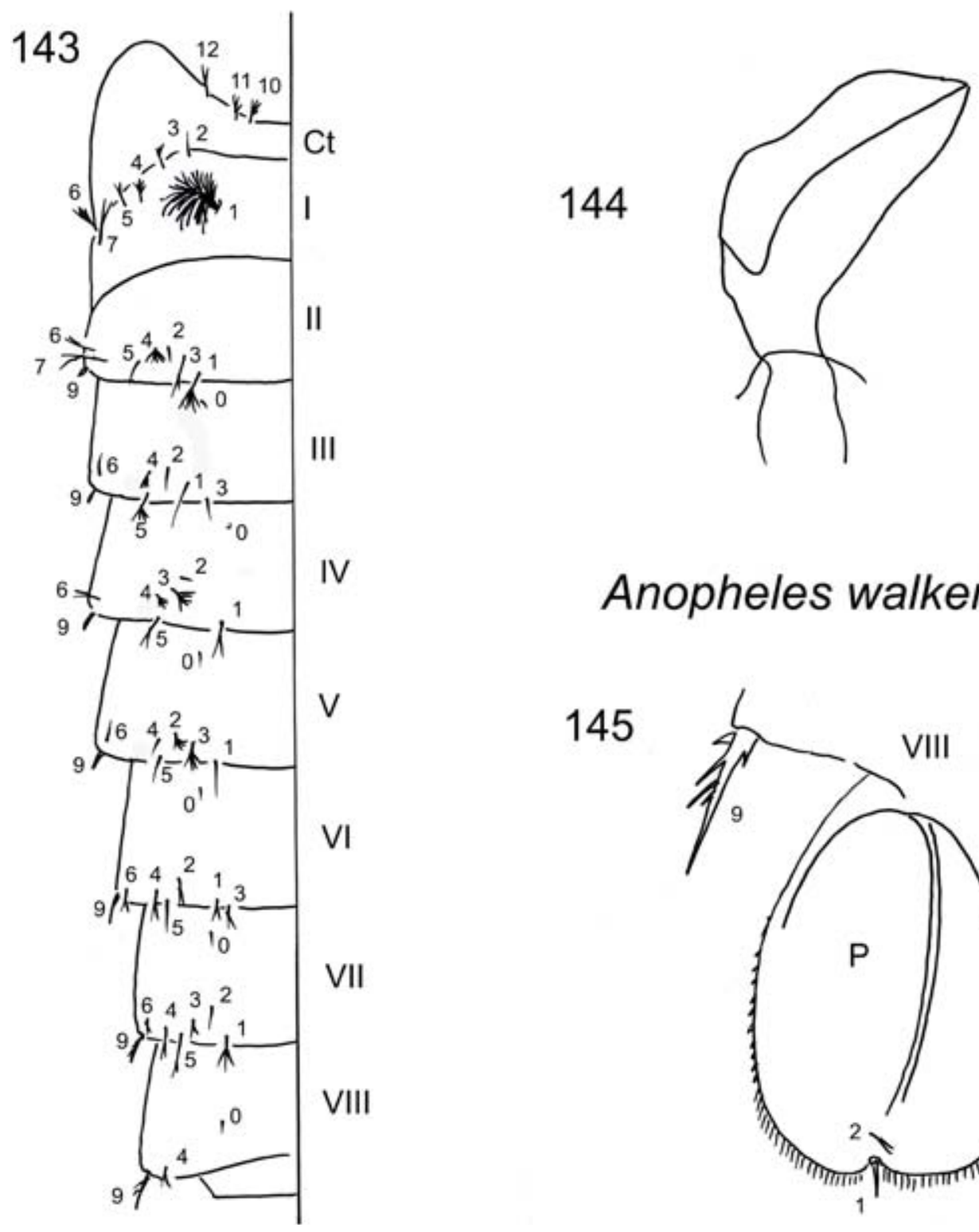

\section{Anopheles walkeri}

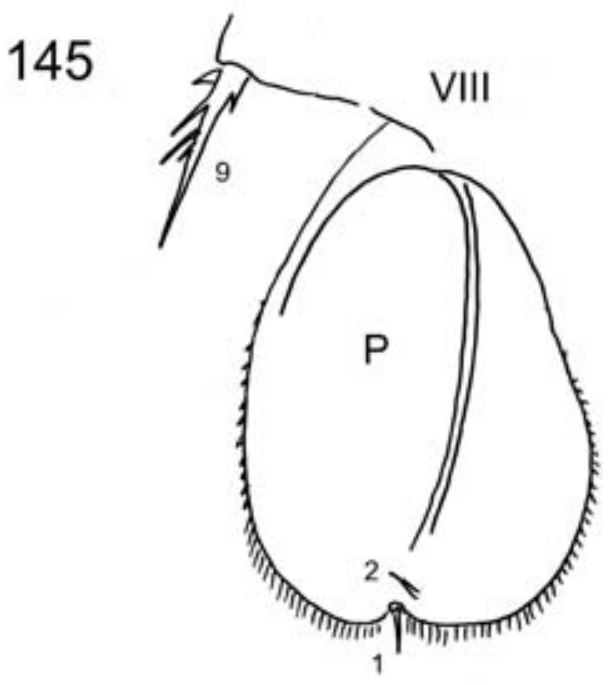

Figuras 143-145. Pupa de Anopheles (Anopheles) walkeri (redibujada de Penn, 1949). 143: Segmentos abdominales I-VIII vista dorsal. 144: Trompeta ventiladora. 145: Paleta natatoria izquierda vista dorsal. 
subapical larga y delgada. Edeago cilíndrico, ancho y bifurcado en la base, con tres a cinco pares de hojillas lanceoladas en el ápice. Noveno terguito moderadamente esclerotizado, lóbulos delgados, adelgazados hacia la punta. (Carpenter \& LaCasse Op. cit.).

Material examinado. No se encontró ningún ejemplar de esta especie dentro de las colecciones revisadas.

Distribución Conocida. Sur de Canadá, noreste de Estados Unidos, y México (Knight \& Stone 1977). En México fue colectado en Tuxpan y en Pánuco, Veracruz (Rozeboom 1941, Vargas \& Martínez-Palacios 1956).

Distribución en Veracruz. Mpo. Pánuco: Pánuco.

Datos bionómicos. Las larvas se desarrollan en agua dulce, en corrientes tranquilas, canales, pozos y lagos con vegetación flotante o emergente o con restos vegetales flotantes. Las hembras entran a las habitaciones a alimentarse y luego se retiran a sus lugares de descanso (Carpenter \& LaCasse Op. cit.).

Importancia médica. Es un vector potencial de malaria en los Estados Unidos (WRBU 2008).

Comentarios. Se puede distinguir de otras especies por las siguientes características: Larva: sedas 3-C densamente ramificadas dicotómicamente desde cerca de la base, sedas $0-\mathrm{IV}-\mathrm{V}$ bien desarrolladas con tres a siete ramas; Pupa: sedas 1-II-V con cuatro a siete ramas, 1-VII con tres o cuatro ramas y 1-VII larga, bifurcada; Hembra: palpo maxilar con escamas claras en las articulaciones de los palpómeros 2-3, 3-4, 4-5 y en el ápice del 5, ala únicamente con escamas negras, con cuatro zonas más o menos distinguibles de escamas más oscuras; Macho, terminalia: lóbulo dorsal de la claspeta con uno o dos espinas largas, redondeadas en el ápice o ligeramente capitadas, lóbulo ventral de la claspeta con una espina apical larga y puntiaguda y una espina subapical larga y delgada, edeago con tres a cinco pares de hojillas lanceoladas en el ápice.

La hembra presenta características similares a las de Anopheles quadrimaculatus, sin embargo es fácil diferenciarlas por el patrón de coloración del palpo maxilar, ya que en An. walkeri las articulaciones de los palpómeros 2-3, 3-4, 4-5 y el ápice del 5 tienen escamas claras.

Solo se tiene un registro de esta especie en Veracruz, tal vez debido a la falta de una colecta de anofelinos bien realizada, por lo tanto no se puede decir mucho de su distribución en el estado. 


\section{Subgénero Kerteszia Theobald 1905}

Diagnosis. LARVA. Cabeza: se caracteriza por presentar todas las sedas sencillas, con algunas ramas cortas apicales; en raras ocasiones las sedas 8-10-C con dos a tres ramas; seda 11-C con pocas ramas apicales cortas. Antena: seda 1-A sencillas; sedas 2-3-A puntiagudas. Tórax: sedas 1-P y 3-P no palmeadas; seda 9-P sencilla o con muy pocas ramas cortas; seda 3-T larga, con algunas ramas laterales. Abdomen: seda 0-II-VIII minúscula, sencilla; sedas 2-II-VI generalmente sencillas; seda 6-I-II y 7-I-II plumosa, con pocas ramas; seda 6-III-V larga, sencilla, poco a moderadamente ramificada (Zavortink 1973). PUPA. En general presenta las sedas poco a moderadamente desarrolladas, cortas y con pocas ramas. Trompeta: angusticorne, sin surco meatal; pinna corta, menor a la mitad de la longitud de la trompeta. Abdomen: sedas 1-II-VII y 5-III-VII poco desarrolladas, con una a cinco ramas; sedas 9-VI-VIII espiniformes, largas, ligeramente pigmentadas y con ramas muy cortas en el borde externo (excepto en Anopheles bambusicolus) (Zavortink Op. cit.). HEMBRA. Cabeza: palpo maxilar con predominancia de escamas negras, con parches de escamas claras en la superficie dorsal apical de algunos o todos los segmentos 2-5. Tórax: integumento del escudo con cuatro franjas longitudinales no pruinosas. Patas: fémur de la pata posterior sin escamas apicales sobresalientes; tarsómeros 3-5 de la pata posterior nunca completamente blancos. Ala: costa, radio y radial 1 con las manchas pálidas basal, humeral, del presector, del sector, subcostal y preapical presentes; fleco con predominancia de escamas oscuras y dos a cinco manchas claras. Abdomen: terguitos sin mechones de escamas posterolaterales, ni escamas erectas (Zavortink Op. cit.). MACHO. Terminalia: gonostilo largo y delgado, uña gonostilar corta y puntiaguda. Una espina parabasal fuerte, curva y con la punta redondeada que nace de un tubérculo. Dos espinas accesorias fuertes, aplanadas apicalmente que nacen a 0.6-0.7 de la base del gonocoxito. Una espina interna fuerte en los 0.4-0.5 basales. Lóbulo dorsal de la claspeta con dos grupos de 3-5 sedas muy largas, delgadas, sinuosas y aplanadas. Lóbulo ventral de la claspeta generalmente expandido lateral y distalmente con espículas en el margen. Edeago delgado, largo, casi recto, con o sin un par de hojillas subapicales (Zavortink Op. cit.).

\section{Anopheles (Kerteszia) neivai Howard, Dyar \& Knab 1912(1913)}

(Figs. 146-156)

Anopheles neivai Howard, Dyar \& Knab 1912-1917: 41(hembra, larva). Localidad tipo: Fuerte San Felipe, Bahía de Porto Bello, Panamá. Referencias adicionales.- Komp 1937: 502 (recuperado de la sinonimia con Anopheles cruzii), 509 (macho, hembra, larva), 521 (sinonimia); Senevet \& Abonnenc 1938: 509 (macho, pupa, larva); Rozeboom 1941: 107 (bionomía); Komp 1942: 77 (hembra), 129 (larva), 163 (macho); Levi-Castillo 1945: 118 (macho, hembra, larva); Lassmann 1948: 11 (distribución 

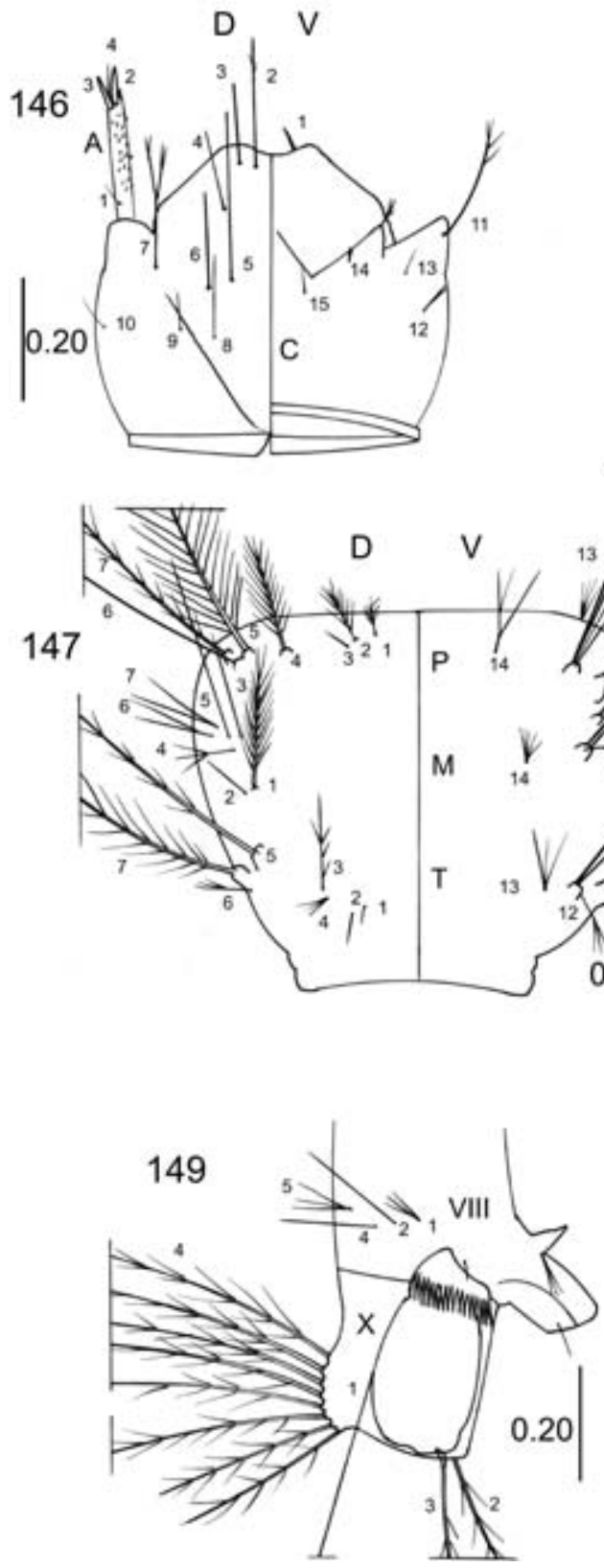

148

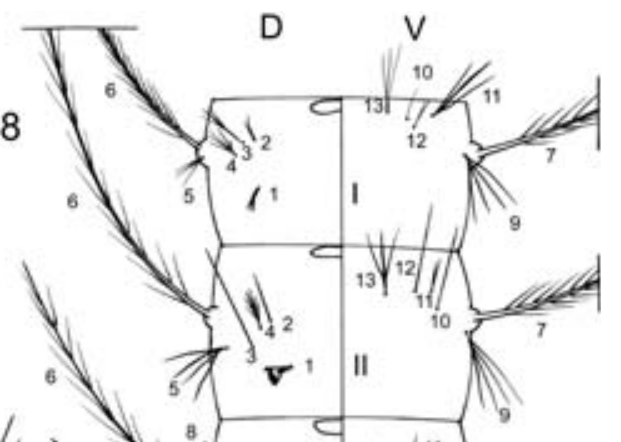



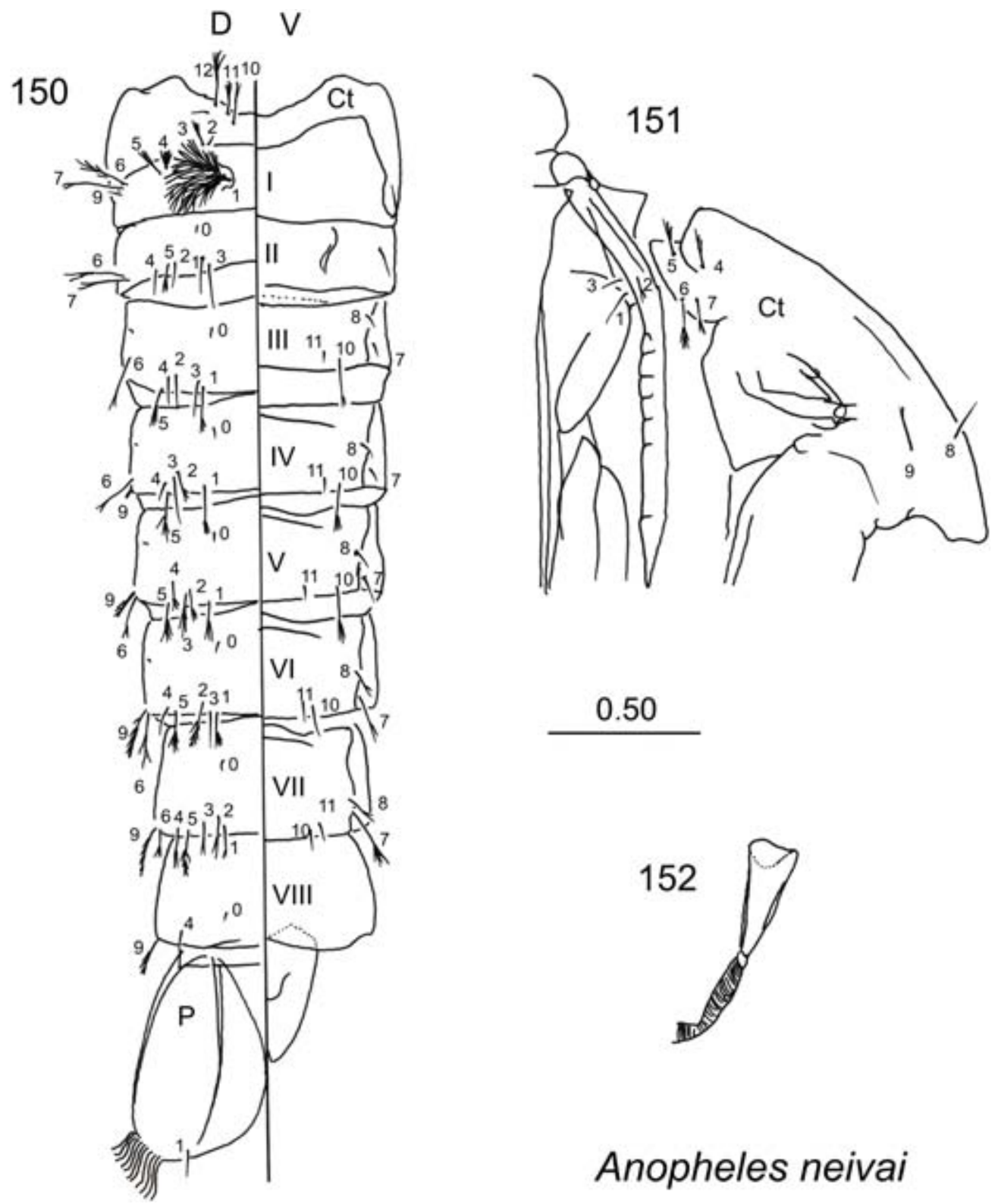

\section{Anopheles neivai}

Figuras 150-152. Pupa de Anopheles (Kerteszia) neivai (redibujada de Zavortink, 1973). 150: Abdomen. 151: Cefalotórax. 152: Trompeta ventiladora. 
en Veracruz); Floch \& Abonnenc 1951: 70 (macho, hembra, larva); Lane 1953: 283 (hembra, macho, larva); Stone \& Knight 1956: 279 (designación del lectotipo); Vargas \& Martínez-Palacios 1956: 52 (claves pupa), 132 (hembra, macho, larva); Vargas 1959: 376 (claves macho); Stojanovich et al. 1966: 4 (claves larva), 22 (claves hembra), 34 (bionomía); Gorham et al. 1973: 117 (hembra), 127 (larva), 146 (bionomía); Zavortink 1973: 11 (macho, hembra, pupa, larva y distribución); Baerg \& Boreham 1974: 629 (huevo); Zimmerman 1992: 376 (bionomía).

Anopheles hylephilus Dyar \& Knab 1912-1917: 38 (hembra). Localidad tipo: Gatún, zona del Canal de Panamá. Referencias adicionales.- Komp 1937: 521 (sinonimia); Belkin, Schick \& Heinemann 1965: 44 (designación del lectotipo).

Anopheles (Dendropaedium) neivai Dyar 1918: 146.

Anopheles (Nyssorhynchus) neivai Root 1922: 391.

Anopheles (Nyssorhynchus) bellator var. neivai Christophers 1924: 42.

Anopheles (Dendropaedium) cruzii raza neivai Dyar 1925: 26-27.

Anopheles (Dendropaedium) hylephilus Dyar 1918: 146.

Anopheles (Nyssorhynchus) bellator var. hylephilus Christophers 1924: 42; Edwards 1932: 46.

Anopheles (Anopheles) bellator Bonne \& Bonne-Wepster 1925: 504.

Diagnosis. LARVA (Figs. 146-149). Cabeza: se caracteriza por presentar todas las sedas sencillas o sólo con pocas ramas distales. Antena: sedas 2-3-A puntiagudas. Tórax: seda 11-P bien desarrollada, larga. Abdomen: sedas 1-II-VII palmeadas, con las ramas cortas y delgadas, truncas (Vargas \& Martínez-Palacios 1956, Zavortink 1973). PUPA (Figs. 150-152). Trompeta: angusticorne (parecida a la de culicinos), con un surco meatal poco profundo. Abdomen: seda 9-IV corta y delgada, con la punta redondeada, o moderadamente larga con forma de espina; sedas 9-V-VII espiniformes y ramificadas Paleta natatoria: más o menos truncada oblicuamente, margen externo con espículas que se extienden desde la parte final del refuerzo; parte distal del margen externo con acículas filamentosas largas (Zavortink 1973). HEMBRA (Figs. 153-155). Cabeza: palpo maxilar con predominancia de escamas oscuras, ápice del palpómero 4 y a veces del palpómero 5 con una mancha de escamas claras. Tórax: integumento del escudo pruinoso con cuatro franjas no pruinosas; mesepimerón con un mechón pequeño de escamas. Patas: fémur de la pata posterior con una línea de escamas negras a lo largo de la superficie ventral; tarsómeros de la pata posterior con bandas claras apicales. Ala: manchas pálidas del presector, del sector y subcostal presentes; vena radial $4+5$ sin escamas claras o restringidas a una macha basal pequeña; cúbito generalmente con una mancha pálida sub-basal; vena anal negra totalmente. Abdomen: terguitos y esternitos sin escamas evidentes (Wilkerson et al. 1993, Zavortink Op. cit.). MACHO. Terminalia (Fig. 156): gonostilo largo y ensanchado basalmente; uña gonostilar puntiaguda. Gonocoxito con sedas y numerosas escamas. Una 
espina parabasal fuerte, curva y con la punta redondeada que nace de un tubérculo. Dos espinas accesorias fuertes, aplanadas apicalmente que nacen a 0.6-0.7 de la base del gonocoxito. Una espina interna fuerte, aplanada, ensanchada apicalmente. Lóbulo dorsal de la claspeta con dos grupos de 3-5 sedas muy largas, delgadas, sinuosas y aplanadas. Lóbulo ventral de la claspeta generalmente expandido lateral y distalmente con espículas en toda su superficie. Edeago con el ápice estrecho, sin hojillas. Noveno terguito sin lóbulos (Vargas \& Martínez-Palacios 1956, Zavortink Op. cit.).

Material examinado. 6 ejemplares. México: Chiapas, Mpo. Comitán, Independencia, 14-11-1952 (1 H, CAIM CulH/alf-01987), Santa Rosa, 14-10-1952 (2 H, CAIM CulH/alf-01986 y CAIM CulH/alf-01987); Mpo. Palenque, El Naranjo, 25-03-1958 (3 L, CAIM CulH/lam-01669, CAIM CulH/lam-01666 y CAIM CulH/lam-01663).

Distribución conocida. Desde el sureste del México, hasta Ecuador y la Guyana Francesa, también se ha reportado su presencia en Bolivia, norte de Brasil y Perú (Zavortink 1973). En México se ha reportado en los estados de Chiapas y Veracruz (Vargas \& Martínez-Palacios Op. cit.).

Distribución en Veracruz. Mpo. Córdoba: Córdoba.

Datos bionómicos. La larva y pupa generalmente se crían en el agua acumulada en las axilas de las hojas de las bromelias epífitas y terrestres, raramente en las axilas de las hojas de las aráceas y en huecos de los árboles (Rozeboom 194, Zavortink 1973). Los adultos hembra comúnmente pican al hombre, particularmente en la tarde y en las primeras horas de la noche (Zavortink Op. cit.).

Importancia médica. Es vector primario de la malaria humana en la costa sur de Colombia. Se ha encontrado infectado con la Encefalitis equina venezolana, con los virus Ilehus y Guroa en Panamá (Zavortink 1973).

Comentarios. Se distingue de otras especies por las siguientes características: Larva: cabeza con todas las sedas sencillas o con pocas ramas distales. Pupa: sedas 9-V-VII espiniformes y ramificadas. Hembra: integumento del escudo con cuatro franjas no pruinosas y tarsómeros de la pata posterior con bandas claras apicales. Terminalia macho: uña gonostilar puntiaguda, dos espinas accesorias, Edeago angosto, sin hojillas, lóbulo dorsal de la claspeta con 3 a cinco sedas largas, sinuosas y aplanadas, lóbulo ventral de la claspeta expandido lateralmente, no fusionado.

Esta especie, y en general el subgénero Kerteszia, tiene algunas similitudes con el subgénero Nyssorhynchus e incluso se ha llegado a clasificar dentro de este último, sin embargo Peyton y colaboradores encontraron en 1992 suficientes diferencias en 

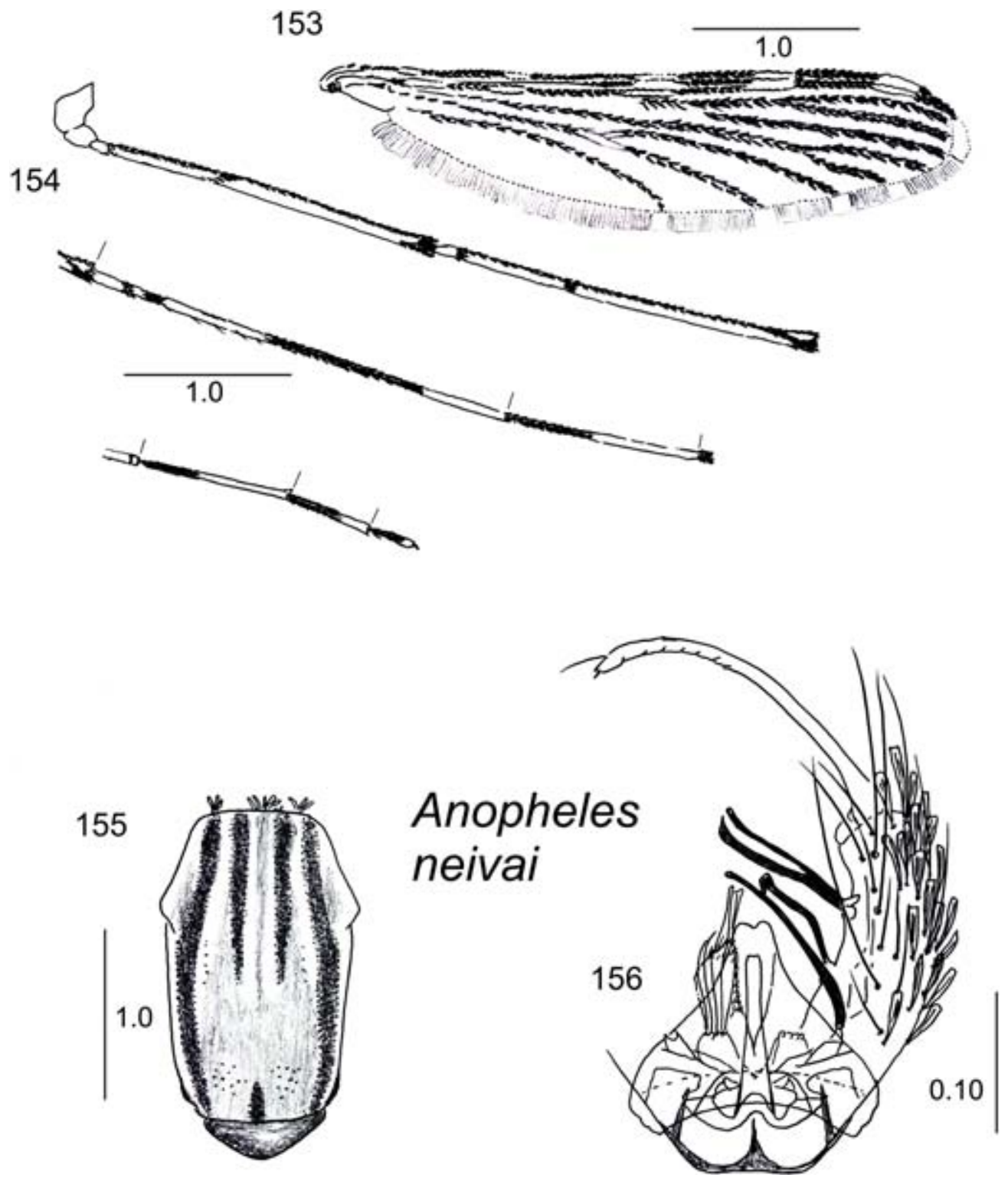

Figuras 153-156. Adultos de Anopheles (Kerteszia) neivai. Hembra. 153: Ala. 154: Pata posterior. 155: Escudo y escudete. Macho. 156: Terminalia(redibujados de Zavortink, 1973). 

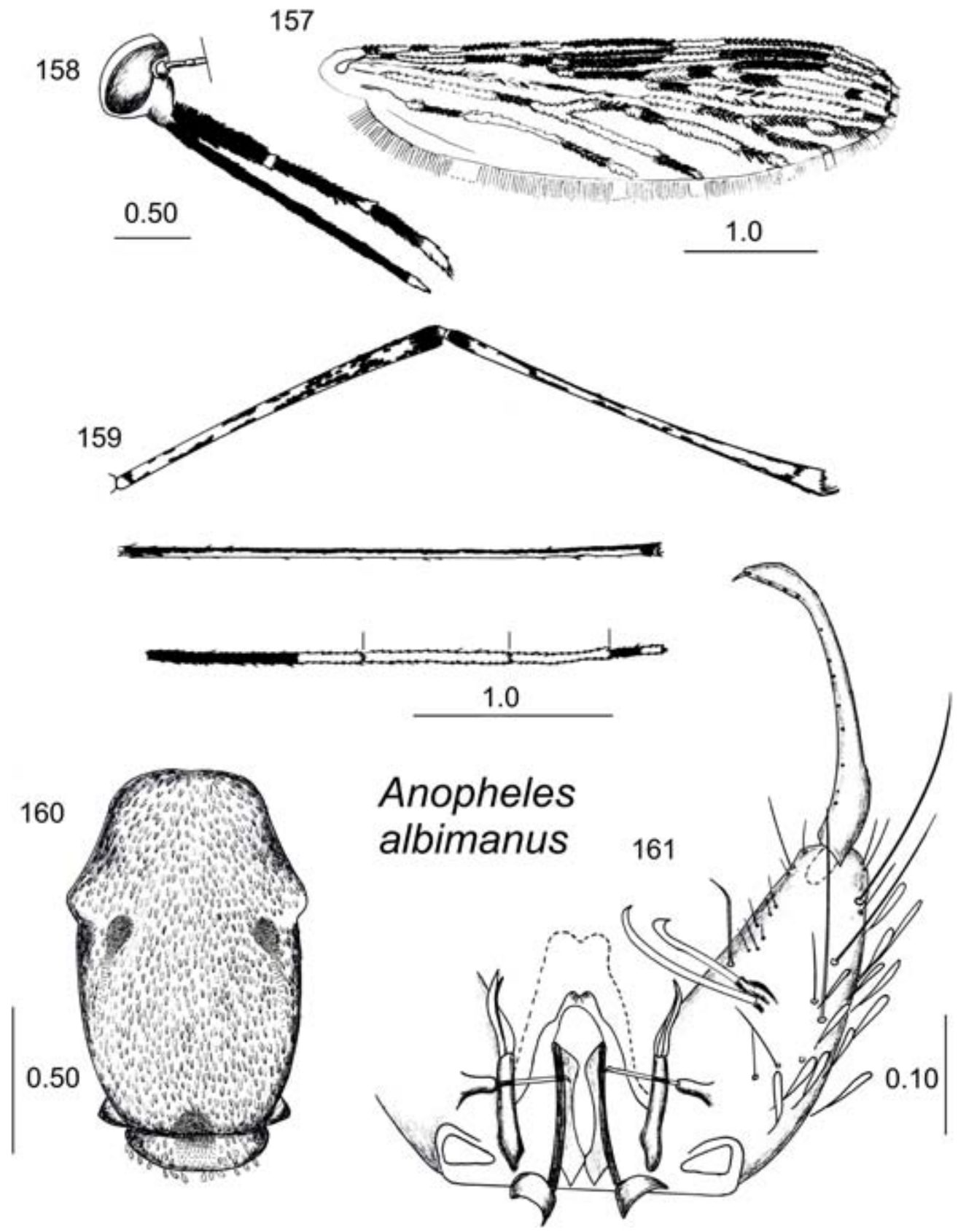

Figuras 157-161. Adultos de Anopheles (Nyssorhynchus) albimanus. Hembra. 157: Ala. 158: Palpo maxilar. 159: Pata posterior. 160: Escudo y escudete. Macho. 161: Terminalia. 
la morfología de Kerteszia para considerarse un subgénero, y si se toma en cuenta que en México sólo se ha informado una especie (Anopheles neivai), no se tienen problemas para su determinación.

Se considera una especie muy poco abundante en Veracruz, ya que sólo se ha informado en una localidad en Córdoba, donde se encuentra una parte de bosque mesófilo de montaña, lo que es lógico si se sabe que la larva de esta especie se cría en las platas epífitas como las bromelias. Esta situación podría indicar que las colectas en este tipo de hábitats no se llevaron a cabo de manera correcta.

Su condición como vector de malaria en Veracruz hasta el momento es desconocida, no obstante, el que sea un vector comprobado en otras regiones implica que debe mantenerse bajo vigilancia ante nuevos registros de esta especie en el estado.

\section{Subgénero Nyssorhynchus Blanchard, 1902}

Diagnosis. LARVA. Cabeza: sedas 5-7-C plumosas; seda 11-C ramificada desde cerca de la base. Antena: sedas 2-3-A puntiagudas. Tórax: seda 9-P sencilla (ramificada únicamente en Anopheles albimanus); seda 3-T palmeada. Abdomen: seda 1-III-VII palmeada, bien desarrollada con las ramas delgadas y de bordes lisos; seda 6-I-II y 7-I-II plumosa, con muchas ramas (Faran 1980, Linthicum 1988, Peyton et al. 1992). PUPA. Trompeta: angusticorne, con un surco meatal profundo; pinna larga, mayor a la mitad de la longitud de la trompeta. Abdomen: sedas1-II-III con varias ramas; sedas 1-IV-VII largas, de longitud mayor a la del segmento; sedas 5-V-VII largas, de al menos 0.7 veces la longitud del segmento, generalmente más largas (Faran 1980, Linthicum 1988, Peyton et al. 1992). HEMBRA. Patas: pata posterior con los tarsómeros 3 y 4 completamente claros. Ala: costa generalmente con las manchas pálidas basal, prehumeral, humeral, del sector, accesoria del sector, subcostal, preapical y apical presentes. Abdomen: al menos algunos de los terguitos II-VIII con mechones de escamas caudolaterales (excepto el grupo Myzorhynchella) (Faran Op. cit., Linthicum Op. cit; Peyton et al. Op. cit.). MACHO. Terminalia: gonostilo delgado, uña gonostilar delgada y puntiaguda. Dos espinas accesorias curvadas que nacen a $0.4 \mathrm{de}$ la base del gonocoxito, una espina parabasal que nace en un tubérculo, una espina interna más delgada que las accesorias. Lóbulos dorsales de la claspeta con un grupo de dos a tres sedas aplanadas apicalmente cada uno .Lóbulos ventrales de la claspeta con el ápice fusionado, formando una sola estructura. Edeago ancho, con o sin hojillas (Faran Op. cit., Linthicum Op. cit., Peyton et al. Op. cit.).

\section{Anopheles (Nysorrhynchus) albimanus Wiedemann 1820}

(Figs. 1-7, 157-161, 162)

Anopheles albimanus Wiedemann 1820: 10 (hembra). Localidad tipo: Ins. De Santo Domingo, República Dominicana. Referencias adicionales.- Gerry 1932: 36 (hem- 
bra); Rozeboom 1938: 99 (huevo); Cova-García 1939: 18 (larva), 25 (hembra); Rozeboom 1941: 99 (distribución y bionomía); Komp 1942: 67 (hembra), 115 (larva), 154 (macho); Rozeboom \& Gabaldón 1941: 95 (taxonomía); Galvao 1943: 146 (macho); Ross \& Roberts 1943: 35 (macho, hembra, larva); Levi-Castillo 1945: 92 (huevo, larva, pupa, hembra, macho); Lassmann 1948: 10 (distribución en Veracruz); Vargas 1948: 153 (macho), 157 (hembra); Penn 1949: 68 (pupa); Belkin 1952: 122 (larva); Lane 1953: 270 (hembra, macho, pupa, larva, huevo); Carpenter \& LaCasse 1955: 55 (macho, hembra, larva, bionomía); Horsfall 1955: 172 (distribución y bionomía); Vargas \& Martínez-Palacios 1956: 55 (claves pupa), 119 (hembra, macho, larva); Vargas 1959: 376 (claves macho); Belkin et al. 1970: 24 (macho, hembra, pupa, larva); Gorham et al. 1973: 110 (hembra), 136 (larva), 140 (bionomía); Heinemman \& Belkin 1977: 490, 495, 513, 521 (distribución); Faran 1980: 35 (hembra, macho, pupa, larva); Zimmerman 1992: 376 (bionomía).

Anopheles cubensis Agramonte 1900: 460 (macho, hembra). Localidad tipo: varias localidades en Cuba. Referencias adicionales.- Theobald 1907: 106 (sinonimia).

Anopheles argyrotarsis albipes Theobald 1901: 125 (macho, hembra). Localidad tipo: Jamaica. Referencias adicionales: Belkin 1968: 8 (diseño del lectotipo).

Cellia tarsimaculata Goeldi 1905: 133 (nom. nov. para A. albipes). Referencias adicionales.- Rozeboom \& Gabaldón 1941:96 (sinonimia).

Anopheles gorgasi Dyar y Knab 1907: 198 (hembra). Localidad tipo: La Boca, zona del Canal de Panamá. Referencias adicionales.- Rozeboom \& Gabaldón 1941: 96 (sinonimia); Faran 1980: 14 (nomen dubium).

Anopheles (Nys.) albimanus bisignatus Hoffmann 1938: 176. Localidad tipo: Varias localidades de Tamaulipas, México. Referencias adicionales.- Ross \& Roberts 1943: 36 (sinonimia).

Anopheles (Nys.) albimanus trisignatus Hoffmann 1938: 177. Localidad tipo: Tampico, Tamaulipas, México. Referencias adicionales.- Ross \& Roberts 1943: 36 (sinonimia).

Diagnosis. LARVA (Figs. 1-4). Cabeza: sedas 2-C con ocho a diez cerdillas; sedas 3-C plumosa con ocho a doce ramas cortas o moderadamente largas. Antena: sedas 23-A puntiagudas. Tórax: seda 1-P larga, con el eje plano expandido y con veintiuna a veinticuatro ramas laterales; seda 9-P pectinada, con cuatro a seis ramas largas; sedas 10, 12-P sencillas y largas; seda 11-P bifurcada o trifurcada. Abdomen: sedas 0-IIVI con dos a cuatro ramas; seda 1-I palmeada, con doce a catorce ramas lanceoladas semi-pigmentadas; sedas 1-II-VII palmeadas con ramas anchas muy pigmentadas con los bordes lisos (Faran 1980). PUPA (Figuras 5-7). Trompeta: angusticorne, poco pigmentada; con un surco meatal profundo; pinna de 3.3-4.0 la longitud del meato. Abdomen: Seda 0-I-VII generalmente con al menos dos ramas; seda 9-II-III muy corta; 9-IV redondeada apicalmente, de aproximadamente 2.0 la longitud de 9-III y 0.33 


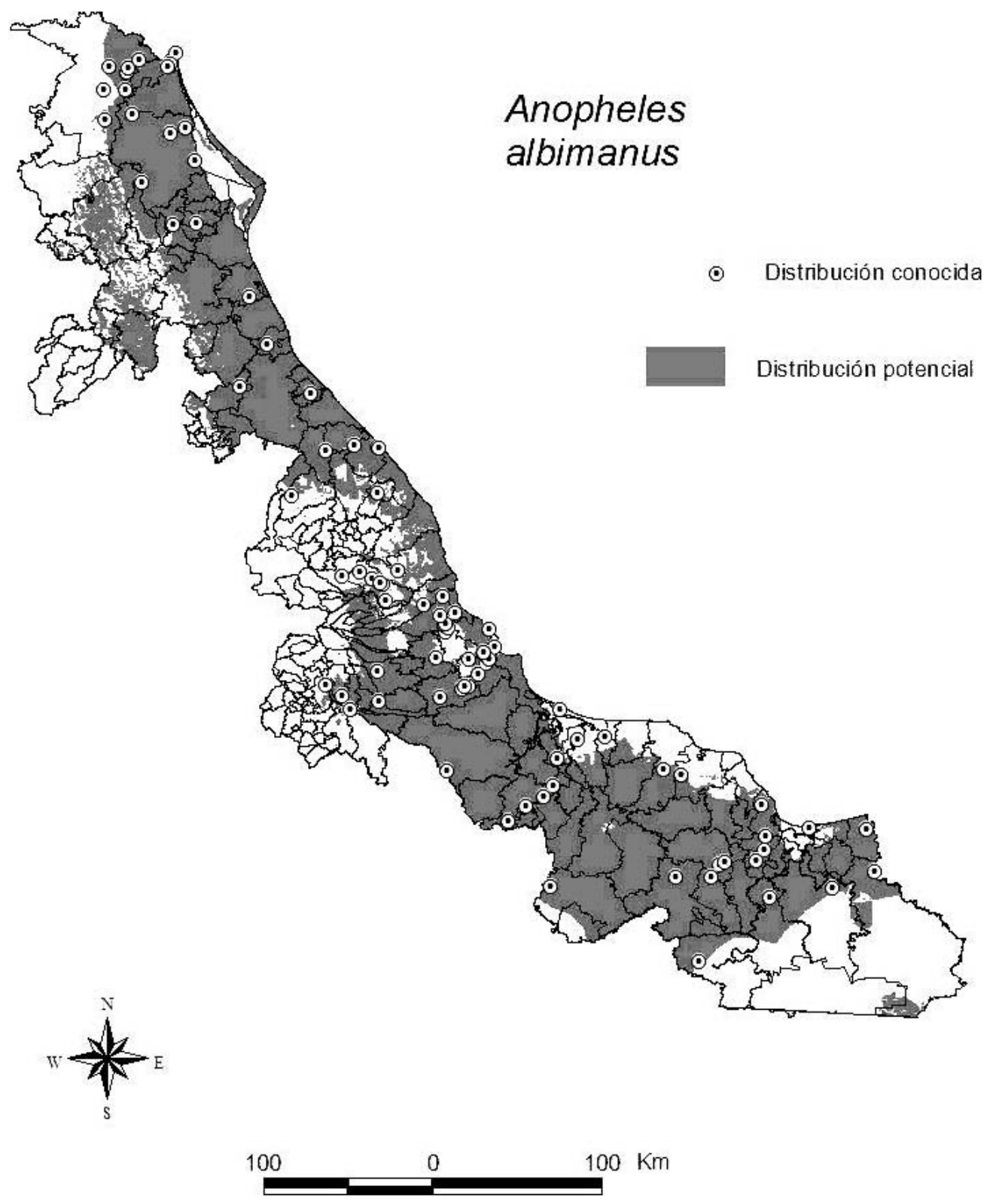

Figura 162. Mapa de la distribución conocida y potencial de Anopheles(Nyssorhynchus) albimanus. 

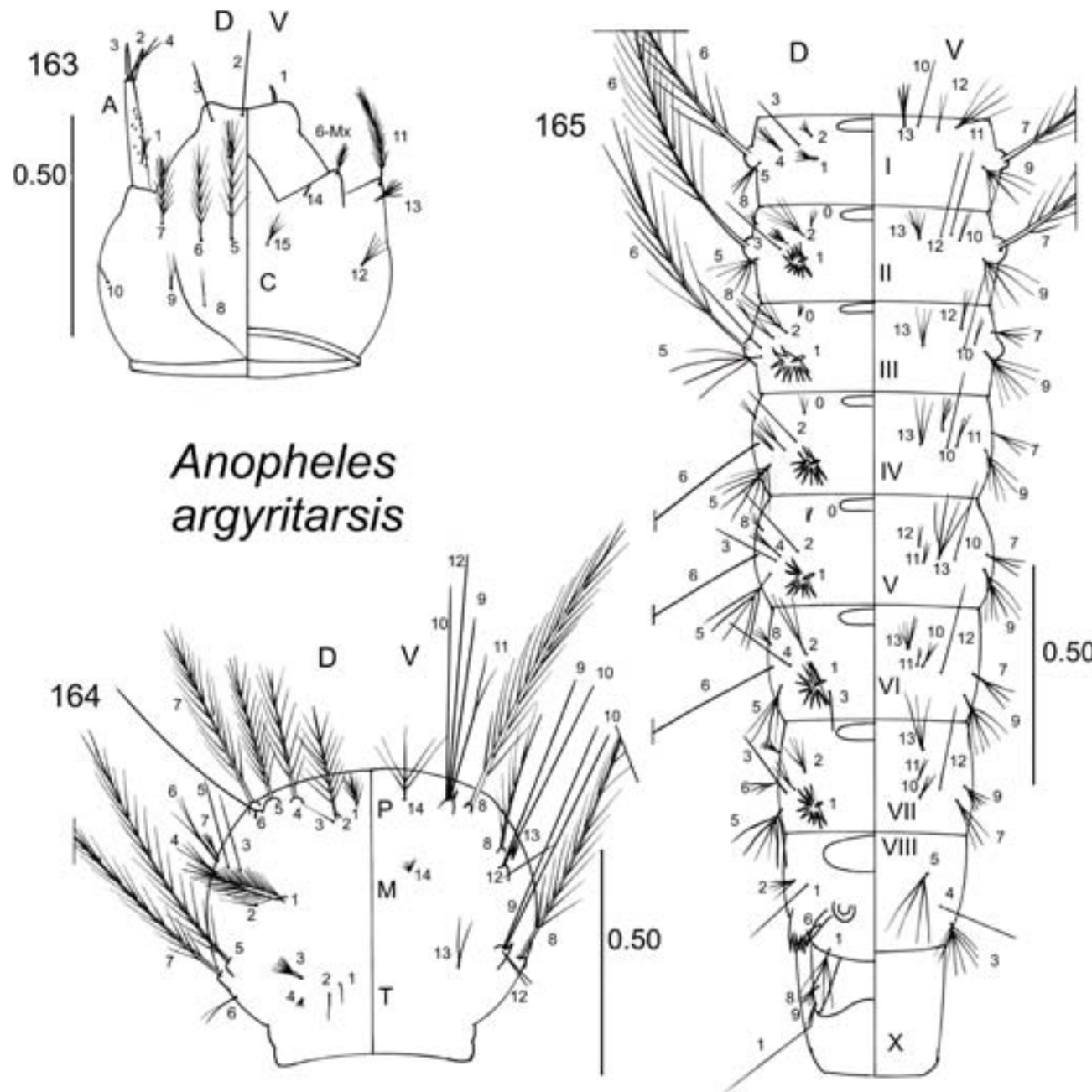

Figuras 163-165. Larva de Anopheles (Nyssorhynchus) argyritarsis. 163: Cabeza. 164: Tórax. 165: Abdomen.

la longitud de 9-V; sedas 9-V-VIII largas, sencillas y atenuadas hacia el ápice; 1-IVVII largas y sencillas. Paletas natatorias: pigmentadas uniformemente, excepto por el soporte del margen externo y la vena media; márgenes externo e interno con espículas filamentosas débiles y ampliamente separadas; seda 1-P sencilla, fuerte; 2-P muy delgada, sencilla o bifurcada, de la misma longitud que 1-P (Faran 1980, Belkin et al. 1970). HEMBRA (Figs. 157-160). Cabeza: palpo maxilar con predominancia de escamas negras, palpómero 4 totalmente negro o con algunas escamas color amarillo 
a pardo dorado (nunca blancas) en la superficie medio-lateral, palpómero 5 sólo con escamas claras. Tórax: escudo con tres áreas de pruinosidad color plateado a rojizo, dos en posición anterolateral con respecto a las bases de las alas, que se difuminan en dirección al escudete, y una tercera en el área prescutelar; el resto del escudete con escamas delgadas. Patas: tarsómero 5 de la pata anterior negro en su totalidad; tarsómeros 3 y 4 de la pata posterior completamente blancos, tarsómero 5 de la pata posterior con una banda oscura basal, y el resto del artejo blanco. Abdomen: segmentos III-VII con mechones posterolaterales de escamas oscuras (Faran Op. cit., Wilkerson et al. 1993). MACHO. Terminalia (Fig. 161): margen ventro-mesal del gonostilo con una línea de espículas; uña gonostilar delgada y puntiaguda. Gonocoxito con escamas laterales. Dos espinas accesorias largas con el ápice curvado. Una espina interna del mismo largo que la espina accesoria más corta y atenuada apicalmente. Una espina parabasal que nace en un tubérculo. Lóbulo dorsal de la claspeta aproximadamente de 0.5 la longitud del gonocoxito, con hojillas anchas, lanceoladas. Lóbulo ventral de la claspeta de aproximadamente 0.32-0.40 la longitud del gonocoxito, sin sedas, con el ápice fusionado en dos lóbulos redondeados con forma más o menos cilíndrica, estriados, separados por un surco poco profundo, sin sedas evidentes, con dos estructuras ovoides en la parte basal, edeago largo, moderadamente delgado, con el ápice redondeado, ligeramente más ancho que largo, con un borde membranoso distintivo, sin hojillas, noveno terguito no esclerotizado, sin lóbulos laterales (Belkin et al. Op. cit., Faran Op. cit.).

Material examinado. 38 ejemplares. México, Veracruz, Mpo. Actopan, P. Villa Rica, 14-02-2008 (1 H); Mpo. Boca del Río, Boca del Río, sin fecha (9 L, CAIM CulH/lam-01865, CAIM CulH/lam-01875, CAIM CulH/lam-01876, CAIM CulH/ lam-01878, (2) CAIM CulH/lam-01890, CAIM CulH/lam-01887, CAIM CulH/lam01884 y CAIM CulH/lam-01881); Mpo. Chinameca, Chinameca, 01-09-1941 (2 L, CAIM CulH/lam-01891 y CAIM CulH/lam-01892); Mpo. Martínez de la Torre, Guadalupe, 15-10-1956 (2 L, CAIM CulH/lam-01888 y CAIM CulH/lam-01889), La Unión Paso Largo, 15-10-1956 (1 L, CAIM CulH/lam-01867); Mpo. San Andrés Tuxtla, San Andrés Tuxtla, 01-09-1941 (4 L, CAIM CulH/lam-01866, CAIM CulH/ lam-01874, CAIM CulH/lam-01877 y CAIM CulH/lam-01885); Mpo. Tlacotalpan, Tlacotalpan, 17-11-1956 (2 L, CAIM CulH/lam-01868 y CAIM CulH/lam-01869); Mpo. Tuxpam, Tuxpam de Rodríguez, 01-02-1942 (5 L, CAIM CulH/lam-01872, CAIM CulH/lam-01873, CAIM CulH/lam-01879, CAIM CulH/lam-01883 y CAIM CulH/lam-01886); Mpo. Vega de Alatorre, E. Carranza, 19-02-2008 (1 H); Mpo. Veracruz, Veracruz, 01-03-1942 (4 L, CAIM CulH/lam-01880, CAIM CulH/lam01882, CAIM CulH/lam-01893); Mpo. Indeterminado, Paso Real, 25-06-1956 (3 L, CAIM CulH/lam-01871, CAIM CulH/lam-01870 y CAIM CulH/lam-01894); Chiapas, Tapachula, Tapachula, sin fecha (1 MT, CAIM CulH/lam-05580); Tamaulipas, 
Mpo. Tampico, Tampico, 04-1949 (3 P, CAIM CulH/lam-05620, CAIM CulH/lam05619 y CAIM CulH/lam-05616).

Distribución conocida. Es una especie predominantemente tropical, de tierras bajas, siendo muy abundante en las planicies costeras. Se encuentra desde el sureste de Estados Unidos y se extiende a lo largo de México y Centroamérica, por la costa del Caribe de Colombia, hasta la Península de Paria en Venezuela. En el lado del Pacífico se extiende desde Baja California Sur, México, hasta el norte de Perú (Faran 1980). En México se ha reportando en los estados de Campeche, Chiapas, Colima, Guerrero, Michoacán, Nayarit, Nuevo León, Oaxaca, Quintana Roo, San Luis Potosí, Sinaloa, Tabasco, Tamaulipas, Veracruz y Yucatán (Vargas \& Martínez-Palacios 1956).

Distribución en Veracruz (Fig. 162). Mpo. Acayucan: Acayucan; Mpo. Acula: Acula; Mpo. Actopan: Actopan; Mpo. Alvarado: Alvarado; Mpo. Amatlán de los Reyes: Amatlán de los Reyes; Mpo. Amatlán de Tuxpan: Naranjos; Mpo. Ángel R. Cabada: El Mesón; Mpo. La Antigua: Villa Cardel, Pureza; Mpo. Apazapan: Chahuapa; Mpo. Atzalan: Cuazapotitlán; Mpo. Boca del Río: Boca del Río, Primero de Mayo; Mpo. Catemaco: Catemaco; Mpo. Cazones: Cazones; Mpo. Coatepec: Pacho Viejo; Mpo. Coatzacoalcos: Agua Dulce, Coatzacoalcos; Mpo. Coatzintla: Coatzintla, Poza Rica de Hidalgo; Mpo. Colipa: Colipa; Mpo. Cosamaloapan: Cosamaloapan, Paraíso Novillero, El Tinaco, Vista Hermosa; Mpo. Cotaxtla: Higueras, La Capilla, La Colonia, Cotaxtla, Mata del Caballo, Mecayucan; Mpo. Cuichapa: Cuichapa; Mpo. Cuitláhuac: Cuitláhuac; Mpo. Chacaltianguis: Chacaltianguis; Mpo. Chapopotla: Nanchital; Mpo. Chinameca: Chinameca; Mpo. Contla: Magosal; Mpo. Emiliano Zapata: Cerro Gordo, Corral Falso, Mata de Caña, Venta del Encero; Mpo. Fortín: Fortín; Mpo. Gutiérrez Zamora: Gutiérrez Zamora; Mpo. Hidalgotitlán: Hidalgotitlán; Mpo. Jáltipan: Jáltipan de Morelos; Mpo. Jamapa: Jamapa; Mpo. Jesús Carranza: Jesús Carranza; Mpo. Las Choapas: Las Choapas; Mpo. Lerdo de Tejada: Lerdo de Tejada; Mpo. Manlio Fabio Altamirano: Paso Real, Martínez de la Torre, Paso Largo, San Rafael; Mpo. Martínez de la Torre: La Unión Paso Largo; Mpo. Medellín: Juan de Alfaro, El Mangal, Medellín, Paso del Toro, El Tejar; Mpo. Minatitlán: Las Choapas, Francita; Mpo Nautla: Barra de Palmas, Jicaltepec, El Raudal; Mpo. Otatitlán: Otatitlán; Mpo. Ozulama: Chijol Corona, Horconcitos, La Laja, La Mina; Mpo. Pajapan: Coscapa, Pajapan; Mpo. Pánuco: Campo Caracol, Dos Calentadores, Dos Huastecas, Col. Centro de Higuerón, Pánuco, Tamós, Topila; Mpo. Paso de Ovejas: Plan del Manantial, Puente de Jula, Tierra Colorada, Tolomé; Mpo. Paso del Macho: Paso del Macho; Mpo. Playa Vicente: Playa Vicente; Mpo. Pueblo Viejo: Bella Vista, Ciudad Cuauhtémoc, Mata Redonda, Villa Cuauhtémoc; Mpo. Puente Nacional: Puente Nacional; Mpo. San Andrés Tuxtla: San Andrés Tuxtla; Mpo. San Juan Evangelista: Juan Rodríguez Clara, Juanita, San Juan Evangelista; Mpo. Sayula: Sayula; Mpo. 

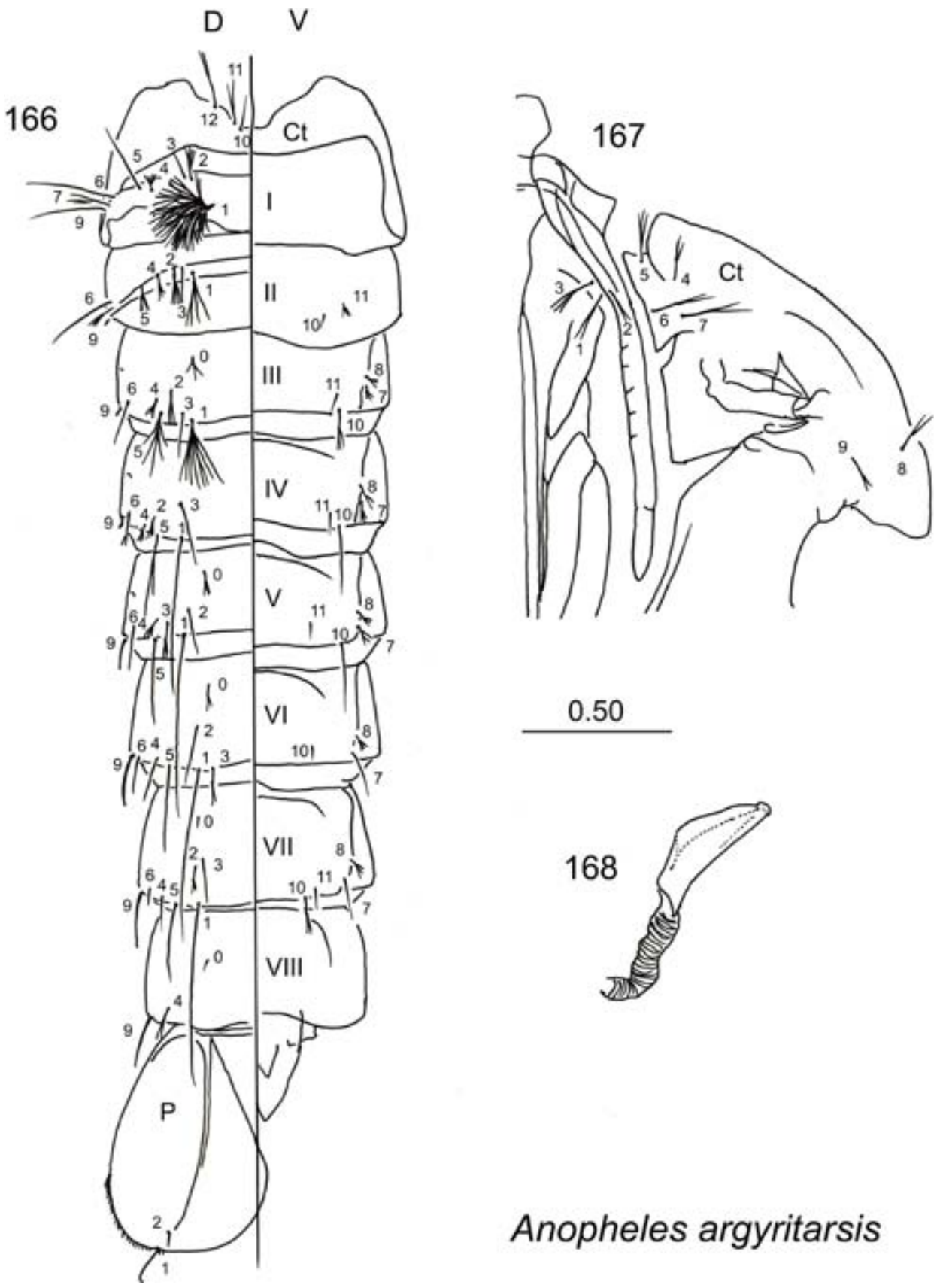

\section{Anopheles argyritarsis}

Figuras 166-168. Pupa de Anopheles (Nyssorhynchus) argyritarsis (redibujada de Linthicum, 1988). 166: Abdomen. 167: Cefalotórax. 168: Trompeta ventiladora. 

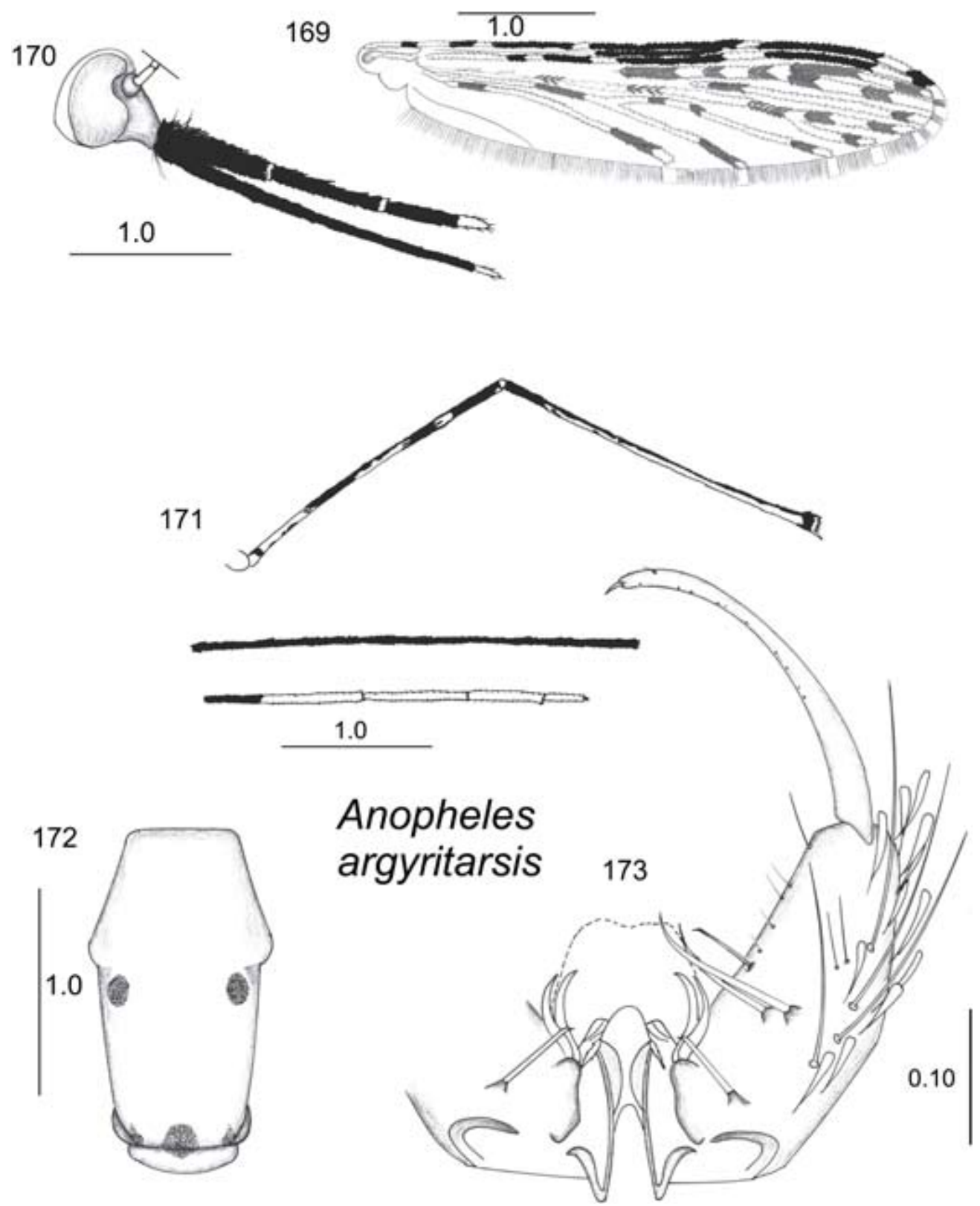

Figuras 169-173. Adultos de Anopheles (Nyssorhynchus) argyritarsis. Hembra. 169: Ala. 170: Palpo maxilar. 171: Pata posterior. 172: Escudo y escudete. Macho. 173: Terminalia. 
Soconusco: Soconusco; Mpo. Soledad de Doblado: Soledad de Doblado; Mpo. Tamalín: Tamalín; Mpo. Tlacotalpan: Tlacotalpan; Mpo. Tierra Blanca: Tierra Blanca; Mpo. Tuxpan: Tuxpan de Rodríguez Cano; Mpo. Veracruz: Veracruz. Mpo. Indeterminado: El Raudal; Mpo. Indeterminado: Ingenio Novillero; Mpo. Indeterminado: Jicaltepec; Mpo. Indeterminado: Santa Cruz; Mpo. Indeterminado: Paso Real; Mpo. Indeterminado: Guadalupe; Mpo. Indeterminado: Anáhuac.

Datos bionómicos. La larva se desarrolla en una gran variedad de hábitats acuáticos, tanto de agua dulce como salobre. Requiere gran cantidad de luz solar por lo que es difícil encontrarla en aguas con mucha sombra. Los sitios de cría se caracterizan por abundante vegetación con desechos y algas, y regularmente son turbios con un fondo fangoso. Los inmaduros se colectan comúnmente en aguas contaminadas, en áreas con vegetación secundaria como plantaciones, campos abiertos y praderas. Las plantas acuáticas asociadas a los inmaduros son Pistia sp., Elodea sp., Naias sp., Chara sp. y Utricularia sp. (Faran 1980) En Yucatán, México se han encontrado larvas en recipientes artificiales como piletas y tanques de riego en jardines y huertos (Hoffman 1931). Los adultos son grandes voladores y la hembra se alimenta del hombre, aunque prefiere hacerlo de animales domésticos, particularmente ganado y caballos; su domesticidad está ligada a la proximidad de los asentamientos humanos a los criaderos y a la atracción que ejerce la luz sobre las hembras, por lo que es común encontrarlas en las habitaciones por la noche, pero regresan a sus lugares de descanso, fuera del domicilio, por la mañana (Bordas et al. 1951, Carpenter \& LaCasse 1955).

Importancia médica. Es el vector primario de la malaria en 17 de 20 países del Caribe y en las planicies costeras de México y Centroamérica, ya que se ha encontrado infectado naturalmente con Plasmodium en casi todos los sitios donde se ha colectado. (Faran 1980, Loyola et al. 1993, WRBU 2008). También se demostró que bajo condiciones de laboratorio esta especie es capaz de transmitir en Virus de la Encefalomielitis Equina (cepa TC-83) (Bautista-Garfias et al. 1977).

Comentarios. En general esta especie es similar a las que pertenecen al mismo subgénero Nyssorhynchus; sin embargo, se puede distinguir por las siguientes características. Larva: seda 1-I palmeada, con doce a catorce ramas lanceoladas semipigmentadas; Pupa: longitud de la seda $9-\mathrm{V}$ igual o mayor que 2.3 veces la longitud de la seda 9-IV, aunque en raras ocasiones puede ser tan larga como 2.0, seda 9-VI larga, 9-VII con 1.0 a 1.5 veces la longitud de 9-VI, seda 7-CT bifurcada con las ramas de longitud similar; Hembra: palpómero 4 totalmente negro o con algunas escamas color amarillo a pardo dorado (nunca blancas) en la superficie mediolateral, palpómero 5 sólo con escamas claras, tarsómero 5 de la pata posterior con una banda 
oscura basal, y el resto del artejo blanco; Macho, terminalia: lóbulos ventrales de la claspeta con el ápice fusionado en dos lóbulos redondeados con forma más o menos cilíndrica, estriados, separados por un surco poco profundo, sin sedas evidentes, con dos estructuras ovoides en la parte basal, edeago largo, moderadamente delgado, con el ápice redondeado, ligeramente más ancho que largo, con un borde membranoso distintivo, sin hojillas.

Parece ser una especie común y abundante en lugares de altitud menor a los 800 msnm. En el mapa de su distribución potencial se observa claramente que los hábitats adecuados de esta especie se encuentran a lo largo de prácticamente toda la planicie del estado en altitudes menores a los $1000 \mathrm{~m}$ snm.

Anopheles albimanus es considerado el vector primario de plasmodios de malaria humana en zonas de planicie costeras, por lo que debe mantener bajo vigilancia constante, sobretodo si se considera su amplia distribución en Veracruz.

\section{Anopheles (Nyssorhynchus) argyritarsis Robineau-Desvoidy 1827}

(Figs. 163-173, 174)

Anopheles (Nyssorhynchus) argyritarsis Robineau-Desvoidy 1827: 411 (hembra). Localidad tipo: Río de Janeiro, Brasil. Referencias adicionales.- Cova-García 1939: 18 (larva), 25 (hembra); Pinto 1939:1 (larva); Rozeboom 1941: 101 (distribución y bionomía); Rozeboom \& Gabaldón 1941: 95 (taxonomía); Komp 1942: 62 (hembra), 109 (larva), 149 (macho); Galvao 1943: 148 (hembra); 150 (larva); Cova-García 1946, fig. 1 (huevo), 28 (larva), 81 (hembra) 115 (macho); Lassmann 1948: 10 (distribución en Veracruz); Senevet 1948: 437 (pupa); Lane 1953: 251 (hembra, macho, pupa, larva, huevo); Horsfall 1955: 181 (distribución y bionomía); Vargas \& Martínez-Palacios 1956: 54 (claves pupa), 123 (hembra, macho, larva); Vargas 1959: 376 (claves macho); Belkin 1968:9 (taxonomía); Belkin et al. 1971: 5 (Localidad tipo; taxonomía); Gorham et al. 1973: 109 (hembra), 134 (larva), 142 (bionomía); Kreutzer et al. 1975: 354 (cromosomas salivares); Heinemman \& Belkin 1977: 491, 520 (distribución); Linthicum 1988: 139 (macho, hembra, pupa, larva).

Anopheles rooti Brèthes 1926: 106 (macho). Localidad tipo: Tucumán, Argentina. Referencias adicionales.- Edwards 1932: 44 (sinonimia); Belkin et al. 1968: 10 (localidad tipo, sinonimia).

Diagnosis. LARVA (Figs. 163-165). Cabeza: sedas 2-C separadas entre sí por una distancia menor al diámetro de uno de los alveolos que les da origen; seda 3-C con cinco a diez ramas cortas o moderadamente largas, de 0.65 veces la longitud de la seda 2-C. Antena: sedas 2-3-A puntiagudas. Tórax: seda 3-T con forma de abanico con ramas filiformes. Abdomen: sedas 1-II-VII palmeadas, con ramas lanceoladas angostas, no pigmentadas y con el borde liso (Linthicum 1988, Vargas \& Martínez- 


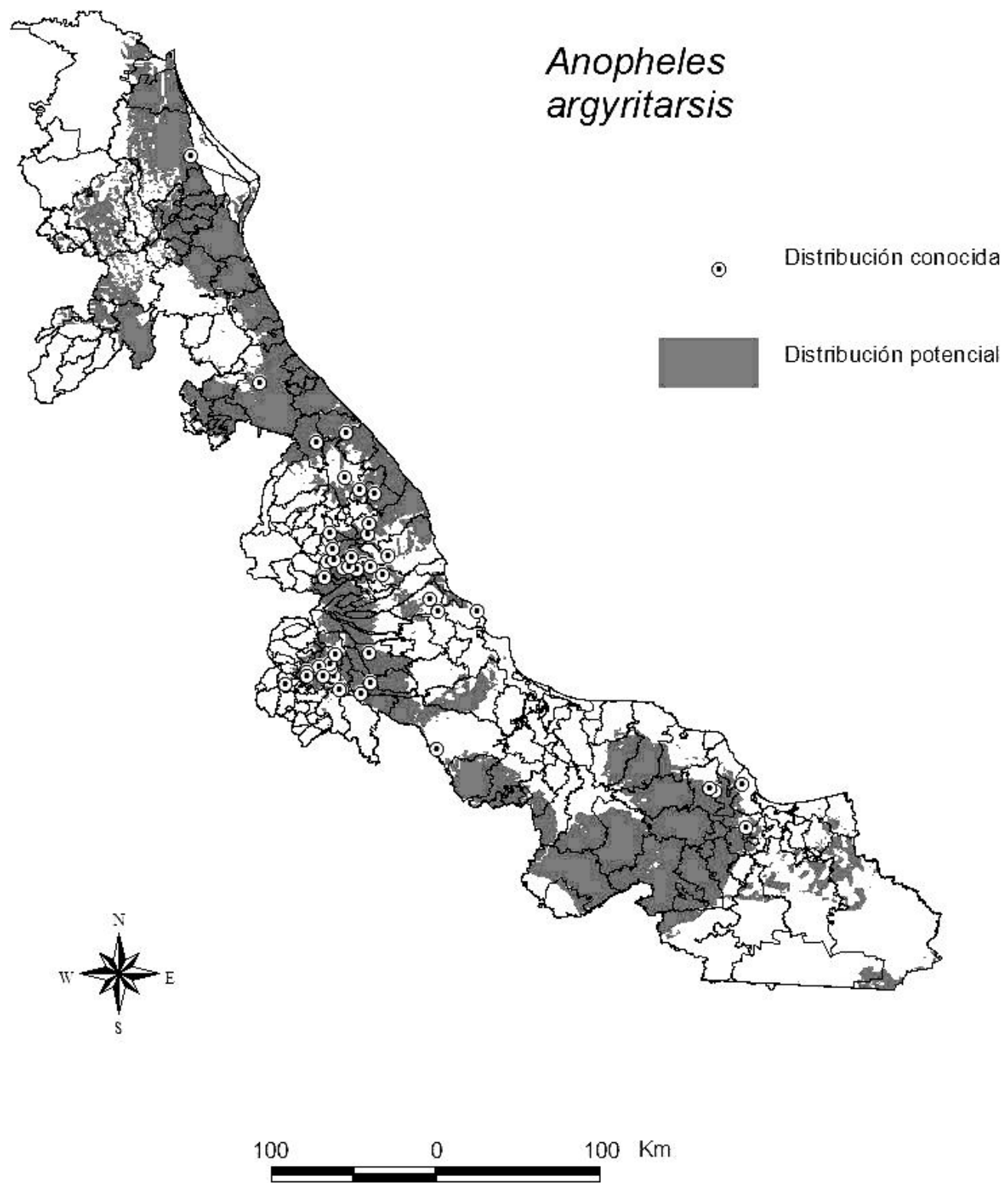

Figura 174. Mapa de la distribución conocida y potencial de Anopheles(Nyssorhynchus) argyritarsis. 

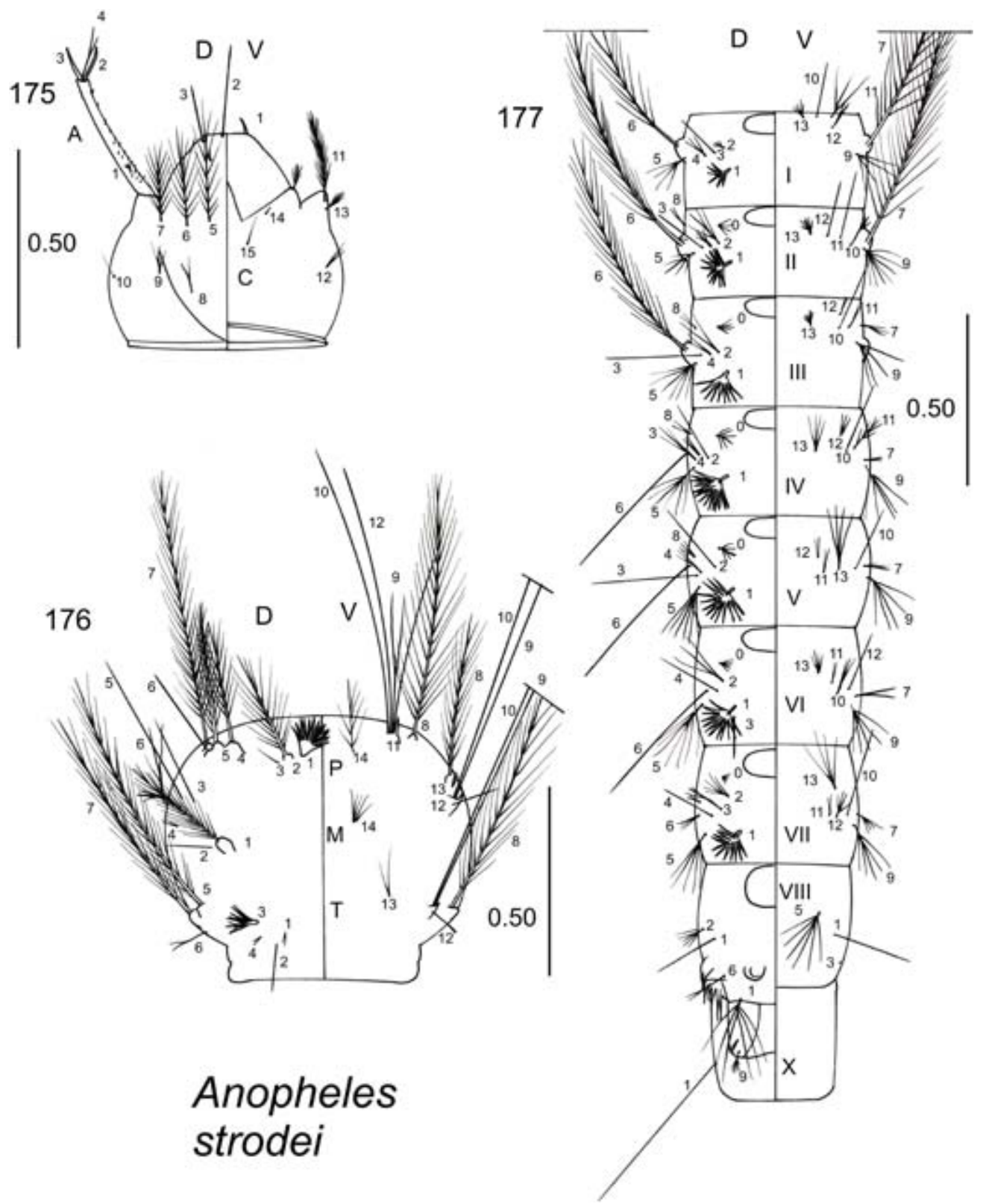

Figuras 175-177. Larva de Anopheles (Nyssorhynchus) strodei. 175: Cabeza. 176: Tórax. 177: Abdomen. 
Palacios 1956). PUPA (Figs. 166-168). Trompeta: angusticorne, con un surco metal profundo. Abdomen: sedas 1-IV-VII sencillas, de 1.50-1.75 la longitud del segmento; seda 2-I pectinada, bien desarrollada; sedas 9-III-IV pigmentadas, con la punta redondeada, sedas 9-V-VII sencillas fuertemente pigmentadas, espiniformes y curvadas. Paleta natatoria: seda 1-P a manera de gancho (Linthicum Op. cit.). HEMBRA (Figs. 169-172). Cabeza: palpo maxilar con predominancia de escamas negras, palpómero 3 con una línea delgada apical de escamas claras, palpómero 4 sin escamas claras; palpómero 5 totalmente blanco. Tórax: escudo con el integumento pruinoso, con líneas oscuras muy pronunciadas; mesepimeron con un parche de escamas claras mesepimerales superiores. Ala: con manchas pálida basal y pálida humeral; mancha pálida humeral larga, no menor que 1.25 veces la longitud de la mancha oscura prehumeral. Patas: tarsómero 2 de la pata posterior con la parte $0.15-0.4$ basal oscura, tarsómero 5 de la pata posterior completamente blanco. Abdomen: segmentos III-VII con mechones caudolaterales de escamas claras cortas, terguito I con pocas escamas color blanco, terguitos II-VII con escamas predominantemente color crema (Linthicum 1988, Wilkerson et al. 1993). MACHO. Terminalia (Fig. 173): uña gonostilar moderadamente corta, puntiaguda y esclerotizada. Gonocoxito con escamas y de cuatro a cinco sedas mediotergales. Una sola espina parabasal curvada apicalmente de aproximadamente 2.8 veces la longitud de su tubérculo. Dos espinas accesorias moderadamente anchas y largas. Una espina interna delgada, poco curvada. Lóbulo dorsal de la claspeta de aproximadamente 0.25 la longitud del gonocoxito, con dos a tres sedas en el ápice, muy curvadas. Lóbulo ventral de la claspeta de aproximadamente 0.25 la longitud del gonocoxito con los ápices fusionados resultando en dos lóbulos redondeados con un surco mediano entre ellos. Edeago de aproximadamente 0.45-0.50 la longitud del gonocoxito, con un par de hojillas moderadamente esclerotizadas con el borde aserrado (Linthicum Op. cit.).

Material examinado. 11 ejemplares. México: Veracruz, Mpo. Amatlán de los Reyes, Amatlán de los Reyes, 16-01-1948 (1 P, CAIM CulH/lam-05731); Mpo. Chinameca, Chinameca, 05-1942 (1 H, CAIM CulH/alf-02146); Mpo. Fortín, Fortín de las Flores, 11-1939 (1 H, CAIM CulH/alf-2180); Mpo. Martínez de la Torre, Zanja de Piedra, 15-10-1956 (2 L, CAIM CulH/lam-01919 y CAIM CulH/lam-01921); Mpo. Misantla, Misantla, 08-10-1956 (1 L, CAIM CulH/lam-01920); Mpo. Tierra Blanca, Tierra Blanca, sin fecha (1 MT, IB07-459); Mpo. Xalapa, Xalapa-Enríquez, sin fecha (1 H, CAIM CulH/lam-02153); Tabasco, Mpo. Teapa, Teapa, 10-1946 (1 P, CAIM CulH/lam-05725); (2 MT, CAIM CulH/lam-05736 y CAIM CulH/lam-05732).

Distribución conocida. Brasil, Argentina, Uruguay, Paraguay, Bolivia, Venezuela, Colombia, Trinidad y Tobago, Guyana, Centroamérica, Antillas bajas y México. (Knight \& Stone 1977). En México se ha encontrado en los estados de Campeche, 
Chiapas, Hidalgo, Michoacán, Nayarit, Oaxaca, San Luis Potosí, Tabasco, Tamaulipas y Veracruz (Vargas \& Martínez-Palacios 1956).

Distribución en Veracruz (Fig. 174). Mpo. Actopan: Actopan; Mpo. Alto Lucero: Alto Lucero, Xomotla; Mpo. Amatlán de los Reyes: Amatlán de los Reyes; Mpo. Banderilla: Banderilla; Mpo. Camerino Z. Mendoza: Cuidad Mendoza; Mpo. Chinameca: Chinameca; Mpo. Coatepec: Coatepec, Col. Bella Esperanza, Cosolapan, Pacho Viejo; Mpo. Córdoba: Col. México, Amatlán de los Reyes, Córdoba, La Providencia, Los Filtros, Paso Coyol, Río Tiburcio, Las Tinajas; Mpo. Cuichapa: Cuichapa, Ingenio la Providencia; Mpo. Cuitláhuac: Cuitláhuac; Mpo. Emiliano Zapata: Corral Falso, Chavarrillo, Mata de Caña, Paso Grande, Plan de Nacaxtle, Plan del Río, La Venta de Lencero; Mpo. Fortín: Barranca de Cuiapichapan, Cuiapichapan, Fortín, Villa Unión; Mpo. Huatusco: Laguna de Santo Domingo; Mpo. Ixtaczoquitlán: Escamela, Ixtaczoquitlán; Mpo. Xalapa: Xalapa-Enríquez; Mpo. Jilotepec: Esquilón; Mpo. Juchique de Ferrer: Juchique de Ferrer; Mpo. Manlio Fabio Altamirano: Martínez de la Torre; Mpo. Martínez de la Torre: Zanja de Piedra; Mpo. Mecayapan: Mecayapan; Mpo. Misantla, Misantla; Mpo. Nautla: Jicaltepec; Mpo. Ozulama: La Laja; Mpo. Pajapan: Pajapan; Mpo. Papantla: Papantla; Mpo. Paso de Ovejas: Puente de Jula, Tolomé; Mpo. Paso del Macho: Paso del Macho; Mpo. Sotepan: Sotepan; Mpo. Tenaja de Mata: Omelaca; Mpo. Teocelo: Teocelo; Mpo. Tierra Blanca: Tierra Blanca; Mpo. Veracruz: Veracruz; Mpo. Yecuatla, Yecuatla.

Datos bionómicos. Las larvas se crían en aguas claras de arroyos pequeños con media sombra o soleados; se encuentran a los largo de las orillas con pastos de arroyos, y también en pozas tranquilas de los arroyos y en pozos de lluvia con pastos. Las hembras parecen no ser atraídas por los humanos, por lo que no se les encuentra en el intradomicilio (Rozeboom 1941). Los adultos son abundantes en el peridomicilio y en el intradomicilio (Horsfall 1955).

Importancia médica. Se ha encontrado infectado naturalmente con Plasmodium, sin embargo raramente se encuentra dentro del domicilio y pocas veces se alimenta de humanos, por lo que en general no se considera un vector primario de la malaria y solo podría ser de importancia cuando su densidad poblacional aumenta (Linthicum 1988).

Comentarios. Esta especie es muy similar a las restantes del subgénero Nyssorhynchus, sin embargo puede diferenciarse por las siguiente combinación de características presente en Anopheles argyritarsis. Larva: sedas 2-C separadas entre sí por una distancia menor al diámetro de uno de los alveólos que les da origen, sedas abdominales 1-II-VII bien desarrolladas; Pupa: seda 1-P grande y a manera de gancho; Hem- 


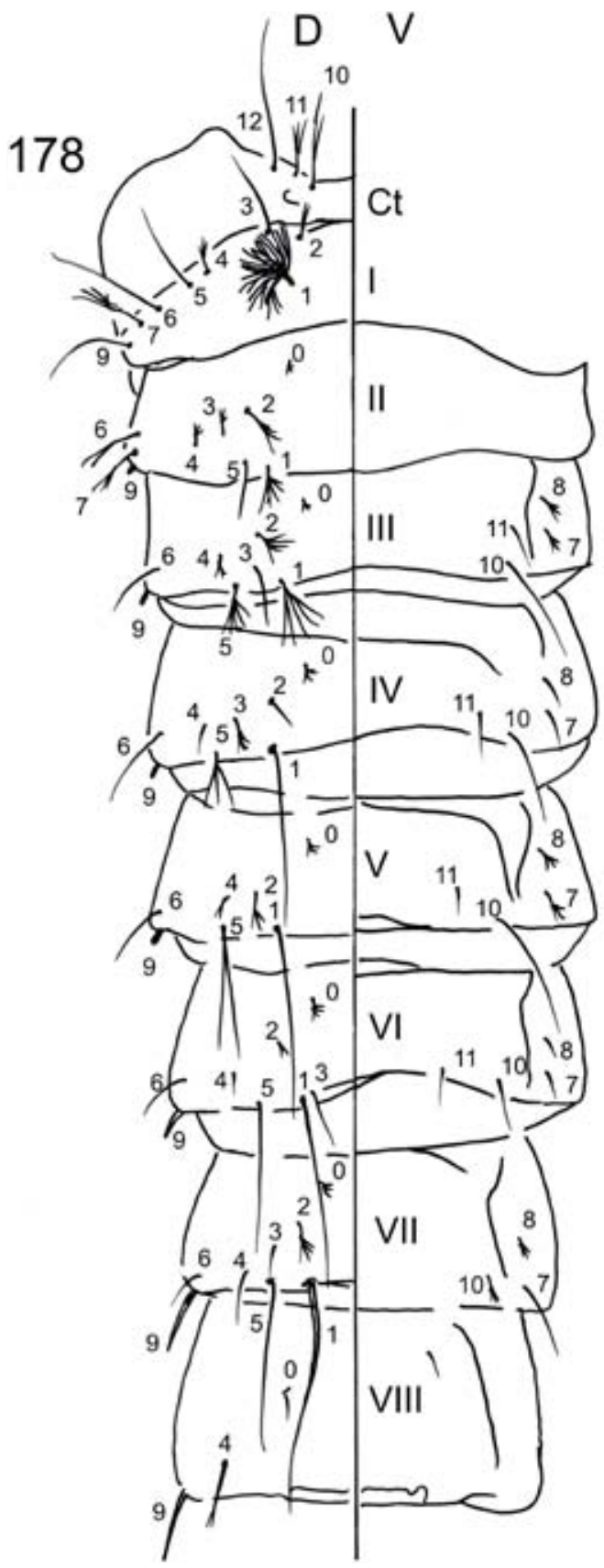

\section{Anopheles strodei}

179
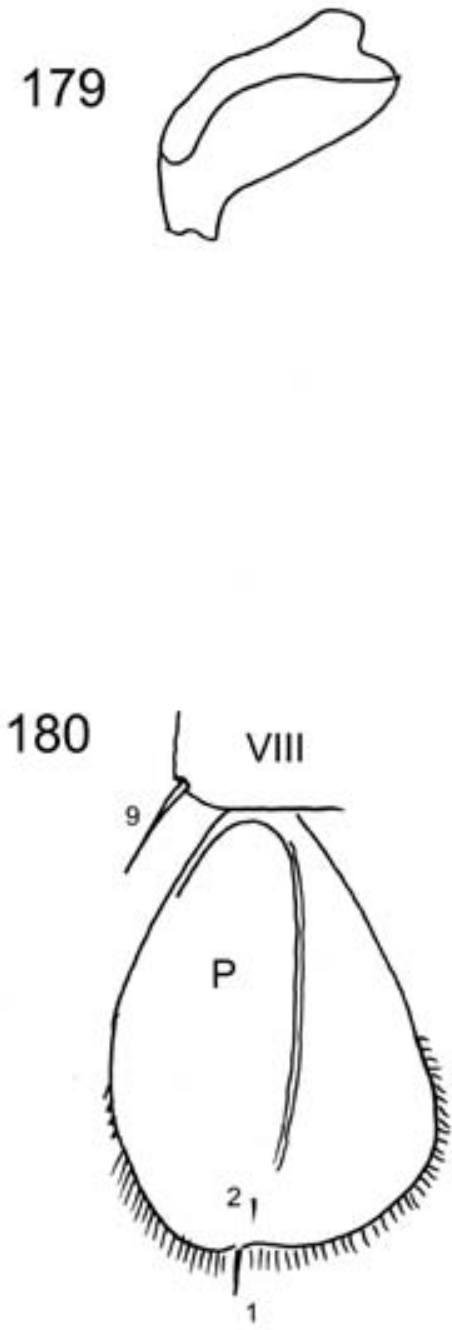

Figuras 178-180. Pupa de Anopheles (Nyssorhynchus) strodei (redibujada de Senevet, 1934). 178: Segmentos abdominales I-VIII. 179: Trompeta ventiladora. 180: Paleta natatoria izquierda vista dorsal. 


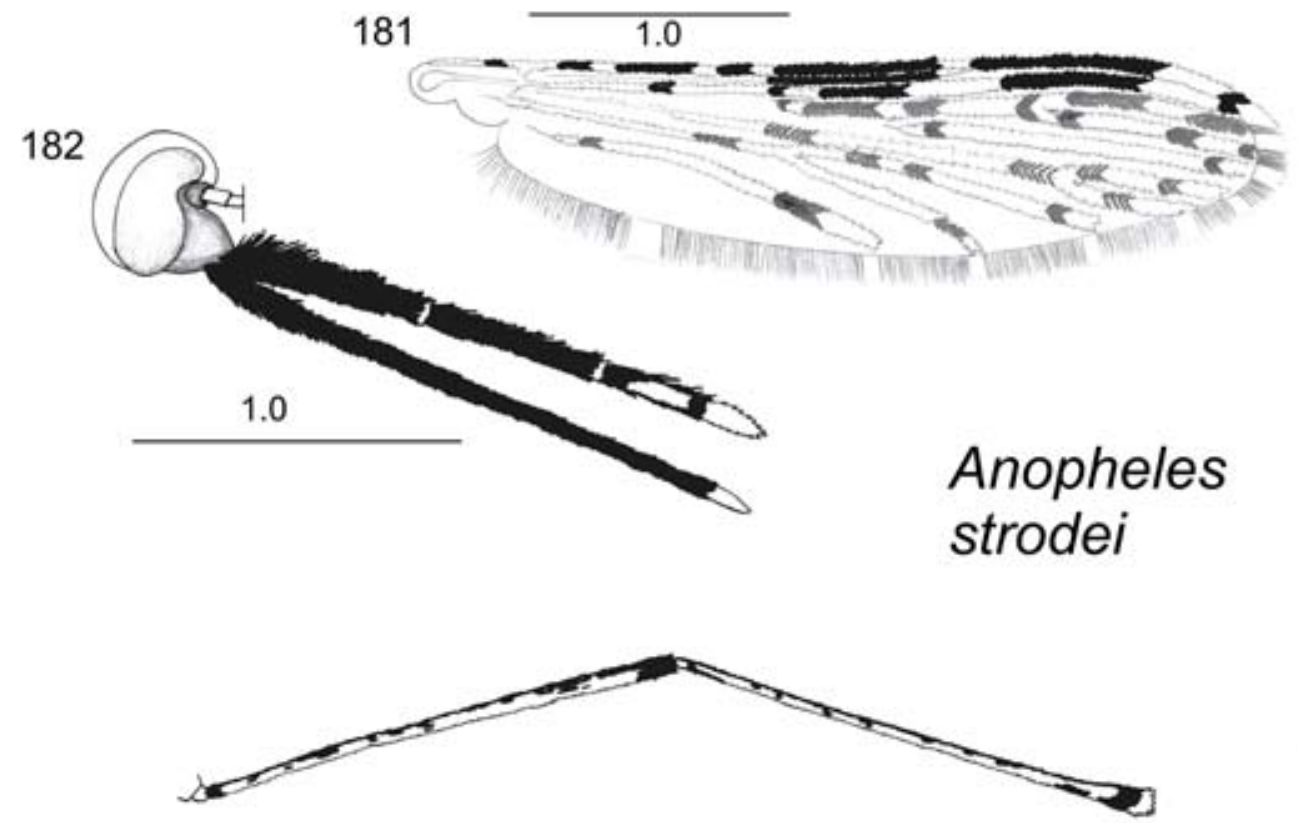

183

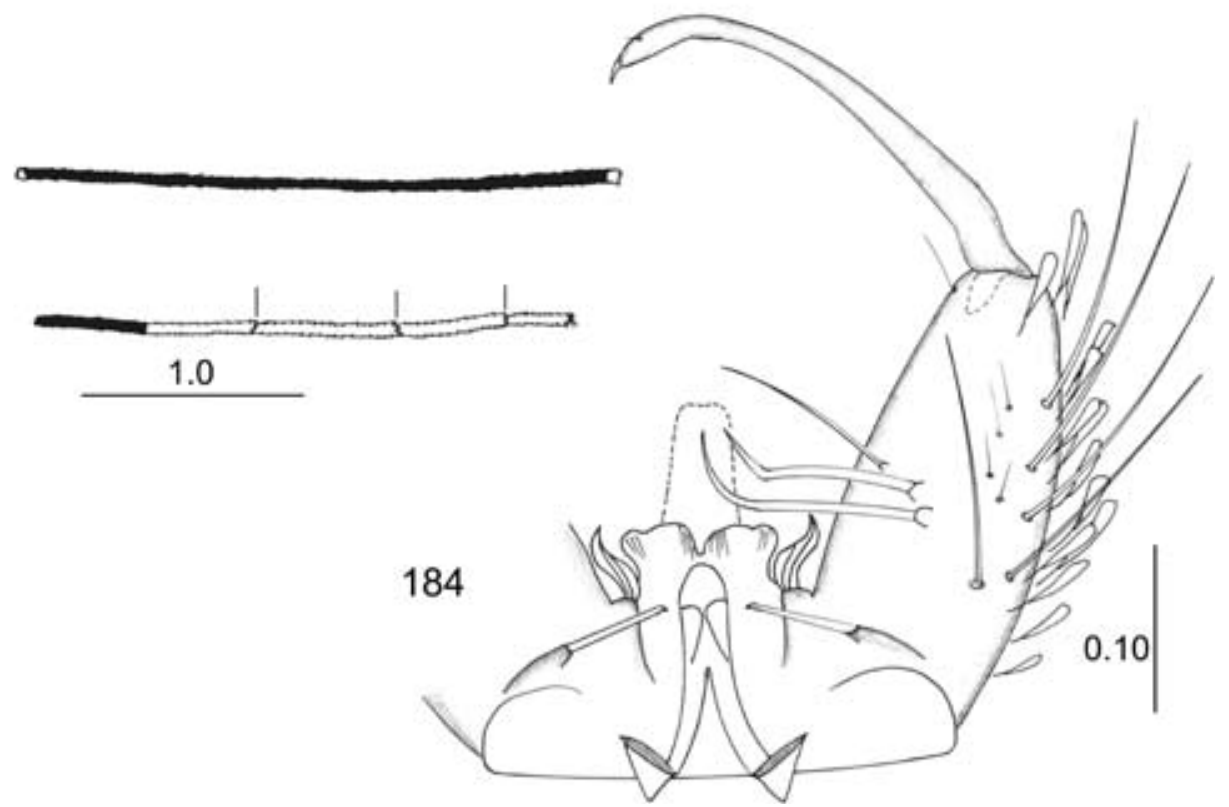

Figuras 181-184. Adultos de Anopheles (Nyssorhynchus) strodei. Hembra.181: Ala. 182: Palpo maxilar. 183: Pata posterior. Macho. 184: Terminalia. 
bra: Pata posterior con el tarsómero 5 revestido en su totalidad con escamas claras. Ala con la vena costal presentando la mancha clara humeral más larga que la mancha oscura prehumeral; Macho, terminalia: edeago con un par de hojillas.

Parece ser una especie de amplia distribución en Veracruz y común en la zona centro del estado, dónde se observan dos concentraciones de los puntos de presencia en localidades que se encuentran entre los 820 y los 1560 msnm. En el mapa de la distribución potencial se observan además de estas, otras áreas hacia en norte y sur que podrían ser adecuadas como hábitat de esta especie.

\section{Anopheles (Nyssorhynchus) strodei Root 1926}

(Figs. 175-184)

Anopheles (Nyssorhynchus) strodei Root 1926: 711 (macho, pupa, larva). Localidad tipo: Agua Limpa cerca de Juiz de Fora, Minas Gerais, Brasil. Referencias adicionales.- Senevet 1934: 52 (pupa); Galvao \& Lane 1936: 275 (macho, hembra, larva, huevo); Cova-García 1939: 18 (larva), 25 (hembra); Pinto 1939: 425 (sinonimia); Galvao 1941: 516 (macho, hembra, larva); Rozeboom 1941: 102 (distribución y bionomía); Rozeboom \& Gabaldón 1941: 97 (taxonomía); Komp 1942: 71 (hembra), 120 (larva), 158 (macho); Rozeboom 1942: 240 (huevo; taxonomía); Galvao 1943: 143 (taxonomía), 149 (claves hembra, macho, larva); Cova-García 1946: fig. 1 (huevo), 40 (larva), 91 (hembra), 126 (macho); Lassmann 1948: 10 (distribución en Veracruz); Lane 1953: 270 (hembra, macho, pupa, larva, huevo); Horsfall 1955: 185 (distribución y bionomía); Stone \& Knight 1956: 280 (diseño del lectotipo); Vargas \& Martínez-Palacios 1956: 55 (claves pupa), 129 (hembra, macho, larva); Vargas 1959: 382 (claves macho); Faran 1980: 123 (macho, hembra, pupa, larva; recuperado de la sinonimia con evansi).

Anopheles (Nys.) strodei var. ramosi Unti 1940: 489 (larva). Localidad tipo: Lorena, Sao Paulo, Brasil. Referencias adicionales.- Faran 1980: 123 (taxonomía, sinonimia).

Anopheles (Nys.) strodei var. strodei Unti 1940: 393 (biología).

Anopheles (Nys.) strodei var. arthuri Unti 1941: 9 (huevo). Localidad tipo: Río Paraiba Sao Paulo, Brasil. Referencias adicionales.- Faran 1980: 123 (taxonomía, sinonimia).

Anopheles (Nys.) strodei var. artigasi Unti 1941: 9 (huevo). Localidad tipo: Río Paraiba, Sao Paulo, Brasil. Referencias adicionales.- Galvao 1943: 144 (sinonimia); Faran 1980: 123 (taxonomía, sinonimia).

Anopheles (Nys.)strodei var. albertoi Unti 1941: 9 (huevo). Localidad tipo: Río Paraiba Sao Paulo, Brasil. Referencias adicionales.- Faran 1980: 123 (taxonomía, sinonimia).

Anopheles (Nys.)strodei var. lloydi Unti 1941: 10 (huevo). Localidad tipo: Panamá. Referencias adicionales.- Faran 1980:123 (taxonomía, sinonimia). 
Diagnosis. LARVA (Figs. 175-177). Cabeza: sedas 2,3-C sencillas, con cerdillas en la mitad apical; sedas 3-C de 0.6 veces la longitud de las 2-C; sedas 2-C separadas por una distancia igual al diámetro de uno de los alveolos que les da origen. Antena: sedas 2-3-A puntiagudas. Tórax: seda 1-P palmeada, con trece a diecisiete ramas delgadas lanceoladas; sedas 9, 10, 12-P sencillas, seda 11-P bifurcada; seda 1-M con treinta y una a treinta y cinco ramas, siendo las apicales mucho más cortas que las laterales. Abdomen: sedas 0-II-VI con cuatro a nueve ramas moderadamente largas a largas; seda 1-I palmeada con doce a dieciséis ramas lanceoladas delgadas, poco pigmentadas; sedas 1-II-VII palmeadas con las ramas largas, pigmentadas y delgadas a moderadamente anchas; seda 2-V sencilla; sedas 6-IV-V sencilla; seda 13-V muy larga, extendiéndose más allá del margen caudal del segmento (Faran 1980). PUPA (Figs. 178-180). Trompeta: angusticorne, con un surco meatal profundo. Abdomen: seda 5-II con de tres a cinco ramas, moderadamente larga; suma de las ramas de las sedas 1-III, 5-III y 0-VI menor a dieciocho; seda 6-II sencilla o hasta con tres ramas, muy larga, de al menos 2.0 veces la longitud de 7-II; seda 9-II pequeña, no pigmentada; seda 9-III corta, gruesa, no pigmentada a fuertemente pigmentada, menos de 2.0 veces la longitud de 9-II, 9-V ligeramente curvada, 9-VI curvada y moderadamente larga, 9-VII-VIII sencillas, adelgazadas hasta un ápice muy fino, muy larga, de aproximadamente 0.5 veces la longitud del segmento. Paletas natatorias: margen con espículas filamentosas que se extienden desde la parte distal del refuerzo del margen externo, hasta la mitad del margen interno; seda 1-P sencilla; seda 2-P sencilla o bifurcada (Faran Op. cit.). HEMBRA (Figs. 181-183). Cabeza: palpómeros 2 y 3 con pocas escamas claras en la superficie dorsal y con una banda apical de escamas claras, palpómero 4 con escamas blancas en la superficie mediolateral, palpómero 5 completamente blanco. Tórax: escamas claras del escudo y escudete de color plateado; área del promontorio anterior con escamas largas que se extienden hacia en área acrostical. Ala: manchas claras generalmente blancas, ocasionalmente crema muy claro en la costa; mancha oscura basal de la costa pequeña; mancha pálida humeral a 2.0-4.0 de la mancha oscura basal; mancha pálida subcostal de la costa a 0.25-0.50 de la mancha oscura subcostal. Patas: escamas claras de la coxa color blanco o crema muy claro; tarsómero 2 de la pata anterior claro en los 0.25 (0.18-0.35) apicales; tarsómero 3 de la pata anterior claros en los 0.5 (0.25-0.8) apicales; tarsómero 5 de la pata anterior generalmente totalmente dorado o pardo con pocas escamas claras apicales y en raras ocasiones con la mitad apical más clara que la basal; tarsómero 5 de la pata media generalmente con una banda pequeña color crema en los 0.3 apicales; pata posterior con el tarsómero 2 pardo en los 0.35-0.45 basales y el tarsómero 5 con una banda basal de escamas oscuras. Abdomen: esternito I con pocas sedas laterales y en ocasiones con escamas claras lanceoladas, terguitos II-VII con mechones caudolaterales de escamas oscuras (Faran Op. cit.). MACHO. Terminalia (Fig. 184): gonostilo más corto que el gonocoxito, delgado, ensanchado en su parte basal; uña gonostilar 

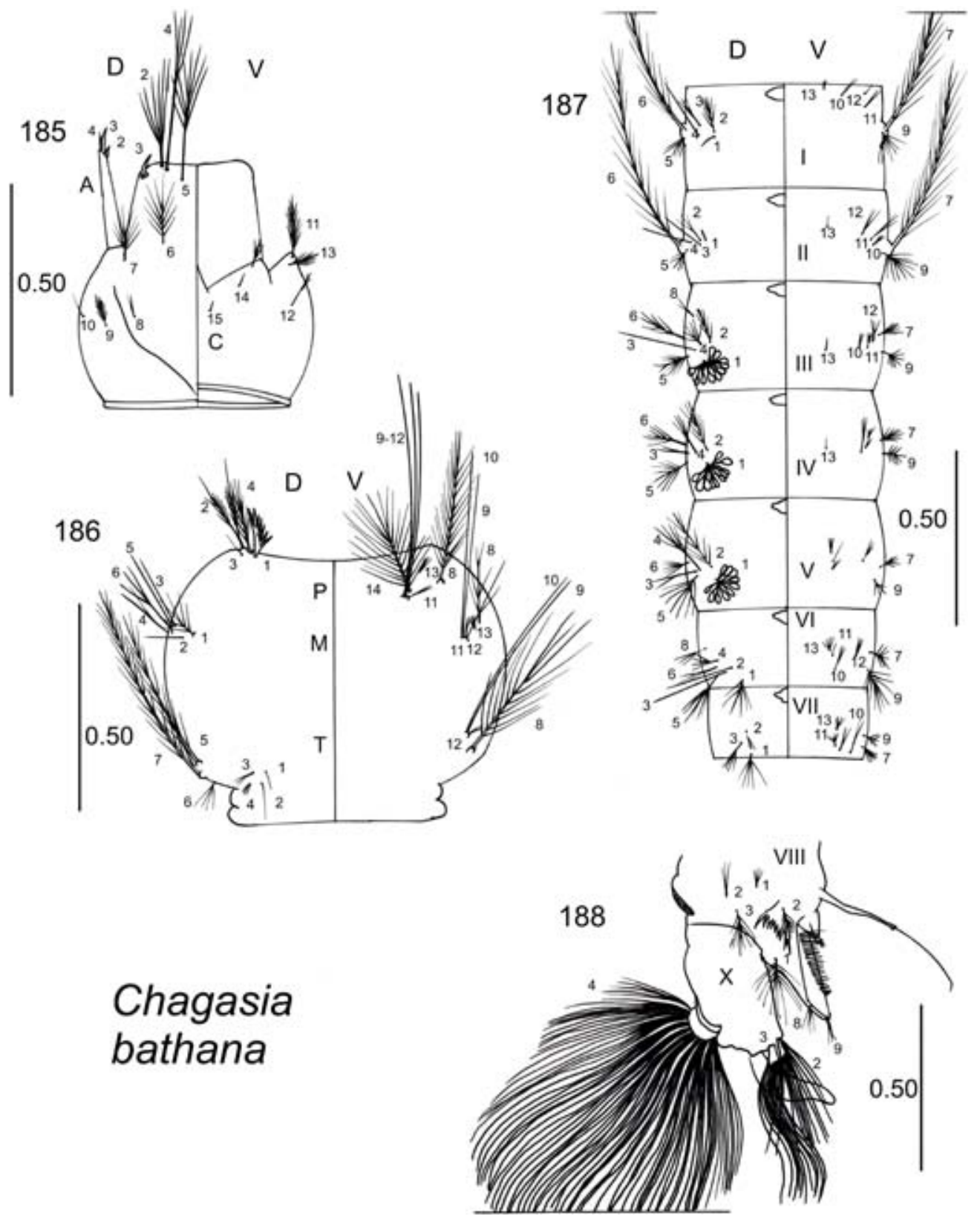

Figuras 185-188. Larva de Chagasiabathana. 185: Cabeza.186: Tórax. 187: Segmentos abdominales I-VII. 188: Segmentos abdominales VIII-X vista lateral. 

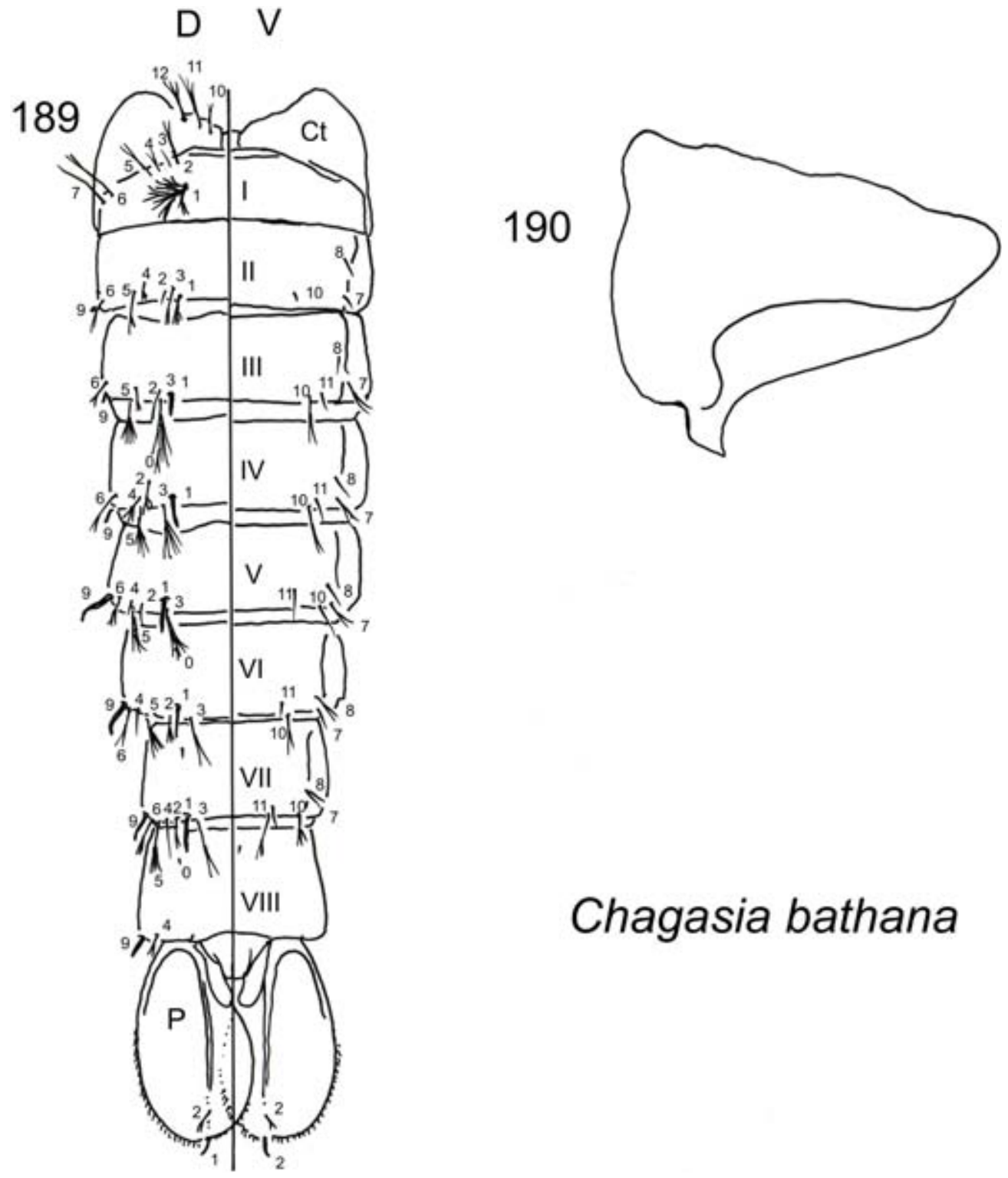

Figuras 189-190. Pupa de Chagasiabathana. 189: Abdomen (redibujado de Knighty Chamberlain, 1948). 190: Trompeta ventiladora (redibujada de Gabaldónet al., 1940). 
puntiaguda. Gonocoxito con escamas y cuatro a seis sedas mediotergales y una o dos sedas apicolaterales. Espina parabasal moderadamente delgada. Dos espinas accesorias fuertes. Una espina interna del mismo largo que la espina accesoria más corta y atenuada apicalmente. Lóbulo dorsal de la claspeta de aproximadamente 0.5 la longitud del gonocoxito, con tres hojillas lanceoladas, de un poco menos que 0.5 la longitud de la claspeta, una de estas con una proyección basomesal. Lóbulo ventral de la claspeta de 0.45-0.52 la longitud del gonocoxito, con el ápice expandido lateralmente, sin sedas y con un surco en forma de " $V$ " entre los dos lóbulos fusionados, con sedas basales evidentes en los márgenes laterales. Edeago con el ápice redondeado, sin hojillas. Noveno terguito sin lóbulos laterales (Faran 1980).

Material examinado. 42 ejemplares. México, Veracruz, Mpo. Chinameca, Chinameca, 01-03-1940 (8 L, CAIM CulH/lam-01961, CAIM CulH/lam-01962, CAIM CulH/lam-01963, CAIM CulH/lam-01964, CAIM CulH/lam-01965, CAIM CulH/ lam-01966, CAIM CulH/lam-01967 y CAIM CulH/lam-01968), 20-09-1941 (3 H, CAIM CulH/alf-02187, CAIM CulH/alf-02188 y CAIM CulH/alf-02189), 01-121941 (10 L, CAIM CulH/lam-01937, CAIM CulH/lam-01938, CAIM CulH/lam01939, CAIM CulH/lam-01940, CAIM CulH/lam-01941, CAIM CulH/lam-01942, CAIM CulH/lam-01943, CAIM CulH/lam-01944, CAIM CulH/lam-01945 y CAIM CulH/lam-01946), 20-12-1941 (1 H, CAIM CulH/alf-02167), 12-1941 (1 MT, CAIM CulH/lam-05744), 05-05-1942 (12 L, CAIM CulH/lam-01950, (2) CAIM CulH/lam01951, CAIM CulH/lam-01952, CAIM CulH/lam-01953, CAIM CulH/lam-01954, CAIM CulH/lam-01955, CAIM CulH/lam-01956, CAIM CulH/lam-01957, CAIM CulH/lam-01958, CAIM CulH/lam-01959 y CAIM CulH/lam-01960), 05-03-1958 (2 L, CAIM CulH/lam-01971 y CAIM CulH/lam-01972), 31-03-1958 ( 2 L, CAIM CulH/lam-01969 y CAIM CulH/lam-01970), sin fecha, (3 L, CAIM CulH/lam-01947, CAIM CulH/lam-01948 y CAIM CulH/lam-01949).

Distribución conocida. Argentina, Bolivia, Brasil, Colombia, Costa Rica, Guyana Francesa, Guatemala, Guyana, Honduras, México, Panamá, Paraguay, Suriname, Trinidad y Tobago, Venezuela (WRBU 2008).

Distribución en Veracruz. Mpo. Chinameca: Chinameca; Mpo. Las Choapas, Las Choapas; Mpo. Minatitlán: Las Choapas; Mpo. Veracruz: Paso de San Juan.

Datos bionómicos. Los estados inmaduros se desarrollan predominantemente en pozos. Adicionalmente ha sido colectada en huellas de animales, lagos, pantanos, márgenes de arroyos, hoyos de rocas. Solo se desarrolla en agua dulce, generalmente expuesta totalmente a la luz del sol o con sombra parcial, pero ocasionalmente también en sombra total. Se encuentra comúnmente en áreas montañosas y planicies. Los 
inmaduros se asocian con abundante vegetación como pastos, algas y Utricularia sp. Pueden tolerar grandes fluctuaciones de temperatura (17.5-33.0 $\left.{ }^{\circ} \mathrm{C}\right), \mathrm{pH}(5.9-7.2) \mathrm{y}$ cantidades de materia orgánica. Las hembras se alimentan del hombre y otros mamíferos, principalmente en el peridomicilio, raramente entran a las casas (Faran 1980).

Importancia Médica. Se ha encontrado infectado en la naturaleza con Plasmodium vivax (Pessôa \& Paula-Souza 1937), sin embargo por sus hábitos exófilos y zoófilos, se puede considerar un posible problema para la salud sólo cuando se encuentra en altas densidades (Faran Op. cit.).

Comentarios. Esta especie es muy similar a las demás del subgénero Nyssorhynchus, pudiéndose distinguir por la combinación de las siguientes características presente en Anopheles strodei. Larva: sedas 2-C separadas por una distancia igual al diámetro de uno de los alvéolos que les da origen, seda 1-P palmeada, sedas 9-P sencillas; Pupa: seda 7-CT con dos ramas, una de ellas evidentemente más larga que la otra, seda 1-P nunca a manera de gancho; Hembra: tarsómero 5 de la pata anterior generalmente totalmente dorado o pardo con pocas escamas claras apicales, tarsómero 5 de la pata posterior con una banda basal de escamas oscuras, abdomen con el terguito II con mechones postero-laterales de escamas oscuras; Macho, terminalia: claspeta con los lóbulos ventrales fusionados con sedas basales evidentes en los márgenes laterales.

Esta especie parece ser abundante en el municipio de Chinameca, ya que todos los ejemplares revisados pertenecen a este municipio, sin embargo se tienen pocos puntos de colecta, lo que podría deberse a la falta de una colecta de anofelinos bien realizada,

En Veracruz esta especie puede llegar a ser de importancia médica, tomando en cuenta situaciones en las que su densidad poblacional es alta.

\section{Género Chagasia Cruz, 1906}

Diagnosis. LARVA. Cabeza: sedas 3-C transformadas en una espina, situada en los ángulos anteroexternos del clípeo. Tórax: seda 2-P dividida cerca de la base en dos ramas gruesas. Abdomen: sedas 1-III-VII palmeadas, con las ramas muy ensanchadas en la porción distal (forma de raqueta); placa del lóbulo espiracular anterior con un proceso mediano anterior largo (Levi-Castillo 1945). PUPA. Abdomen: segmentos abdominales posteriores a partir del VI considerablemente delgados en comparación con los segmentos anteriores seda 2-III-VII espiniforme, corta, gruesa y oscura (Vargas \& Martínez-Palacios 1956). HEMBRA. Tórax: escudete trilobulado, con tres grupos de sedas separados entre sí; con dos mechones de escamas espatuladas largas en posición anterior a la inserción del ala; postpronoto con sedas y escamas Patas: algunos tarsómeros con bandas claras. Ala: con escamas ovaladas claras y oscuras alternadas, sin que formen un patrón de manchas definido (Levi-Castillo Op. cit.). MA- 
CHO. Terminalia: uña gonostilar corta y de punta redondeada. Gonocoxito corto, con sedas largas, sin escamas. Lóbulos de la claspeta fusionados, membranosos, revestidos por numerosas sedas cortas. Edeago fuerte, sin hojillas (Levi-Castillo Op. cit.).

\section{Chagasia bathana (Dyar 1928)}

(Figs. 185-193)

Anopheles (Chagasia) bathanus Dyar 1928 In: Curry 1928: 244 (hembra, pupa, larva) Localidad tipo: Gatun, Panamá.

Chagasia bathana (Dyar) 1928. Referencias adicionales.- Senevet 1934: 29 (pupa); Gabaldón et al. 1940: 58 (claves hembra, pupa, larva); Rozeboom 1941: 98 (distribución y bionomía); Komp 1942: 46 (hembra), 82 (pupa, larva), 133 (macho); Levi-Castillo 1945: 17 (larva, pupa, hembra, macho); Knight \& Chamberlain 1948: 11 (pupa); Lassmann 1948: 9 (distribución en Veracruz); Lane 1953: 146 (hembra, pupa, larva, huevo); Horsfall 1955: 41 (distribución, bionomía); Vargas \& MartínezPalacios 1956: 52 (pupa), 62 (hembra, macho, larva); Villanueva 1961: 217 (distribución, bionomía); Fauran \& Pajot 1974: 100 (distribución); Baerg \& Boreham 1974: 631 (huevo).

Diagnosis. LARVA (Figs. 185-188). Presenta numerosas espículas en todo el cuerpo. Cabeza: sedas 2-C muy grandes con largas ramas laterales, las 3-C transformadas en una espina, situada en los ángulos anteroexternos del clípeo, las 4-C largas, ramificadas de la misma forma que las sedas 2-C. Antena: sedas 2-3-A cortas, puntiagudas. Tórax: seda 1-P con un tallo grueso y varias ramas lanceoladas; seda 2-P dividida cerca de la base en dos ramas gruesas con ramas delgadas distales. Abdomen: sedas 1-III-VI palmeadas con ramas estrechas en la mitad basal y ensanchadas en la porción distal (en forma de raqueta), cada una con un filamento terminal largo; seda 6-I-II largas y ramificadas; aparato respiratorio característico con la placa del lóbulo espiracular anterior con un proceso mediano anterior largo y la placa del lóbulo espiracular posterolateral con un fleco de sedas aplanadas (Vargas \& Martínez-Palacios 1956). PUPA (Figs. 189-190). Trompeta: laticorne, sin surcos. Abdomen: segmento VI con un marcado estrechamiento que se acentúa más en el VII, segmento VIII del mismo ancho que el VII pero con los ángulos posteriores salientes; sedas 2-III-VII transformadas en una espina; sedas 9-V-VII anchas, puntiagudas, curvadas en forma de "S", seda 9-VII espiniforme, ligeramente curvada, 9-VIII espiniforme, recta. Paletas natatorias: con serraciones en el margen externo; seda 1-P espiniforme; 2-P bifurcada (Vargas \& Martínez-Palacios Op. cit., Senevet 1934). HEMBRA (Figs. 191-192). Cabeza: occipucio con escamas bifurcadas; con sedas y escamas postpronotales. Tórax: escudete ligeramente trilobulado, con sedas confinadas a los lóbulos; con un mechón de escamas negras cerca de la base del ala. Ala: revestida de escamas ovaladas, anchas, negras, pardas y blanco-amarillentas entremezcladas, sin que formen un 
191
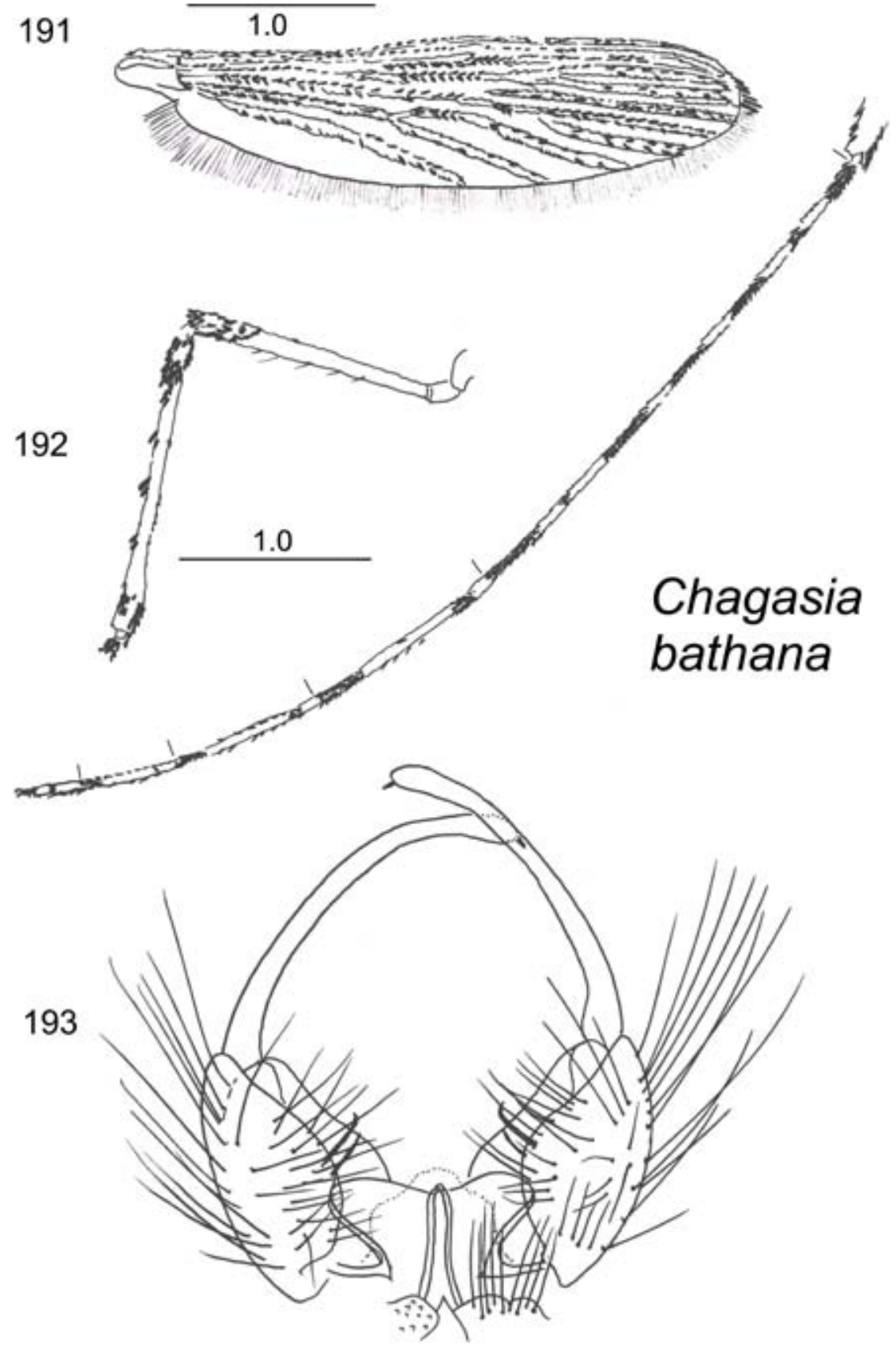

Figuras 191-193. Adultos de Chagasiabathana. Hembra. 191: Ala. 192: Pata posterior. Macho. 193: Terminalia (redibujados de Lane, 1953). 
patrón de manchas definido. Patas: oscuras con manchas blancas; ápices de tibias y fémures con escamas claras; tarsómero 1 de la pata trasera con cinco anillos de escamas blancas. Abdomen: integumento pardo oscuro; con sedas oscuras y sin escamas (Curry 1928, Vargas \& Martínez-Palacios Op. cit., Wilkerson et al. 1993). MACHO. Terminalia (Fig. 193): gonostilo más largo que el gonocoxito con la porción basal ensanchada, uña gonostilar pequeña y con la punta redondeada. Gonocoxito corto, con sedas largas, sin escamas. Lóbulos de la claspeta fusionados, membranosos, revestidos por numerosas sedas cortas. Edeago fuerte, con la parte apical ligeramente curvada, sin hojillas apicales. Noveno terguito delgado en la porción central; muy ensanchado lateralmente; con dos grupos de sedas largas a los lados de la línea media (Vargas \& Martínez-Palacios Op. cit.).

Material examinado. 6 ejemplares: México: Veracruz, Mpo. Acayucan, Acayucan, 03-1945 (1 H, CAIM CulH/lalf-02359; 1 M, CAIM CulH/lalf-02358); Chiapas, Mpo. Palenque, Palenque, 01-04-1942 (2 L, CAIM CulH/lam-01976, y CAIM CulH/lam01974); Mpo. Indeterminado, Macachi, 28-04-1942 (1 L, CAIM CulH/lam-01975); Tabasco, Mpo. Teapa, San Joaquín Teapa, 20-01-1955 (1 H, CAIM CulH/alf02356).

Distribución. Panamá, Nicaragua, Belize, Guatemala, Guyana Francesa, México, Venezuela, Colombia, Ecuador, Perú, Costa Rica (Fauran \& Pajot 1974, Knight y Stone 1977). En México se ha colectado en los estados de Chiapas, Tabasco y Veracruz (Vargas \& Martínez-Palacios 1956).

Distribución en Veracruz. Mpo. Acayucan: Acayucan: Mpo. Sayula: Sayula.

Datos bionómicos. Las larvas se encuentran en agua limpia, con movimiento, con sombra o media sombra y en ocasiones con completa exposición a la luz solar, siendo más abundantes entre las raíces de los árboles y en los márgenes con pastos. Están asociadas a vegetación helófita y flotante (Villanueva 1961, Horsfall 1955).

Comentarios. Esta especie por pertenecer a otro género, presenta características morfológicas muy distintivas con respecto a las demás especies de anofelinos presentes en el estado, mismas que se tratan en la diagnosis.

Se trata de una especie rara en Veracruz, estando distribuida en un área muy pequeña al sur del estado, únicamente ha sido informada en dos localidades localizadas entre los 80 y los 100 msnm. Podría ser que esta distribución tan restringida se deba, como en otras especies, a la falta de una buena colecta de anofelinos.

Chagasia bathana nunca ha sido incriminada como vector de ninguna enfermedad, y considerando que es una especie rara en el estado, su importancia médica es nula. 


\section{DISCUSIÓN}

Se considera que Veracruz es una entidad rica en especies de anofelinos, ya que si se compara el número de especies informadas para este estado con el de otras colindantes, se asume que el primero tiene una mayor riqueza de especies de la subfamilia Anophelinae, ya que se han informado 18 especies para Veracruz, 13 para Chiapas, 12 para Tabasco, 10 para San Luis Potosí, 7 para Oaxaca, 5 para Tamaulipas, 5 para Hidalgo, 2 para Puebla y una para Tlaxcala. Además de que estas 18 especies corresponden al 64\% de las conocidas para México (28 especies) y al 30\% de Norte y Centroamérica.

En el presente trabajo se reúnen por primera vez las descripciones de las fases de larva, pupa y adultos de las especies de anofelinos de Veracruz, así como las claves para su identificación. En el caso de las pupas, se presentaron dificultades para su descripción y elaboración de las claves ya que los trabajos anteriores que abordan estos temas se encuentran dispersos y en muchos casos la descripción es muy vaga. Esto se debe a que a partir de los años 60s, los trabajos referentes a la morfología de anofelinos se han enfocado a las especies vectoras de malaria. Por otro lado, en general las pupas no se utilizan para la identificación de las especies, sino que se espera a que emerja el adulto para realizar la determinación, lo que contribuye a la falta de estudios sobre morfología de pupas de anofelinos. Es por esto que se recomienda que en un futuro se realicen más trabajos sobre morfología de pupas de anofelinos, en primer lugar porque en algunos casos, como el de An. bradleyi y An crucians, la determinación taxonómica por carácterísticas morfológicas hasta el nivel de especie solo se puede realizar en las fases de larva y pupa; y en segundo lugar porque las características de los organismos se conservan mejor en preparaciones permanentes que en organismos adultos montados en alfiler, por lo que si se quiere realizar una consulta de alguna colección histórica, las primeras resultarán de mayor ayuda.

Se considera que 14 de las especies de anofelinos presentes en Veracruz tienen importancia médica por su condición como vectores de los plasmodios que causan la malaria humana, pudiéndose dividir en tres grupos de riesgo.

En el primer grupo se encuentran las especies más significativas: Anopheles (Ano.) pseudopuntipennis y Anopheles (Nys.) albimanus, ya que ambos son vectores primarios comprobados en varias regiones de México y América, además de estar ampliamente distribuidos en el estado.

En un segundo grupo de especies con interés regional o de vectores secundarios se encuentran las siguientes especies que se recomienda estén bajo vigilancia, aunque no se tenga la certeza de que estas funjan como vectores en Veracruz: Anopheles (Ano.) quadrimaculatus, ya que es un vector primario en Estados Unidos pero no tiene una distribución muy amplia en el estado; Anopheles (Ano.) punctimacula que ha sido incriminada como vector de malaria en Centro y Sudamérica, pero en el caso de Veracruz nunca ha sido incriminada, a pesar de que parece ser común en el centro 
del estado; Anopheles (Ano.) vestitipennis, que ha sido incriminada como vector de malaria en Chiapas, pero no lo ha sido en Veracruz, a pesar de su amplia distribución en el estado; Anopheles (Nys.) argyritarsis que se considera tienen una distribución amplia y es común en la zona centro del estado, además de ser vector secundario en otras zonas; Anopheles (Ano.) neomaculipalpus, que se considera un vector secundario de malaria en otras regiones, en zonas recientemente colonizadas por el hombre; Anopheles (Ano.) crucians, que se ha incriminado como vector de malaria en Estados Unidos; Anopheles (Ano.) bradleyi, que se ha logrado infectar con plasmodios experimentalmente; y Anopheles (Nys.) strodei, que se considera vector secundario de malaria en otras regiones.

En el tercer grupo de bajo riesgo, se encuentran tres especies que solo han sido informadas para una localidad, pero que se alguna manera han sido incriminadas como vectores de malaria: Anopheles (Ker.) neivai, que es un vector comprobado en otras regiones; Anopheles (Ano.) walkeri, que se considera un vector secundario en Estados Unidos; y por último Anopheles (Ano.) punctipennis, que se ha infectado con plasmodios experimentalmente. Las especies restantes nunca han sido incriminadas como vectores de ninguna enfermedad.

Las especies restantes corresponderían a especies no riesgosas ya que nunca han sido incriminadas como vectores de patógenos, no obstante, Anopheles (Ano.) apicimacula, se considera debiera mantenerse bajo vigilancia por su distribución en el estado.

En cuanto a la distribución potencial de las especies se sabe que el algoritmo genético GARP permite predecir áreas potenciales de distribución de las especies, aun en regiones donde no se ha colectado y en situaciones en las que únicamente se cuenta con datos de presencia de las especies (Peterson 2001), como es el caso de datos obtenidos de colecciones históricas. Estos modelos se han aplicado para conocer la distribución de insectos de importancia médica (Foley et al. 2008, Levine et al. 2004a, 2004b, Peterson et al. 2005, Sandoval-Ruiz et al. 2008; Sweeney et al. 2006). Sin embargo, se debe de tomar en cuenta que estos mapas predicen una distribución potencial, mas no la distribución actual de las especies (Foley et al. 2008), ya que se toman en consideración los registros por localidad de colecta y factores como la temperatura, humedad y otros datos de índole topográfica. Estos son datos recientes, por lo que en algunos casos la distribución potencial puede dejar fuera algunos de los puntos donde hace tiempo se había encontrado la especie. La mayoría de los datos de presencia con los que se elaboraron los mapas de distribución, son de mediados del siglo XX mientras que las coberturas bioclimáticas utilizadas son actuales. En años recientes la vegetación se ha fragmentado severamente y muchos factores que influyen en la distribución de los mosquitos se han alterado, como por ejemplo, la calidad de los cuerpos de agua por contaminación. No obstante, se ha demostrado que se pueden obtener distribuciones potenciales aceptables utilizando registros pasados 
y actuales, con coberturas bioclimáticas actuales (Raxwothy et al. 2003). Es por esto que se considera que algunos de los mapas de distribución potencial obtenidos en este estudio pueden tomarse como una base para el posterior desarrollo de mapas de riesgo de transmisión de malaria en Veracruz.

Para poder desarrollar en un futuro los mapas de riesgo de transmisión de malaria en el estado, se necesita reconocer y evaluar las variables climáticas que influyen en la distribución de cada una de las especies de interés, así como la variación de estas a través del tiempo, además de incluir otros factores como la demografía y el cambio de uso de suelo.

AGRADECIMIENTOS. Esta es una contribución producto del proyecto "Estratificación de tres enfermedades prioritarias en zonas de riesgo con base en sus insectos vectores en el estado de Veracruz" (FOMIX- CONACYT- Gobierno del Estado de Veracruz de Ignacio de la Llave- Salud, No. 68317), Coordinado por Sergio Ibáñez-Bernal, del Instituto de Ecología, A. C. (INECOL), y en el cual participan los Servicios de Salud de Veracruz (SESVER) y el Instituto de Diagnóstico y Referencia Epidemiológicos, Secretaría de Salud, México (InDRE). Adriana Beltrán Aguilar agradece la beca de Ayudante de Investigación I otorgada mediante este proyecto por CONACYT. A Herón Huerta Jiménez por las facilidades brindadas para la consulta de la Colección de Artrópodos con Importancia Médica (CAIM), del InDRE. Los autores también agradecen a tres revisores anónimos sus comentarios, los cuales enriquecieron el presente trabajo.

\section{LITERATURA CITADA}

Agramonte, A. 1900. Los mosquitos malaricos. El Progreso Médico, 10: 455-465.

Aitken, T. H. G. 1945. Studies on the Anophelinae Complex of Western America. University of California Publications in Entomology, 7: 273-364.

Alvarado, C. A. \& R. L. Heredia. 1947. Observaciones sobre una nueva variedad del Anopheles (A.) pseudopunctipennis Theobald 1901, encontrada en la provincia de Tucuman (Nota previa). Anales del Instituto de Medicina Regional, 2: 73-78.

Baerg, D. C. \& M. M. Boreham. 1974. Anopheles neivai Howard, Dyar \& Knab: laboratory observations on the life cycle and description of the egg stage (Diptera: Culicidae). Journal of Medical Entomology, 11: 629-630.

Bautista-Garfias, C. R., S. Mercado-Sánchez \& A. Morilla-González. 1977. Experimental infection of Anopheles albimanus and Culex thriambus mosquitoes with Venezuelan Equine Encephalomyelitis Virus TC-85 strain. Mosquito News, 72: 15-18.

Belkin, J. N. 1952. The homology of the chaetotaxy if inmature mosquitoes and a revised nomenclature for the chaetotaxy of the pupae. Proceedings of the Emtomological Society of Washington, 54: 115130.

Belkin, J. N. 1968. The type specimens of New World mosquitoes in European museums. Contributions of the American Entomology Institute, 3: 1-69.

Belkin J. N., R. X. Schick \& S. J. Heinemann. 1965. Mosquitoes originally described from Middle America. Contributions of the American Entomology Institute, 1: 1-95.

Belkin J. N., R. X. Schick \& S. J. Heinemann. 1966. Mosquitoes originally described from North America. Contributions of the American Entomology Institute, 1: 1-39. 
Belkin, J. N., R. X. Schick \& S. J. Heinemman. 1968. Mosquitoes originally described from Argentina, Bolivia, Chile, Paraguay, Peru and Uruguay. Contributions of the American Entomology Institute, 4: 11-29.

Belkin, J. N., S. J. Heinemann \& W. A. Page. 1970. The Culicidae of Jamaica. Contributions of the American Entomology Institute, 6: 1- 458.

Belkin, J. N., R. X. Schick \& S. J. Heinemman. 1971. Mosquito studies (Diptera: Culicidae). XXV. Mosquitoes originally described from Brazil. Contributions of the American Entomology Institute, 7: 1-64.

Bellamy, R. E. \& R. P. Repass. 1950. Notes on the ova of Anopheles georgianus King. Journal of the National Malaria Society, 9: 84-88.

Blanchard, R. 1902. Nouvelle note sur les moustiques. Comptes rendus de la Société de Biologie, 54: 793-795.

Bonne, C. \& J. Bonne-Wepster. 1925. Mosquitoes of Surinam. A study on Neotropical mosquitoes. Vol. 13. Royal Colonial Institute of Amsterdam. 558 pp.

Bordas, E., L. Navarro \& W. G. Downs. 1951. Estudio comparativo de los hábitos del adulto de tres especies de Anopheles mexicanos. Revista del Instituto de Salubridad y Enfermedades Tropicales, 12: 35-38.

Boyd, M. F. 1949. Malariology. A comprehensive survey of all aspects of this group of diseases from a global standpoint. Vol. 1.787 pp.

Boyd, M. F. \& W. K. Stratman-Thomas.1934. The comparative susceptibility of Anopheles quadrimaculatus Say and Anopheles crucians Wied. (inland variety) to the parasites of human malaria. The American Journal of Hygiene, 20: 247-257.

Boyd, M. F., W. K. Stratman-Thomas \& S. F. Kitchen. 1935. On the relative susceptibility of Anopheles quadrimaculatus to Plasmodium vivax and Plasmodium falciparum. The American Journal of Tropical Medicine, 15: 485-493.

Boyd, M. F. \& S. F. Kitchen. 1936. The comparative susceptibility of Anopheles quadrimaculatus Say and Anopheles punctipennis, Say to Plasmodium vivax, Grassi and Feletti, and Plasmodium falciparum, Welch. The American Journal of Tropical Medicine, 16: 67-71.

Boyd, M. F., S. F. Kitchen \& J. A. Mulrennan. 1936. On the relative susceptibility of the inland and coastal varieties of A. crucians Wied. to P. falciparum Welch. The American Journal of Tropical Medicine, 16: 159-161.

Bradley, G. H. 1932. On the identification of Anopheles mosquito larvae in Florida. Proceedings of the Entomological Society of Washington, 34: 41-43.

Bradley, G. H. 1936. On the identification of mosquito larvae of the genus Anopheles occurring in the United States (Diptera: Culicidae). Southern Medical Journal, 29: 859-861.

Breeland, S. G. 1951. Identification of the early larval instars of three comon anophelines of Southern Georgia, USA. Journal of the National Malaria Society, 10: 224-232.

Brèthes, J. 1912. Los mosquitos de la República Argentina. Boletín del Instituto de la Patagonia, 1: $1-48$.

Brèthes, J. 1926. Notas sobre los anophelinos argentinos. Physis, 8: 305-315.

Carpenter, S.J. \& W. J. LaCasse. 1955. Mosquitoes of North America (North of Mexico). University of California Press. 495 pp.

Carpenter, S. J., W. W. Middlekauff \& R. W. Chamberlain. 1946. The Mosquitoes of the Southern United States, East of Oklahoma and Texas. The University of Notre Dame, Notre Dame, Ind. 292 pp.

Christophers, S. R. 1924. Provisional list and reference catalogue of the Anophelini. Indian Medical Research, 3: 1-105. 
Coetzee M., J. G. Estrada-Franco, A. A. Wunderlinch \& R. H. Hunt. 1999. Cytogenetic evidence for species complex within Anopheles pseudopunctipennis Theobald (Diptera: Culicidae). The American Journal of Tropical Medicine and Hygiene, 60: 649-653.

Coquillet, D. W. 1902. New forms of Culicidae from North America. Journal of the New York Entomological Society, 10: 191-194.

Correa, R. R. 1942. Das formas evolutivas do Anopheles (Anopheles) eiseni Coquillet, 1902. Archivos de Hygiene e Saude Pública, 7: 25-33.

Cova-García, P. 1939. Notas sobre los anofelinos de Venezuela y su identificación. Publicaciones de la División de Malariología. Ministerio de Sanidad y Asistencia Social de Caracas, Venezuela. 2: 1-34.

Cova-García, P. 1946. Notas sobre los anofelinos de Venezuela y su identifcación. XII Conferencia Sanitaria Panamericana. Cuadernos Amarillos No 1. Ed. Grafalit. Caracas, Venezuela. 208 pp.

Cruz, O. G. 1906. Um novo genero da sub-familia Anophelina. Brazil-medico, 20: 199-200.

CSVA, 2006. Consejo del Sistema Veracruzano del Agua. Participación del estado de Veracruz en el IV Foro Mundial del Agua, 2006. Disponible en: www.csva.gob.mx/foromundial/Material/ doc_CSVA_070206. pdf

Curry, D. P. 1928. A new anophelinae mosquito Anopheles (Chagasia) bathanus Dyar, discovered in the Canal Zone. American Journal of Tropical Medicine, 8: 243-248.

Curry, D. P. 1931. Anopheles (Anopheles) neomaculipalpus. A new species of the Arribalzagaia group of Anopheles from Panama. The American Journal of Hygiene, 13: 643-647.

Darsie, R. F. 1949. Pupae of the Anophelinae mosquitoes of Northeastern United States (Diptera, Culicidae). Rev. de Entomologia, 20: 509-530.

Darsie, R. F. \& R. A. Ward. 2005. Identification and geographical distribution of the mosquitoes of North America, North of Mexico. University Press of Florida, Gainesville, USA. 383 pp.

De León, J. R. 1938. El Anofelismo de altura en Guatemala. Boletín de la Dirección General de Sanidad Pública, 9: 411-429.

DGEPI. 2009 Dirección General de Epidemiología. Vigilancia epidemiológica semana 20. Disponible en: www.dgepi.salud.gob.mx/boletin/2009/sem20/pdf/ cua7.pdf

Diario Oficial de la Federación. 10 de abril de 2006. Criterios para la certificación de áreas geográficas que han logrado la eliminación de la transmisión de paludismo.

Dozier, H. L. 1936. Observations on breeding places and winter activities of mosquitoes in the vicinity of New Orleans, Louisiana. Proceedings of the Entomological Society of Washington, 38: 148155.

Dyar, H. G. 1918. Notes on American Anopheles. Insecutor Inscitiae Menstruus, 6: 141-151.

Dyar, H. G. 1925. Note on bromelicolous Anopheles (Diptera: Culicidae). Insecutor Inscitiae Menstruus, 13: 25-27.

Dyar, H. G. \& F. Knab. 1906a. Diagnoses of new species of mosquitoes. Proceedings of the Biological Society of Washington, 12: 133-142.

Dyar, H. G. \& F. Knab. 1906b. Notes on some American mosquitoes with descriptions of new species. Proceedings of the Biological Society of Washington, 19: 159-172.

Dyar, H. G. \& F. Knab. 1907. Descriptions of new mosquitoes from the Panama Canal Zone. Jounal of the New York Entomological Society, 15: 197-212.

Edwards, F. W. 1932. Genera Insectorum. Diptera. Fam. Culicidae. Fascicle 194. Bélgica. 258pp.

Estrada-Franco, J. G., M. C. Ma, G. C. Lanzaro, R. Gwadz, C. Galván-Sánchez, J. L. Céspedes, R. Vargas-Sagarnaga \& R. Rodríguez. 1993a. Genetic Evidence of a Species Complex in Anopheles pseudopunctipennis sensu lato. Bulletin of PAHO, 27: 26-31. 
Estrada-Franco J. G., M. C. Ma, R. Gwadz, R. Sakai, G. C. Lanzaro, A. Laughinghouse, C. Galván-Sánchez, J. L. Céspedes \& R. Vargas-Sagarnaga. 1993b. Evidence through crossmating experiments of a species complex in Anopheles pseudopunctipennis sensu lato: a primary malaria vector of the American Continent. The American Journal of Tropical Medicine and Hygiene, 49: 746-755.

Evans, A. M. 1922. Notes on Culicidae in Venezuela, with descriptions of new species. II. Annals of Tropical Medicine and Parasitology, 16: 213-222.

Faran, M. E. 1980. A revision of the Albimanus section of the subgenus Nyssorhynchus of Anopheles. Contributions of the American Entomology Institute, 15: 1-214.

Fauran, P. \& F. X. Pajot. 1974. Complement to the catalog of the Culicidae recorded from French Guiana (South America). Mosquito Systematics, 6: 99-110.

Fitch, A. 1847. Winter insects of Eastern New York. American Journal of Agriculture Science, 5: 274284.

Floch, H. \& E. Abonnenc. 1951. Anopheles de la Guyane Française. Archives de l'Institute Pasteur de la Guyane et du territoire d l'Inini, 296: 1-91.

Floore, T. G., B. A. Harrison \& B. F. Eldridge. 1976. The Anopheles (Anopheles) crucians subgroup in the United States (Diptera: Culicidae). Mosquito Systematics, 8: 1-109.

Foley, L. H., L. M. Rueda, A. T. Peterson \& R. C. Wilkerson. 2008. Potential distribution of two species in the medically important Anopheles minimus complex (Diptera: Culicidae). Journal of Medical Entomology, 45: 852-860.

Gabaldón, A., J. Herrera, M. A. Pérez-Vivas \& J. A. Rausseo. 1940. Estudio sobre anofelinos, serie I. 6. Chagasia bathanus Dyar, 1928: su hallazgo en Venezuela y nota sobre variaciones morfologicas de las pupas. Publicaciones de la División de Malariología, 5: 57-62.

Galvao, A. L. A. 1941. Notas sobre algunos anofelinos do sub-género Nyssorhynchus do Norte do Brasil. Revista do Biologia e Hygiene do São Paulo, 11: 92-96

Galvao, A. L. A. 1943. Chaves para a desterminação das espécies do subgénero Nyssorhynchus do Brasil. Archivos de Hygiene e Saude Pública, 8: 141-162.

Galvao, A. L. A. \& J. Lane. 1936. Notas sobre os Nyssorhynchus de São Paulo. Annaes da Faculdade de Medicina de São Paulo, 12: 269-288.

Gerry, B. I. 1932. Morphological studies of the female genitalia of Cuban mosquitoes. Annals of the Entomological Society of America, 24: 31-75.

Gobierno del Estado de Veracruz. 2008. El Entorno y la Población (Semblanza de Veracruz). Disponible en: www.veracruz.gob.mx.

Goeldi, E. A. 1905. Os Mosquitos no Pará. Memorias do Museu Goeldi. Vol. 4. Brasil. 154 pp.

Gómez-Dantés H \& A. E. Birn. 2000. Malaria and social movements in Mexico: the last 60 years. Parassitologia, 42: 69-85.

Gorham, J. R., C. J. Stojanovich \& H. G. Scott. 1973. Clave ilustrada para los mosquitos anofelinos de Sudamérica occidental. Mosquito Systematics, 5: 97-156.

Gratz, N. G. 1999. Emerging and resurging vector-borne diseases. Annual Review of Entomology, 44: 51-75.

Harbach, R. E. \& K. L. Knight. 1980. Taxonomists' glossary of mosquito anatomy. Ed. Plexus Publishing. E. U. A. 415 pp.

Harbach, R. E. \& T. M. Howard. 2007. Corrections in the status and rank of names used to denote varietal forms of mosquitoes (Diptera: Culicidae). Zootaxa, 1542: 35-48.

Heinemann, S. J. \& J. N. Belkin. 1977. Collection Records of the Project "Mosquitoes of Middle America” 9. Mexico (MEX, MF, MT, MX). Mosquito systematic, 9: 483-534.

Herms, W. B. \& H. F. Gray. 1940. Mosquito control. The Commonwealth Fund, New York. 317 pp. 
Hijmans, R. J., S. E. Cameron, J. L. Parra, P. G. Jones \& A. Jarvis. 2005. Very high resolution interpolated climate surfaces for global land areas. International Journal of Climatology, 25: 19651978.

Hoffmann, C. C. 1931. Anopheles pseudopunctipennis y su relación con el paludismo en la República Mexicana. Traducción del trabajo presentado por invitación especial del "Nacional Malaria Comittee” de los Estados Unidos en su Sesión Anual celebrada en Nueva Orleans del 17 al 20 de noviembre de 1931. Revista de Salubridad, 2: 179-187.

Hoffmann, C. C. 1938. La formación de razas en los Anopheles mexicanos II. Anopheles albimanus y sus variedades en la República Mexicana. Anales del Instituto de Biología, 9: 167-180.

Hoffmann, C. C. 1939. La formación de razas de Anopheles mexicanos III. Anopheles chiriquiensis Komp en el interior del estado de Chiapas. Anales del Instituto de Biología, 10: 347-352.

Horsfall, W. R. 1955. Mosquitoes, their bionomics and relation to disease. The Ronald Press Company. New York. 723 pp.

Howard, L. O., H. G. Dyar \& F. Knab. 1912-1917. The mosquitoes of North and Central America and the West Indies. Carnegie Institute of Washington Publication 159, 4 Vols. 1064 pp.

Hurlbut, H. S. 1938a. Study of the larval chaetotaxy of Anopheles walkeri Theobald. The American Journal of Hygiene, 28: 149-173.

Hurlbut, H. S. 1938b. Further notes on the overwintering of the eggs of Anopheles walkeri Theobald with a description of the eggs. The Journal of Parasitology, 24: 521-526.

Ibáñez-Bernal, S. 1988. Perspectivas de la investigación entomológica del paludismo en México. Folia Entomologica Mexicana, 76: 249-264.

Ibáñez-Bernal, S., S. Strickman y C. Martínez-Campos. 1996. Culicidae (Diptera). In: Llorente, B. J., A. N. García y E. González (Eds.). Biodiversidad, taxonomía y biogeografía de artrópodos de México: hacia una síntesis de su conocimiento. Universidad Nacional Autónoma de México. 660 pp.

INEGI, 2009. Mapa de Fisiografía de Veracruz. Disponible en: http://mapserver.inegi.org.mx/geografia/espanol/estados/ver/fisio.cfm?c=444\&e $=11$

Johnson, C. W. 1919. A revised list of the Diptera of Jamaica. Bulletin of the American Museum of Natural History, 41: 421-449.

King, W. V. 1939. Varieties of Anopheles crucians Wied. The American Journal of Tropical Medicine, 19: 461-471.

King, W. V. \& G. H. Bradley. 1941. General morphology of Anopheles and classification of Neartic species. American Association for the Advancement of Science, 15: 63-87.

King, W. V., G. H. Bradley \& T. E. McNeel. 1939. The mosquitoes of the Southeastern States. United States Department of Agriculture, Miscellaneous Publication, 336: 1-91.

Kitzmiller, J. B., D. Joslyn \& H. W. Kreutzer. 1974. The Salivary gland crhomosomes of Anopheles walkeri Theobald. Mosquito News, 34: 22-28.

Knight, K. L \& R. W. Chamberlain. 1948. A new nomenclature for the chaetotaxy of the mosquito pupa, based on a comparative study of the Genera (Diptera: Culicidae). Proceedings of the Helmintological Society of Washington, 15: 1-18.

Knight, K. L. \& A. Stone. 1977. Catalog of the mosquitoes of the World (Diptera: Culicidae). 2a ed. Entomological Society of America. 611 pp.

Komp, H. W. 1937. The species of the Subgenus Kerteszia of Anopheles (Diptera: Culiicidae). Annals of the Entomological Society of America, 30: 492-529.

Komp, W.H.W. 1941. The classification and identification of the Anopheles mosquitoes of Mexico, Central America, and the West Indies. The American Association for the Advancement of Science, Publications, 15: 88-97. 
Komp, W. H. W. 1942. The Anopheline mosquitoes of the Caribbean region. National Institute of Health Bulletin, 179: 1-195.

Kreutzer, R. D. 1977. Hybridization between the Nearctic Anopheles punctipennis and the Paleartic Anopheles atroparvus. Canadian Journal of Genetics and Cytology, 19: 265-270.

Kreutzer, R. D. \& J. B. Kitzmiller. 1971. Hibridization between Anopheles crucians and Anopheles bradleyi. Evolution, 25: 195-206.

Kreutzer, R. D. \& J. B. Kitzmiller. 1972. Hybridization between two species of mosquitoes Anopheles punctipennis Say and Anopheles perplexens Ludlow. Journal of Heredity, 63: 191-196.

Kreutzer, R. D., J. B. Kitzmiller \& M. G. Rabbani. 1975. The salivary gland chromosomes of Anopheles argyritarsis compared with those of certain other species in the subgenus Nyssorhynchus. Mosquito News, 35: 354-365.

Kumm, H.W. 1941. The eggs of some Costa Rican anophelines. American Journal of Tropical Medicine, 21: 91-102.

Lahille, F. 1912. Sobre un Anopheles, una Stegomyia y la notación de las nervaduras alares de los mosquitos. Anales del Museo Nacional de Buenos Aires, 23: 253-263.

Lane, J. 1953. Dixinae, Chaoborinae and Culicinae, tribes Anophelini, Toxorhynchitinae and Culicini (Genus Culex only). Neotropical Culicidae Vol. I. University of São Paulo, Brasil. 548 pp.

Lassmann, G. W. 1948. Distribución de los Anopheles en el Estado de Veracruz. Boletín de los Servicios Coordinados de Salubridad y Asistencia en el Estado de Veracruz, 4: 6-11.

Levi-Castillo, R. 1944. El complejo "Pseudopunctipennis" en el Ecuador (Diptera -Culicidae). Universidad de Guayaquil, Ecuador, 28: 1-7.

Levi-Castillo, R. 1945. Los anofelinos de la República del Ecuador. Vol. 1. Disponible en: http://www. mosquitocatalog.org/pdfs/077800-1.pdf

Levine, R. S., A. T. Peterson \& M. Q. Benedict. 2004a. Geographic and ecologic distributions of the Anopheles gambiae complex predicted using a genetic algorithm. American Journal of Tropical Medicine and Hygiene, 70: 105-109.

Levine, R. S., A. T. Peterson \& M. Q. Benedict. 2004b. Distribution of members of Anopheles quadrimaculatus Say s.l. (Diptera: Culicidae) and implications for their roles in malaria transmission in the United States. Journal of Medical Entomology, 41: 607-613.

Linley, J. R. \& P. E. Kaiser. 1994. The eggs of Anopheles punctipennis and Anopheles perplexens (Diptera: Culicidae). Mosquito Systematics, 26: 43-56.

Linley, J. R., P. E. Kaiser \& A. F. Cockburn. 1993. A description and morphometric study of the eggs of species of the Anopheles quadrimaculatus complex (Diptera: Culicidae). Mosquito systematic, 5: 124-147.

Linthicum, K. J. 1988. A revision of the Argyritarsis section of the subgenus Nyssorhynchus of Anopheles (Diptera: Culicidae). Mosquito Systematics, 20: 98-271.

Loyola E. G., J. I. Arredondo-Jiménez, M. H. Rodríguez, D. N. Brown \& M. Vaca-Marín. 1991. Anopheles vestitipennis, the probable vector of Plasmodium vivax in the Lacandon forest of Chiapas, México. Transactions of the Royal Society of Tropical Medicine and Hygiene, 85: 171-174.

Loyola E. G., L. González-Cerón, M. H. Rodríguez, J. I. Arredondo-Jiménez, S. Bennett \& D. N. Brown. 1993. Anopheles albimanus (Diptera: Culicidae) host selection patterns in three ecological areas of the Coastal Plains of Chiapas, Southern Mexico. Journal of Medical Entomology, 30: 518523.

Ludlow, C. S. 1919. Mew mosquitoes from Panama. Psyche, 26: 166-169.

Manguín, S., D. R. Roberts, E. L. Peyton, E. Rejmankova \& J. Pecor. 1996. Characterization of Anopheles pseudopunctipennis larval habitats. Journal of the Mosquito Control Association, 12: 619-626. 
Manguin S., D. R. Roberts, E. L. Peyton, I. Fernández-Salas, M. Barreto, R. Fernández, R. Elgueta, R. Martínez \& M. H. Rodríguez. 1995. Biochemical systematics and population genetic structure of Anopheles pseudopunctipennis, vector of malaria in Central and South America. The American Journal of Tropical Medicine and Hygiene, 53: 362-377.

Mann, F. G. 1950. Dos nuevas sub-especies del Anopheles pseudopunctipennis Th. 1901. Biologica, 13-21: 33-42.

Martínez-Palacios, A. \& D. J. Pletsch. 1963. Highlights of mosquito investigation and control in Mexico: past, present and future. Proceedings of the fiftieth annual meeting of the New Jersey Mosquito Extermination Association, pp. 72-80.

Martini, E. 1932. Dos nuevos mosquitos Anopheles, procedentes del Estado de Chiapas, México. Revista Mexicana de Biología, 12: 98-102.

Martini, E. 1935. Los mosquitos de México. Departamento de Salud Pública. Boletines Técnicos, Serie A, No. 1. 65 pp.

Meigen, J. W. 1818. Systematische Beschreibung der bekannten europaischen zweiflugeligen Insekten. Vol. 1. 333 pp.

Moreno, J. E., Y. Ribio-Palis, E. Páez, E. Pérez, V. Sánchez \& E. Vaccari. 2005. Anopheles (Anopheles) neomaculipalpus: a new malaria vector in the Amazon basin? Medical and Veterinary Entomology, 19: 329-332.

Mulhern, T. D. 1941. Mosquito control in New Jersey in 1940 and its contributions to national defense. Proceedings of the New Jersey Mosquito Extermination Association, 28: 72-114.

Neiva, A. 1906. Uma nova especie de Anophelina brazileira. Brazil-Medico, 20: 3-8.

O’Malley, C. 1992. The Biology of Anopheles quadrimaculatus Say. Proceedings of the New Jersey Mosquito Control Association, 79: 136-144.

OMS. 2005. World Malaria Report. Disponible en: http://rbm.who.int/wmr2005/

OMS. 2007. World Health Report. 2007. Disponible en: http://www.who.int/whr/2007/whr07_en.pdf.

OPS. 1985. El Control de las enfermedades transmisibles en el hombre. 14 a edición. 536 pp.

OPS (1998). 2000. Report on the situation of malaria programs in the Americas Revista Panamericana de Salud Pública 8: 363-367. Disponible en: http://www.scielosp.org/ scielo.php?

Osorno-Mesa, E. \& F. Muñoz-Sarmiento. 1948. Una nueva variedad de Anopheles pseudopunctipennis. Caldasia, 5: 105-113.

Panday, R. S. 1975. Mosquito identification studies in a savanna forest in Surinam. Mosquito News, 35: 141-146.

Pampana, E. 1966. Erradicación de la Malaria. Ed. Limusa-Wiley. México. 605 pp.

Pelaez, D. 1945. Anofelinos de México. Clave para la determinación de especies y subespecies basada en los caracteres de las hembras adultas. Ciencia, 6: 69-77.

Penn, G. H. 1949. Pupae of the neartic Anopheline mosquitoes North of Mexico. Journal of the National Malaria Society, 8: 50-69.

Pessôa, S. B. \& Paula-Souza, G. H. 1937. Notas sobre os Nyssorhynchus de S. Paulo. IV. Sobre a infeç̧ão experimental do Anopheles algitarsis e A. strodei da ciudade de São Paulo, pelo Plasmodium vivax. Folia Clinica et Biologica, 3: 65-69.

Peterson, A. T. 2001. Predicting species’ geographic distributions based on ecological niche modeling. The Condor, 103: 599-605.

Peterson, A. T., C. Martínez-Campos, Y. Nakazawa y E. Martínez-Meyer. 2005. Time-specific ecological niche modeling predicts spatial dynamics of vector insects and human dengue cases. Transactions of the Royal Society of Tropical Medicine and Hygiene, 99: 647-655.

Peyton, E. L., R. C. Wilkerson \& R. E. Harbach. 1992. Comparative analysis of the subgenera Kerteszia and Nyssorhynchus of Anopheles (Diptera: Culicidae). Mosquito Systematics, 24: 51-69. 
Pinto, C. 1939. Chave para identificacão das larvas de Anofelinas de interesse medico, observadas no Brasil. Disponible en : http://www.mosquitocatalog.org /pdfs/102700-3.pdf

Pratt, H. D. 1943. The identification of first stage larvae of Puerto Rican Anopheles. Public Health Report, Washington, 58: 1715-1717.

Reinert J. F., P. E. Kaiser \& J. A. Seawright. 1997. Analysis of the Anopheles (Anopheles) quadrimaculatus complex of sibling species (Diptera: Culicidae) using morphological, cytilogical, molecular, genetic, biochemical, and ecological techniques in an integrated approach. Journal of the American Mosquito Control Association, 13 (supplement): 1-102.

Robineau-Desvoidy, J. B. 1827. Essai sur la tribu des culicides. Memoires de la Société d'Histoire Naturelle de Paris, 3: 390-413.

Rodríguez, M. H., R. A. Betanzos, L. R. Danis, C. L. González, A. L. Durán, G. J. Méndez, M. M. Vázquez, M. O. Velásquez, B. H. Holguín \& C. R. Tapia. 2004. An ecosystem approach study of malaria transmission and control interventions in southern Mexico. Global Forum for Health Research, Forum 8. Disponible en: http://www.globalforumhealth.org/Forum8/Forum8-CDROM/ Posters/Rodriguez\% 20MH\%20F8-181.doc.

Rodríguez, M. H., B. Chavez, A. Orozco \& A. Martínez-Palomo. 1996. Fine structure of the eggs of Anopheles (Anopheles) apicimacula (Diptera: Culicidae). Journal of the American Mosquito Control Assocciation, 12: 454-459.

Rodríguez, M. H., B. Chavez, A. Ulloa \& J. I. Arredondo-Jiménez. 2002. Fine structure of the eggs of Anopheles (Anopheles) punctimacula. Journal of the American Mosquito Control Association, 18: 1-9.

Root, F. M. 1922. Notes on mosquitoes and other blood-sucking flies from Porto Rico. The American Journal of Hygiene, 2: 394-405.

Root, F. M. 1924. Notes on the mosquitoes of Lee County, Georgia. The American Journal of Epidemiology, 4: 449-455.

Root, F. M. 1926. . Studies on Brazilian mosquitoes. I. The anophelines of the Nyssorhynchus group. The American Journal of Hygiene, 6: 684-717.

Root, F. M. 1929. Anopheles. In: Animal parasitology. D. Appleton-Century Co., Inc. New York, USA. Págs 476-502.

Ross, E. S. \& H. R. Roberts. 1943. Mosquito Atlas. Part I. The Neartic Anopheles important malaria vectors of the Americas and Aëdes aegypti, Culex quinquefasciatus. The American Entomological Society, the Academy of Natural Sciences. Philadelphia, USA. 44 pp.

Roth, L. M. 1944. A key to the Anopheles of the southeastern United States, by male genitalia (Diptera, Culicidae). The American Midle Naturalist, 31: 96-110.

Rozeboom, L. E. 1938. The eggs of the Nyssorhynchus group of Anopheles (Culicidae) in Panamá. The American Journal of Hygiene, 27: 95-107.

Rozeboom, L. E. 1941. Distribution and ecology of the Anopheles mosquitoes of the Caribbean Region. American Association for the Advancement of Science, 15: 98-115.

Rozeboom, L. E. \& A. Gabaldón. 1941. A summary of the "Tarsimaculatus" complex of Anopheles (Diptera: Culicidae). The American Journal of Hygiene, 33: 88-100.

Rueda, L. M., E. L. Peyton \& S. Manguin. 2004. Anopheles (Anopheles) pseudopunctipennis Theobald (Diptera: Culicidae): Neotype Designation and Description. Journal of Medical Entomology, 41: $12-22$.

Russell, P. F., L. E. Rozeboom \& A. Stone. 1943. Keys to the anopheline mosquitoes of the World. The American Entomological Society. The Academy of Natural Sciences. Philadelphia, USA. 152 pp.

Russell, P. F. 1953. Paludismo. Compendio de principios básicos. Ed. La Prensa Médica Mexicana. México. 205 pp. 
Sandoval-Ruiz, C. A., J. L. Zumaquero-Ríos \& O. R. Rojas-Soto. 2008. Predicting geographic and ecological distributions of Triatomine species in the Southern Mexican State of Puebla using ecological niche modeling. Journal of Medical Entomology, 45: 540-546.

Say, T. 1823. Descriptions of dipterous insects of the United States. Journal of the Academy of Natural Sciences of Philadelphia, 3: 9-54.

Say, T. 1824. Appendix. Part I.- Natural history. 1. Zoology. E.Class Insecta. 378. In: Keating, W. H. Narrative of an expedition to the source of St. Peter's River. Vol. 2. Philadelphia. 459 pp.

Scachetti-Pereira, R. 2003. Desktop GARP user's manual. Disponible en: http://beta.lifemapper.org/ desktopgarp/

Senevet, G. 1931. Contibution a l'étude des nymphes d'anophélines (2a mémoire). Archives $d$ l'Institute Pasteur D’Algérie, 9: 17-112.

Senevet, G. 1934. Contribution a l'étude des nymphes d'anophélinés ( $4^{\mathrm{a}}$ mémoire). Archives $d$ l'Instiyute Pasteur D’Algérie, 12: 29-76.

Senevet, G. 1948. Au sujet de quelques nymphes de Nyssorhynchus. Archives $d$ l'Institute Pasteur D’Algérie, 26: 4363-440.

Senevet, G. \& E. Abonnenc. 1938. Quelques anophéliés de la Guyane Française. Archives d l'Institute Pasteur D’Algérie, 16: 486-512.

Simmons, J. S. 1937. Observations on the importance of Anopheles punctimacula as a malaria vector in Panama, and report of experimental infections in A. neomaculipalpus, A. apicimacula, and A. eiseni. American Journal of Tropical Medicine, 17: 191-212.

Soto, E. M. \& E. García. 1989. Atlas climático del estado de Veracruz. Instituto de Ecología, A. C. $125 \mathrm{pp}$.

Stearns, L. A. 1940. The present mosquito control situation in Delaware. Proceedings of the New Jersey Mosquito Extermination Association, 27: 106-112.

Stockwell, D. \& D. Peters. 1999. The GARP modelling system: problems and solutions to automated spatial prediction. International Journal of Geographical Information Science, 13: 143-158.

Stojanovich, C. J., J. R., Gorham \& Scott, H. G. 1966. Clave Ilustrada para los mosquitos anofelinos de América Central y Panamá. U.S. Department of Health, Edication and Welfare. Atlanta, Georgia. $44 \mathrm{pp}$.

Stone, A. \& K. L. Knight. 1956. Type specimens of mosquitoes in the United States National Museum: III, The genera Anopheles and Chagasia (Diptera, Culicidae). Journal of the Washington Academy of Sciences, 46: 276-280.

Sweeney, A. W., N. W. Beebe, R. D. Cooper, J. T. Bauer \& A. T. Peterson. 2006. Environmental factors associated with distribution and range limits of malaria vector Anopheles farauti in Australia. Journal of Medical Entomology, 43: 1068-1075.

Tamayo, M. O. \& C. A. Gargia. 1907. Las aquas de Huacachina informe presentado a la Sociedad Geografica de Lima. Memorias de la Municipalidad de Lima, 1906: 1-63.

Theobald, F. V. 1901. A monograph of the Culicidae or mosquitoes. Vol. 2. British Museum of Natural History, London, England. 391 pp.

Theobald, F. V. 1903. A monograph of the Culicidae of the World. Vol. 3. British Museum of Natural History, London, England. 351 pp.

Theobald, F. V. 1905. A catalogue of the Culicidae in the Hungarian National Museum, with descriptions of new genera and species. Annales Musei Nationalis Hungarici, 3: 61-120.

Theobald, F. V. 1907. A monograph of the Culicidae or mosquitoes. Vol. 4. British Museum of Natural History, London, England. 639 pp.

Thowson, H. Nathan, M. B., Zaim, N., Guillet, P. Manga, L., Bos, R. \& Kindhauser, M. 2005. Exploiting the potential of vector control for disease prevention. Bulletin of the World Health Organization, 83: 942-947. 
Ulloa, A., M. H. Rodríguez, J. I. Arredondo-Jiménez \& I. Fernández-Salas. 2005. Biological variation in two Anopheles vestitipennis populations with different feeding preferences in Southern Mexico. Journal of the American Mosquito Control Association, 21: 350-354.

Unti, O. 1940. Anofelinos do Vale do Paraíba. Nota 111. Biologia do Anóphéles (Nyssorhynchus) strodei Root, 1926 com a descrição d'uma variedade nova Anóphéles (Nyssorhynchus) strodei ramosi var. n. Annaes Paulistas de Medicina é Cirugia, 15: 489-491.

Unti, O. 1941. Anofelinos do vale do Paraíba, Anopheles (Nyssorhynchus) strodei Root 1926, com a descrição de tres variedades novas. Publicaciones del Servicio de Profilaxis de la Malaria, 33: 318.

Van Der Wulp, F. M. 1867. Eenige Noord-Americaansche Diptera. Tijdschrift voor Ent. 10: 125-130.

Vargas, L. 1939. Datos acerca del A. pseudopunctipennis y de un Anopheles nuevo de California. Revista Mexicana de Medicina,19: 356-362.

Vargas, L. 1940a. Clave para identificar las hembras de Anopheles mexicanos. Revista del Instituto de Salubridad y Enfermedades Tropicales, 1: 199-203.

Vargas, L. 1940b. Clave para identificar las larvas de Anopheles mexicanos. Ciencia, México, 1: 6668.

Vargas, L. 1941a. Anopheles (Anopheles) gabaldoni n. sp. en el estado de Tabasco, México (Dipt. Culicidae). Revista Medicina de México, 21: 385-394.

Vargas, L. 1941b. El problema de las variedades de A. punctipennis. Revista de la Sociedad Mexicana de Historia Natural, 2: 175-186.

Vargas, L. 1941c. Notas sobre los huevecillos de Anopheles mexicanos. Gaceta Médica de México, 71: 107-123.

Vargas, L. 1941d. Anopheles pseudopunctipennis willardi n. var. (Dipt. Culicidae). Revista de la Sociedad Mexicana de Historia Natural, 2: 47-49.

Vargas, L. 1948. Nota sobre la antigua presencia de Anopheles (Nyssorhynchus) albimanus Wiedemann, 1821 en Brasil. Revista del Instituto de Salubridad y Enfermedades Tropicales, 9: 153-163.

Vargas, L. 1949. Caracteres morfológicos diferenciales de algunas pupas de anofelinos neotropicales (Diptera: Culicidae). Rivista di Parassitologia, 10: 231-235.

Vargas, L. 1951. Problemas en la identificación de vectores del paludismo y su biología en las principales zonas endémicas de México. Boletín de Sanidad Militar, 4: 435-439.

Vargas, L. 1959. Lista de Anopheles de las Américas y su identificación por caracteres masculinos (Diptera: Culicidae). Revista del Instituto de Salubridad y Enfermedades Tropicales, 19: 367-386.

Vargas, L. 1963. La interpretación epidemiológica del paludismo, con énfasis en campañas de erradicación. Revista Venezolana de Sanidad y Asistencia Social, 28: 339-509.

Vargas, L. \& A. Martínez-Palacios. 1946. Descripción del huevo, larva y pupa de Anopheles gabaldoni Vargas, 1941. Revista del Instituto de Salubridad y Enfermedades Tropicales, 7: 19-27.

Vargas L. \& A. Martínez-Palacios. 1956. Anofelinos mexicanos. Taxonomía y distribución. Secretaría de Salubridad y Asistencia. Comisión Nacional para la Erradicación del Paludismo. México. 181 pp.

Vargas, M. 1975. Clave para anofelinos adultos (hembras) de Costa Rica. Brenesia, 6: 77-80.

Villanueva, R. C. 1961. Distribución Geográfica de Chagasia bathanus (Dyar, 1928) y algunos aspectos bionómicos de la larva. Revista Brasileira de Entomologia, 10: 217-226.

Villareal C., J. I. Arredondo-Jiménez, M. H. Rodríguez \& A. Ulloa. 1998. Colonization of Anopheles pseudopunctipennis from Mexico. Journal of the American Mosquito Control Association, 14: 369-372.

WRBU. 2008. Walter Reed Biosystematics. Systematic Catalog of Culicidae. Disponible en: http:// www.mosquitocatalog.org/main.asp. 
Weidhaas D. E., D. B. Woodard, C. H. Schmidt \& H. R. Ford. 1965. Biology of Anopheles quadrimaculatus under field conditions in Central America. Annals of the Entomological Society of America, 52: 145-150.

Wilkerson, R. C. 1989. Elevation of Anopheles chiriquiensis from synonymy with Anopheles parapunctipennis and designation of Name-bearing types for Anopheles parapunctipennis and Anopheles parapunctipennis guatemalensis (Diptera: Culicidae). Mosquito Systematics, 21: 178-187.

Wiedemann, C. R. G. 1820. Diptera Exotica. Vol. 1.42 pp.

Wiedemann, C. R. G. 1828. Aussereuropaische zweiflugelige insekten. Vol. 1. 608 pp.

Wilkerson, R. C. 1989. Elevation of Anopheles chiriquiensis from synonymy with Anopheles parapunctipennis and designation of name-bearing types for Anopheles parapunctipennis guatemalensis (Diptera: Culicidae). Mosquito Systematics, 21: 178-187.

Wilkerson, R. C. 1990. Redescriptions of Anopheles punctimacula and An. malefactor (Diptera: Culicidae). Journal of Medical Entomology, 27: 225-247.

Wilkerson R. C., D. Strickman \& T. R. Litwak. 1990. Ilustrated key to the female Anopheline mosquitoes of Central America and Mexico. Journal of the American Mosquito Control Association, 6: 7-34.

Wilkerson R. C., D. Strickman, I. Fernández-Salas, S. Ibáñez-Bernal \& T. R. Litwak, 1993. Clave ilustrada para la identificación de las hembras de mosquitos anofelinos de México y Centroamérica. Secretaría de Salud. Subsecretaría de Coordinación y Desarrollo. México. 46 pp.

Williams, D. D. \& B. W. Feltmate. 1992. Aquatic Insects. Ed. CAB International. Reino Unido. 358 pp.

Yamaguti, S. 1952. Illustrated Keys to the Adult Culicine Mosquitoes of America North of Mexico. Publicado por el autor. 48 pp.

Zavortink, J. T. 1973. A review of the subgenus Kerteszia of Anopheles. Contributions of the American Entomology Institute, 9: 1-54.

Zimmerman, R. H. 1992. Ecology of malaria vectors and future direction. Memorias do Instituto Oswaldo Cruz, 87: 371-383. 